\title{
Towards a General Theory of Markets: A Social Practice Theory Approach
}

\author{
MARTYN JAMES GOSLING
}

\begin{abstract}
A thesis
submitted to the Victoria University of Wellington in fulfilment of the requirements for the degree of

Doctor of Philosophy
\end{abstract}

Victoria University of Wellington

2018 


\begin{abstract}
In recent years new conceptualisations of marketing have been founded in social practice theory. Markets and market boundaries, however, while debated, have not been re-theorised and definitions remain based in the neoclassical economics paradigm. Social practices theory provides a basis for defining markets and market boundaries by practices and their performances by market actors. This thesis advances the debate on a general theory of markets by theorising a new conceptual model of markets as social structures demarcated by nine specific categories of routinised practices described here as parameters. A qualitative study grounded within the social constructionist epistemology was conducted to explore the market practices model, particularly the categories of practices forming the parameters that define market boundaries. The New Zealand mobile telecommunications market provided an opportunity for a situational-specific exploration involving interviews with service providers, users, and regulators as actors performing in the market between 1990 and 2014, triangulated against 26-years of documentary evidence. The research enabled understanding of practices through the comparison of performances between progressive eras in the mobile telephone market in New Zealand. The findings supporting the market practice model not only advance new theory that extends our understanding of markets and market boundaries but also provide context for marketing academics. Furthermore, the model provides new perspectives for business strategy and policy development. The thesis concludes with a summary of contributions to the academic knowledge of markets and an overview of directions for future research and debate.
\end{abstract}




\section{ACKNOWLEDGEMENTS}

Ernest K. Gann, in his autobiography Fate is the Hunter, describes his protagonists as "the tip of the arrow". They were the first to the scene of disaster or success but, regardless of their heroics, their achievements would not have eventuated without the many whose efforts are unsung. A PhD is much the same, for although at times it is a chillingly lonely and dark experience, and any success is hard won, there is an army behind each successful candidate. I am mindful also of Peter Jackson, when picking up an armload of Oscars, saying he could not thank everyone because he did not have all the New Zealand telephone books. What follows is my heartfelt thanks to my army, and an apology to anyone whose names I have omitted.

The earliest support came from John Davies, Val Lindsay and Peter Thirkell. Their enthusiasm was instrumental in my attempting a PhD. Bronwyn Howell said I should stop playing at lecturing and do the job properly. She was right, of course. The academic and administrative staff at the School of Marketing and International Business could not have been more supportive - which is an easy thing for any postgraduate student to say, but I, to mix metaphors, have only too often seen the flurry of paddling feet below a calm surface. Everyone helped me, particularly Jayne Krisjanous, Janine Williams, Micael-Lee Johnstone, Michelle Renton, Cheryl Rivers, Siah Hwee Ang, Kim Fam, Katrina Walsh, Mary Alexander, Clare Williams, Val Hooper, and most of all Aaron Gazley. I am humbled by their kindness.

Others on the PhD pathway, Richa Chugh, Honghong Zhang, Steffen Bertram and Rene Versteegh, are friends who each provided something far more precious than a theoretical contribution. Garry Tansley and I consoled each other that old buggers can do PhDs.

There are two colleagues without whose constant efforts there would be no $\mathrm{PhD}$ : my supervisors. Yuri Seo tended to my theoretical basis with uncommon zeal and patience, for which I am most grateful. To my principal supervisor James Richard goes my deepest thanks 
and a most profound debt of gratitude. Any supervisor is expected to impart wisdom and show interest. He gave more, far more. As a confirmed positivist he would die rather than admit it, but Jim has a very kind and generous heart.

This would not be complete without thanking two very fine men who rode this journey with me: Curtis and Lucas, who are now the tips of their own arrows.

Lastly, and I can hardly write this sentence as there are too many tears in my eyes, but Helen, this is for you. 


\section{CONTENTS}

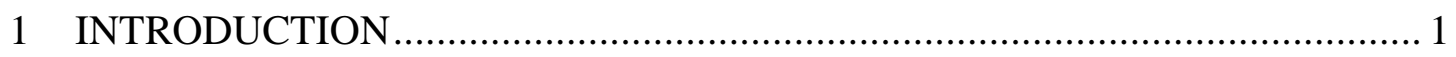

1.1 Background ................................................................................. 1

1.2 Research Objectives ................................................................... 3

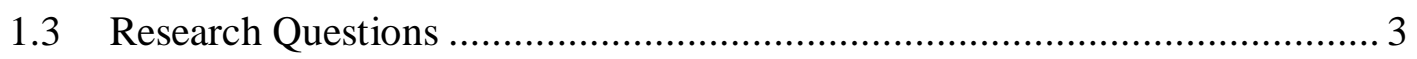

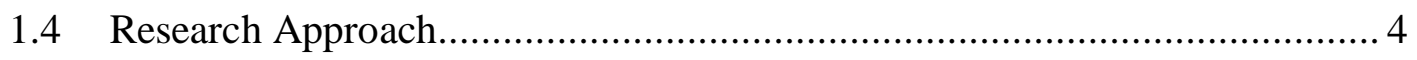

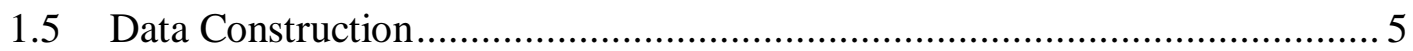

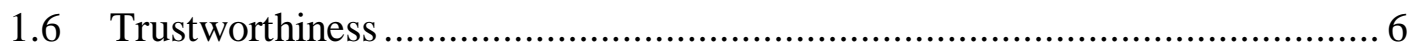

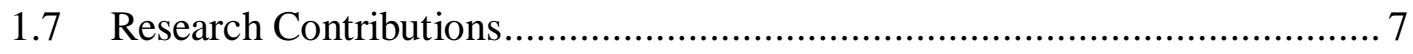

1.7.1 Academic Contributions ................................................................. 7

1.7.2 Management and Policy Contributions............................................. 8

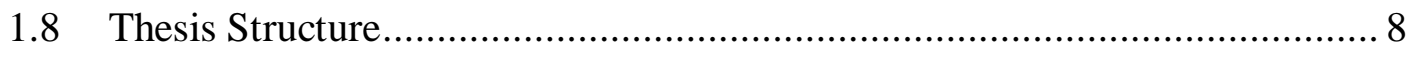

1.9 Summary of Concepts and Definitions................................................. 9

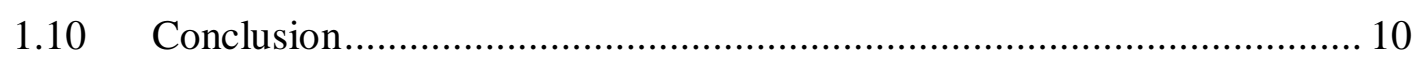

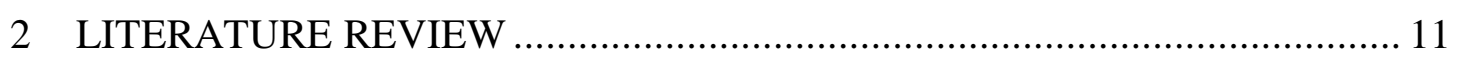

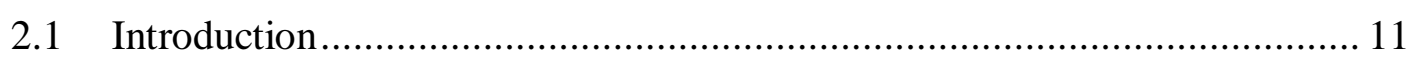

2.2 Neoclassical Economics Perspectives on Markets.................................... 11

2.2.1 Neoclassical ontology - the rational man .......................................... 11

2.2.2 Criticism of the economic rational model........................................ 13

2.3 Marketing Perspectives on Markets .................................................. 15

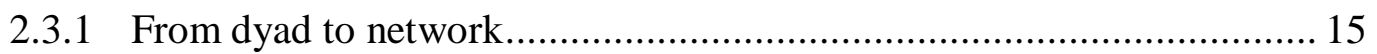

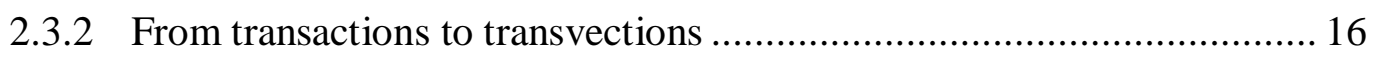

2.3.3 From economic structures to social practice structures ....................... 16

2.3.4 Conceptualisations of exchange and competition ............................. 19

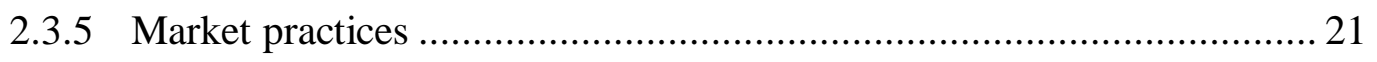

2.4 Perceptions of market boundaries ................................................... 24

2.4.1 Spatial matrix - Us and Other.................................................... 24 
2.5 Discussion and Research Gaps ............................................................ 29

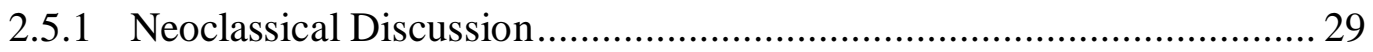

2.5.2 Social practices discussion .......................................................... 31

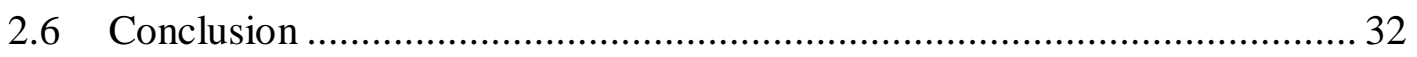

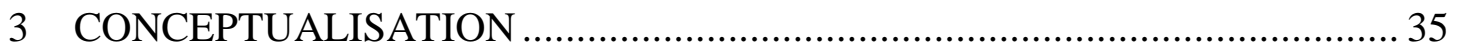

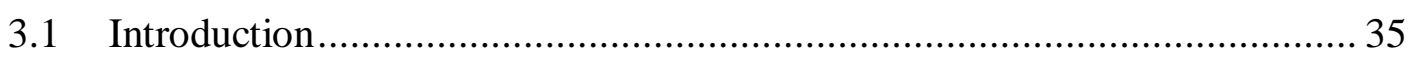

3.2 Conceptual Background - Social Practice Theory .................................... 36

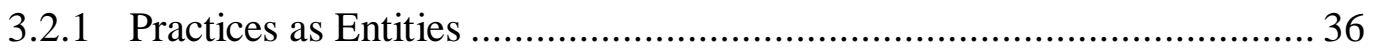

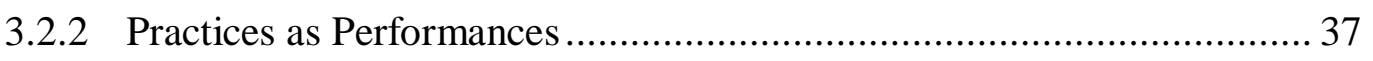

3.2.3 Components of Practices - Competences, Materials, and Meanings ...... 37

3.2.4 Structuration - embedded practices.............................................. 38

3.3 Social Practice Theory and Markets ............................................................ 39

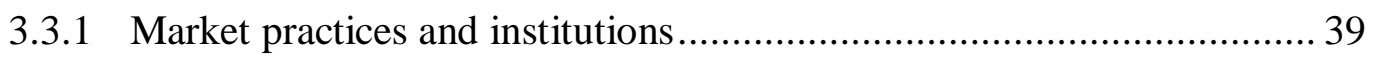

3.3.2 Market boundaries and market space defined by practices .................. 39

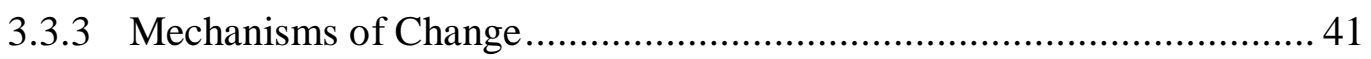

3.3.4 Social Practices summary ............................................................ 43

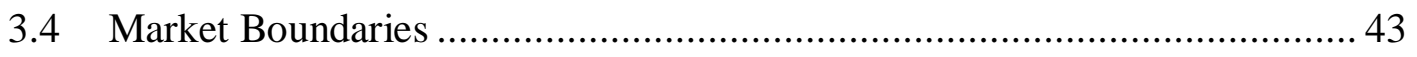

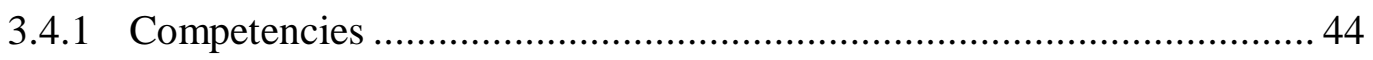

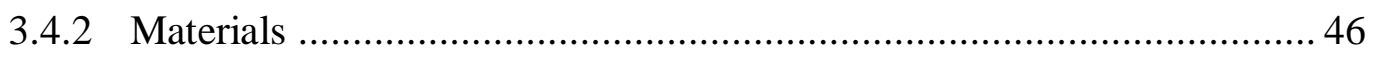

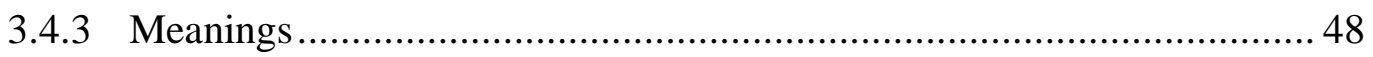

3.5 Towards the Market Practice Model ............................................................ 49

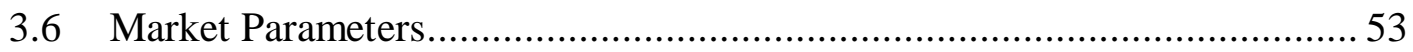

3.6.1 Competences: competitive intensity, legal and economic institutions,

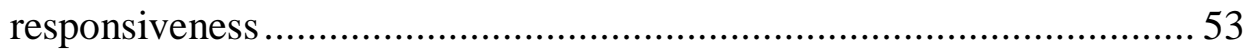

3.6.2 Materials: information, value propositions, technology ....................... 54

3.6.3 Meanings: needs, social and community meanings, spatial matrix........ 54 


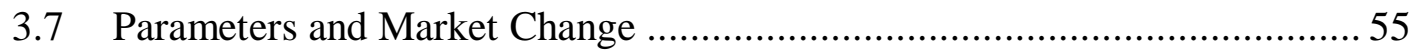

3.8 Market Practice Model summary …........................................................... 56

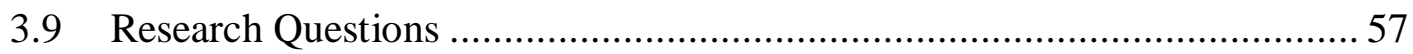

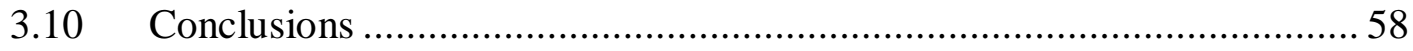

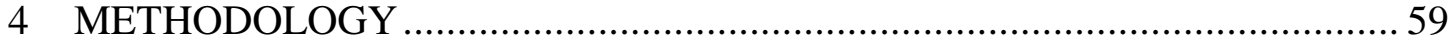

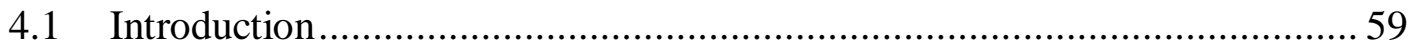

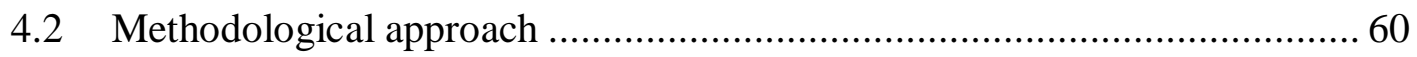

4.2.1 Epistemology - the philosophical grounding for theory exploration ...... 60

4.2.2 Abduction - a way of understanding, interpretation and reflection ........ 61

4.2.3 Research perspective - quadri-hermeneutics .................................. 62

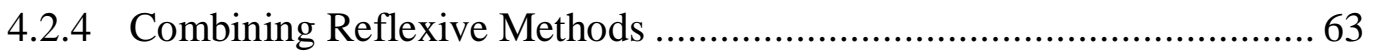

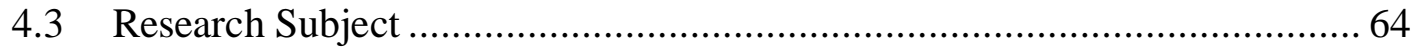

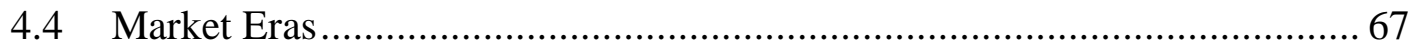

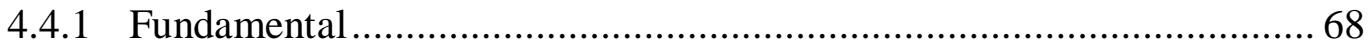

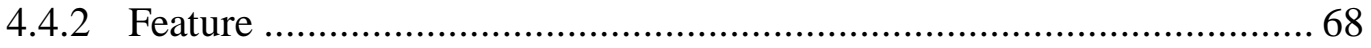

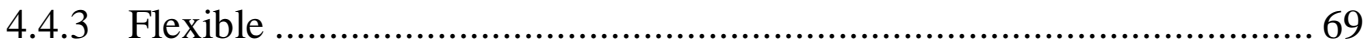

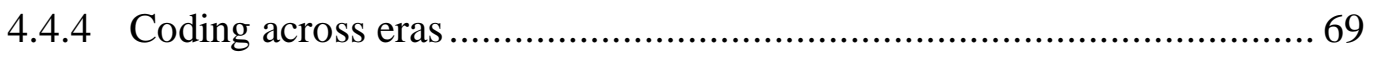

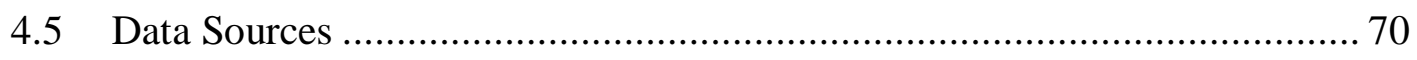

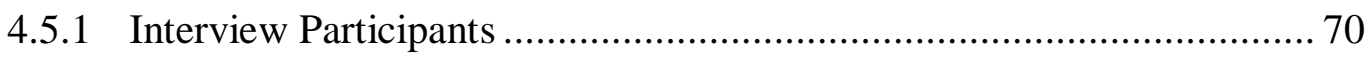

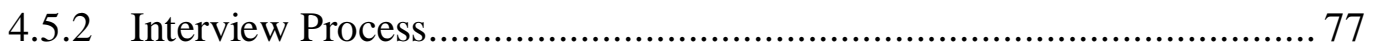

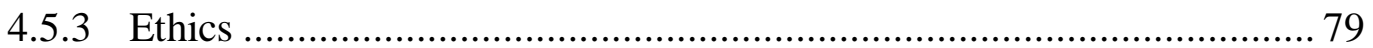

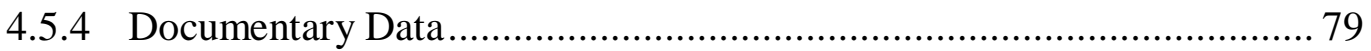

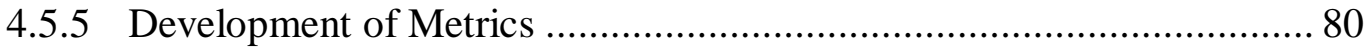

4.6 Trustworthiness, Validation, Triangulation and Reality Tests ...................8 80

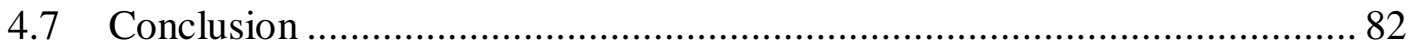

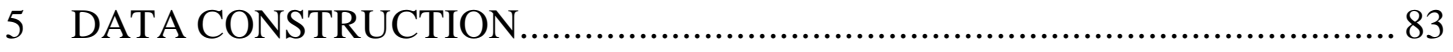

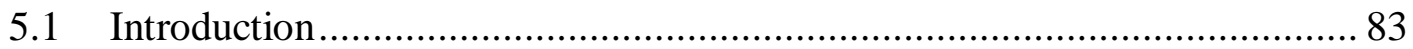


5.1.1 Coding and interpretation

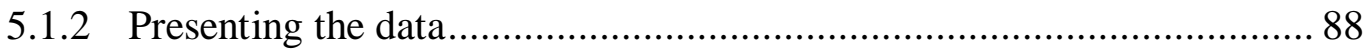

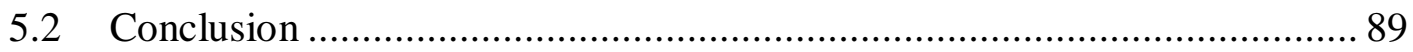

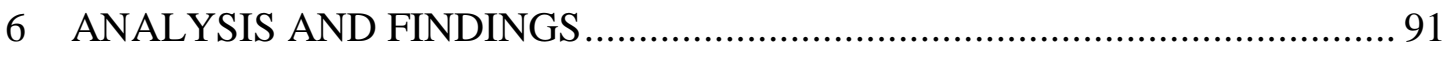

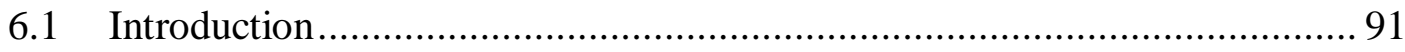

6.2 The political genesis of Telecom New Zealand ..................................... 93

6.31990 - 1998: The Fundamental Era - Mobile as 'other' ............................. 94

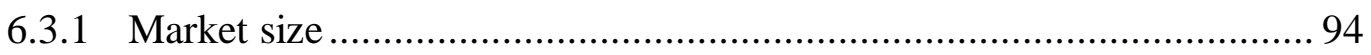

6.3.2 Regulators - performance of practice ............................................ 95

6.3.3 Regulators - parameters and institutional practices .......................... 97

6.3.4 Providers - performance of practice ................................................ 98

6.3.5 Providers - parameters and institutional practices .......................... 109

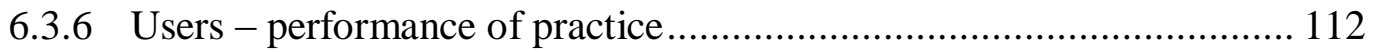

6.3.7 Users - parameters and institutional practices ................................ 119

6.4 199-2007: Feature Era - from Other to Us ......................................... 124

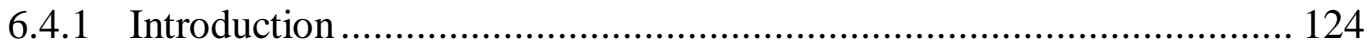

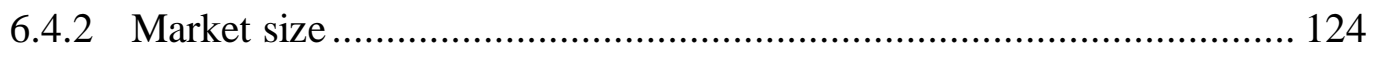

6.4.3 Regulators - performance of practice ......................................... 126

6.4.4 Regulators - parameters and institutional practices ........................ 138

6.4.5 Providers - performance of practice ........................................... 142

6.4.6 Providers - parameters and institutional practices .......................... 154

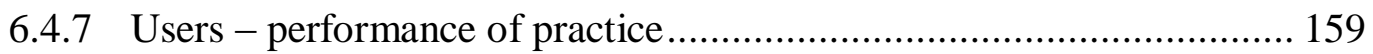

6.4.8 Users - parameters and institutional practices .............................. 168

6.52008 - 2014: Flexible Era - the Data Pipeline ..................................... 173

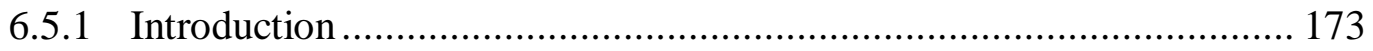

6.5.2 The Market in the Flexible Era .................................................. 174

6.5.3 Regulators - performance of practice ....................................... 175 
6.5.4 Regulators - parameters and institutional practices

6.5.5 Providers - performance of practice ............................................ 181

6.5.6 Providers - parameters and institutional practices ........................... 187

6.5.7 Users - performance of practice ............................................. 190

6.5.8 Users - parameters and institutional practices ................................ 208

6.6 Comparison of Practices Across Eras................................................. 215

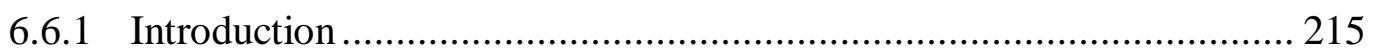

6.6.2 Market Characteristics ............................................................... 217

6.6.3 Linking Parameters and Institutional Practices ............................... 218

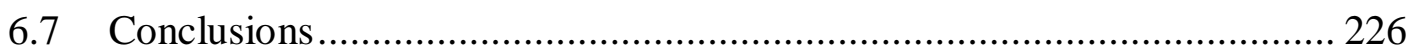

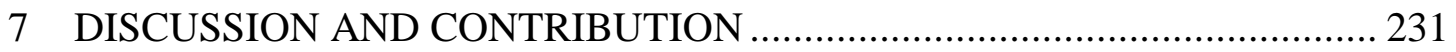

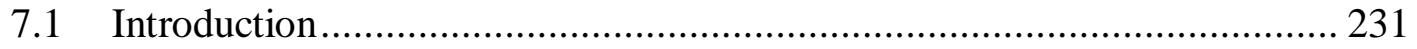

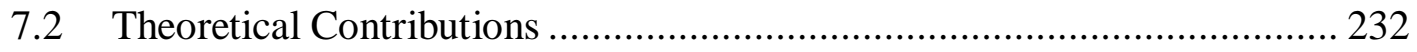

7.2.1 Social Practice Theory - a theoretical basis for markets .................... 232

7.2.2 Towards a general theory of markets.......................................... 234

7.2.3 RQ1 - The Market Practice Model ................................................ 235

7.2.4 RQ2 - Market Parameters ......................................................... 236

7.2.5 RQ 3 - Parameter influence on market change ............................... 238

7.2.6 RQ4 - Motivating Change in Actor Behaviour ................................. 239

7.3 Managerial and Policy Implications ................................................... 240

7.3.1 Strategy development ........................................................... 240

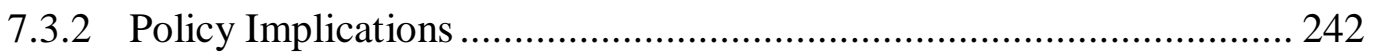

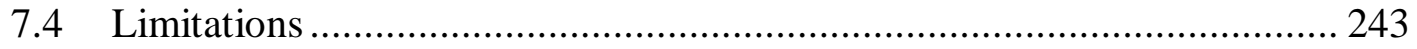

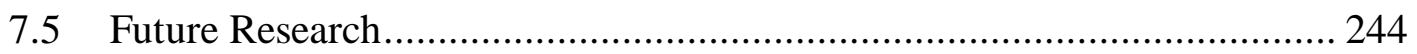

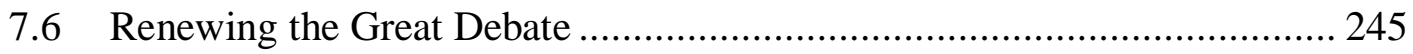

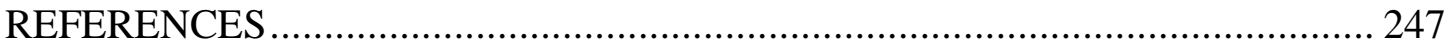

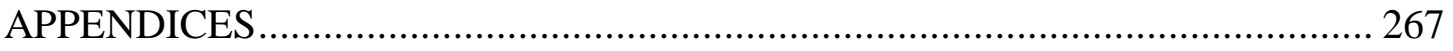




\section{LIST OF TABLES}

Table 1-1Summary of concepts and definitions................................................. 9

Table 2-1 Neoclassical economics and social practices perspective differences........ 23

Table 2-2 Summary of theoretical positions and influences................................... 28

Table 5-1 Linkages - performances, institutional practices and market effects.......... 89

Table 6-1 Regulator practices in the Fundamental Era …...................................... 98

Table 6-2 Provider Practices in the Fundamental Era ............................................ 111

Table 6-3 User practices in the Fundamental Era ............................................... 122

Table 6-4 Regulator practices in the Feature Era ............................................... 141

Table 6-5 Provider practices in the Feature Era................................................. 157

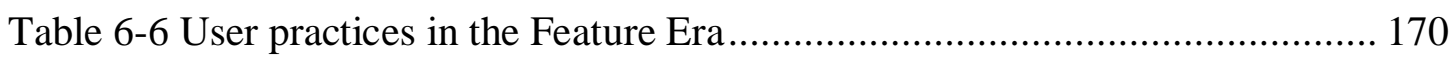

Table 6-7 Regulator practices in the Flexible Era ............................................. 180

Table 6-8 Provider practices in the Flexible Era ................................................ 188

Table 6-9 User practices in the Flexible Era..................................................... 211

Table 6-10: Parameters: a comparison across market eras ................................... 228

\section{LIST OF FIGURES}

Figure 3-1 The Market Practice Model. ............................................................... 52

Figure 3-2 Influence of parameters on performances and institutional practices ....... 55

Figure 5-1 Method-in-use Fundamental Era ..................................................... 86

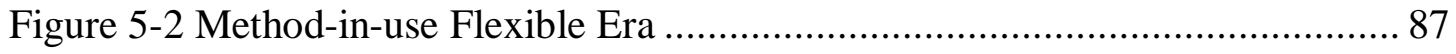

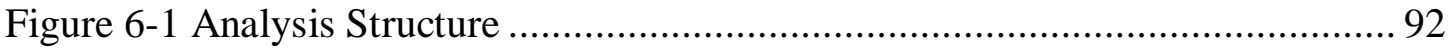

Figure 6-2 Fundamental Era: Mobile subscriptions in millions and as a percentage of the population

Figure 6-3 Feature Era: Mobile subscriptions in millions and as a percentage of the

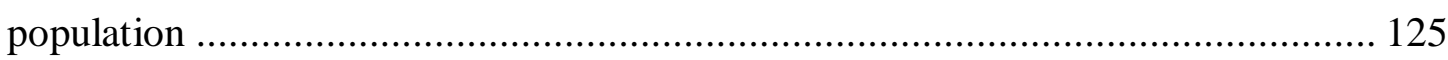

Figure 6-4Mobile market share 1994 - 2007................................................... 138

Figure 6-5Flexible Era: Mobile subscriptions in millions and as a percentage of the

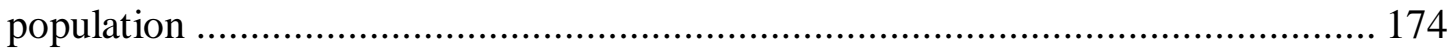

Figure 6-6 Market share across the Flexible Era................................................. 175

Figure 6-7 The growth of the New Zealand mobile market ................................ 218

Figure 7-1 Cumulative parameter change ........................................................ 241 


\section{INTRODUCTION}

"For a profession that purports to be interested in what happens in markets, we devote surprisingly few resources to defining what might naturally be regarded as our basic unit of analysis." Paul Geroski (1998, p. 678)

\subsection{Background}

Markets are interesting because exciting things happen there. Most of marketing study is, however, focused on those exciting things and market models and market boundary definitions tend to be taken as a given. Nevertheless, the definitions of markets and market boundaries provide the ontological perspective and context for marketing theorising and for marketing strategy (Geroski, 1998). It is therefore important for marketing theorists to base their understanding in a market model that not only reflects contemporary conceptualisations but also provides for future theorising.

Marketing adopted its market understanding from neoclassical economics which itself emerged from the philosophical debates in German universities from the 1850s (Jones \& Monieson, 1990; Lawson, 2005, 2010). The ontological foundation for neoclassical economics was that of the homo economicus rational man whose world could be explained through mathematics (Lawson, 2005; Reckwitz, 2002). This is problematic. The nature of markets and marketing, and our understanding of mankind, has changed over the past 160 years. The neoclassical perspective was spawned before the petrol engine, but today marketers as practitioners and academics are concerned about the search engine. The internet, and then the mobile telephone, enabled individuals to trade with partners anywhere in the world at any time. Traditional boundaries, including national boundaries, have blurred. Free trade and globalisation have transfigured markets and market boundaries. 
Furthermore, since the 1980s marketing has diverged from the neoclassical economics perspective of the buyer-seller dyad, price-defined market boundaries, and markets in equilibrium, towards a social practice theoretical basis of people, communities, and of value exchange, as evidenced, for example, in service dominant logic (Vargo \& Lusch, 2016) and consumer culture theory (Arnould, 2007; Arnould \& Thompson, 2005). The neoclassical model of markets has been further challenged by recent conceptualisations of markets as social structures ( Layton, 2011; Mele, Colurcio, \& Russo-Spena, 2014; Mele, Pels, \& Storbacka, 2015; Nenonen, Kjellberg, et al., 2014; Nenonen \& Storbacka, 2011; Storbacka \& Nenonen, 2011a) and the need for new models to contextualise marketing research have been repeatedly expressed (Kjellberg et al., 2012; Penaloza \& Venkatesh, 2006; Vargo et al., 2017; Venkatesh \& Penaloza, 2006). Marketing has not, however, replaced the neoclassical economics conceptualisation of where people trade and engage with a socially structured model of markets that reflects theoretical approaches founded in social practice.

Neoclassical economics market boundaries are defined by price and geography through the spatial range of the demanded and/or supplied goods and services and thus intensity of spatial spending power. Markets are perceived as static (Brooks, 1995; Löffler, 1998). The price-geography and static model is regarded as problematic and illusory (Baker, 2007; Geroski, 1998) and attempts have been made to define dynamic boundaries by broadening definitions such as to include value chains (Commerce Commission of New Zealand, 2014b). Contemporary marketing theorising has explored market boundaries, but while some boundary characteristics are identified (Nenonen, Kjellberg, et al., 2014; Nenonen \& Storbacka, 2011; Nenonen, Storbacka, \& Rehl, 2014) a definition of boundaries is incomplete. Conceptualisations of markets, such as a systems or ecosystems approach, have also been offered (Vargo et al., 2017; Vargo \& Lusch, 2011) but suggest little on market boundaries, and themselves refer to social practice theory as a basis for market theorising. 
Social practice theory provides approaches that are an alternative to the neoclassical economics perspective by recognising social structures are dynamic and are delineated from others by the practices recognised and routinised by actors within the structure (Giddens, 1984; Gosling, Richard, \& Seo, 2017; Lindeman, 2012).

The fundamental theoretical gap, and the focus of this exploratory thesis, is a social practice-based model of markets and market boundaries, that reflects, and therefore allows for, new theorising in marketing.

\subsection{Research Objectives}

This thesis aims to inform our understanding by exploring a social practices-based approach to markets and market boundary definition. Such a study promises insights into the structure of markets and the routinised behaviour of market actors. Market boundary definition principles would enable understandings of markets for either theorising or for practical strategy development. Accordingly, the two specific and linked objectives of this study are:

1. To explore a social practices model of markets and market boundaries to provide a foundation for future marketing theorisation; and

2. To explore a markets and market boundary theory that expands our understanding of market emergence and evolution.

\subsection{Research Questions}

While recent literature has been centred in social practice theory, the literature is itself fragmented and omnidirectional. The elements of a market model - what marketing theorists conceive, consciously or unconsciously, as a socially structured market and what it must contain and what it must do - can, however, be abducted from the literature. For instance, that boundaries of a market are necessarily plastic and porous and thus are destabilising (Nenonen \& Storbacka, 2011). Vargo et al. (2017), while describing theoretical challenges facing market 
model alternatives, suggest elements that a market model must contain: firstly, that a market model would have to define how elements in market interrelate, whereby a change in any component would cause a corresponding change in the operation of the market; secondly, that a market model should describe how actors are motivated to change their behaviours; and further, that a market model must describe how markets emerge and evolve and cease to exist. The review of the literature suggested these four research questions:

1. How does a social practice theory-based Market Practice Model contribute to a dynamic general theory of markets?

2. What parameters forming market boundaries can be identified?

3. How do parameterising practices forming market boundaries influence how markets emerge and evolve?

4. How are market actors motivated to change their behaviour?

\subsection{Research Approach}

The research aims, objectives and questions position the study in a social constructionist epistemology for exploring new theory through interpretations based on distinct decision frameworks. Epistemology provides a philosophical grounding for what kinds of knowledge are possible and how material knowledge is both adequate and legitimate (Crotty, 1998). Social constructionism as an epistemology suggests truth or meaning comes into existence from our engagement with the realities in our world. Social constructionism, therefore, is a function of shared meanings, sustained and reproduced through social life in a specific circumstance (Guba \& Lincoln, 1994). As social phenomena stem from human action, then the process of bringing these social realities into being requires interpreting and reinterpreting them (Crotty, 1998; Eco, 1992). For this thesis, the researcher's approach to social constructionism was guided by Cayla and Eckhardt (2008), Humphreys (2010), Miles, 
Huberman, and Saldaña (2013), O'Driscoll (2006), and Thompson (1997), and the abductive research strategy and hermeneutic methodology by Alvesson and Sköldberg (2009). Abduction recognises that understanding results from pre-understanding, interpretation, and reflection, and contextually-based reinterpretations of interpretations of patterns constructed from data (Alvesson \& Sköldberg, 2009; Aspers, 2007). Hermeneutics is a mode of analysis based on practical judgment and cultural/historical connection for understanding textual data, and a reflecting practice of unmasking and deciphering indirect or hidden meanings beneath apparent ones (Alvesson \& Sköldberg, 2009; Crotty, 1998; Myers, 1997). Thus, the framework provides for emergent insights and conclusions to be constructed from interpretive readings of market actor recollections and historical documentary material.

\subsection{Data Construction}

Given the constructionist epistemology, and the exploratory and conceptual nature of this research, data construction methods were chosen that could provide an insight into perspectives and interpretations from interviews and textual evidence.

The New Zealand mobile telecommunications market between 1990 and 2014 offered an informative context as the market's rapid unfolding from creation to maturity would likely illuminate changes to practices. The research was structured to enable comparison of practices between three distinct but overlapping market eras delineated by the technology predominantly in use, thus enabling changes in actor performances between and during market eras to be compared. A narrative is thus presented for each market era providing evidences of performances by market actors (Martin \& Schouten, 2014; Schau, Muñiz Jr, \& Arnould, 2009; Shove \& Pantzar, 2005).

Thematic, topic-centred, sequenced open questions provided a fluid semi-structured interviewing process enabling an interactional exchange of dialogue (Cavana, Delahaye, \& 
Sekaran, 2001; Mason, 2002). Interviewees were selected according to criteria to provide assurance of being both informative and representative of a much wider group (Mason, 2002). This research involved interviews with providers, users, and regulators acting in the New Zealand mobile telecommunications market between 1990 and 2014.

Documentary data included 26 years of annual reports of a mobile telecommunication provider, Telecom New Zealand (later Spark New Zealand), and annual and industry analysis reports of the Commerce Commission of New Zealand, as market regulator, covering the entire research period plus a further year. Quantitative market metrics were used to identify delineating characteristics of each market era. The extent of movements in social practice were measured through the differences in performances over specific time frames, and baseline comparison between those practices of 1990 and intervening periods to 2014 (Cayla \& Eckhardt, 2008; Gummesson, 2000; O'Driscoll, 2006; Thompson, 1997).

Data was subjected first to coding using NVivo11 and secondly to hermeneutic analysis grounded in the social practice theory approach to markets and market boundaries (Gosling et al., 2017; Shove, Pantzar, \& Watson, 2012) and according to predetermined decision rules for each layer of interpretation (Easton, 2010; Nili, Tate, Johnstone, \& Gable, 2014; Zaltman, LeMasters, \& Heffring, 1982).

\subsection{Trustworthiness}

Social constructivist research relies heavily on trustworthiness in establishing plausibility and validity (Guba \& Lincoln, 1994). Trustworthiness is more likely through rigorous methodology (Rynes \& Gephart jr, 2004) perhaps through a spread of participants such as through different firms, levels and backgrounds, or through triangulation (Miles et al., 2013). Zaltman et al. (1982) argues for theory construction based on reality tests derived from the researcher's frame of reference built of assumptions, expectations and decision rules. In this 
research, procedures developed to encourage trustworthiness involved the use of numerous interviews with individuals with both similar and different characteristics and the correlation and comparison of data. Interview texts were corroborated against documentary evidence such as historical organisational reports, and against quantitative metrics derived from multiple sources (Cavana et al., 2001). The specifically constructed coding process using NVivo11 enabled post-analysis confirmation and reflection of the methods and consistent analytical streams from codes to categories. Convergence of similar themes emerging from all three data collection methods - interviews, documents and metrics - indicated enhanced trustworthiness of the material (Cavana et al., 2001; Mason, 2002; Miles et al., 2013). A Research Analytic Memorandum was maintained to keep track of thoughts, processes, and specific issues and events. There was frequent discussion with supervisors throughout the research process.

\subsection{Research Contributions}

\subsubsection{Academic Contributions}

Marketing scholars have moved away from neoclassical economics conceptualisations of markets and towards a socially-based paradigm. This research promises a contribution to academic knowledge through the exploration of a social practices-based Market Practices Model that provides a rational and dynamic approach as to how markets are created, how they evolve and how they cease to exist, how innovations shape markets and how market actors are motivated to change.

A key contribution of the Market Practices Model is that boundaries are formed from nine specific categories of practices termed parameters, and that markets change as parameters emerge and evolve or dissipate. Individual parameters, and combined influences of parameters, vary over time, and change in one or more parameters may not only change the boundaries of a market but also force changes to the embedded institutional practices describing the market paradigm (Gosling et al., 2017; Kjellberg \& Helgesson, 2006, 2007). The thesis further 
contributes by suggesting two distinct but related approaches to the willingness of market actors to perform in accordance with practices within a specific market delineated by specific market parameters.

\subsubsection{Management and Policy Contributions}

An understanding of markets and market boundaries from a social practices perspective has important implications for managers and for public policy. Market shaping strategy could be based on identifying cumulative practice trajectories, and the likely impacts.

Market definition and market boundary definitions are critical for anti-competitive and merger-acquisition policies. To date, policies have centred on neoclassical economics-based approaches of geographical and price boundaries even where notably deficient (Baker, 2007; Commerce Commission of New Zealand, 2014b; Farmer, 2002; Geroski, 1998). A contribution of the market model based in social practices is that market boundaries, market change, and exchange processes may be more accurately and objectively described.

\subsection{Thesis Structure}

Following this introductory chapter, the thesis is organised into six further chapters. The next chapter reviews literature of market conceptualisation from the neoclassical economics perspective through to contemporary theorisations of market boundaries, value creation, and exchange. The third chapter provides the conceptualisation of the Market Practices Model including the definition of market boundaries through nine specific categories of practices termed parameters. The fourth and fifth chapters describe the methodology and processes of data construction for the empirical research spanning 25 years of the New Zealand mobile telephone market. Chapter six provides the analysis and findings from the hermeneutic exploration of interview text and documentary evidence. The final chapter draws conclusions 
and discusses the relevance and importance of findings in light of the identified gaps in extant marketing literature and theorisation.

\subsection{Summary of Concepts and Definitions}

To assist with clarification, table 1-1 provides a summary of concepts and definitions employed in this thesis.

Table 1-1Summary of concepts and definitions

\begin{tabular}{|c|c|c|}
\hline CONCEPT & THEORETICAL BASIS & DEFINITION \\
\hline Market Actors & $\begin{array}{l}\text { Agency Theory, } \\
\text { Institutional Theory, } \\
\text { Service-Dominant Logic }\end{array}$ & $\begin{array}{l}\text { Actors are performers of practices - the routinized ways of } \\
\text { doing, understanding, and desiring. Market actors are all } \\
\text { the parties who are active in a market: suppliers, firms, } \\
\text { customers, infrastructures, authorities and so on. The } \\
\text { actors include all the organisations, networks of industries, } \\
\text { and facilitators of exchange, all of whom may exist in } \\
\text { overlapping markets. }\end{array}$ \\
\hline $\begin{array}{l}\text { Market } \\
\text { Performances }\end{array}$ & Social Practice Theory & $\begin{array}{l}\text { The undertaking of practices by market actors - their } \\
\text { routinized sayings and doings within market boundaries. }\end{array}$ \\
\hline Parameters & $\begin{array}{l}\text { Social Practice Theory, } \\
\text { Agency Theory, Markets } \\
\text { as Networks Theory, } \\
\text { Structuration Theory. }\end{array}$ & $\begin{array}{l}\text { The specific categories of interrelated practices establishing } \\
\text { the physical and virtual limits of a market within which } \\
\text { specific exchange performances are understood and } \\
\text { enacted by a set of market actors. }\end{array}$ \\
\hline Practices & & $\begin{array}{l}\text { Practices are a nexus of routinized sayings and doings - } \\
\text { behaviours, mental activities, things and their use, } \\
\text { background knowledge, states of emotion, and the world } \\
\text { understood. }\end{array}$ \\
\hline Market Practices & $\begin{array}{l}\text { Institutional Logic, } \\
\text { Structuration Theory, } \\
\text { Social Practice Theory, } \\
\text { Agency Theory, Market }\end{array}$ & $\begin{array}{l}\text { Market practices include all activities that constitute } \\
\text { markets - what is done in a market, how it is done and what } \\
\text { actors do in the highly specific sense of a particular market. }\end{array}$ \\
\hline Institutional Practices & Practice Theory & $\begin{array}{l}\text { Social structures, such as markets, are determined by the } \\
\text { limit of their institutions - the clustering of connected and } \\
\text { persistent routinized normalising, representational and } \\
\text { exchange practices describing in social contextual what is } \\
\text { done, and how it is done, and how value is ascribed, in a } \\
\text { specific market. }\end{array}$ \\
\hline Transvections & $\begin{array}{l}\text { Markets as Networks } \\
\text { Theory, Macromarketing }\end{array}$ & $\begin{array}{l}\text { The successive stages of exchanges whereby a single end } \\
\text { product is placed in the hands of a consumer after moving } \\
\text { through an entire sequence of intermediate exchanges, } \\
\text { transactions and transformations from original raw } \\
\text { materials. }\end{array}$ \\
\hline
\end{tabular}




\subsection{Conclusion}

This thesis presents a fresh approach to the discussion on a general theory of markets. The exploration of a market model grew from insights evidenced from the literature that contemporary marketing and market theorising had diverged from the neoclassical economics explanations of markets and market boundaries, and that social practice theory provided a theoretical basis for a market model that provided context for future market and marketing theorising. Social practice theory now forms the foundation for both theoretical and practical market and marketing analysis. The market model explored in this thesis suggests a flexible and generalisable approach to how markets form, function, stabilize, destabilize and change. My research specifically identifies the categories of social practices forming boundaries, or parameters, and describe the influences of evolving parameters on market performances. Describing markets in terms of social practices and performances conceptualises markets as places where actors integrate resources and relationships to co-create value. Describing market boundaries in terms of practices further describes how actors amend their own performances in order to function within a market. 


\section{LITERATURE REVIEW}

\subsection{Introduction}

Recent debate, evidenced from marketing literature, argues for a new general model of markets allowing new perceptions of marketing and exchange. While some elements of a general market model have been described, the debate is not complete and the definitions of markets and market boundaries are not made explicit. Furthermore, while marketing as a discipline diverges from neoclassical economics, an alternative ontology by which to conceptualise and redefine markets and marketing is not yet offered.

In this chapter a hermeneutic abductive analysis is provided of market perspectives from neoclassical economics, marketing, management, and sociological literature to provide a foundation for the market and market boundary conceptualisations that follow in subsequent chapters. The elements that would comprise a market conceptualisation become apparent from the literature including a basis for markets, market function and exchange, and perspectives of market change and market boundaries.

\subsection{Neoclassical Economics Perspectives on Markets}

\subsubsection{Neoclassical ontology - the rational man}

Neoclassical economics emerged from the German Historical School debates of the 19th century from which was developed an ontology of rational man (Brennan, 2006; Jones \& Monieson, 1990; Lawson, 2010, 2013). Marketing's origins were framed on a neoclassical model by American scholars at German universities in the late 1800s who later led American university economics departments. The earliest marketing literature was created in 1906 by Samuel Sparling. Edward David Jones had by 1914 built a marketing discipline and introduced the first university courses and literature in marketing (Jones \& Monieson, 1990). Until the 1980s marketing, particularly in the United States, remained constructed on neoclassical economics (Webster, 1992). 
Neoclassical economics theory purports a market as a place facilitating the exchange of rights of ownership; more particularly a place where prices are established. Markets are any arrangement that facilitates buying and selling of goods and services, and where individual decisions are coordinated through price adjustments. A market is shaped by the concentration of rational buyers and sellers who influence price in their own best interest, the differentiation between competing producers, and the conditions of entry. Buyers and sellers are separate entities who control their own resources and make rational decisions that reflect their preferences and best interest, but who function within the constraints of marketplace rules. At least three actors are needed for a market to exist - at least one independent actor on the one side of a market who is aware of at least two independent actors on the other side whose offers can be evaluated in relation to each other (Aspers, 2007; Callon \& Muniesa, 2005; Horsman \& St John, 1992; McGuigan \& Moyer, 1989; McMillan, 2002; Milgrom \& Roberts, 1992; Parkin, 1993; Webster, 1992). In the market forum it is assumed that information flows freely, property rights are protected, people can be trusted to live up to their promises, and competition is fostered, although it does not have to be present (McMillan, 2002). Explicitly, the interactions and actions of market actors, markets and market boundaries, must be determined mathematically (Brennan, 2006; Lawson, 2013). In essence, markets are economic structures for the exchange of rights and the evaluation and pricing of products (Aspers, 2007). The neoclassical definition of the size of a market results from the spatial range of the demanded and/or supplied goods and services. Thus from a neoclassical economics perspective, market boundaries result from the intensity of spatial spending power (Brooks, 1995; Löffler, 1998).

Despite, however, the dominance of neoclassical economics perceptions of markets shaping social science, including the marketing discipline, economics struggles with a broader description of a market's boundaries or who, or what, may influence these (Fourcade, 2007; Zuckerman, 2003). The neoclassical economics conception of market boundaries from a rigid, 
two-dimensional price-equalization geographical perspective provides analytical outcomes that are often illusory (Baker, 2007; Farmer, 2002; Geroski, 1998). Indeed, recent economic dialogue suggests there is no single substantive economics definition of markets and market boundaries (Berndt \& Boeckler, 2009; Boeckler \& Berndt, 2013).

\subsubsection{Criticism of the economic rational model}

Since the 1980s, the economics perspective has been criticised as under-socialised and increasingly separate from the rest of society (Granovetter, 1985). Economics perceives human behaviour as being affected minimally by social relations - indeed, social relations are seen as impeding competitive markets. Instead, Granovetter argues, markets should be described as social structures with actors whose goals may not be strictly economic. Gummesson (2002) argues social, legal, cultural and other forces are understated or ignored by economics and instead envisages a sociological approach. Layton (2008, p. 224) notes: "In neoclassical microeconomics, the assumptions of perfect rationality and full information lead to a theory of perfectly competitive markets in equilibrium that is clearly at odds with the underlying reality. Dynamic disequilibrium becomes the norm”. Brennan (2006) maintains economics makes untenable assumptions of human behaviour. "Economists conceive of their subject as being concerned only with the pricing system and anything outside this is considered as no part of their business. What happens in between the purchase of the factors of production and the sale of the goods that are produced by these factors is largely ignored. What is studied is a system which lives in the minds of economists but not on earth. I have called the result 'blackboard economics'. The firm and the market appear by name but they lack any substance." (Coase, 2005, pp. 32-33). “...discussion of the market itself has entirely disappeared” (Coase, 1988, p. 7). Geroski (1998, p. 678) notes "For a profession that purports to be interested in what happens in markets, we devote surprisingly few resources to defining what might naturally be regarded as our basic unit of analysis." 
Market definitions matter because market boundaries were a driver of strategic innovation and had extremely powerful effects on a firm's identity and the skills or capabilities required to compete (Geroski, 1998).

Geroski (1998) describes how the neoclassic definition of a market as a place of exchange dated back a century to some of the first thoughts about the nature of commerce where market definition was based solely on price equalisation - a market was where a collection of individuals paid the same price for a particular product. Defining a market this way was a difficult thing to do (Baker, 2007; Farmer, 2002; Geroski, 1998). Geroski advocates a market definition broader than the buyer-seller dyad, noting that firms looked up their value chain to suppliers to develop process innovation and to drive down costs, while differentiating firms looked down the value chain. Attempts to use only people, places, needs and functions, or any particular supply side factor to define a firm's market, were fundamentally incomplete, he argues. Instead, Geroski suggests the market definition must also encompass consumer groups, consumer functions and technology. The New Zealand Commerce Commission's Mergers and Acquisitions Guidelines (2014b) provides an example of this approach where the commission acknowledges there may not be a distinctive separation between products that are within a market from those outside, and acknowledges that actions in one part of the supply chain may affect another, that different links in the chain may be impacted differently, and that different customer types may also be affected differently. In critiquing the neoclassical approach, Mele et al. (2015) note that the focus on the exchange of products and the buyerseller dyad obscures the way market actors define a market and industry, and that the dyad is actually part of a much greater network of actors who contribute to the creation of value and who supported the success of the dyad. The emergence of billion-strong markets, such as Amazon and Facebook, illustrate the shortcomings of market conceptualisations that fail to 
account for market complexity that might best be captured by integrating perspectives from different research fields (Mele et al., 2015).

The next section first explores the broadening of perspectives from markets based on collections of transactions between buyer-seller dyads to an understanding of markets based on transvections - transformations and transactions - between networks of actors some of whom were not directly involved. The section then traverses the conceptual shift towards markets as social structures.

\subsection{Marketing Perspectives on Markets}

\subsubsection{From dyad to network}

Despite the importance of an understanding of markets as a contextual foundation for marketing (Kjellberg et al., 2012), marketing as a discipline struggles with defining marketing while ignoring markets (e.g., Ringold, 2006; Seth \& Sisodia, 2006; Wind, 2006). By the late 1990s marketing theorists had recognised the market as a basic unit of analysis - a market is the arena in which exchange takes place and the exchange is the fundamental purpose of the marketing process - but the question as to how a market should be defined required resolution (Buzzell, 1999). For example, Hunt (1983) describes marketing as the institutional framework directed at consummating and/or facilitating exchange. In comparison, Day and Montgomery (1999) argue the relationships in marketing have been expanded from the dyad of seller and customer to include partnerships up and down the value chain (such as suppliers, the customers of customers, channel intermediaries). Indeed, Thorelli (1986) argues entire economies could be seen as interlaced networks. Integral to networks is trust - buyers and sellers are active participants in an exchange process that accounts for previous and future transactions (McLoughlin \& Horan, 2002). The network perspective embraces not just the buyer-seller dyad but also the seller's own suppliers, competitors, middlemen, public authorities, media, and other entities in society that exert influences on market behaviour. A company is a node 
for an ever-widening pattern of interactions in which it is sometimes a direct participant, and some of which occurs independently of it (Gummesson, 2002). From the markets-as-networks perspective the market is seen as a far broader performance of actors than envisaged by the neoclassical view (Layton, 2007).

\subsubsection{From transactions to transvections}

Macromarketing theory describes markets as a social mechanism for managing production, distribution and consumption decisions, and their relationships with society. Markets are complex, adaptive, social networks in which structure and function are important and which derive from a dynamic matching of products and needs (Layton, 2007). Layton argues for market boundaries based on the participating actors (individuals, organisations, and the levels of aggregation involved) and a specification of the linkages between them. Deciding which actors are to be included is an essential step in defining market boundaries. Markets are based not on single transactions but on transvections - the successive stages of exchanges whereby a single end product is placed in the hands of a consumer after moving through an entire network of intermediate exchanges, transactions and transformations from original raw materials (Alderson \& Martin, 1965; Layton, 2007). Markets-as-networks and macromarketing theories contribute to a general theory of markets through perceiving markets as networks involving more actors than those involved directly in the exchange, which includes all those involved in transvection and which encompasses those who facilitate exchange but who physically take no direct part, such as banks and insurers.

\subsubsection{From economic structures to social practice structures}

\section{Market definition}

Markets, in the neoclassical ontology, rely on price signals to coordinate the production and distribution of goods and services and exchange of property rights. Glynos (2011) argues 
markets from an alternative ontological standpoint whereby human beings are meaningproducing animals and markets are spheres of meaning. Thus, markets are perceived not only as economic constructs, but also as social phenomena. Markets are also shaped by the performances of actors that are developed and reinforced over time, and different social enactments of markets are possible. Market boundaries are similarly social constructions with equivocal meanings (Rosa, Porac, Runser-Spanjol, \& Saxon, 1999).

The market practice view combines actor-network theory, markets-as-networks, and social practice theory (Storbacka \& Nenonen, 2011a). Markets are social phenomena based on relationships involving shared understandings of what is exchanged and how value is ascribed. Markets are shaped by the performances of actors that are developed and reinforced over time, and different social enactments of markets are possible. Webster and Lusch (2013) propose shifting from the neoclassical focus on transactions, exchange, and the buyer-seller dyad, to encompass all the actors and social roles in the complex value creation process. Webster and Lusch (2013) describe a person who buys a car as also being a customer of insurers, oil companies, petrol retailers, government agencies, auto parts suppliers - all of which are to a certain degree dependent on the others. Many activities require multiple interactions and partnerships with other actors in multiple roles, the value embedded in the product being replaced by co-creation of value by all participants in the system. The nature of the market is based on the social need of the participants and these social aspects could change. Webster and Lusch (2013) define a market as a set of institutions or actors, physical or virtual space, discourses, and practices, but the authors do not attempt to explain what the market would look like, how it would function, or how boundaries could be determined. Venkatesh and Penaloza (2006, p. 136) define a market as "a set of institutions and actors located in a physical or virtual space where marketing-related transactions and activities take place. Typically, these institutions and actors include sellers, buyers, customers, retail stores, sales offices, commercial 
banks, advertising agencies, and the like. Thus the key concepts are a set of institutions or actors, physical or virtual space, discourses, and practices."

Institutional logic (Thornton \& Ocasio, 2008), with its foundations in structuration (Giddens, 1984; Schatzki, 1996) and institutional theory (Scott, 1995, 2008) and its acknowledgement of material and cultural foundations of institutions which parallel the elements of social practices (Shove et al., 2012), recognises the role of culture and cognition in the integration of organisations with other organisations in a variety of contexts, including markets, and provides a link between individual agency and socially constructed institutional practices and rules structures (Thornton, Jones, \& Kury, 2005; Thornton \& Ocasio, 2008). The social context regularises behaviour and provides opportunity for engagement and change. Markets function because of both formal laws and normative expectations, whereby a market in one social context would not be the same as a market in another (Thornton \& Ocasio, 2008). Thus, markets and the performances and structures of corporates are directly shaped by social and community meanings (Bhappu, 2000; Kilduff, Funk, \& Mehra, 1997; Thornton \& Ocasio, 2008).

\section{Market boundaries}

Finch and Geiger (2010) describe a market as a socio-technical organisation that connects many actors and products (including services) and which enables comparisons between offerings. Market boundaries are porous and could be upset through bringing new or previously excluded dimensions and products into the market place (Finch \& Geiger, 2010). Nenonen, Kjellberg, et al. (2014) define markets as ongoing socio-material enactments that organise economised exchanges. These enactments are ongoing because they are created and enacted by sets of interconnecting practices. An outcome of the interconnections is that market boundaries are blurred. Market structures describe where markets take form through change in the number of actors participating in the market or in the roles of the market actors and the relationships 
between them. Market structures change as a result of the strategic actions and rivalry between and across firms, through entry into or exit from the market, or via changes in the degree of product substitutability (which redrew market boundaries, including or excluding products and/or firms). Market structures are thus stabilised by the technological, economic, and policy conditions that apply (Nenonen, Kjellberg, et al., 2014).

The conceptual shift towards practice in markets illuminates the role of the actor and raises the question of how "actor" may be defined. The definition of actor draws on both agency theory and institutional theory (Dacin, Goodstein, \& Scott, 2002), whereby an actor is a socially-constructed identity, marked by continuity and uniqueness, and shaped and held accountable by common bonds with other actors (Andersson, Aspenberg, \& Kjellberg, 2008). Andersson et al. (2008) advocate inclusion of non-humans as actors if all the practices that make up economic exchange are to be examined. The actor, either human or organisational, was the entity to which practices could be attributed (Whetten \& Mackey, 2002). Aspers (2009) defines a market as a social structure for exchange that becomes stable because of actors' shared practices and cognitive frames. The term "structure" implies that the market exists over time, similar offers are traded in the same market, the rules of engagement are defined in a culture where actors understand what the market is and how they should normally behave, and actions, offers, and prices are to some degree predictable (Aspers, 2009). In brief: what is sold, how it is sold and how prices are set depend on the practices performed by market actors who are defined by, and who helped define, particular socially constructed structures called markets.

\subsubsection{Conceptualisations of exchange and competition}

Not only do marketing perspectives of markets evolve away from the neoclassical, but also evolving are perspectives on what is exchanged within markets and how value is created. Gummesson (1994) advocates a service paradigm where the customer is a co-producer of 
value, but where value is also created independently by the provider and the customer. Gummesson (1994, p. 78): "Customers do not buy goods or services in the traditional sense. They buy an offering which renders services which create value for the customer. The offering and the value consists of many components, some of them being activities (services), some being things (goods). As a consequence, the traditional division between goods and services is long outdated. Instead, it is a matter of redefining services and seeing them from a customer perspective: activities render services, things render services." In essence, the customer buys all the practices that form the service. Service-dominant logic expands conceptualisations of products and the exchange of value processes by arguing that all offerings are services, defined as specialised competencies, where value is defined by, and co-created with, the consumer (Vargo \& Lusch, 2004a, 2004b, 2008, 2011, 2014, 2016) . Organisations integrate and transform specialised competences into complex services demanded in the market place. Service is described as the basis of exchange and goods are an exchange mechanism. When goods are purchased, the consumer buys all the knowledge that created that good and transported it to the place of exchange (Vargo \& Lusch, 2016). By describing all social and economic actors as resource integrators, markets become an aggregation of capabilities and competencies.

Conceptualisations of exchanges as being broader than the buyer-seller dyad, and where 'exchange of value' is superseded by 'creation of value' thus challenges the neoclassical perception of markets and the actors within markets. Storbacka and Nenonen (2011a) describe markets as configurations of interdependent elements that increase the density of resources for the participating actors, and marketness as the degree of evolution of the configuration. Storbacka and Nenonen define market actors as all parties that are active in the market: suppliers, firms, customers, authorities and so on, who make subjective decisions by identifying in which relevant market networks they will participate. In this logic, market actors 
interact in a market to increase their density of resources and thus increase value. Therefore, market actors attempt to alter the configurations in their favour by improving the configurative fit of the elements. The elements of market configurations are the market actors' mental models, their business models, and the market practices that connect the different actors' business models (Storbacka \& Nenonen, 2011b).

\subsubsection{Market practices}

Social practice theory relates market actors as enacting markets through their behaviours based on embedded codes of conduct and social norms as described by the specific meanings and perceptions of their community. As the community changes over time, and meanings and perceptions change, then the market changes also (Alderson \& Martin, 1965; Araujo, 2007; Grönroos, 1989, 1994; Halkier \& Jensen, 2011; Miller, 2002; Penaloza \& Venkatesh, 2006; Rosa et al., 1999; Shove \& Pantzar, 2005).

Kjellberg and Helgesson (2006, 2007) translate social and community perspectives of markets into market practices. Market practices include all activities that constitute markets what is done in a market, how it is done and what actors do in the highly specific sense of a particular market. Markets are constructed and held together by interlinked groups of practices: exchange practices - the individual economic exchanges of goods; normalising practices - how a market and its actors were shaped; and representational practices - how markets and offerings are understood (Kjellberg \& Helgesson, 2006, 2007). Market practices change through a social process of translation whereby a rule, product, truth, technique or idea spreads across time and space. Further, all actors engaged in market practice - buyers, sellers and objects given value and exchanged - are chains of translations linking normalising, representational and exchange practices. Different markets, or a market over time, would see perhaps wide variation in the specific configuration and intensity of practices and their translational links (Kjellberg \& Helgesson, 2006, 2007). Such practices are the stickiness that holds markets together in that 
they are resistant to change, and evolve over time (Vargo \& Lusch, 2014). Due to their persistent, routinised, and socially contextual nature, both preceding and superseding market actors, for the purposes of the Market Practice Model of markets, the clusters of normalising, representational and exchange practices (Kjellberg \& Helgesson, 2006, 2007) are designated collectively as institutional practices which constitute a paradigm that both stabilises a market and describes how a market functions (Giddens, 1984; Gosling et al., 2017).

Korkman, Storbacka, and Harald (2010) argue that practices are not only what actors think or act upon but are something actors take part in during the integration of resources, and thus instead of examining the practices of actors in markets it was more illuminating to perceive practices as markets. Market actors created value through introducing new practice elements. Analysis of such elements enabled understanding of emergent economic exchange. Gosling et al. (2017) summarise recent theoretical arguments of practices-based understandings of markets and conclude performances by market actors are held in place by institutional practices that define, contextualise and stabilise a market, and market boundaries are defined and parameterised as the limits of specific categories of market practices.

Furthermore, individual actors are incentivised to perform in specific ways in order to be accepted by the collective. Nenonen, Kjellberg, et al. (2014) recognise how market institutions stabilise markets by the benefits they offer to transacting parties and the elaborate systems for upholding and maintaining the institutions. Araujo (2007) describes the institutions as structures stable enough to influence and constrain behaviour. Consumer culture theory perceives behavioural choices and practices as social and cultural phenomena that are heterogeneous distributions of meanings and unifying values shared by members of a society, such as a market (Arnould \& Thompson, 2005). Consumer culture theory, with its social construct view of the market, perceived culture as the fabric of experience, meaning and action, and provides actors with the framework and limitations of their performances (Arnould \& 
Thompson, 2005). Consumers are viewed as individual actors of social roles in a market. Consumers are not mere carriers of accepted culture but rather are co-producers of culture, creating and evolving beliefs that form the rules of performance in a market. Beliefs are aggregated in the institutions that constrain and enable actors by describing what will be exchanged in a particular market and the acceptable performances that enact the exchanges. Thus, individual actors are provided with incentives whereby performances that comply with the institutions, and therefore social beliefs, are rewarded with acceptance by the collective thereby enabling exchange. The mode of market change is also evident where impacts upon the social are reflected in altered beliefs whereby new meanings are ascribed to actions and symbols leading to amended performances and institutions (Arnould, 2007; Arnould \& Thompson, 2005). That incentives are offered to actors to comply with the cultural norms and rules of performance of the consumer community in order to participate as a member, is a similarity shared with the institutional economics perspective (Ménard \& Shirley, 2005; North, 2005). The conceptual differences between the neoclassical and social practice perceptions of markets are presented in Table 2-1.

Table 2-1 Neoclassical economics and social practices perspective differences

NEOCLASSICAL ECONOMICS PERSPECTIVES
MARKET PRACTICES

PERSPECTIVES

$\begin{array}{cll}\begin{array}{l}\text { Theoretical } \\ \text { perspective }\end{array} & \begin{array}{l}\text { Human behaviour is rational, framed in } \\ \text { self-interest, and affected minimally by } \\ \text { social relations. }\end{array} & \begin{array}{l}\text { Actor behaviour and social relations are } \\ \text { fundamental in forming and routinising } \\ \text { market practices. }\end{array} \\ \begin{array}{c}\text { Market } \\ \text { definition }\end{array} & \begin{array}{l}\text { The market is an economic construct } \\ \text { shaped by price calculation. }\end{array} & \text { shaped and legitimised by community } \\ & & \text { perspectives; and defined in aggregations of } \\ & & \text { social practices. }\end{array}$

Market action 
The market enables a transaction - an

exchange of value and ownership rights

between a buyer-seller dyad.

Transactions are enabled through

mutual voluntary exchange and the keeping of promises.

Change driven by technological

revolution

Market boundaries

Market boundaries based on price.
The market enables transvections - multiple

transformations and transactions of value creation and ownership rights - between networks of market actors, some of whom may be facilitators who take no direct involvement in the exchange.

Transvections are enabled through mutual voluntary exchange and the keeping of promises.

Change driven by social and technological revolution.

Market boundaries are plastic and porous, and parameterised by practices of which value propositions is one.

\subsection{Perceptions of market boundaries}

\subsubsection{Spatial matrix - Us and Other}

The social construction of meanings and values influences social practices and social perceptions including the ways actors perceive, agree upon, and use, the space around them (Stewart, 1995). Philosophy and sociology literature defines the space agreed by actors as the spatial matrix (Lefebvre \& Nicholson-Smith, 1991; Morley \& Robins, 1995; Stewart, 1995). Lefebvre and Nicholson-Smith (1991) describe space as a complex social construction acting not only as the terrain for social relations and actions but also determining that social relations and actions will occur in a certain way. Space is a structure that individuals help to construct and hence space is a social product which depends on the social construction of meanings and values influencing perceptions and social practices. Thus, there exist multiple spaces that as a result of social practices are produced socially. Collective identities are constituted through the cultural construction of boundaries, which allow distinctions to be made between those who 
belonged within the space as 'us' and those who did not as 'other'. Morley and Robins (1995) describe the construction of symbolic geography for separating insiders from outsiders such as who is in the market and who is not, based on the coherence, cohesion and continuity of the market actors through a collective memory. Maintaining boundaries requires ongoing interpretive efforts of promulgation and definition of the attributes of similarity among the societal members.

Instead of conclusively defined hard boundaries, markets as social space have porous boundaries mediated by social action and interpretation of symbols and enable not only recognition of 'us' and 'other' but also enable societal actors to pass in and out of the structure through adopting the social practices by which the society is defined (Eisenstadt $\&$ Schluchter, 2001; Jessop, 2012; Jessop, Brenner, \& Jones, 2008).

Concepts of 'us' and 'other' based on shared symbolic geography and practices helps, for example, to explain the specific performances by market actors relating to specific markets. Internet-based communities, for example, enable people to find and relate to others with similar interests, define who is 'us' and within their space and who is 'other' without their space. Communities form in their own virtual space, with a language and culture (practices) particular to that space and community, and which identifies people as part of the community (Araujo, 2007; Seo \& Jung, 2016).

Providers, as market actors, can themselves 'shape' the market. That is, through their mental models of the market and their actions to intentionally define the spatial matrix as a preface to market influencing while also redefining the boundary between 'us' and 'other' (Nenonen, Möller, \& Storbacka, 2017; Nenonen \& Storbacka, 2011; Nenonen, Storbacka, et al., 2014). The inference that providers can intentionally shape their market suggests that providers can define and influence the market space unintentionally. Furthermore other actors, 
such as regulators, who employ efforts to intentionally shape markets (e.g., Rebstock, Mazzoleni, \& Pickering, 2008), may also have unintentional or unconscious market influences (Evans, Grimes, Wilkinson, \& Teece, 1996; Howell, 2007). Users, through their collective decision-making and purchases, or through their use of alternate markets or market structures, may also unintentionally or unconsciously, shape or influence markets (Arnould \& Thompson, 2007). An example of the unintentional, yet emphatic, reshaping of markets due to the movement in user mental models of the market and their actions is the occurrence of substantial online shopping with the unintended consequences impacting the viability of physical stores. The spatial matrix is thus perceptual, subjective, and specific. Actor perceptions will be based on the intangible and the tangible such as infrastructure or how the infrastructure should be used or what it represents in terms of market boundaries (Layton, 2015). The spatial matrix can thus be defined as the subjective perceptions of market actors of the physical and virtual, tangible and intangible, symbolic limits of their space and place.

Markets, as societal structures, are thus unities defined by a clustering of practices whereby a market is separated from other markets by the practices (meanings and actions) specific to each market including perceptions of the spatial matrix. Market actors thus recognise the 'us' from within their market from the 'other' from outside based on shared understanding of the market space. The boundaries by which the market could be distinguished from others are plastic and form and reform as meanings, and actions are shaped and reshaped by changing practice that are accepted and adopted by those within (Giddens, 1984; Glynos, 2011; Nenonen \& Storbacka, 2011). Thus there is a need to turn now to the process by which practices become accepted, or legitimated.

\subsubsection{Legitimation}

Legitimation applies social practice theory to understandings of market creation that involve cultural, legal, and social frameworks (Kotler, 1986; Scott, 1995). Legitimation occurs where 
practices or institutions (a cluster of embedded practices) become socially, culturally, and politically acceptable within a particular context, such as a market, where producers, users, and their broader community come to shared understandings of what is being exchanged and how (Humphreys, 2010). Humphreys suggests that market creation is largely a process of institutionalising certain understandings and practices of exchange and gives as an example of the United States casino industry where shifts in cultural-cognitive legitimacy (public acceptance) occurred before shifts in regulatory legitimacy. It followed that public acceptance can be provided or withdrawn, with subsequent reflections in regulatory legitimacy, such as the opening of a legal market for marijuana in Colorado, which followed social legitimation of that market, or where with the Euro-North American slave trade the legal end clearly followed the public's changed mood against slavery.

Legitimation is thus dependent on debate by market actors in the public sphere. The public sphere is a virtual space where individual actors autonomous from state and economic power engage collectively in discursive exchange of information, ideas and critique, (Blanning, 2015; Dahlberg, 2001; Eder, 2006; Hauser, 1999; Papacharissi, 2002). The public sphere is the extent and manner of the general population's input into the functioning of society generally via some form of mass popular media (Ferree, Gamson, Gerhards, \& Rucht, 2002; Koopmans \& Erbe, 2004). In essence, a boundary of the market can be assumed from the social and community meanings assembled through the public sphere.

Table 2.2 summarises theoretical positions on markets and marketing, their theoretical dimensions, and their influences on the Market Practices Model conceptualised in the following chapter. 
Table 2-2 Summary of theoretical positions and influences

\begin{tabular}{|c|c|c|c|}
\hline $\begin{array}{l}\text { REPRESENTATIVE } \\
\text { PAPERS }\end{array}$ & $\begin{array}{l}\text { THEORETICAL } \\
\text { POSITION }\end{array}$ & DIMENSIONS & INFLUENCE \\
\hline $\begin{array}{l}\text { Jones and } \\
\text { Monieson (1990); } \\
\text { Webster (1992); } \\
\text { Brooks (1995) } \\
\text { Baker (2007); } \\
\text { Farmer (2002); } \\
\text { Geroski (1998); } \\
\text { Layton (2015); } \\
\text { Storbacka and } \\
\text { Nenonen (2011b) }\end{array}$ & $\begin{array}{l}\text { Neoclassical } \\
\text { economics }\end{array}$ & $\begin{array}{l}\text { Economics-based perspectives on } \\
\text { market and boundary definitions } \\
\text { incomplete. }\end{array}$ & $\begin{array}{l}\text { Markets as } \\
\text { economic } \\
\text { structures are } \\
\text { challenged by } \\
\text { contemporary } \\
\text { conceptualisations } \\
\text { of markets and } \\
\text { marketing. }\end{array}$ \\
\hline $\begin{array}{l}\text { Giddens (1984); } \\
\text { Schatzki (1996); } \\
\text { Reckwitz (2002) } \\
\text { Schatzki (1996); } \\
\text { Shove et al. (2012) } \\
\text { (Schatzki, 1996); } \\
\text { Warde (2005); } \\
\text { Hargreaves (2011); } \\
\text { Layton (2015) }\end{array}$ & $\begin{array}{l}\text { Structuration } \\
\text { Social practices } \\
\text { Practices as } \\
\text { entities } \\
\text { Practices as } \\
\text { performances }\end{array}$ & $\begin{array}{l}\text { Practices - routinized human action } \\
\text { that define societies and society } \\
\text { boundaries. } \\
\text { Shared or collective symbolic } \\
\text { structures of knowledge. } \\
\text { The actor is a performer of practices. }\end{array}$ & $\begin{array}{l}\text { Social practice } \\
\text { theory provides a } \\
\text { basis for } \\
\text { reconceptualising } \\
\text { markets and } \\
\text { market boundaries. }\end{array}$ \\
\hline $\begin{array}{l}\text { Giddens (1984); } \\
\text { (Shove et al., 2012) }\end{array}$ & $\begin{array}{l}\text { Components of } \\
\text { practices } \\
\text { Boundaries } \\
\text { defined by } \\
\text { practices }\end{array}$ & $\begin{array}{l}\text { Places defined by communities of } \\
\text { interdependent practices categorised } \\
\text { as: Competences, Materials, and } \\
\text { Meanings. } \\
\text { A society is a unity with boundaries. } \\
\text { Markets, as social structures, are } \\
\text { defined and demarcated by the limit } \\
\text { of their institutions - connected and } \\
\text { long-lived routinised practices. }\end{array}$ & $\begin{array}{l}\text { Markets are } \\
\text { defined by the } \\
\text { identification of } \\
\text { those practices, or } \\
\text { bundles of } \\
\text { practices, that } \\
\text { describe } \\
\text { boundaries. }\end{array}$ \\
\hline $\begin{array}{l}\text { Lefebvre and } \\
\text { Nicholson-Smith } \\
\text { (1991) Morely and } \\
\text { Robins (1995) }\end{array}$ & & $\begin{array}{l}\text { Collective identities construed through } \\
\text { cultural constructions of boundaries, } \\
\text { enabling identity of 'us' and 'other'. }\end{array}$ & \\
\hline Rosa et al. (1999) & Product markets & $\begin{array}{l}\text { Market boundaries inferred from fuzzy } \\
\text { signals about supply and demand. }\end{array}$ & \\
\hline $\begin{array}{l}\text { Alderson and } \\
\text { Martin (1965); } \\
\text { Gummesson } \\
\text { (2002); Layton } \\
\text { (2007); McLoughlin } \\
\text { and Horan (2002); } \\
\text { Thorelli (1986); } \\
\text { Layton (2007); } \\
\text { Storbacka and } \\
\text { Nenonen, (2011a); }\end{array}$ & $\begin{array}{l}\text { Market } \\
\text { practices, actor- } \\
\text { network, } \\
\text { markets-as- }\end{array}$ & $\begin{array}{l}\text { Markets as social structures with } \\
\text { boundaries based on networks of } \\
\text { market actors involved not in } \\
\text { transactions but in transvections } \\
\text { including actors not directly engaged } \\
\text { in the exchange. } \\
\text { Markets are social phenomena shaped } \\
\text { by the performances of actors } \\
\text { involving shared understandings of }\end{array}$ & $\begin{array}{l}\text { Markets as socially- } \\
\text { structured spaces } \\
\text { which enable } \\
\text { transvections, and } \\
\text { which are } \\
\text { described and } \\
\text { parameterised by } \\
\text { practices that } \\
\text { reflect, and impact } \\
\text { on, what is }\end{array}$ \\
\hline
\end{tabular}




\begin{tabular}{|c|c|c|c|}
\hline $\begin{array}{l}\text { Webster and Lusch } \\
\text { (2013) }\end{array}$ & $\begin{array}{l}\text { networks, and } \\
\text { social practice } \\
\text { theories }\end{array}$ & $\begin{array}{l}\text { what is exchanged and how value is } \\
\text { ascribed. }\end{array}$ & $\begin{array}{l}\text { acceptable to the } \\
\text { market community. }\end{array}$ \\
\hline $\begin{array}{l}\text { Andersson et al. } \\
\text { (2008); Dacin et al. } \\
\text { (2002); Nenonen et } \\
\text { al. (2014); } \\
\text { Thornton et al. } \\
\text { (2005); Thornton } \\
\text { and Ocasio (2008); } \\
\text { Whetten and } \\
\text { Mackey ( } 2002\end{array}$ & $\begin{array}{l}\text { Institutional } \\
\text { logic, } \\
\text { institutional } \\
\text { theory, agency } \\
\text { theory }\end{array}$ & $\begin{array}{l}\text { The link between individual agency } \\
\text { and socially constructed practices are } \\
\text { provided by institutions - long-serving } \\
\text { embedded practices. }\end{array}$ & \\
\hline $\begin{array}{l}\text { Kjellberg and } \\
\text { Helgesson (2006, } \\
\text { 2007); } \\
\text { Ménard and Shirley } \\
\text { (2005); North, } \\
2005\end{array}$ & $\begin{array}{l}\text { Practices as } \\
\text { institutions, } \\
\text { new } \\
\text { institutional } \\
\text { economics }\end{array}$ & $\begin{array}{l}\text { Markets are economic and social } \\
\text { constructs based on evolving, yet } \\
\text { persistent, rules of performance that } \\
\text { constrain and enable actors by } \\
\text { describing what will be exchanged in a } \\
\text { particular market and the acceptable } \\
\text { performances that enact the } \\
\text { exchanges. }\end{array}$ & \\
\hline $\begin{array}{l}\text { Arnould (2007); } \\
\text { Arnould and } \\
\text { Thompson (2005) }\end{array}$ & $\begin{array}{l}\text { Consumer } \\
\text { culture theory }\end{array}$ & $\begin{array}{l}\text { Practices are social and cultural } \\
\text { phenomena that are shared by } \\
\text { members of a society, such as a } \\
\text { market, with incentives for actors to } \\
\text { comply with the practices in order to } \\
\text { participate. }\end{array}$ & \multirow{3}{*}{$\begin{array}{l}\text { Market space } \\
\text { defined by shared } \\
\text { knowledge of } \\
\text { spatial boundaries }\end{array}$} \\
\hline $\begin{array}{l}\text { Lefebvre and } \\
\text { Nicholson-Smith } \\
\text { (1991) Morley and } \\
\text { Robins (1995) }\end{array}$ & & $\begin{array}{l}\text { Collective identities construed through } \\
\text { cultural constructions of boundaries, } \\
\text { enabling identity of 'us' and 'other'. }\end{array}$ & \\
\hline Humphreys (2010) & Legitimation & $\begin{array}{l}\text { Practices become embedded as } \\
\text { institutions as they become socially, } \\
\text { culturally, and politically acceptable. }\end{array}$ & \\
\hline
\end{tabular}

\subsection{Discussion and Research Gaps}

\subsubsection{Neoclassical Discussion}

Neoclassical economics have tended to dominate theorising on markets but Coase (1988) and Geroski (1998) identify that economic theorising has not extended conceptualisation of the market beyond price-based definitions that date back a century.

Neoclassical theories perceive product-driven and price-oriented markets which enable acts of exchange between a dyad of buyer and seller. Economics quantifies the extent of exchanges, but hesitates when describing the actions, transactions and relationships that lead 
to exchange, why the exchange is conducted in a particular way outside economic-cost definitions of efficiency, or where it will happen: the boundaries of the market are obscure. While there are suggestions that neoclassical economics should look beyond the buyer-seller dyad and pricing in defining markets and market boundaries - such as including all the actors involved in a network of transactions, or anything of non-economic socially-driven value economic theorists have not delivered such definitions (Coase, 1988; Geroski, 1998). Thus, neoclassical economic models of markets assist in describing how markets enact exchange, but do not sufficiently explain the actions that lead to the exchange in a way that reflects or satisfies marketing's contemporary understandings of social practices and relationships, or how performances change.

Neoclassical economics tends to exclude non-rational human behaviour and social relations. Perez (2009), for example, takes only the techno-economic perspective of market revolutions. The Industrial Revolution was, however, ignited and enabled by revolutions in social practice as much as technical. The micro-processor revolution was also enabled by social practice changes.

Social practice theory suggests that elements of neoclassical economics should be included in any new model of markets. The first, and most evident, is that a market is a structure where exchange takes place. The question becomes one of what sort of structures and institutions and what is actually exchanged and how? The second element is that a market is a place of trust where there is a willingness of market actors to rely on each other, with confidence, to behave in a particular way and to fulfil their obligations. Trust growth precedes income growth whereby the more people trust each other in a society the greater the transactional friction reduction and the more prosperous that society becomes (Arrow, 1974; Ridley, 2010). Furthermore, exchange is constrained and enabled by institutions - to act in this market, actors must follow specific rules and procedures or corrective action will be taken. 
However, to constantly invoke rules would be time consuming and non-economic. In this manner, for example the finance districts of London and New York operate daily at high levels of efficiency bound by rules and also by trust. Within the shadow of these financial markets operate illicit narcotics markets which have a different set of rules and institutions and their own corrective actions when trust is disturbed. While the geographic location of these markets is the same, the market space is very different. The difference between market place and market space becomes important when theorising market models.

\subsubsection{Social practices discussion}

Vargo and Lusch (2014), in conceptualising service dominant logic, suggest that while neoclassical economic and marketing theories have generally been built on models of rational humans involved in extensive calculation of the economic value of products, this activity was not nearly as extensive or universally employed as economics suggested. Service dominant logic and market-practice theory (Kjellberg \& Helgesson, 2007), while not re-theorising markets, challenge the neoclassical market concepts of where and how exchange happens. Geiger, Kjellberg, and Spencer (2012), in highlighting that markets are ever-changing sociotechnical arrangements, and Lindeman (2012), in defining markets as ongoing processes of economic organising and as bundles of practices, move forward definitions of the market.

Layton (2008) attempts to extend service-dominant logic, arguing for a shift in focus from reciprocal creation of value through an exchange transaction to the marketing system in which the transaction is embedded. The unit of analysis is therefore not the exchange, but the market system. By marketing system, Layton (2011) means a network of individuals, groups and entities embedded in the social matrix structured in the institutional and knowledge environments in which they are located, and which emerge in response to, or in anticipation of, customer demand. The development of a market is deeply influenced by formal and informal rules, beliefs, and norms held by the community within which a market evolves. The evolution 
is impacted by changing technology and is underpinned by information that is often a means of bringing parties together (Layton, 2011). In effect, Layton is describing a market in social practice terms.

Marketing theorists evolved market conceptualisations from a principally economic construct to focus on a social practice construct where markets are both economic and sociological phenomena established and maintained through routinized practices - the behaviours and understandings of the actors in the market. Markets are no longer seen as a purely physical arena for the buyer-seller dyad to effect a single transaction. Markets are now seen as socially-structured spaces enabling transvections involving an ever-widening network of actors who are in any way connected and whose practices reflect, and impact on, their communities. The community determines what will be exchanged and how, and the value (economic and/or social) ascribed to those things being exchanged. The market itself is described by the practices of the actors, of which the exchange is but one practice. Practices tend to be stable and may outlive the interest of the actors in any particular market.

Giddens (1984) and Perez (2009) note change occurs through episodes of conflict or intensified competition. Competitive intensity thus drives the efforts of market actors, either individually or collectively, to reshape market configurations, either intentionally or unintentionally, depending on how responsive the actors are to the actions of others. A gap in the literature, then, is the influence of competitive intensity on market boundary change when competitive intensity increases not only between corporate market actors but also between market actors at the consumer level.

\subsection{Conclusion}

This chapter has reviewed literature relevant to an exploration of a market model. There are in the literature, however, few compelling or complete conceptualisations of a market model that 
reflects contemporary perceptions of market actors, markets as a space of transvections, or which provides definitions of market parameters. Conceptualisations, such as a systems or ecosystems approach, have been offered (Vargo et al., 2017) but are incomplete.

Recent marketing literature has centred in social practice theory, in particular theorising markets are social structures separated from other markets by the practices routinised by market actors that are in some way different from those practices of other markets. Furthermore, while the most embedded market practices, as institutions, reflect and stabilise the market paradigm of accepted performances, the boundaries of a market are necessarily porous and destabilising.

The literature suggests a research gap firstly in the need for a market model that reflects and provides context for market and marketing theorising, and secondly that social practice theory provides a basis for a market model, or what could be termed a Market Practices Model. The Market Practices Model is conceptualised in the following chapter. 


\section{CONCEPTUALISATION}

\subsection{Introduction}

In this chapter the Market Practice Model is conceptualised that describes and defines in social practice theoretical terms how markets form and over time evolve and stabilise, the functions of a market, the performances by specific actors comprising the market, the practices by which a market paradigm (the specific market functions reproduced and understood by market actors) is defined, and the parameters that define market boundaries and also enable change in a market.

The Market Practice Model reflects recent literature which describes a market as a social construct determined by social practices, and where actors and exchanges are shaped by, and contribute to, the routinised day-to-day activities ensuring the market's continuation (Giddens, 1984; Lindeman, 2012; Reckwitz, 2002; Schatzki, 1996; Warde, 2005). The model theorises exchange takes place via transvections involving an ever-widening network of market actors, some of whom may be independent of a particular exchange. Furthermore, the model conceptualises exchange involving value propositions that are evaluated and where purchaser and seller are partners in the co-creation of economic and non-economic value. Market practices are performances by all the buyers and all the sellers, and all their collections of core competencies, at individual and industry level including all the facilitators of exchange such as banks and insurers (Alderson \& Martin, 1965; Gummesson, 2002; Layton, 2007, 2011; McLoughlin \& Horan, 2002; Thorelli, 1986).

Social practice theory has substantially shaped and informed contemporary marketing theory and provides the conceptual background for the market practice model of markets described in this chapter (Andersson et al., 2008; Kjellberg \& Helgesson, 2006, 2007; Mele et al., 2015; Nenonen, Kjellberg, et al., 2014; Storbacka \& Nenonen, 2011a; Vargo \& Lusch, 2016; Venkatesh \& Penaloza, 2006). This chapter thus begins with a review of social practice theory 
(Schatzki, 1996) which incorporates structuration (Giddens, 1984), and more recent theorising and explication by Reckwitz (2002), Warde (2005), Hargreaves (2011), and Shove et al. (2012).

The chapter then describes the influences of social practice theory on market conceptualisation including practices particular to markets, market space and with particular emphasis on the parameters forming market boundaries, and the means of market change through the evolution of market practices. The Market Practice Model is then presented and explained. The chapter concludes with research objectives and specific research questions.

\subsection{Conceptual Background - Social Practice Theory}

Social practice theory explains both action and social order through highlighting the significance of the shared symbolic structures of knowledge - social practices - and the dynamic processes inherent both in business and in other realms of everyday life (Shove et al., 2012). The first and most basic identifying feature of a social structure is that the society has boundaries determined by the limit of their institutions - the clustering of connected and longlived routinised practices - that mark it off from other surrounding societies (Giddens, 1984). The direct implication is that markets, as social structures, are similarly defined by specific bundles of practices. The following sections explain the context of practices as entities and performances, and the construction of practices of component elements, as a prelude to the sections describing practices specific to markets.

\subsubsection{Practices as Entities}

Human agency, or how humans behave, is defined by specific complexes of practice. A practice is a nexus of routinised behaviours - sayings and doings - which govern how people act and which are understandable not only to the actor who performed them but also to observers from the same culture (Schatzki, 1996; Shove et al., 2012). Practices do not exist 
unless recurrently enacted. If new practices are to take hold, they have to become embedded in the details of daily life and thus in the ordering of society (Shove et al., 2012). Practice theories present a pluralistic and flexible picture of the constitution of social life whereby practices are the centre of understanding. Both social order and individuality result from practices (Schatzki, 1996). By social, Schatzki meant human co-existence, and the ordering of collective social life.

\subsubsection{Practices as Performances}

A market actor is constrained by the society in which the market resides. Society sets limits to what can be enacted while also providing for those routinised social practices endemic to markets to be replicated (Schatzki, 1996). Warde (2005) describes how the actor is a performer of practices - the routinised ways of understanding - but that performances and understandings change with time. The practices themselves are therefore the focus of analysis (Hargreaves, 2011). The exploration of a market model necessarily scrutinises the performances of practices, and recognises that practices change as society changes.

To summarise, through a social practice lens the market becomes a nexus of routinised practices of shared understandings. From practice reproduction comes both social order and the calculative abilities where actors assign economic value to objects (Callon \& Muniesa, 2005), while recognising that perceptions of value may extend beyond economic value. A framework for markets, and marketing, can thus be derived from understanding the practices of a market - what is done and how things are done by market actors.

\subsubsection{Components of Practices - Competences, Materials, and Meanings}

Practices are constituted of elements that are integrated when practices are enacted (Shove et al., 2012). Practices are defined by the interdependent relations between:

Competences - skills, know-how and techniques; 
Materials - things, technologies, tangible physical entities; and

Meanings - symbolic meanings, ideas and aspirations.

While materials (such as a mobile telephone) are readily transported between markets or between actors, competences and meanings (how to use the device, social acceptance of use, and a reason to use) can only travel if there is a base or foundation of existing competence and social understanding on which to build (Shove et al., 2012). Any product, such as a mobile telephone, can only be exchanged and used if the competences, materials and meanings allow for it. When the links between the elements of practices are no longer sustained the practice disintegrates (Shove et al., 2012).

Communication evolves as elements change, therefore materials such as a fax machine may exist still, the telephone lines exist still but as other communications materials evolved, and meanings changed so too did competencies, and the practices (and market) associated with fax machines disintegrated as previously for telegraph (materials), and Morse code (competencies).

\subsubsection{Structuration - embedded practices}

Structuration suggests markets are a social as well as an economic construct. Structures are embedded sets of routinised and generalisable rules that provide a forum for the enactment and reproduction of social practices (Giddens, 1984; Schatzki, 1996). Formulated rules such as laws or regulations are codified interpretations of social rules. Social rules, such as those of structured language, are more powerful than codified law (Giddens, 1984).

Structures both pre-exist and outlast the individual. Giddens (1984) argues that the most deeply embedded structures are institutions. Interpretations of structures and institutions suggest parallels with markets, particularly how market paradigms, as institutions, predate and surpass the actors who engage day-to-day in a market. 


\subsection{Social Practice Theory and Markets}

\subsubsection{Market practices and institutions}

Social practice theories directly relate to markets and market boundaries, and the mechanisms of market change, and therefore provide the backdrop for the conceptualisations of markets and market boundaries that follow. Further, if the changes to the interlinked elements of practices - competences, materials, and meanings - explains the changes within a society, then a similar change mechanism must apply to the markets that reside in a society (Shove et al., 2012). A key requirement in defining a market and market boundaries is the identification of those practices, or bundles of practices, that define boundaries, perhaps through a series of snapshots over time, each capturing the competences, materials, and meanings involved at each phase or era.

While social practice provides the conceptual foundation, the expression market practice both places in context and reflects contemporary theorising (Andersson et al., 2008; Hagberg \& Kjellberg, 2010; Kjellberg \& Helgesson, 2007)

Marketing theorists recognise that value propositions (Vargo \& Lusch, 2004a, 2014) are insufficient on their own in describing a market, particularly as markets involving identical or similar products can be substantially different in the way they operate (Lindeman, 2012). Markets are, therefore, defined by the embedded institutional practices routinised by market actors and which reflect the understanding and influences of a broader community (Kjellberg \& Helgesson, 2006, 2007). Furthermore, markets are founded on trust between market actors that institutional practices will be followed (Granovetter, 1985; McLoughlin \& Horan, 2002).

\subsubsection{Market boundaries and market space defined by practices}

Understanding market boundaries provides the means to explore the scope and scale of a market, and also provides both a theoretical context for what happens within markets, and a framework for analysis of how markets emerge, evolve, and decline (Layton, 2015). 
Structuration has direct implications for markets in that a society (or a market) is a unity with boundaries which mark it off from other societies (or markets). While societies do not always have clearly demarcated boundaries each society stands out because structural principles produce a specifiable clustering of institutions by which members of the society claim a common identity. Secondly, while each market has boundaries, and boundaries are plastic in reacting and reshaping in reaction to change (Nenonen, Kjellberg, et al., 2014), the boundaries are determined by the limits of routinised practices that both constrain the market actors by clearly influencing what can and what cannot be done, and also enable them by providing a forum for what practices are acceptable. Such practices can be the language used, the understandings held, or the value propositions on offer (Giddens, 1984).

Social practice theory challenges concepts of geographical boundaries of social spaces such as markets and contributes to market theorising through perceptions of practice space (Schatzki, 1996; Shove et al., 2012). Practice space suggests an equivocal or dynamic arena which changes with the advent of new practices shaped by new information, or new social and community meanings reflected in the actors' evolving understandings (Lefebvre \& NicholsonSmith, 1991; Morley \& Robins, 1995; Stewart, 1995). Therefore, a change perhaps in information, or how information was perceived, may cause space destabilisation through impacts on competition, needs and value propositions (Shove et al., 2012).

By participating in some practices but not in others, individuals locate themselves within a society or space (Shove et al., 2012). Markets are thus defined by communities of practice, including those who are in objective terms widely dispersed but who inhabit the same practice space. People using the internet to play poker with others from around the world is not a matter of overcoming distance but of creating and reproducing a distinctive but distributed place of practice (Shove et al., 2012). Consider also internet shopping, academic sharing via Google Scholar, even Facebook, or Twitter, all of which are designed to overcome the 
constraints of physical space, replacing it with practice space. Thus, social practice theory provides a basis for conceptualising markets not by price or geographic location as argued in neoclassical economics (e.g., Brooks, 1995; Löffler, 1998; Stigler \& Sherwin, 1985) but as space defined by specific practices. Market boundaries are thus defined by a particular collection of market practices.

It follows that if the changes to the interlinked elements of practices explain the changes within a society's boundaries, then a similar change mechanism must apply to markets (Shove et al., 2012). Thus, there is an emphasis in the Market Practice Model of identifying practices that define market boundaries.

The term perimeter implies a rigid outer boundary of an enclosed two-dimensional geographical area. The neoclassical economics perspective of market boundaries determined by price-equalisation and geography is an attempt at defining such perimeters. Plasticity (Nenonen, Kjellberg, et al., 2014) suggests markets are instead a flexible multi-dimensional space shaped by exogenous forces and also by impetus from within the market and defined by a mesh of interrelated specific categories of practices. The term parameter implies plasticity, where within flexible high and low limits normal life or operation is possible and where some change, at least, is expected and accepted. Parameters, rather than just an outer skin, are thus a surface to core framework. A change within one parameter will impact directly on the others. An understanding of parameters provides key insights into market change, to which the chapter now turns.

\subsubsection{Mechanisms of Change}

Structuration is based on human activity being shaped and enabled by structures of rules and meanings, and structures are reproduced by the flow of human action through largely routinised social life (Giddens, 1984). Thus, day-to-day activity of social actors draws upon and 
reproduces structural features of a wider social system. The emphasis is on societal reproduction, but this leaves open the questions of how practices emerge, evolve, and disappear (Shove et al., 2012; Vargo et al., 2017). Indeed, the conceptualisation of the Market Practice Model is focused on the mechanisms of change.

Practices arise and disappear as a consequence of competition with other practices (Shove et al., 2012). Shove et al. describe evolutionary change depending on transformation processes and stability within and between social practices. Practices expire when changes are wholesale or a practice is no longer carried out. Innovations, such as those introduced through technology, destroy some practices while replacing them with others. At a minimum, emergence and disappearance are related and cumulatively important. How any one practice is reproduced, how consistently, for how long, and on what scale, depends on changing populations of more or less faithful actors (Leonardi, 2011; Martin \& Schouten, 2014; Shove et al., 2012). Evolving practices routinely change the margins of relevant networks and the scope of who they do and do not include.

When practices, or structures, are sufficiently rigorous - as in broadly-held societal norms, dominant designs, or market paradigms - then, rather than incremental innovation, change requires radical, revolutionary impetus, (Giddens, 1984; Shove et al., 2012). Giddens (1984) notes the resistance of practices to change, theorising that states change, sometimes incrementally and sometimes cataclysmically, as impacted by internal and external crisis or conflict. The longer embedded institutions exist the more resistant they are to change. Radical change, Giddens argues, needs substantial momentum and conflict is an essential ingredient. The greater the competition and conflict, the greater the potential change.

The implication for markets, is that boundaries change as practices emerge and evolve or dissipate. Furthermore, while change may be incremental, substantial and lasting market 
and social change requires a conflict or paradigmic disturbance to spark radical change or revolution (Giddens, 1984; Perez, 2009).

\subsubsection{Social Practices summary}

In summary, through a social practices lens, a market, as a social structure, can be described thus:

1. A market is a nexus of specific routinised and reproduced performances of practices;

2. A market is differentiated by practices that are in some way different from the practices of other societies;

3. Social practices are comprised of materials, competences and meanings;

4. A market paradigm, or dominant way of functioning reproduced in performances, is comprised of structures of embedded practices, the most resilient of which are institutions. Structures, and thus institutions, are inherently stable;

5. Market actors trust other market actors to perform specific routinised practices;

6. Market boundaries are plastic and change in response to exogenous and internal forces that have altered materials, competences or meanings; and

7. Market boundaries are comprised of specific categories of practices (parameters) that are inherently unstable.

\subsection{Market Boundaries}

This section discusses the performances of practice within a market that provide essential differences from other markets (Giddens, 1984). Theorising the market as a collection of interrelated practices suggests that the parameters should be classifiable under the three interdependent elements of practice: competences, materials, and meanings (Shove et al., 2012). 


\subsubsection{Competencies}

Competences are actor skills, knowledge and capabilities, and the willingness to use them (Shove et al., 2012).

Competitive intensity reflects the practices of market actors amidst competing transvectional networks who have the skills, knowledge, capability, and the willingness to compete. Where there is no competitive intensity, such as natural monopolies or centralised economies, then markets exist in stasis and change slowly, if at all. Competitive intensity furthermore builds on the conceptualisations of Nenonen, Storbacka, et al. (2014) whereby a firm's market control, or clout, assists in its ability to 'shape' the market in its favour by seizing emergent opportunities. Inherent, but unstated in the literature, is the influence of the extent of the willingness or ability of firms to compete, and that, therefore, the determination to compete impacts on market practices and thus parameters.

Building on resource density and market configuration conceptualisations (Storbacka \& Nenonen, 2011a) enables explanations of why markets evolve, why market boundaries change, or why market actors engage in market shaping activities. Resource density challenges occur at a micro or meso level. Market change may occur, however, at the macro level and may be initiated by actors not directly and deliberately engaged in either the market or in market shaping. Giddens (1984) specifically does not divide micro and macro in social life and thus conceptualisations of market boundaries, and therefore market change, should reflect the practices of actors amidst competing transvectional networks. At a macro level the influences of market boundary change may incorporate competing social attitudes. Resource density could thus be understood as a primary element, among perhaps several, comprising competitive intensity. 
Furthermore, market shaping is conceptualised as intentional efforts but, in conceptualising competitive intensity, market shaping may also be an unintentional or unconscious outcome of firm activities. For example, when Telecom New Zealand first introduced mobile telephones to New Zealand in 1987 the market shaping consequences were unknown. The actions Telecom subsequently took in the mobile market were in direct response to intensified competition, while simultaneously competitive intensity in traditional services was falling away. Furthermore, competitive intensity occurs not only between providers. Market actors other than firms have themselves clout to shape the market - a regulator is specifically established and empowered to shape a market particularly where there are perceptions of insufficient competitive intensity. Users may also through their inadvertent but dominant collective demands similarly shape the market whereby providers have little choice but to adjust value propositions to suit. Beatlemania, for example, that between 1963 and 1967 drove the direction not only of popular music but also of western culture, was the collective market-shaping effort of Beatles fans competing against each other for recognition (Arnould \& Thompson, 2005) and well beyond the intentional efforts of the Fab Four. Thus boundary change conceptualisations must include elements outside the influence of any particular group of actors, and further must include the spark for change.

Markets are influenced by, and in turn influence, the institutional and knowledge practices of the society in which they are located (Layton, 2011). Market actor capabilities and willingness to compete are thus constrained and enabled by legal and economic institutions which incorporate competences in, for example, market regulations, the trustworthiness of regulations and regulators, the ability and willingness to enforce regulation, and the acceptance of enforcement (Humphreys, 2010; Lindeman, 2012; McMillan, 2002; Shove et al., 2012). Regulations in this context may not directly impact market practices but may enable and constrain, for example, practices within economic institutions such as capital markets, currency 
recognition, availability, strength and exchange processes, banking and insurance, the presence, structure, capabilities, and integrity of which impact on market practices and thus market boundaries. Legal and economic institutions have a profound effect on both competitive intensity and responsiveness (e.g., Patterson, Mazzoleni, \& Pickering, 2011; Rebstock et al., 2008).

Demand in the neoclassical economic sense is the number of consumers willing and able to respond to the value propositions offered by providers (Milgrom \& Roberts, 1992). There is no market, however, unless there is a provider who is willing and able to respond to those who want to buy. Those able to provide may instead provide alternative, perhaps less attractive, value propositions, or provide them somewhere more conveniently positioned or where rewards are higher. Thus, consumer purchase requires not only a user who is responsive, but also a provider who is responsive. Similarly. in the neoclassical economic sense. price is used as a market boundary delineator (Brooks, 1995; Milgrom \& Roberts, 1992). Value propositions, however, are comprised of more than price and consumers make decisions based on factors other than price (Vargo \& Lusch, 2004a). Price and demand do not provide for market boundaries in a market practice sense. Hence responsiveness of market actors delineates a market's boundary. The market boundary occurs at the point where market actors begin responding to the practices of other actors. On the outside of the market actors no longer respond to each other: users no longer respond to the value propositions of providers, or providers no longer respond to the market signals of particular users, or providers no longer have the desire, skills, creativity and access to resources necessary to adapt and innovate (Layton, 2011; Martin \& Schouten, 2014; McMillan, 2002).

\subsubsection{Materials}

Materials are the things, technologies, and tangible entities that actors need to perform (Shove et al., 2012). Eco $(1976,1992)$ proposes that every cultural phenomenon may be studied as 
communication. Information is thus closely linked to responsiveness as market actors can only respond where they have information about each other. Information practices underpin exchange and are often the means of bringing parties together including the networks or facilitators of exchange (Layton, 2011). Martin and Schouten (2014) describe how the development of information potential increased the density of users able to respond to other market actors, including other users and providers (Casson \& Lee, 2011; Clark, 2001; Layton, 2011; McMillan, 2002).

Value propositions are themselves practices - the core competencies, knowledge and skills promised by a provider, the perceived benefits of which users integrate into their own practices to meet their specific needs (Korkman et al., 2010; Storbacka \& Nenonen, 2011a; Vargo \& Lusch, 2008). Practices within a market may change through the adoption and diffusion of competing practices associated with competing value propositions.

Technologies follow or enable specific performances of practices (Layton, 2011; Leonardi, 2011; Perez, 2009). For example, the Agricultural Revolution and the Industrial Revolution were made possible by steam engine technology, which increased production and transport efficiency, and enabled rapid flows of information (Clark, 2001). As markets expanded, exchange became more dependent on services-dominant transvectional networks permitting rapid transvections, trading and services through intermediaries, transport over increasing distances, and the creation of new information, trading and credit services, such as newspaper advertisements, auctions, and insurance (Casson \& Lee, 2011; Lloyd's, 2015). A more recent example of revolutionary market transformation through changes to information, value proposition, and technology parameters is the disintermediation of accounting services through cloud technology by information technology services providers (Gosling et al., 2017). 


\subsubsection{Meanings}

Meanings include the symbolism, ideas, understandings and aspirations acceptable and important within the social (Shove et al., 2012). The market is created by those actors having needs within a space. Needs are socially defined practices of acquisition and are reflective of the symbolism, ideas, understandings and aspirations acceptable and important within the space in which social acceptance is provided. As examples, the Industrial Revolution brought revolutionary change in market performances where to meet new consumer needs, new means of intermediated markets were developed and methods of trade previously seen as illegal or discouraged were legitimated and seen as indispensable. More recently, new sets of consumer needs have encouraged the emergence of dis-intermediated markets through internet trade. (Arnould \& Thompson, 2005; Casson \& Lee, 2011; Gosling et al., 2017; Humphreys, 2010; Lindeman, 2012).

Market practices therefore reflect the meanings and understandings of the society in which the market is situated (Giddens, 1984; Humphreys, 2010; Penaloza \& Venkatesh, 2006; Reckwitz, 2002; Shove \& Pantzar, 2005; Shove et al., 2012) Social and community expressions of value and meanings are normative but change over time, and legal and economic institutions, for example, reflect revised social and community perceptions (Humphreys, 2010; Lindeman, 2012). Thus, as social and community meanings change and become normative, other market practices change and become normative.

Perceptions of space are subjective. The spatial matrix (Morley \& Robins, 1995) is based on shared historic experience by market actors of the physical and virtual, tangible and intangible, and symbolic, limits of their space. The spatial matrix thus includes non-human market actors, such as infrastructure (e.g., ports, railways and fibre networks), as much as actor perceptions on how the infrastructure should be used or what infrastructure represents in terms of market boundaries. Spatial matrix implies an equivocal or dynamic space capable of change 
with the advent of new practices shaped by new and specific social and community meanings in that the symbolic limits of the market reflect the ways actors within a societal structure such as a market differentiate who are 'us', and who are 'other' on the outside of the social or market boundary. The spatial matrix and social and community meanings are closely linked in terms of institutional practices - how offerings and market exchanges are understood, represented, normalised and routinised (Arnould \& Thompson, 2005; Giddens, 1984; Humphreys, 2010; Kjellberg \& Helgesson, 2006, 2007; Layton, 2007, 2011; Lefebvre \& Nicholson-Smith, 1991; Morley \& Robins, 1995; Reckwitz, 2002; Scaraboto \& Fischer, 2013; Shove et al., 2012; Thornton \& Ocasio, 2008). For example, personal transportation by Uber, or virtual dating services such as Tinder, exemplify circumstances where geography has been supplanted by space bounded only by acceptance of the service within social and community meanings.

The Market Practice Model founded on these parameterising characteristics, and which provides a definition of a market, describes the boundaries to a market, and describes in the next section how a market is created, and evolves and declines.

\subsection{Towards the Market Practice Model}

Markets occur when exchange practices become sufficiently routinised as to become institutions recognised and understood by actors and thus enabling repeated exchanges (Aspers, 2007). Hence an exchange - such as the bartering of a piece of sharpened stone for a chunk of deer meat - cannot become a market until the actors understand that stone and meat can be exchanged between them in a particular setting. That is, that their exchange practices have become routinised and legitimated, creating a community of market practices with predictable and shared understandings of what is to be exchanged, where and how, and that other actors can be trusted. Furthermore, markets change when understandings change. Contemporary theoretical perspectives of markets provide the principles of a practices-based model of markets underpinned by foundational premises. 
Foundational premise 1: Markets, as social structures, are a nexus of specific routinised performances of practice.

Foundational premise 2: The plastic boundaries of Markets are delineated by nine categories of practices termed parameters.

Foundational premise 3: Market institutional practices are inherently stable and change only when subjected to substantial reformation amongst parameters.

The Market Practice Model (Figure 3.2.) is based on these foundational premises whereby a market is a social entity of performances held in place by stabilising institutional practices, with boundaries parameterised by the performance of practices that are by their nature destabilising. The model is presented here for the sake of clarity and to assist with understanding the material in this and subsequent chapters. Elements of the model, particularly parameter nomenclature and definitions, were amended several times upon reflection prompted by data analysis and further review of the literature.

In the Market Practice Model, a market is defined thus:

A social structure for the exchange of value;

The aggregation of market performances effecting transvections;

The centre of integration of resources and relationships;

The hub of practices that constrain and enable market activity; and

Where promises are kept.

Market performances are practices by actors in the market. Actors are all the buyers, all the sellers, and all the offerings - collections of core competencies (Vargo \& Lusch, 2016) that are evaluated and priced (Callon \& Muniesa, 2005; Miller, 2002). The actors include all the organisations and networks of industries and all the facilitators of exchange who may exist in overlapping markets (Andersson et al., 2008; Vargo \& Lusch, 2011). 
The market's functions are defined and stabilised by institutional practices comprised of exchange, normative and representational practices (Kjellberg \& Helgesson, 2006, 2007). Institutional practices give the market shape, meaning, function, and resilience. They are the glue that holds the market together (Vargo \& Lusch, 2014).

Market boundaries are the flexible physical and virtual limits of a multidimensional space defined and shaped by specific practices understood and performed by a set of actors, and which reflect the understanding and influences of a broader community. Performances within a market's boundaries are in some key ways different from those performed in markets outside the boundaries. Market boundaries necessarily overlap, as market practices may be performed by actors involved simultaneously in multiple markets, as much as actors may be involved simultaneously in many practices. Furthermore, practice changes can occur without changing a market's boundaries, but market boundaries will change where practices substantially alter performances which then become routinised and legitimated as new institutions. In the depiction of the Market Practice Model, the arrows represent the flow of influences between and within parameters, performances and institutional practices. 


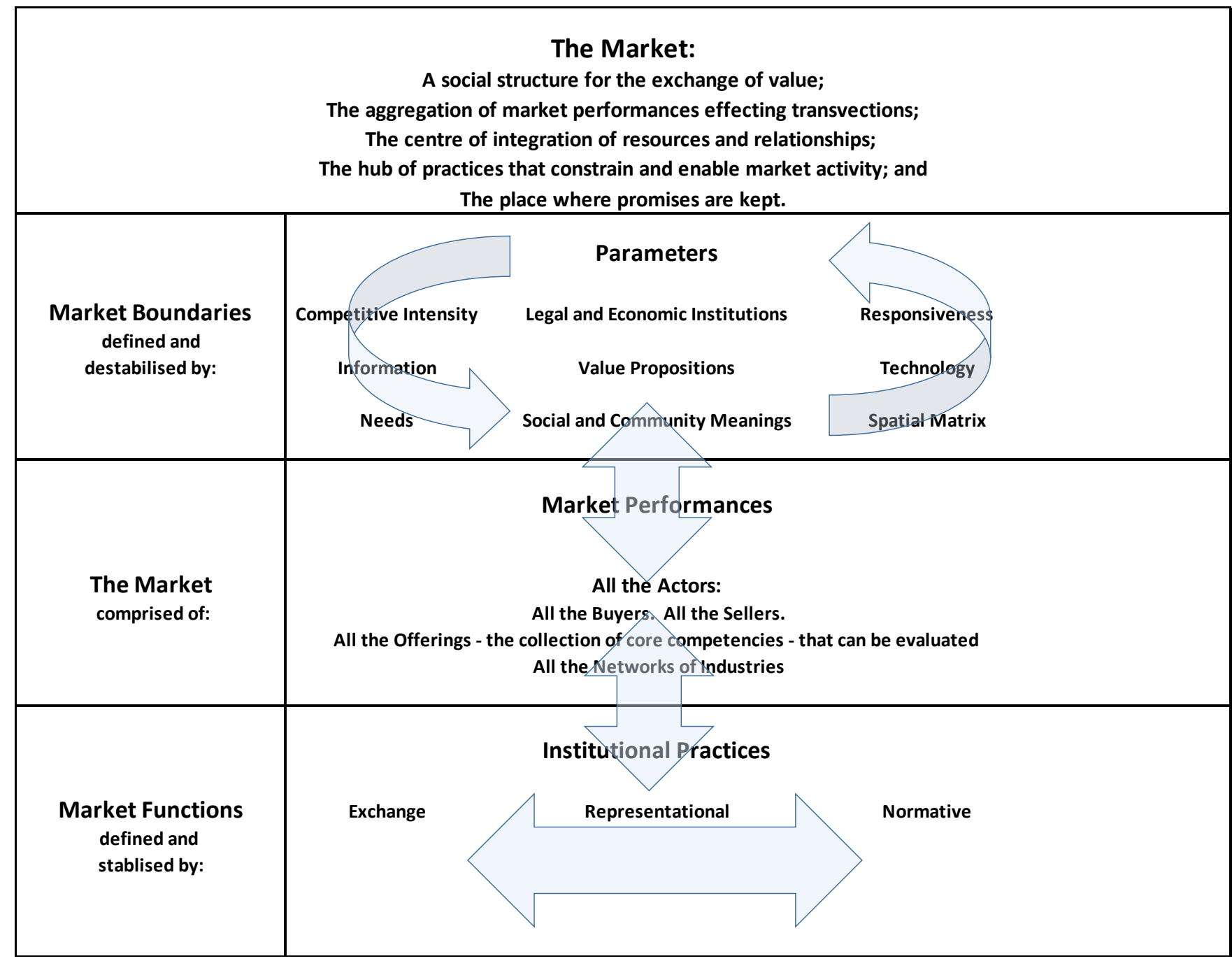

The nine market parameters form dynamic, plastic, boundaries that in response to exogenous or endogenous stimuli may change and reform, and so change the market. (Nenonen, Kjellberg, et al., 2014). Parameters are thus inherently destabilising. Parameters, therefore, act in tension, either complementing or constraining one another. Thus, in a market, a change in information or technology, for example, is reflected in changed market boundaries. As parameters change, the performances within the market change. As performances change, the institutional practices change to reflect the new paradigm and thus enable and constrain future performances. Market parameters are defined further in the following section. 


\subsection{Market Parameters}

Foundational premise 2 theorises a market's plastic and porous boundaries are defined by nine specific categories of practices described as parameters: Competitive Intensity, Legal and Economic Institutions, Responsiveness, Information, Value Propositions, Technology, Needs, Social and Community Meanings and Spatial Matrix.

Parameters show not only the boundaries of a market but also the extent of difference between one market and any other market, even where markets and practices overlap. Parameters include practices which may be trialled and adopted from other markets. Market actors may stop performance of a practice as parameters evolve and practices are replaced by others that are performed in turn. Parameters may therefore be practices that have not yet become, and may never become, embedded as institutional practices. Parameters are a way of explaining how markets form, evolve, and cease to exist.

Parameters definitions were abducted from common themes surfaced from various streams of literature and from reflection upon themes emerging from the empirical data. In this section each parameter is defined. The parameters are presented in alphabetical order in each element rather than any order of priority; a priority would likely change as emphasis or expansion of any parameter changed.

\subsubsection{Competences: competitive intensity, legal and economic institutions, responsiveness}

Competitive Intensity: The practices of market actors amidst competing transvectional networks who have the capability and willingness to compete. Furthermore, competitive intensity occurs not only between providers but also between users. 
Legal and Economic Institutions: Competences in, and trustworthiness of, legal institutions such as laws, regulations, political and court processes, and in economic institutions such as capital markets, currency, banking and insurance.

Responsiveness: The capability, willingness and agility of market actors, whether providers, users, or regulators, to respond to the market practices of other actors.

\subsubsection{Materials: information, value propositions, technology}

Information: The awareness of information by which market actors respond to each other and the value propositions presented.

Value propositions: The core competencies, knowledge and skills promised by a provider whereby users integrate into their own practices perceived benefits to meet their specific needs.

Technology: Specific tools, materials, and related competences that enable specific performances of practices.

\subsubsection{Meanings: needs, social and community meanings, spatial matrix}

Needs: Socially defined practices of acquisition, reflective of the symbolism, ideas, understandings and aspirations acceptable and important within the practice space.

Social and Community Meanings: Accepted understandings and symbolism of the social or community in which the market is situated.

Spatial Matrix: The equivocal and dynamic, physical and virtual, tangible and intangible, and symbolic, limits of space by which market actors differentiate between 'us' and 'other'. The Spatial Matrix includes non-human market actors, such as infrastructure. 


\subsection{Parameters and Market Change}

A social practice approach invited a wider perspective on market change processes (Kjellberg et al., 2012). A critical re-theorising in this thesis is that market change occurs when the destabilising forces apparent in parameters have sufficient momentum through specific social practice disruption that market performances change in, for example, the understanding of actors as to how and what will be exchanged in what space (Figure 3-2). Furthermore, as market performances change, the institutional practices realign to reflect the new understandings of the market (Abernathy \& Utterback, 1978; Giddens, 1984; Kjellberg \& Helgesson, 2006, 2007; Lindeman, 2012; Nenonen, Kjellberg, et al., 2014; Perez, 2009).

\section{Figure 3-2 Influence of parameters on performances and institutional practices}

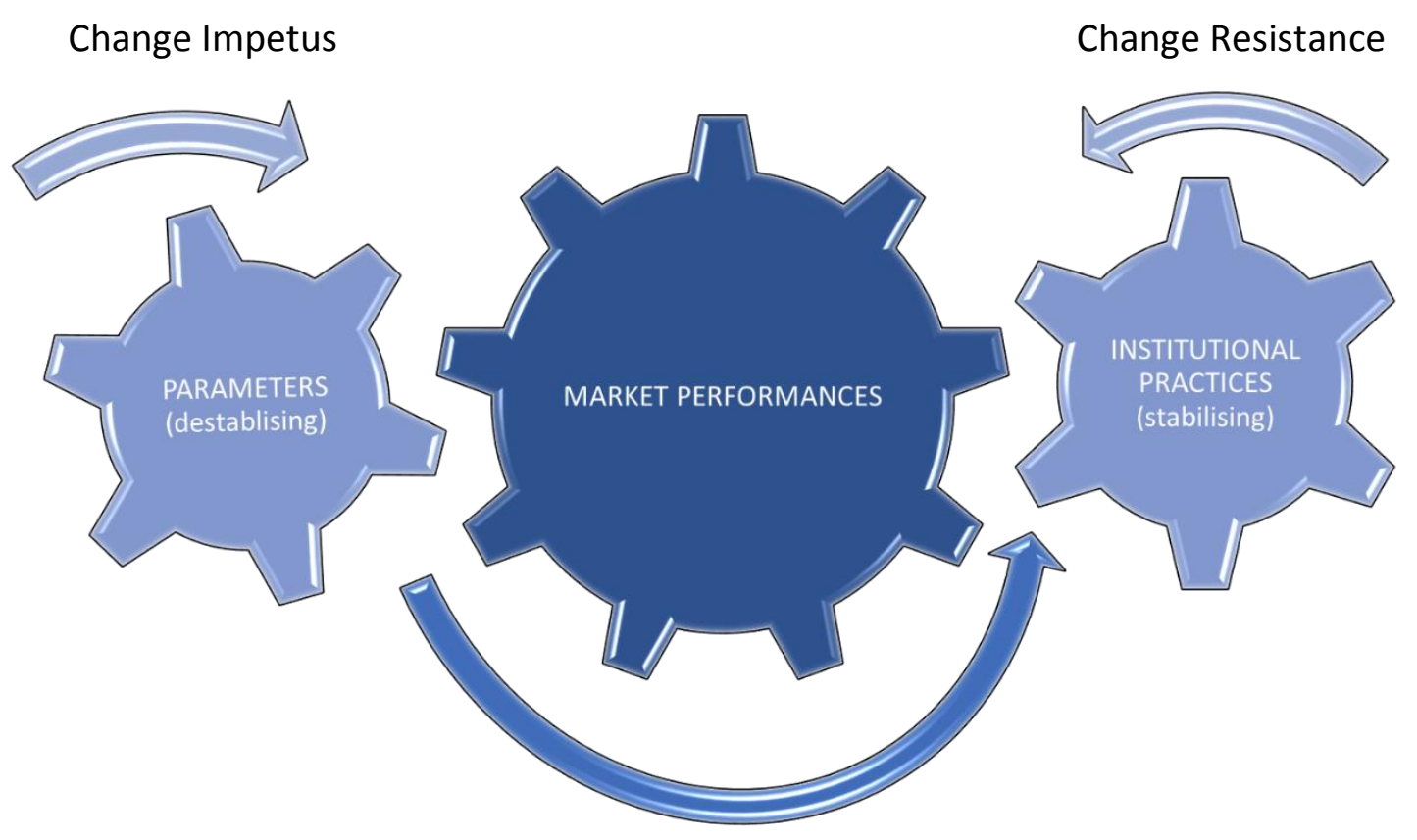

Change Extent

Parameter destabilisation occurred through one of two key processes, each driven by competitive intensity (Giddens, 1984). Firstly, competitive intensity obliges changes in market parameters in ways that may be incremental and continuous. This reflects the day-to-day 
reproduction of practices where each replication may be slightly different (Halkier \& Jensen, 2011; Shove et al., 2012). In such a case, a value proposition may incrementally change as actors compete with new products or product extensions. Incremental changes do not change the fundamental nature of the market - parameters do not substantially change, performances do not substantially change, and the institutional practices do not change. However, substantial destabilisation of social practices occurs when brought about by sudden, substantial, and sustained disruptive actions initiated by social-technological crisis such as revolutionary competition in the form of new Information or new Value Propositions (Giddens, 1984; Lindeman, 2012; Perez, 2009). Competitive disruptions are cyclical - preceded and followed by periods of stasis or incremental changes. Once embedded as institutional practices, the new practices become increasingly resistant to change until destabilising actions create the next rapid disruptive change (Perez, 2009).

\subsection{Market Practice Model summary}

Social practice provides a foundation for generalisable re-theorising of markets and marketing shaped by contemporary marketing thought. The Market Practice Model advances markets from places of exchange through transaction and price calculation to a nexus of practices enabling transvections where networks of actors integrate resources and relationships to cocreate value. Markets are dynamic entities and therefore the model describes the mechanisms of market change through the destabilising influences of parameters that provide the plastic and porous boundaries of markets. These concepts of markets, market boundaries and market change form the basis for the research to which the thesis now turns. 


\subsection{Research Questions}

The following logic and imperatives drive this research:

1. Marketing as a discipline needs a market conceptualisation sufficiently compelling as to supersede alternatives, such as those based on neoclassical economics;

2. Marketing needs a dynamic and unifying framework that reflects and advances contemporary market and marketing conceptualisations;

3. Development of a practices-based model of markets would contribute to the growing social practices theoretical foundation of markets and marketing;

4. Understanding of market parameters would underpin a practices-based model of markets; and so

5. This research will explore the catalogue of practices forming market parameters.

While evident from the literature, and while there will be a particular reference to Competitive Intensity, Legal and Economic Institutions, Responsiveness, Information, Value Propositions, Technology, Needs, Social and Community Meanings and Spatial Matrix, the research will be explicitly open to inclusion of other elements and the redefinition, or elimination, of those already suggested.

Social practices are so ingrained in everyday sayings and doings that parameters and their interrelationships may be more readily identifiable when thrown into stark relief such as during revolutionary market change. The technological and social revolutions of the last twenty years in the New Zealand mobile telecommunications industry, which can be measured over time against recognised industry indices, suggest a research focus that would offer an informative context for exploration of the general theory. 
The exploratory objective would be achieved through these research questions:

1. How does a social practice theory-based Market Practice Model contribute to a dynamic general theory of markets?

2. What parameters forming market boundaries can be identified?

3. How do parameterising practices forming market boundaries influence how markets emerge and evolve?

4. How are market actors motivated to change their behaviour?

\subsection{Conclusions}

This chapter presented social practice theory as the conceptual background for a social practicebased model of markets. A social practice-based model reflects contemporary literature on markets and marketing, and itself provides a framework for future theorising. The Market Practice Model described a market as a nexus of routinised and embedded institutional practices performed by market actors within market parameters. The chapter catalogued and defined nine specific categories of parameters. The influence of market parameters on market change was described. The exact nature and construction of parameters required further exploration. Research logic, imperatives and objectives were described leading to the presentation of research questions.

The following chapter describes the research methodology employed to answer the research questions. The focus of the research will be the exploration of parameters describing the market boundaries of a specific market. 


\section{METHODOLOGY}

\subsection{Introduction}

This chapter describes the research methodology employed to address the research questions.

The chapter begins by providing an explanation of the methodological approach of this research. The chapter provides an understanding of principles in the building of social research theory (Crotty, 1998) and consideration of abduction as the social constructionist epistemological pathway. A rationale is provided for the quadri-hermeneutic theoretical perspective, and the combination of reflexive methodologies used, as appropriate for the research strategy, research purpose, and research questions (Alvesson \& Sköldberg, 2009). Next, the chapter describes the research subject, and the methodological procedures used to consistently source and construct data, including participant selection and interview processes, the collection of historical documentary material, and the tabulation of metrics for each of the three eras identified across the research period. The techniques used to satisfy the requirements of consistency and trustworthiness of the data analysis and findings are included (Cavana et al., 2001; Guba \& Lincoln, 1994; Miles et al., 2013). The chapter concludes with a summary of the main features of the methodological process.

Dubois and Gadde (2014) argue that too many qualitative researchers do not sufficiently explain their research design and data analysis methods and thus provide relatively little detail by which readers can make informed judgements. Nenonen et al. (2017) provide further guidance on the necessity for explicit detail of the methodology and analytical process. Furthermore, the quadri-hermeneutic methodology developed in this thesis for the interpretation and reinterpretation of data across multiple layers of understanding is itself a contribution to qualitative research. Therefore, this chapter, and the chapter that follows on data construction, are extensive and explanatory in their approach. 


\subsection{Methodological approach}

This section presents the methodological approach of this thesis, beginning with a discussion on the epistemological grounding. In regard to frames of reference and the mapping of perceptions of reality, the epistemology was guided by Zaltman et al. (1982) and Crotty (1998), and in terms of causality, generalisation and explanation by Gregor (2006). The section then turns to the researcher's approach to social constructionism, which was guided by Cayla and Eckhardt (2008), Humphreys (2010), Miles et al. (2013), O'Driscoll (2006), and Thompson (1997), and secondly outlines the abductive research strategy and hermeneutic methodology (Alvesson \& Sköldberg, 2009; Crotty, 1998).

\subsubsection{Epistemology - the philosophical grounding for theory exploration}

Epistemology is concerned with providing a philosophical grounding for what kinds of knowledge are both adequate and legitimate (Crotty, 1998). In this section an explanation is given for the adoption of a social constructionist epistemology for exploring new theory through interpretations based on distinct decision frameworks.

Social constructionism, as an epistemology, suggests truth or meaning comes into existence from interpreting and reinterpreting realities in the world to construct a meaning in a specific circumstance, in this instance, within a market (Guba \& Lincoln, 1994). Social constructionist explorations of theory generally involve the researcher's own subjective experience, knowledge and understanding to enable interpretation (Crotty, 1998; Eco, 1992; Zaltman et al., 1982). Constructing meaning involves not being bound to traditional meanings but being open to new and reinterpreted meanings (Crotty, 1998). Thus, in this research it was not sufficient to restate events and sayings. Instead an abductive exploration was required based on layers of interpretation founded in an understanding of specific theories and circumstances and thus suggesting a probable basis for new theory (Savitt, 1980). The categories of practices forming market parameters could thus be abstracted from multiple 
layers of interpretation of meanings and understandings, and from these understandings new theory could be explored.

Consistent interpretation is assisted through the development and use of decision rules and reality tests (Zaltman et al., 1982). In this research, theory building was achieved through a pre-understanding of a model of markets and market boundaries based in social practice theory. Interpretations were guided by predetermined decision rules whereby data from, for example, historical documents could be related to specific practices and then further interpreted as to be related to individual parameters.

To summarise, social constructionism provides the epistemology, or philosophical grounding, that guides theory exploration in this thesis. Social constructionism, in the context of this exploration, involves an abductive research process based on understanding of markets interpreted through the social practice theoretical lens, and where interpretation is guided by specific decision rules. The abductive approach is discussed in the following section.

\subsubsection{Abduction - a way of understanding, interpretation and reflection}

Abduction is a constructionist approach recognising that understanding of data is the result of pre-understanding, interpretation, and reflection, and then contextually-based reinterpretations of the found patterns. The emerging patterns are adjusted and refined as the data is examined, reflected upon, and understanding develops (Alvesson \& Sköldberg, 2009; Aspers, 2007). Thus abductive research, in seeking opportunities for understanding, is a process that alternates between previous literature and conceptualisations and the empirical data where successive reinterpretations are made of both in the light of the other. The circumstances behind the interpretations thus become key: that social practice theory forms the basis for conceptualising market boundaries by categories of practices termed parameters. The nature of exploration assumes, however, that the understanding of parameters and practices may be adapted as 
exploration and interpretation progresses. In turn, the interpretation, in being suggestive rather than deterministic, points to probable connections between practice and parameters (Savitt, 1980).

\subsubsection{Research perspective - quadri-hermeneutics}

In this research the actions of market actors were extracted from the text of interview transcripts and from historical documentary material, as guided by Hagberg and Kjellberg (2010). The longitudinal nature of the research material for this thesis, and the substantial additional tiers of interpretation and re-interpretation required to extract and explore underlying or indirect meaning, and thus the connections between practices and parameters, however, forced development of an extended form of abductive research (Alvesson \& Sköldberg, 2009; Hagberg \& Kjellberg, 2010). The research thus employed quadri-hermeneutics as the theoretical perspective (Ager \& Loughry, 2004; Alvesson \& Sköldberg, 2009; Humphreys, 2010; Lindeman, 2012; O'Driscoll, 2006; Spiggle, 1994).

Hermeneutics is both an underlying philosophical approach to human understanding and a specific approach to interpretation: a mode of analysis based on practical judgment and cultural/historical connection for understanding textual data, and a reflecting practice of unmasking and deciphering indirect or hidden meanings beneath apparent ones (Alvesson \& Sköldberg, 2009; Crotty, 1998; Giddens, 1993; Myers, 1997; Thompson, 1997). Hermeneutics relies both on the intuition of the researcher where patterns in complex wholes are illuminated giving an immediate and complete overview, while conversely recognising that the whole can only be understood as the composition of its parts (Alvesson \& Sköldberg, 2009). Hermeneutics thus enables a critique of text, seeking a hidden meaning beyond what may have been intended by the text authors, whether they are interview subjects or document creators, as is the case in this thesis. 
Quadri-hermeneutics involves further processual circles of understanding between the part and the whole, between levels of understanding, and where interpretation and reinterpretation leads to further reflection and a questioning of the text (Alvesson \& Sköldberg, 2009; Ginev, 1998). A strength of the quadri-hermeneutic process lies in the involvement of the researcher whose interpretative orientation - such as understanding of the subject and theoretical basis - enables attuning to the specific characteristics and patterns afforded by the textual data, while being open to possibilities and revisions of the interpretative standpoint which by definition must expand during the research process (Thompson, 1997). For example, this research could not be limited to what was said in organisational annual reports or in the recollections of a market actor, but must interpret what was said, against the conceptual framework, and where the researcher must consider insights that were never in the minds of the actors and nor included in the text (Crotty, 1998). The hermeneutic approach in longitudinal research was further guided by Humphreys (2010) and O'Driscoll (2006).

\subsubsection{Combining Reflexive Methods}

A further research challenge was that the connections between text and the categories of practices comprising parameters were firstly unlikely to be overt, and secondly the layers of interpretation enabling logical and transparent relationships had to be applied consistently. To enable multiple layers of consistent interpretation, a method was developed combining reflexive methodologies. Alvesson and Sköldberg (2009) and Lindseth and Norberg (2004) provided a process of developing meaning through multiple layers. Urquhart, Lehmann, and Myers (2010), while centred on grounded theory, provided suggestions for constant comparison, iterative conceptualization, and theoretical integration. Nili et al. (2014) and Wilson and Hutchinson (1991), while also embedded in grounded theory, provided an approach for a bottom-up deductive method that is readily adjusted for a bottom-up and top-down quadrihermeneutic abductive process. Easton (2002, 2010), while based in critical realism, provided 
a model of analysis where text was developed into experiences, and where experiences were channelled through an interpretative mechanism that functions as a bridge whereby text and text interpretations were further interpreted and refined.

In the combined method developed for this research, texts were drawn from interview transcripts and documents. In the first interpretation, the text was condensed into an experience, that is, an understanding of what the text meant as a practice performance. Performances were then further interpreted and condensed into practice elements, and then reinterpreted and condensed a third time into categories, thus providing the researcher with an understanding of how practice elements are connected to specific parameters. Thus interpretation and understanding moved from text (a small section, perhaps a single line or sentence, of the interview transcription or report) to the whole (the market model as a social construct bounded by parameters) and from the whole back to text to confirm and strengthen meaning and understanding, while being open to the possibility that theoretical understanding might evolve with subsequent adjustment to the parameters, or definitions, or understanding of the literature (Alvesson \& Sköldberg, 2009; Easton, 2002, 2010; Nili et al., 2014; Thompson, 1997).

This section has described the process adopted for this research to enable the logical and transparent interpretation of data. The thesis now turns to the research subject.

\subsection{Research Subject}

The research focused on the practices of providers, users and regulators in the mobile telecommunications market in New Zealand from 1990 to 2014. The thesis turns now to the reasons why this research subject was chosen to explore market parameters and how exploration was achieved. 
Complex social processes can be studied by introducing changes and observing the effects (Baskerville, 1999). Changes could include shifts in language or clusters of particular processes, actions and words (Humphreys, 2010; Miles et al., 2013; O'Driscoll, 2006). This suggested that the research subject should be a market that from a period of stasis has experienced disruptive change impacting not only itself but also the broader industry and society (Perez, 2009). Such a process from stasis through revolutionary change to a new market paradigm can be observed in the New Zealand mobile telecommunications market.

The New Zealand mobile telecommunications market offered an informative context for defining market boundaries because the market's revolution would illuminate changes to practices in ways that make practices observable. From a paradigm of landlines and slow growth in the use of pre-1990 mobile technology, the mobile telecommunication market underwent substantial technological and social change in a relatively brief timeframe. The post-1990 revolutionary changes were subsequently embedded into a new paradigm which by 2014 was exemplified by comparatively incremental technological and social change. Social practice changes of revolutionary magnitude between 1990 and 2014 firstly suggested that the practices comprising market parameters would be observable as they changed, formed and reformed. Secondly, the revolutionary changes suggest that both users and providers were open to new technologies and not overly constrained by practices that might inhibit adoption.

The New Zealand mobile telecommunications market is favoured also because individuals, who as users, providers and regulators were directly engaged in the technological and social shifts throughout the research period from 1990 until 2014, were available for interviews, could describe their "sayings and doings", and provide market descriptions that gave context. 
The New Zealand mobile telecommunications market is particularly richly documented in general media, government reports, and other company and sector historical documentary material from which practice changes and industry metrics, such as connection numbers and the uptake and usage of voice, text and data-sharing technologies, were extracted (Humphreys, 2010; Miles et al., 2013; O'Driscoll, 2006). Also, compared with other industries, the New Zealand telecommunications industry is particularly responsive to market interventions, such as regulation, and the intended impacts of regulation are often more readily apparent, at least at provider level (Patterson et al., 2011; Rebstock et al., 2008).

Furthermore, the New Zealand mobile telecommunications market is contained within a defined and isolated geographic space. Physical isolation suggested that the practices of a specific group of telecommunication providers influenced only the population of New Zealand users, and that the practices of a specific population of users influenced only those providers. By comparison, a city of similar population overseas may experience significant daily migrations whereby so many users may be influenced by any number of providers within and without the city, and vice versa, that determining who was influenced by what, and the effects on market practices, could be problematic.

While 1990 marked the start of the 'mobile phone' for calls-only paradigm, by the 2010s the new paradigm of the 'mobile computer' with constant internet connectivity had become embedded, and no further evolution is yet apparent in what is now a mature market, in terms at least of subscriptions per person (Howell \& Obren, 2003). To provide some benefit of hindsight whereby the effects of, for example, competitive, regulatory, or social actions could become more apparent, and to enable sufficient statutory reporting - such as Spark New Zealand and Telecommunications Commissioner annual reports - 2014 was chosen as the final year for this exploration. 
Single industries, and even single firms, have been used effectively to inform general theory development (Cayla \& Eckhardt, 2008; Humphreys, 2010; Lindeman, 2012; O'Driscoll, 2006; Thompson, 1997).

This section has described the research subject, and highlighted the characteristics that made the New Zealand mobile telecommunications market particularly apt for the research, especially the market's revolutionary change over the 25 -year research period, and the availability of both interview subjects and extensive documentary material. The following section describes how the research period was divided into market eras to enable the identification and comparison of market practices.

\subsection{Market Eras}

An important foundation in the research was that practices endemic in a market should be most readily observed during periods of change, and thus the evolution of market practices observed from the data should enable the categories of practices forming parameters to be identified. Compartmentalising the 25-year research period by year or other temporal criteria, or through alternative means such as by market actor, would not readily permit the required distinctions by which market practices could be identified. The methodology, therefore, was structured to enable comparison of practices between three distinct but overlapping market eras delineated by the technology predominantly in use. The temporal divisions between technologicallydefined market eras are blurred because the precise dates of the introduction of, for example smart-phone technology, do not reflect either the start or end of market practices. The market eras, Fundamental, Feature and Flexible, are thus coarsely defined periods reflecting each phase of mobile telephone handheld device development and thus the practices associated with each phase. This research differentiates these eras thus: 


\subsubsection{Fundamental}

In this era, from 1990 to around 1998, the second-generation digital cellular mobile device had elementary capabilities for making and receiving telephone calls as a substitute or supplement for a landline telephone. Purchase was based on this single function. Mobile devices were generally purchased by an organisation and were primarily used for commercial purpose. Users were comparatively few in number, generally of mature age, and in senior positions within organisations, and possession of a device thus implied status. In the early years of this era supply of devices in New Zealand was provided by only one manufacturer (who at one stage provided only one model) and one service provider, Telecom New Zealand. User purchase choice was limited to battery size and the number of call minutes contracted. In later years of this era more choices became available to users in terms of device manufacturers, models and service providers. Communication was one-to-one. Frequency of use was costdriven and as-required.

\subsubsection{Feature}

In the Feature Era, predominantly from around 1998 to around 2008, the third-generation mobile telephone commonly in use had calling, texting, and an array of attributes or features specific to the model of telephone. A feature mobile telephone may have been provided by an employer, but an important difference from the Fundamental Era was that the device may also have been purchased by an individual for personal use. The device was a supplement or substitute for a landline telephone but purchasing decisions were often based on one or more distinctive features of the device and these were often not related to communication - a smaller telephone was seen as more technologically advanced, more expensive, and thus more prestigious. Elementary games, diaries, or basic cameras and data storage for photographs, may have been included. The number of users greatly multiplied from introduction of the fundamental to the feature mobile devices, and by the end of the Feature Era the characteristics 
of users had crossed social-economic boundaries. Communication was still one-to-one. Frequency of use was on a cost-driven, as-required, basis. The low purchase cost and simplicity means providers in 2018 still make feature mobile telephones available.

\subsubsection{Flexible}

From around 2008 to 2014, a fourth-generation internet-protocol mobile device known as a 'smart phone', combined communications with processing capabilities comparable to a mobile computer. The devices merged the mobile telephone with the internet and for many users have supplanted both landlines and laptop or netbook computers. The devices are described in this thesis as flexible, as users customize the capabilities of their devices through an extensive suite of downloadable applications to suit their personal, specific, and evolving needs, and the applications can be readily adopted, discarded, and expanded for a multitude of purposes. Flexible mobile telephones routinely include the non-communication capabilities of other devices such as taking and storing images, location-finding or as an access way to musicentertainment repositories. Mobile devices are seen as egalitarian - available to, and used by, a very wide population regardless of all age and socio-economic status. Communications may be one-to-many, many-to-one, or many-to-many through internet applications. Usage is socially driven and constant. Many users expect constant connectivity with other users, or with their interests, via the internet.

\subsubsection{Coding across eras}

Codes used in NVivo 11 across market eras may have similar designations and definitions to enable ready comparison of practices between eras. Comparison between codes enabled differences in market boundaries to be determined as market actors engaged in evolving practices (Leonardi, 2011). Furthermore, practices that exist in one era, but not in others, become readily apparent. 


\subsection{Data Sources}

This section describes the process used for ensuring consistent data sourcing to provide a foundation for consistent data interpretation. A challenge for a constructionist methodology is to interpret and then present data in ways that a reader can understand and readily accept. In this research, a narrative is presented for each market era providing evidences of performances by market actors (Martin \& Schouten, 2014; Schau et al., 2009; Shove \& Pantzar, 2005). This research involved interviews with providers, users, and regulators acting in the New Zealand mobile telecommunications market between 1990 and 2014. Documentary data included annual reports of a mobile telecommunication provider, Telecom New Zealand (later Spark New Zealand) and annual and industry analysis reports of the Commerce Commission of New Zealand, as market regulator, between 1990 and 2015.

\subsubsection{Interview Participants}

Interviewees were selected from providers, users, and regulators of mobile telephone services in New Zealand.

\section{Providers}

A decision rule was that all three market eras be sufficiently covered, and that participants be of sufficient stature within the provider organisation, and within the New Zealand and global mobile telecommunications sector, as to be able to describe in detail corporate strategies and policies for which they were personally responsible. This rule was met by interviewing past and present chief executives and chairmen. Technical expertise was also sought to gain provider and market insights perhaps obscure to the senior executives.

P1 was chief executive of Telecom and immediately upon retiring from that role became its chairman. His terms in these two roles lasted more than 14 years and covered the very start of the Fundamental Era through to the beginning of the Flexible 
Era. Until recently P1 was an active board member and chair of large companies in New Zealand and overseas and he remains as chair or patron of national charities.

P2 joined Telecom in the Fundamental Era and rose to be the company's chief operations officer. P2 left the firm at the start of the Flexible Era to be the chief executive of another very large commercial organisation. He returned to Telecom as its chief executive in the late Flexible Era and remains in that role.

P3 is a globally recognised technical expert who helped set up Telecom's mobile group. P3 was involved in the international development and delivery of mobile telecommunications even prior to the research period, and is still very active in mobile technology and standards development.

All provider participants accepted their confidentiality could not be assured, particularly in respect of New Zealand readers and agreed to be interviewed without hesitation. Regardless, provider participants are represented only by their research identifier.

\section{Users}

User interviewees were chosen firstly, for their involvement as users of mobile telephone devices and the likelihood of their being representative of a particular market era (Mason, 2002) and secondly for their ability to verbally express themselves. Furthermore, the interview participants, while sharing characteristics of other interviewees from a market era, were also to be substantially different in some key aspect as to enable a broad as well as deep reach into practices. A further decision rule was that all three market eras be sufficiently covered by participant involvement in the market to ensure strong, repeated, similarities in the expressed experiences. Selection criteria included: 
Fundamental Era:

The interview participant was involved as a user of mobile devices in the New Zealand market from 1990 until 1998 (or later).

The interview participant was representative of other users in the Fundamental Era in terms of lifestyle, socio-economic status, and mobile device use characteristics, but had differences to other participants.

Feature Era:

The interview participant was involved as a user of mobile devices in the New Zealand market from 1998 (or earlier) until 2008 (or later).

The interview participant was representative of other users in the Feature Era in terms of lifestyle, socio-economic status, and mobile device use characteristics, but had differences to other participants.

Flexible Era:

The interview participant was involved as a user of mobile devices in the New Zealand market from 2008 (or earlier) until 2014.

The interview participant was representative of other users in the Flexible Era in terms of lifestyle, socio-economic status, and mobile device use characteristics, but had differences to other participants.

The characteristics of each user interview participant are now described:

SS is a male accountant and financial advisor to governments internationally. The consultancy for which SS worked in the early 1990s purchased fundamental mobile telephones for senior executives including SS. As technology developed, SS was either given by his employers, or purchased for himself and his family after he became a self- 
employed consultant, mobile devices of increasing capability. He now uses a flexible mobile telephone, but as rarely as he can manage.

AS is male and recently retired. He was first provided with a fundamental mobile telephone in 1989 to assist his work with New Zealand Post, the precursor to Telecom New Zealand. The latter half of his career was spent as a vehicle salesman, and until he retired his mobile telephone was provided by his employer. He purchased the feature phone he now uses, mainly for keeping in touch with friends and family by text. Compared with his working years, his use of the device is much reduced.

ML is a female academic who purchased her first fundamental telephone in the early 1990s to ease safety worries about working in remote locations for film production. Changing careers and lifestyles meant she replaced her telephones as needs changed and older models were superseded. She now uses a flexible mobile telephone for professional and personal purposes and worries about the aesthetics of the device.

$\mathrm{AF}$ is a male working as a researcher for a building supplies organisation. As a youth he was given a late era fundamental mobile telephone by his parents. His mobile telephones have primarily been devoted to personal use - for contacting friends and family. He now has a flexible telephone for professional and personal use including exchanging routes and times with other riders of mountain bikes.

$\mathrm{AR}$ is a male engineer who received his first late era fundamental phone from his consultant employer. He travelled extensively in rural and remote areas of New Zealand for his work and the telephone was used for both business and personal use. His work became increasingly complex and his mobile device was updated in parallel. $\mathrm{He}$ is now a senior manager in a large organisation involved in network supply 
throughout New Zealand and is constantly using his flexible mobile device, primarily for business-related activity.

$\mathrm{RG}$ is a female public service senior executive. She acquired her first late era fundamental phone while self-employed, working from her home while also caring for a small child. She replaced her mobile telephone as new options and technologies became available, and passed older phones down to her son. For business and personal use she now uses a flexible mobile telephone, the last several models being passed up from her son. She uses her telephone far less than she once did.

PT is a male retired academic whose first mobile device was a feature telephone. It was bought after much soul-searching and analysis of options and was used for business and personal use. His mobile devices were replaced as they aged and newer options became available. He now uses a flexible telephone primarily for personal use, and somewhat less than he did.

DS is female, now retired as an engineering draughtswoman. She acquired her first mobile telephone after the anxiety of losing track of her sick husband one afternoon. She travels widely, has friends throughout Australasia, and a number of children and grandchildren, and uses her ten-year old feature telephone to stay in touch with all of them through calls and texts.

$\mathrm{RV}$ is a male post-graduate university student. He received his first few feature mobile devices from his parents. He was an early and very enthusiastic adopter of flexible mobile technology and replaces models at least once year. His business and personal use of his flexible telephone is almost continuous.

NL is a female technician. Her mobile telephones - from late era feature to flexible have always been hand-me-downs or gifts from her parents. She uses her flexible phone 
for constant contact with friends either by text or through internet access primarily for social media such as Facebook and Snapchat. She sends and receives hundreds of messages a day.

$\mathrm{AM}$ is a female working for an international consultancy. Her first mobile device was a feature telephone purchased by her parents. She received her first flexible telephone as a hand-me-down from her father and has become a heavy user for personal reasons. She and her friends and flatmates have "house rules" prohibiting the use of mobile telephones at mealtimes.

These participants cover the entire research period from 1990 until 2014. The migration of users from one market era to the next is evident, with one, SS, having substantial involvement in all three eras from the earliest fundamental mobile telephones to the most modern flexible devices. Most, but not all, have migrated to more capable devices as needs changed and opportunities for technological benefits appeared. All remain active users of mobile devices.

\section{Regulators}

While many industries are subject to some form of direct regulation or Government intervention to achieve political or economic outcomes, the New Zealand telecommunications market has been particularly closely engaged with at a Government level. The influence and extent of regulation on the telecommunications markets makes those individuals with regulatory powers particularly important to this study.

Telecommunications Commissioner participants were chosen for their strategic level of involvement in shaping the mobile telecommunications market through regulatory structures and interventions between 1990 and 2014. The Telecommunications Commissioner is an office within the Commerce Commission. The Commission has a regulatory function as a 
Government agency responsible on behalf of consumers for ensuring competitive markets including regulating some industries such as electricity. The Telecommunications Commissioner has particular regulatory responsibilities for the telecommunications market, including mobile. All three individuals who have held the position of Telecommunications Commissioner since the role's creation in 2001 were participants.

R1 was the first Telecommunications Commissioner. R1's tenure included the start of the Feature Era and he remained in the position until the start of the Flexible Era. This covered the period of so-called "soft-regulation" with minimal market intervention.

R2 was the second Telecommunications Commissioner whose tenure covered the first half of the Flexible Era. This period of "hard-regulation" was typified by direct marketshaping intervention in the telecommunications market, including mobile.

$\mathrm{R} 3$ is the third Telecommunications Commissioner whose tenure covered the second half of the Flexible Era up to the present day.

Two Ministers of Communications were interviewed. The Ministers, who are from opposing political parties, were chosen because of their direct involvement during the two critical phases of regulation in the New Zealand telecommunications market.

M1 was Minister during the period of "soft regulation" following the privatisation of Telecom in 1990 through the Fundamental Era to 1999.

M2 was Minister during the period of "hard regulation" from 2004 through to 2008 which led to the legislated structural separation of Telecom into its wholesale, retail and distribution components in 2011. One other Minister held the post between M1 and M2, but the latter Minister was Associate Minister during this time. M2's time as Minister corresponded with the Feature and Flexible Eras. 
All regulatory participants willingly and fulsomely engaged in the interviews and accepted their confidentiality could not be assured for a New Zealand audience of this research. Regardless, regulator participants are represented only by their research identifier.

\subsubsection{Interview Process}

Interviews with market actors revealed the extent of movements in social practice between 1990 and intervening periods to 2014 (Cayla \& Eckhardt, 2008; Gummesson, 2000; O'Driscoll, 2006; Thompson, 1997).

A thematic, topic-centred, sequenced script of open questions provided a fluid and flexible semi-structured interviewing process (Appendix A). Semi-structured interviews were based on the interactional exchange of dialogue, described by Mason (2002, p. 62) as "a conversation with purpose". The "conversation" allowed the researcher and interview participants to focus on relevant specifics while being open to developing unexpected themes (Cavana et al., 2001; Mason, 2002). Semi-structured interviews were preferred over an entirely pre-scripted process because extracting the data required flexibility in taking cues from the ongoing dialogue that allowed supplementary questions, relevant to the context, but which could not have been anticipated (Mason, 2002).

Open-ended questions were delivered appropriate to the situation with wording varied as needed during interviews to encourage unrestricted and critical responses. The researcher's purpose was to ensure relevant contexts were brought into focus to enable situated knowledge to be produced and interpreted (Mason, 2002). When interview subjects had experience of more than one market era, the interview was structured to focus on a specific market era before iteratively moving on to the next era. Iteration helped provide a basis of comparison to place into contrast those practices most involved in change. 
The interviews, each of about an hour, were conducted at locations suiting the interview participants. Interview locations included participant homes, offices, the Wellington Club, Parliament, four were conducted in cafés, and one in a barn. The interview participants had previously been asked by the researcher to participate and the intention of the research made clear. Having agreed to the interview, each interview participant was then sent the interview protocol, Appendix A, explaining the background and intent of the research, the reasons why they had been asked to participate, and material regarding their consent and the confidentiality of their comments. The researcher reiterated this material prior to each interview and ensured the consent forms were signed. Each interview participant agreed to be recorded.

The language of questions necessarily changed from thesis terminology to conversational English to assist interview respondents. The interviews followed the processes described in Mason (2002), with questions asked and the interview participant being able to describe and explain with the least amount of interruption, the intent being to explore and delve into practices rather than to challenge behaviour or actions taken. For example, this often involved asking "what did you do?" rather than "why did you do it?" Silences were used at times to encourage interview participants to expand on their answers in areas where probing questions may not have solicited further detail. Only when interview participants felt they had exhausted their contribution did the researcher move on. The questions were allowed to stray from the protocol to suit the specific circumstances of each interview and were informed by the researcher's prior knowledge derived from documentary material.

The interview recordings were transcribed either by the researcher or by professional transcribers who had signed confidentiality agreements. All the transcriptions were then reviewed by the researcher against the recording to ensure accuracy. A transcript was sent to each interview participant for expansion, correction and elucidation. Changes by interview participants were minimal but often helpful in terms of data collection or researcher 
understanding. The approval of interview participants as to the accuracy of their transcript contributed to triangulation. Finalised transcripts were imported into NVivo11 for coding.

\subsubsection{Ethics}

Although user participants were assured of confidentiality, as stated above, the provider and regulator participants are public figures and readily identifiable, and hence confidentiality could not be assured. The risk to confidentiality was discussed with each provider and regulator participant and all agreed without hesitation to the interview.

\subsubsection{Documentary Data}

Unlike memory-based recollections, documentary data remains unchanged through time and the practices uncovered from the data could be trusted as reflective of an era. Furthermore, just as interviews reflected the interviewees' interpretations of events, so written text, such as a provider's annual report, reflects the interpretation of events made at the time by the report authors (Beard, 2016).

The researcher examined documentary data for indications of priorities, strategies, and of market-place activities, particularly those that indicated organisational direction or focus. Statements made by organisational leaders and specific quantitative data were rich sources of relevant material. The National Library of New Zealand's archives provided most of the documents required for this research. Documents included the annual reports of Telecom (later Spark), from 1990 to 2015 inclusive. The 2015 annual report was examined since, with the relaunching of Telecom as Spark, substantial changes in strategic and internal operations only occurred part way through 2014 and these changes were not fully represented in the 2014 annual report. The Commerce Commission of New Zealand annual reports from 1990 to 2014, and several Telecommunications Commissioner regular and specific reports on the telecommunications industry, were examined. 
The data gathering phase included copying relevant material from the reports into Word documents. After further refinement, the data were imported into NVivo11 for coding.

Analysis of documentary material also provided a means of triangulation for the interview data, whereby actor recollections from interviews were compared against a timeline of events, priorities and quantitatively-evidenced changes in the mobile telecommunications market in New Zealand (Miles et al., 2013; O'Driscoll, 2006; Thompson, 1997).

\subsubsection{Development of Metrics}

Comparison of interview data against metrics helps enable an understanding of both data and the market. Metrics from data extracted from the annual reports of Telecom/Spark and the Commerce Commission, the Commission's industry updates, and from census data, provided evidence whereby market change could be observed and made measurable. A summary of Telecom/Spark metrics, with additional material from the Commerce Commission, is provided in Appendix B. The appendix also provides a contextual timeline of relevant actions by the Commission and Telecom/Spark.

The appendix shows where particular data was presented in annual reports and in what form. Changes in the kinds of data presented were themselves indications of market change in that the metrics reflected what these organisations themselves considered of such importance as to be measured.

Metrics also assisted in establishing the trustworthiness of qualitative data, to which the chapter now turns.

\subsection{Trustworthiness, Validation, Triangulation and Reality Tests}

Social constructivism research, where there is more than one 'truth' possible, relies heavily on trustworthiness in establishing plausibility and validity (Guba \& Lincoln, 1994; Zaltman et al., 1982). Trustworthiness is more likely through using more than one research approach (Rynes 
\& Gephart jr, 2004), through a spread of participants such as through different firms, levels and backgrounds, or through triangulation (Miles et al., 2013).

In this research, procedures developed to encourage trustworthiness involved the use of numerous interviews with individuals who, while sharing some key characteristics, were sufficiently different in perspectives and backgrounds. Interview participants were chosen according to decision rules as described above. Development of trustworthiness involved data management mechanisms including question structure and interview technique and providing transcripts to interview subjects to enable expansion, elucidation and correction. Secondly, material from the interviews was corroborated against documentary evidence such as organisational reports, and against quantitative metrics derived from multiple sources (Cavana et al., 2001). Convergence of similar themes emerging from all three data collection methods - interviews, documents and metrics - indicated enhanced trustworthiness of the material (Cavana et al., 2001; Mason, 2002; Miles et al., 2013). Inconsistent material, where interviewees had conflicting recollections or interpretations, forced explanation of why the conflicts existed. Examination of these critical differences at times led to deeper understanding of motives, actions and consequence, and thus practices (Miles et al., 2013). The gathering of interview and documentary evidence continued until the ideas gained from sources became redundant (Zaltman et al., 1982).

Data was subjected to coding and hermeneutic analysis according to predetermined decision rules for each layer of interpretation (Zaltman et al., 1982) that were grounded in the social practice theory approach to markets and market boundaries (Gosling et al., 2017; Shove et al., 2012). The specifically constructed coding process using NVivo11 enabled post-analysis confirmation and reflection of the methods and consistent analytical streams from codes to categories. 
A Research Analytic Memorandum was maintained to keep track of thoughts, processes, and specific issues and events. There was frequent discussion with supervisors throughout the research process.

\subsection{Conclusion}

This chapter described the methodology incorporated in this research. The research subject of this thesis was based on the mobile telecommunications market in New Zealand which underwent revolutionary changes between 1990 and 2014. A process was developed to consistently source data, including participant selection and interview process, and to construct data from iterative thematic analysis of narrative - the textual data derived from interviews and historical documentary evidence of market actors. Methods of triangulation provided corroboration to enable trustworthiness of the analysis and findings.

Having described the research methodology and data sources, emphasis now turns to data construction. Data construction describes the abductive method used to establish meaning from material gathered through empirical research. The data construction process undertaken to address the objectives and research questions of this study is described in the next chapter. 


\section{DATA CONSTRUCTION}

\subsection{Introduction}

This chapter presents an example of the data construction method-in-use employed to address the objectives and research questions. Tensions can arise where, as in this thesis, substantial adaptation from familiar methodologies has taken place (Ågerfalk \& Fitzgerald, 2006). Further tensions arise because the interpretation of a method is based on the researcher's understanding and values, yet acceptance of the method is dependent on the ability of readers to incorporate the method into their own view of the world (Ågerfalk \& Fitzgerald, 2006). An example of the actual process used in data construction - the method-in-use - is helpful in easing these tensions by assisting understanding of how the methodology and the process of data construction were brought together. The data construction example includes coding of text, understanding of meaning through tiers of interpretation, and the subsequent presentation of the data.

\subsubsection{Coding and interpretation}

Practices are the focus of examination rather than the actors themselves (Warde, 2005). Furthermore, the interview participant cannot be assumed to understand the research subject, nor are they expected to explicitly describe practices, nor ascribe meaning to these practices (Lindseth \& Norberg, 2004). The task for the researcher was to extract essential meaning not only from the practices individual actors described with words (text), but also through collating the meanings derived from the routinised and common sayings and doings of numerous actors over time (Lindseth \& Norberg, 2004; O'Driscoll, 2006; Schau et al., 2009; Warde, 2005). In this thesis meaning was assigned to text through the allocation of codes (Miles et al., 2013).

Refining and then interpreting themes involved repeated readings of the interview and documentary text and the development of thematic codes within the conceptual framework of the researcher's theorising of markets and market boundaries. Firstly, the texts from interviews 
and documents were analysed for evidence of social practices - those routinised sayings and doings of each market actor - and coded as to the nature of the practice. Secondly, comparisons were made across the entire sample of interviews and documents involving a particular market era to establish common themes and to elicit higher-order abstractions (Spiggle, 1994). Iterations of this process continued until all codes were sufficiently described, every interview and document was consistently coded, and the researcher was satisfied as to the consistency of interpretations and coding across the data.

Key to interpretation of the textual data was efficiently and transparently assigning codes to text in ways that could in turn be interpreted and re-interpreted to increasingly higher levels of meaning that enabled direct relationships between the text and a parameter. Combining Easton (2010) and Nili et al. (2014), the method of interpretation follows the quadri-hermeneutic approach of moving from text (a small section, perhaps a single line or sentence, of an interview transcription or document) to the whole (the social practice-based market model with specific reference to the categories of practices forming parameters), and from the whole back to text to confirm meaning and understanding. Understanding of the text was based on understanding of the whole, and understanding was gained by multiple reflexive examinations of both text and meaning (Alvesson \& Sköldberg, 2009; Nili et al., 2014). To illuminate:

1. Based on understanding of the market model and social practice theory, a network of basic codes was developed;

2. A condensed, or explanatory, definition of a market practice was ascribed to each code;

3. Texts (such as a sentence or phrase) were identified and assigned a code. Much of the text was assigned multiple codes reflecting the complexity of understandings; 
4. The number of codes expanded through the analysis as understandings increased. Each new code was assigned a definition;

5. Based on the code, a condensed interpretation of the text was undertaken;

6. Further levels of interpretation were undertaken in relation to the whole;

7. The interpretation was assigned to a mechanism as a coarse filter. Mechanisms, as previously described, act as a bridge between levels of interpretation. The mechanisms of "meanings", "competencies" and "materials" reflect the components of practice (Shove et al., 2012) and the grouping of parameters;

8. The mechanism allowed further refinement of interpretations, and the collation of interpretations, whereby the text and text interpretations were assigned to a category - a particular parameter as an example of market practice undertaken in a particular market during a specific era; and

9. Understanding of the market model changed as a result of interpretations of text and reflection. New understandings resulted not only in amended perceptions and subsequent interpretations of the text, but also in revisions to the model itself.

In the Analysis and Findings chapter which follows, extracts of interviews are presented as part of a narrative - a chronologically structured 'story' of the market. An example of the method-in-use is provided in Figure 5-1 with text from interview participant AS describing attitudes towards his mobile telephone use in 1990. Two codes are represented for each text element. A condensed meaning was developed and interpreted for each text element, and in this example assigned via the mechanism of "meanings" to the category of the Social and Community Meanings parameter (Easton, 2010; Nili et al., 2014). 


\begin{tabular}{|c|c|}
\hline \multicolumn{2}{|c|}{ Category: Social and Community Meanings Parameter } \\
\hline $\begin{array}{r}\text { Mechan } \\
\text { Interpretation: Social Acceptance is unfor } \\
\text { become under } \\
\text { Usage defines the } \\
\text { Usage defines }\end{array}$ & $\begin{array}{l}\text { led but growing and enabling: practices develop, } \\
\text { ood, and integrate. } \\
\text { vice as Life Disruptive. } \\
\text { e user as Innovator. }\end{array}$ \\
\hline $\begin{array}{l}\text { Interpretation: The device conveys social } \\
\text { status. }\end{array}$ & $\begin{array}{l}\text { Interpretation: The device is a socially } \\
\text { disruptive-positive. Society enables. }\end{array}$ \\
\hline $\begin{array}{l}\text { Condensed Meaning: This device makes me } \\
\text { feel important. } \\
\text { Code: FU - Elevated Status } \\
\text { Code: FU - Social Acceptance }\end{array}$ & $\begin{array}{l}\text { Condensed Meaning: Society sees me as } \\
\text { different in a positive way. Society has not yet } \\
\text { developed rules for this new practice. I can do } \\
\text { what I want. I feel good. } \\
\text { Code: FU - Elevated Status } \\
\text { Code: FU - Socia Acceptance }\end{array}$ \\
\hline $\begin{array}{l}\text { "I used to feel quite proud to have that phone } \\
\text { on my shoulder, because it was a mark of } \\
\text { being...or doing an important job." }\end{array}$ & $\begin{array}{l}\text { "I felt enabled. If we were sitting there and it } \\
\text { rang.... You almost wanted it to ring." }\end{array}$ \\
\hline
\end{tabular}

Figure 5.2. involves a text from another interview participant, NS, discussing circumstances, similar to the first example, but occurring in 2014. Figure 5.2. has a further text from AS about perspectives of others on his mobile device use, but this time from his experiences in 2014. A code is again represented for each element of text. A condensed meaning was developed and interpreted for each element of text, and, as in the first example, assigned via the mechanism of "meanings" to the parameter of Social and Community Meanings. 


\begin{tabular}{|c|c|}
\hline \multicolumn{2}{|c|}{ Category: Social and Community Meanings Parameter } \\
\hline $\begin{array}{l}\text { Interpretation: Social Acceptance of mobile } \\
\text { and fully integrated. For its broader benefit, } \mathrm{s} \\
\text { Usage defines the device a } \\
\text { Usage defines } \mathrm{t}\end{array}$ & $\begin{array}{l}\text { m: Meanings: } \\
\text { ephones is complete: practices are well understood } \\
\text { iety applies constraints on the use of these devices. } \\
\text { Life Normative and Egalitarian } \\
\text { user as Conformist. }\end{array}$ \\
\hline $\begin{array}{l}\text { Interpretation: } \text { The device conveys no social } \\
\text { status. }\end{array}$ & $\begin{array}{l}\text { Interpretation: The device is a socially } \\
\text { disruptive-negative. Society imposes constraints. }\end{array}$ \\
\hline $\begin{array}{l}\text { Condensed Meaning: My new iPhone } 7 \text { does } \\
\text { not make me important. I am no different to } \\
\text { others. } \\
\text { Code: FL - Lack of Elevarted Status }\end{array}$ & $\begin{array}{l}\text { Condensed Meaning: Society sees performance } \\
\text { of this practice in a negative way. Society has } \\
\text { thus developed rules for an established practice. } \\
\text { Conformity with a societal rule is expected. I can } \\
\text { no longer do what I want. I no longer feel good. } \\
\text { Code: FL: Socia\Acceptance }\end{array}$ \\
\hline $\begin{array}{l}\text { "Most people kind of only had like iPhone } 4 \mathrm{~s} \\
\text { and iPhone } 3 \text { s and everything, so..." } \\
\text { It didn't make much of an impact at all? } \\
\text { "Not really." }\end{array}$ & $\begin{array}{l}\text { "That's something I really really missed... was } \\
\text { when they changed the laws about talking on the } \\
\text { phone, because I used to basically spend hours } \\
\text { on the phone while I was driving." }\end{array}$ \\
\hline
\end{tabular}

Performances described in the text - using a mobile telephone - are similar, but the practices are substantially different. The movements in practices enabled the researcher to compare the practices contained within the Social and Community Meanings parameter in the Fundamental Era, with those of the Social and Community Meanings parameter in the Flexible Era. The collective changes in practices helped make apparent the changes to the parameters that define plastic market boundaries. 
To explain the method-in-use further, in the example given in Figure 5.1., AS was a user within the New Zealand mobile telephone market which was bounded by parameters comprised of specific practices that were discernibly different to those around him who were outside the market. In 1990 the market consisted of 0.029 million $(29,000)$ connections (Telecom New Zealand, 1992), or just 0.8 percent of the New Zealand population (Statistics New Zealand, 2017). In the second example given, in 2014 NL was very similar to those around her. The devices that were seen by society in 1990 as being status defining - even elitist

- innovative, and life disrupting, were by 2014 accepted by society as egalitarian where a device, and device usage, was life normative. This reflects how the market contained within the parameters had expanded by 2014 , where the number of users within the market boundary had risen to 5.3 million (Commerce Commission of New Zealand, 2015), or 122 percent of the New Zealand population (Statistics New Zealand, 2017). Thus, mobile devices had moved from "status objects" to "egalitarian", users moved from being "innovative" to "conformist", the use of the devices moved from "life disruptive" to "life normative". Furthermore, institutional practices that had not existed in 1990 were evident in 2014 whereby society, having first accepted the use of these devices, for its own good imposed constraints with which actors within the market parameters must comply or face sanction.

\subsubsection{Presenting the data}

Again using text from AS and NL (with M as the interviewer), Table 5.1. depicts an example of the presentation of the data. Suggested, or anticipated, parameters are included in the table. Metrics are included that suggest changes in parameters were reflected in changes evident not only in institutional practices but in the effect on market size. A link is thus drawn between performance changes and changes to institutional practices over time, and further linked to the effect on the market. The Needs parameter is included in this example in recognition of the 
multiple interconnections between parameters. In later presentations the interpretation process is decluttered.

Table 5-1 Linkages - performances, institutional practices and market effects

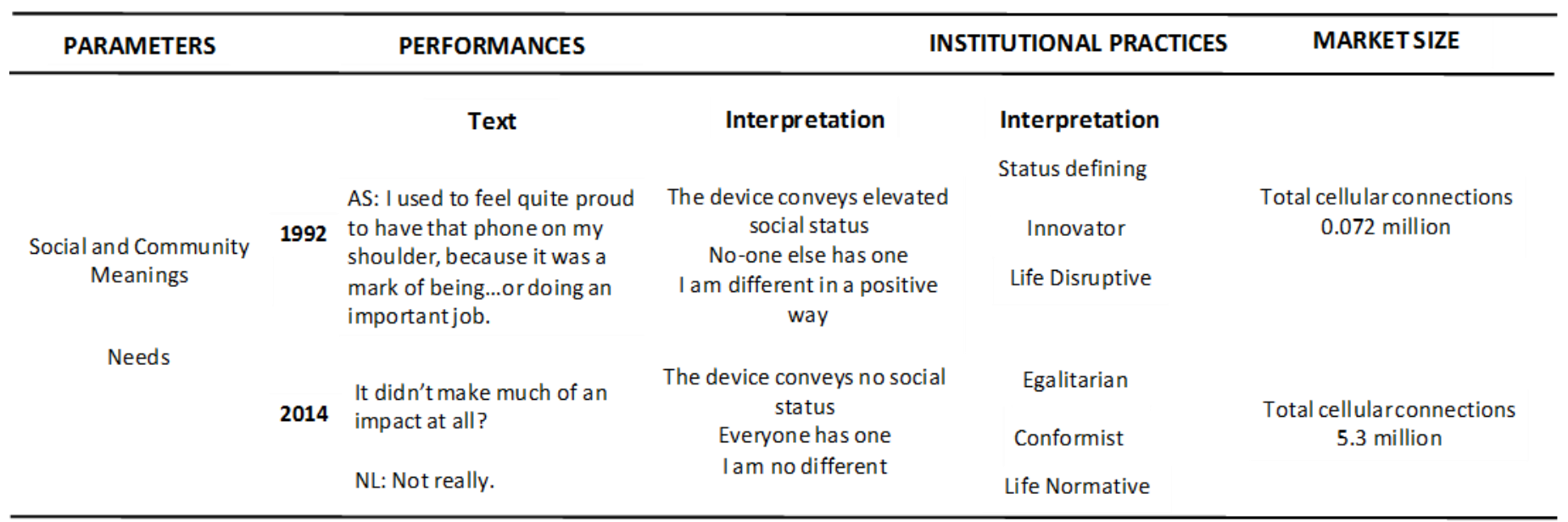

\subsection{Conclusion}

An example of the method-in-use was presented to reduce natural tensions arising from method adaptations. The method-in-use example included coding of text extracted from interviews, the levels of interpretation and reinterpretation, interpretation outcomes, and finally, of data presentation. The scene is now set for the next chapter presenting analysis of the data, and the findings constructed from the data. 


\section{ANALYSIS AND FINDINGS}

\subsection{Introduction}

This chapter presents the analysis and findings that address the objectives and research questions of this study. Three distinct eras are identified in the New Zealand mobile telecommunications market between 1990 and 2014. The extent of change to performances and institutional practices across the eras brings into focus the specific categories of practices termed parameters describing market boundaries, how markets emerge and evolve, and how market actors are motivated to change their behaviour.

The analysis presented in this chapter firstly presents a narrative (Martin \& Schouten, 2014; Schau et al., 2009; Shove \& Pantzar, 2005) of the performances of Regulators, Providers and Users during the Fundamental, Feature and Flexible market eras in turn. A table depicting the performances and institutional practices derived from the narrative (Table 5-1 provided a simplified example), and thereby highlighting the characteristics of the market era, concludes each subsection.

By focusing on the performances of the Regulators, Providers and Users through the three eras, the analysis uncovers and identifies the institutional practices with which market actors complied in each era. The chapter culminates in a comparison across market eras whereby evidence of changes to institutional practices of each era, in step with changes to market characteristics, uncovers and identifies the relevant market boundary conditions and thus the nature and influences of market parameters.

The Regulator analysis primarily involves investigation of ideology held by market regulators as to how competition in the market should be realised.

Provider analysis focuses on the commercial priorities across the eras. 
User analysis investigates the conventions surrounding the purchase and use of mobile communication devices, the position and status of mobile telephones in society, the influence of mobile technologies on User practices and priorities in day-to-day life.

At times, clusters of practices necessarily overlap. Figure 6-1 provides assistance in understanding the structure of the analysis.

Figure 6-1 Analysis Structure

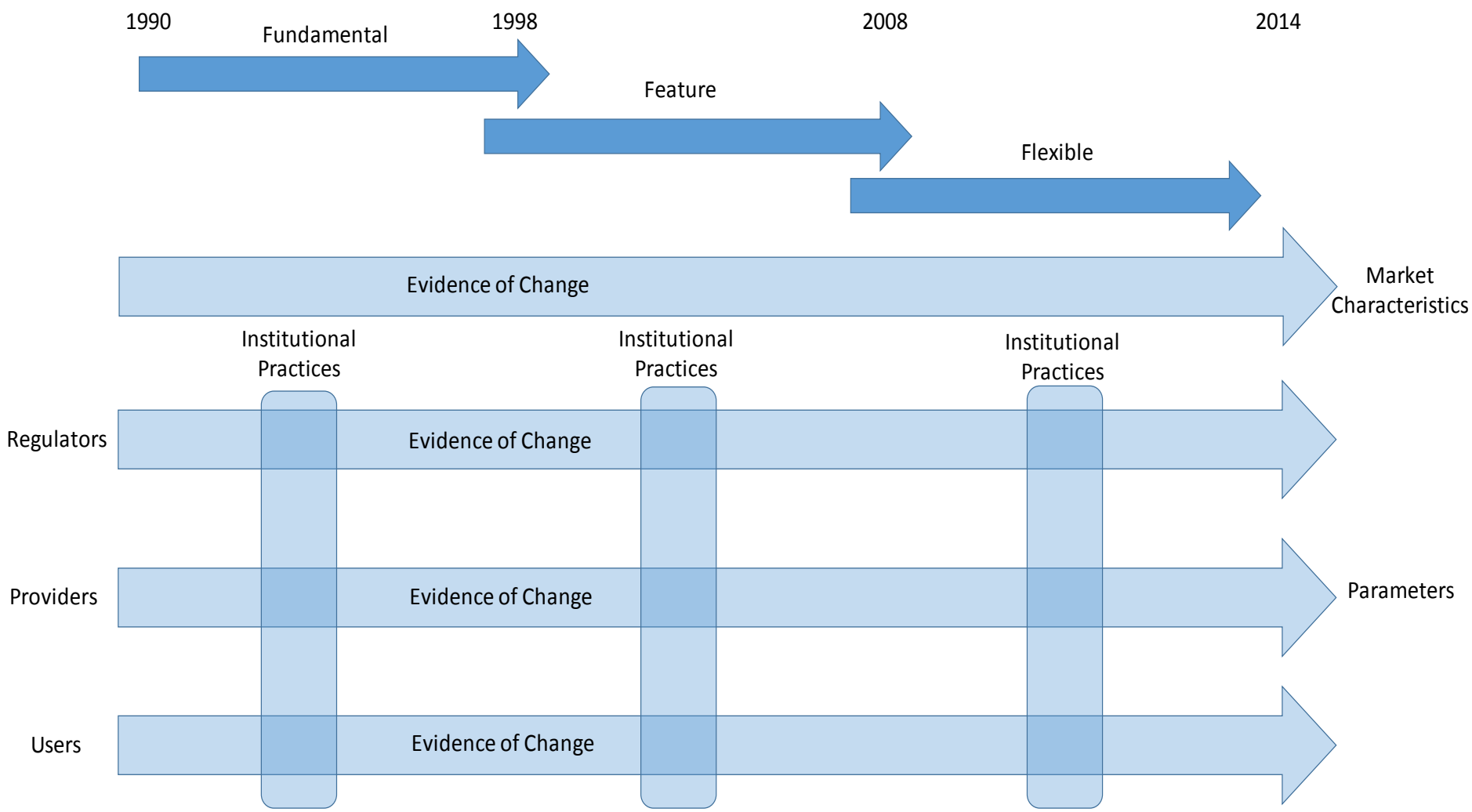

The research focuses on the New Zealand mobile telecommunications market between 1990 and 2014. To provide an informative and contextual foundation for the analysis, a brief history is presented of the early ideologies and actions that influenced the creation of the market, and, in particular, created the provider, Telecom New Zealand. 


\subsection{The political genesis of Telecom New Zealand}

Some of the most powerful changes in the market in terms of technology, ownership, and operation have been the result of direct Government action (Evans et al., 1996). These actions included the creation, and later structural separation, of Telecom New Zealand.

In 1984 the newly elected Labour Government set about dismantling many Government-owned agencies and departments in favour of corporatising some, which became state-owned enterprises, and privatising others, which involved their sale to investors (Scobie \& Janssen, 1993). Corporatised or privatised, these new organisations were to be user-funded, profit-driven, be exposed to competition, and themselves be competitive (Evans et al., 1996; Scobie \& Janssen, 1993). Among the agencies to be targeted for privatisation was the New Zealand Post Office (Evans et al., 1996). The Post Office was split into three new corporations to manage post, banking, and telecommunications ("State-Owned Enterprises Act," 1986). On 1 April 1987 the telecommunications functions were transferred to a new firm, Telecom New Zealand. The privatisation of Telecom New Zealand on 1 September 1990 remains the single largest foreign investment in New Zealand history (P1, 2016). The firm was sold to a consortium of two of the largest telecommunications providers in the United States Ameritech and Bell Atlantic - for $\$ 4.25$ billion (Telecom New Zealand, 1998). Two New Zealand firms, Freightways Holdings Ltd and Midavia Holdings, held options. Following a share float in July 1991 Telecom became the largest listed firm on the New Zealand stock exchange and $380^{\text {th }}$ largest in the world by market capitalization (Telecom New Zealand, 1998). Substantial staff reductions and new processes resulted in greater efficiency but for the new owners of Telecom, more profitability was needed. The board brought in a new chief executive, described in this thesis as P1, with a clear mandate to grow the value of Telecom. This would be achieved by further efficiencies and by growing the landline business (P1, 2016). 
Competition in the tolls market was provided by global market actors entering the New Zealand market such as Clear Communications (NZ) Ltd.

Concurrent reforms also removed 'hard' regulatory controls involving constant and invasive Government intervention in industries to one of 'soft' regulation where normal competition rules would apply (Evans et al., 1996; Howell, 2007). Some specific regulatory restraints were incorporated in legislation and the pre-privatisation agreement between the Government and the new owners of Telecom in regard to the landline network and free local calls (Evans et al., 1996; Howell \& Obren, 2003) By 1992 the supply of services to homes and businesses was deregulated and restrictions on competition removed (Howell, 2007; Telecom New Zealand, 1997).

\subsection{0 - 1998: The Fundamental Era - Mobile as 'other'}

\subsubsection{Market size}

In 1990, there were 0.029 million $(29,000)$ mobile phone users in New Zealand. This was equivalent to 0.8 percent of the New Zealand population. In 1992, second-generation Fundamental mobile telephones were introduced into New Zealand. Competition emerged for the first time in the New Zealand mobile telephone market from 1994 with first BellSouth of the United States and from 1998 by Vodafone of the United Kingdom. By the end of the Fundamental Era, around 1998, the number of mobile phone users had risen to 0.63 million $(630,000)$ or 17 percent of the population (Commerce Commission of New Zealand, 2008). 
Figure 6-2 Fundamental Era: Mobile subscriptions in millions and as a percentage of the population

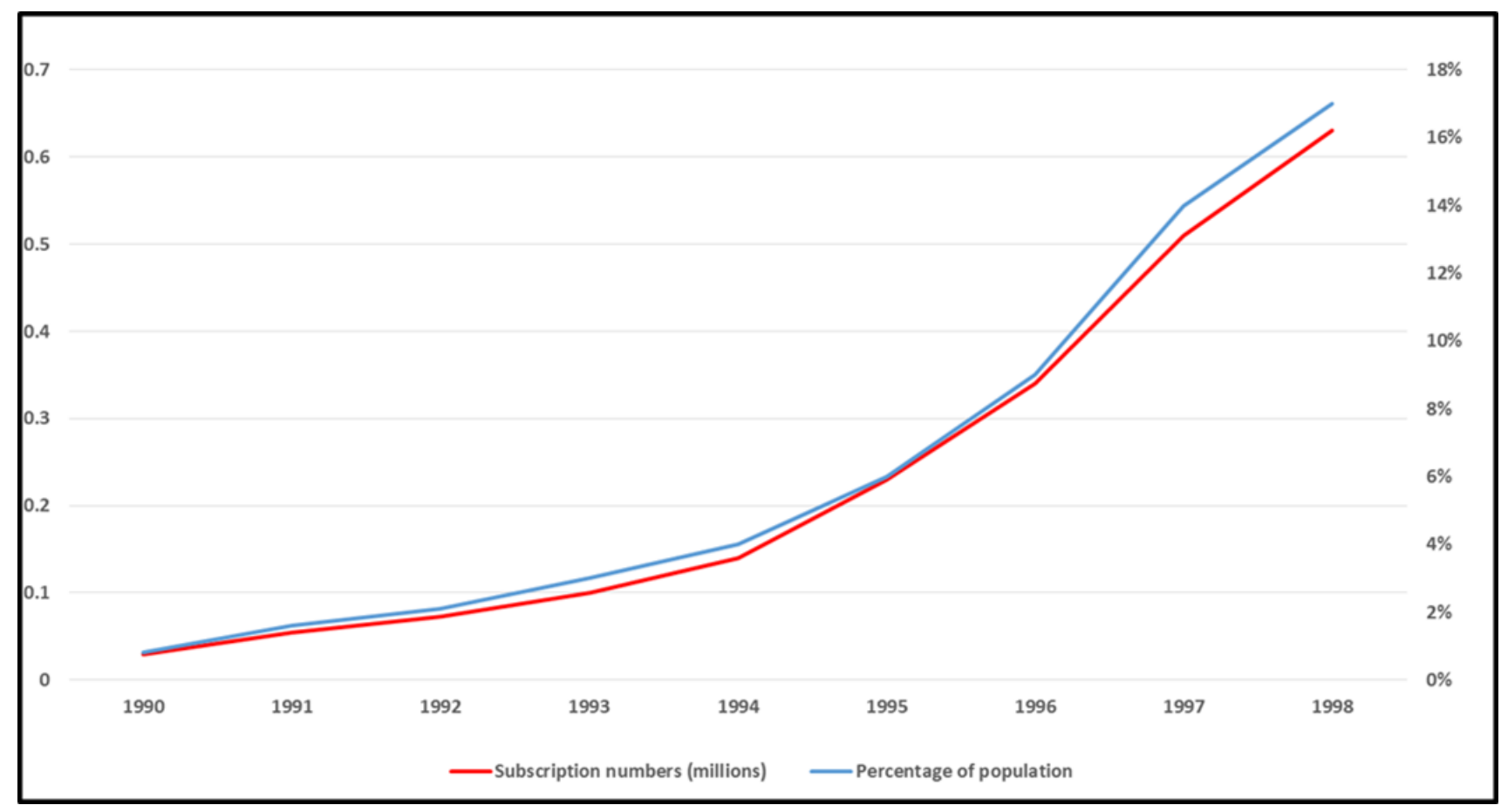

\subsubsection{Regulators - performance of practice}

In November 1990, only two months after the Telecom privatisation, the Labour Government was elected out of office (Levine \& Roberts, 1991). The incoming National Government Telecommunications Minister, M1, had while in Opposition been hearing from constituents and lobbyists that to encourage competition across the New Zealand telecommunications market more regulation was needed (M1, 2016).

They (the buyers of Telecom) wouldn't have spent four and a quarter billion (dollars) if they'd had to give up the numbering plan and allow open access to the local loop, because they were just buying a money machine. And so (National Prime Minister Jim) Bolger asked me to talk to (Finance Minister) Ruth (Richardson) and see whether we would look at some way of a buyback and compensation. And Ruth just says “I'm not buying back any part of a telephone company." And I said, "well if you don't, I've got no moral grounds to regulate them on. Because I can't say well now that we've banked the cheque, and you know there's no rules, right? Well now here's the rules". (M1, 2016, p. 1) 
M1 saw no moral or political grounds for specific 'hard' regulation of the telecommunications market. His perspective did not sit well with actual and potential competitors to Telecom and in his interview M1 was critical of Providers during the Fundamental Era because of their respective stances on regulation and competition. BellSouth, upon entry into the New Zealand market in 1994, made continuous calls for more market regulation to enable, among other things, access to Telecom's network infrastructure and to reduce costs of transferring calls between networks. BellSouth had successfully bid for the GSM mobile frequency, but M1 said he saw their strategy as one whereby they could substantially increase their value by pressing the Government for more regulation (M1, 2016). BellSouth knew the regulatory circumstances into which they were buying, and would have factored this into the price they paid for frequency, he said. He was, however, being strongly pressured into regulating in BellSouth's favour. He was unmoved by the company's protests that competition was impossible without regulated constraints on Telecom and greater access to the Telecom network for themselves. M1 told BellSouth they could have any regulations they wanted, provided they implemented the same access to their own competitors in the United States.

Because if you won't, then you're not genuine. You're only trying to steal a march here, but you don't believe in the principle. (M1, 2016, p. 3)

At a personal, moral, level M1 objected to market actors wanting in New Zealand the very conditions they were opposed to ceding in their home territories (M1, 2016). The reluctance of M1 to provide regulatory assistance to BellSouth continued to negatively impact on his relationship with the American-based provider. The principle of not regulating was not easy to uphold and not evidence of a lack of engagement, he said.

It was a really hard slog trying to bring all the parties to a more market understanding. (M1, 2016, p. 6) It's so much harder not to regulate than it would be to regulate. I wish I could say 
"ah stuff it let's just make interconnection here, and put pricing at that, and stick price caps on this" and so on. It would have been easy. (M1, 2016, p. 8)

While Commerce Commission regulatory actions involving mobile communications during the era were limited to minor advertising and promotional matters by Telecom and its competitors, the events happening across the rest of the telecommunication industry set the pace and direction of regulatory intervention. There were numerous, almost continuous, disputes over landline matters between the Commission, Telecom, and competitors such as Clear and BellSouth, that were contested in courts including the Privy Council. Telecom also successfully challenged that the Commission had acted outside its powers in conducting a formal inquiry into the development of competition in the telecommunications industry (Commerce Commission of New Zealand, 1994, 1996, 1997). Just as M1 was frustrated by the actions of BellSouth and others, he was just as frustrated by the intransigence of Telecom. Each company, he said, was their own worst enemy (M1, 2016).

The following section turns to analysis of Regulator performances in terms of institutional practices and parameters.

\subsubsection{Regulators - parameters and institutional practices}

The mobile telephone market in New Zealand is both responsive and susceptible to regulation. Regulations, and the ideological basis of regulation, are reflective of the performances of regulators. Ideological priorities in the telecommunications market did not substantially alter between the Labour and National Governments. While privatization and corporatisation and the relaxation of market regulation had been initiated by the Labour Government of David Lange, the incoming National Government of Jim Bolger did nothing to reverse or influence the process. The performances of M1 relate firstly to the parameters of Social and Community Meanings (invasive 'hard' regulation was neither needed, nor was politically acceptable) and Legal and Economic Institutions (the limited extent to which regulation of the 
telecommunications market and its providers was expected or even possible). The movements within these market parameters heralded an era of non-invasive, or 'soft' regulation where no substantial specific market regulatory actions were anticipated.

There was also the Social and Community Meanings ideological emphasis in New Zealand, as reflected in M1, of playing the game fairly. If the companies that wanted greater access to the New Zealand market were themselves denying access to competitors in their own domestic market, then they lacked a moral compass. M1 also resented, at a personal level, large companies from other countries expecting to push the New Zealand Government into a regulatory positioning favouring them (M1, 2016). Table 9 describes the parameters, performances and institutional practices for Regulators in the Fundamental Era.

Table 6-1 Regulator practices in the Fundamental Era

Legal and Economic Institutions

Social and Community Meanings
M1. I've got no moral grounds to regulate them on. Because I can't say 'well now that we've banked the cheque, and you know there's no rules, right? Well now here's the rules.

M1. It's so much harder not to regulate than it would be to regulate. I wish I could say "ah stuff it let's just make interconnection here, and put pricing at that, and stick price caps on this' and so on. It would have been easy.

M1. Whatever it is that you write up, whatever you want to go to, you have to also implement that back in your home market where you are the dominant carrier kicking the crap out of any new entrant because you won't let them onto your network. Because if you won't, then you're not genuine. You're only trying to steal a march here, but you don't believe in the principle.
Ideology: non-invasive (soft) regulation
Ideology: Fair Play through 'playing the game'

\subsubsection{Providers - performance of practice}

Mobile radio telephones had existed in some basic, short range, and very heavy form, since the 1950s. By the early to mid-1980s mobile telephones, later known as first generation, had been developed but broad usage continued to be hindered by cost, weight, low battery life, and 
meagre transmission range. By the late-1980s a second generation of mobile telephones was becoming available to consumers. In 1988 "mobile phones were the size and weight of a brick and cost thousands of dollars. Personal computers had only a fraction of the power of today's models yet were many times more expensive. Fax machines were still a novelty and only the US military and university professors used the internet. Who could have predicted the improvements we now take for granted in 1998?" (Telecom New Zealand, 1998, p. 14).

In fact, the improvements had been predicted and were being actively worked on prior to 1990 as a global industry in mobile telecommunications developed (P3, 2016). Telecom's American owners favoured the AMPS spectrum because of its prevalence in the United States, and at a commercial level the way ahead for mobile communications was not clear. From a technical level, however, the view was different.

We had a pretty good understanding of what the global market was likely to do over the next 10 years. You knew that this technology was going to start taking off. It was going to blossom. So we were extremely confident in the '91' 92 type timeframe that we (mobile) were going to take over. Telecom mobile was certainly the dominant player in the marketplace. BellSouth had only come in in '92. So they were, although it was small, in terms of business and market, they were blossoming in terms of the rate of increase of sales and increase in revenue. (P3, 2016, p. 3).

P3 and his global colleagues could see that competition would become intense as providers with the best technologically-based value propositions - including network coverage - would be the most successful. In the early 1990s, the second generation of mobile digital cellular telephones became available in New Zealand. Alongside came awareness by potential users of the benefits of mobile technology which, combined with lowering prices for devices and new usage plans, brought growth in the number of users (Telecom New Zealand, 1992). 
In his "letter to shareholders" in the Telecom New Zealand 1992 annual report, however, chairman Peter Shirtcliffe made no mention of mobile. His attention was on competition in the tolls market, and that there "can be no place for new regulation of telecommunications that would stifle innovation and threaten a thriving, competitive industry of benefit to so many New Zealanders." (Telecom New Zealand, 1992, p. 2). Indeed the first reference to mobile, noting that market penetration in Auckland and Wellington was 3 percent, was not made until page 28 (Telecom New Zealand, 1992). The customer base had expanded to include rural industries, and trade and service companies, and "a significant market niche has been established for personal users who select cellular phones for convenience, security and safety, and for the flexible messaging service offered, Cellular Voice Mail." (Telecom New Zealand, 1992, p. 29). "In the longer term, Telecom expects that both major market players will benefit from the strong underlying growth in the market and compete increasingly on non-price factors as in more mature competitive markets elsewhere." (Telecom New Zealand, 1992, p. 43)

\section{The mobile imperative}

Within Telecom there was a developing imperative to maximise the potential of mobile technology particularly in the business market.

\footnotetext{
The corporate market was taking off at a great rate of knots, and the Telecom mobile business was growing very rapidly. At that stage it had very little competition and it had a very, very, dominant market position so it was making money." (P3, 2016, p. 3)

"(Telecom was) marketing the potential for mobility to change the way in which you do business. Even though it was reasonably expensive for your top team of 100 executives, depending on what size company you were, you were very happy to pay the money." (P3, 2016, p. 3)
} 
By the following year, Telecom's mobile customers had grown to more than 0.1 million $(100,000)$. The chairman said in the company's 1993 annual report that he viewed the company's growth potential with great optimism, despite intense competition. The emphasis of the report was on cost reductions, restructuring, returns to shareholders, and preparing for "many of the most dramatic growth opportunities" that "lie outside our basic area of operations" (Telecom New Zealand, 1993, p. 2). Mobile revenues and costs were still hidden within “other" (Telecom New Zealand, 1993)

In 1992, P1 joined Telecom as chief executive.

Growing toll use was a large part of the strategy because that was where the bulk of the revenue lay at that time. That's where the most intense competition was at that time. So there was a lot of emphasis on growing and sustaining that market. (P1, 2016, p. 2)

The Americans owned all the shares (in Telecom) at that stage but they needed to sell down under the agreement they had with the Government. They had to sell down to a 50 percent holding. There were some New Zealand option holders as well, who were significant players, two of whom were on the board, and so the board view was they wanted to grow the company very strongly in those next couple of years. (P1, 2016, p. 1)

The board felt there was a lot more potential for growth. The mobile business was only just getting under way. Competition was being introduced, mainly at that stage in the form of Clear, and then, of course, BellSouth came into the mobile space. We grew the company quite quickly in the first few years that I was CEO. During the seven year period that I was CEO we grew the share price 30 percent per annum compound. That was really the objective: to grow value in the company. (P1, 2016, p. 1)

In the 1993 annual report Shirtcliffe again placed his emphasis on tolls, with no mention of mobile services. However, P1 noted the increasing importance of mobile revenue streams 
to the company where mobile generated $\$ 142.7$ million, or 5.8 per cent of revenues compared with \$59.8 million and 2.3 percent in 1990 (Telecom New Zealand, 1993, p. 10). BellSouth would compete in the mobile sector from 1994 but P1 noted that regardless of the competition "the potential cellular communications market in New Zealand is large. The Company has already a number of competitive initiatives, including the introduction of digital cellular service and a variety of pricing options." (Telecom New Zealand, 1993, p. 29).

P1 noted that "Telecom cellular services are at the forefront of New Zealand's communications revolution. The cellular network now covers 95\% of the population." (Telecom New Zealand, 1993, p. 16). At the time, however, only 3 percent of New Zealanders were mobile subscribers and coverage was focused primarily on urban centres (Commerce Commission of New Zealand, 2008; Evans et al., 1996).

During 1994 the number of mobile users rose a further 43.5 percent to 0.143 million $(143,800)$. This represented a 100 percent growth in the two years since 1992. All users were with Telecom. In the 1994 annual report, the chairman again focused on actual and potential investors, reminding shareholders that Telecom had record net earnings of \$528.1 million - an increase of 15.4 percent - and a return on average shareholders' equity of 23.6 percent - up from 17.8 percent (Telecom New Zealand, 1994). Only in the fifth paragraph does he mention customers: "Only by focusing hard on the needs of customers can we fulfil our mission to make it easier, more enjoyable and valuable for all New Zealanders to keep in touch. And only by ensuring customer satisfaction can Telecom be a successful business for its shareholders." (Telecom New Zealand, 1994, p. 2). In P1's statement as chief executive the focus was on tolls and the high levels of competition from Clear that had driven down average toll prices by 15 percent over the year. Telecom was looking to ensure a "real customer focus" throughout the firm, and to grow usage of the tolls network through promotion and pricing reductions. The 
factors mentioned draw attention to the emphasis within the telecommunications sector, and within Telecom, on tolls and on growing shareholder value.

\section{Mobile nascent}

The first, and very brief mention, of the mobile market does not materialise in the 1994 annual report until page 33 where P1 notes that BellSouth's cellular network was being developed and Telstra had been awarded spectrum suggesting a third service would become available. The impact, P1 noted, was minimal on market share because Telecom had the advantage of an existing well-established network and was already responding with competitive initiatives including a new digital service and a variety of pricing options (Telecom New Zealand, 1994). The message to investors was that the mobile market had such great potential that the emphasis was not on resisting anticipated competitors but primarily on promoting growth. The mobile market was still extremely small compared with the rest of the New Zealand telecommunications industry to the extent that in the annual report P1 devoted more space to landline voice messaging and that an increasing number of customers were paying their accounts via Freepost or at New Zealand Post shops (Telecom New Zealand, 1994).

There was a distinct market shift emerging, however. The 1994 report noted "Telecom's well-established cellular network makes a growing contribution to the small business endeavours of many thousand New Zealanders. Cellphones give mobility without the loss of valuable business from incoming calls, as borne out by the story of an Auckland plumber. Ken Doyle of Fountain Plumbing and Gas Fitting has no doubts that being on Telecom's cellular network helped keep him afloat during the recession of 1991 and build a thriving business since then. 'Most of our work comes in by phone and my customers really appreciate being able to make contact with me wherever I am during a busy day,' he says." (Telecom New Zealand, 1994, p. 22). The mobile telephone was transitioning from being a status accessory for executives to becoming a tool for tradespeople. 


\section{Mobile competition}

By 1995 competition in the mobile market was evident, as was the mobile market's potential. In the annual report P1, noted "We certainly expect sustained growth in cellular services in both business and consumer markets. Our cellular connections are rising at a rate among the highest in the world but the level of take-up, at $6.4 \%$ of the New Zealand population, is under penetration rates achieved in countries like the United States (7.6\%), Australia (8.6\%) or Sweden (17\%). And those markets are growing at a rapid clip as well. We are basing our marketing strategies on research that suggests New Zealand has the same, if not more, potential." (Telecom New Zealand, 1995, p. 5). P1 then said "Competition has been a great stimulus to growth in New Zealand's telecommunications markets and that is reflected in our volume growth during 1994-95. In the cellular market, BellSouth vigorously promoted its offerings and, in fact, has been virtually giving away cellular phones and air time in an effort to build up its customer numbers. Telecom's cellular services are extremely competitive and the overall effect has been accelerated growth in our new connections. In December 1994, we attracted around 22,000 new customers, a record for any one month since Telecom brought cellular communications to this country in 1987."

P1 noted in his report that 6.4 percent of New Zealanders had become Telecom cellular customers by March 1995. Telecom had launched a cellular service plan for consumer customers who "pay just $\$ 20$ a month in access charges" while off-peak calls could be made "only 20c per minute. This is an example of innovation that helped stimulate growth of $44 \%$ in the volume of calls originated in the Telecom cellular network during 1994-95." (Telecom New Zealand, 1995, p. 2)

The vision was very much around this is a very exciting game to be in, one of the most exciting industries you could be in at that time probably, because there were just so many new innovations occurring. The vision was, really, let's just grow this company as fast as we can in 
these different spaces, and be as innovative as we can grasping the new technologies and making a success of them. $(P 1,2016$, p. 6)

\section{Multiple markets}

Telecom chairman Shirtcliffe opened the company's 1996 annual report by describing Telecom's goal of being one of the best performing telecommunications companies in the world. "The creation of value for shareholders is our ultimate measure of progress towards that goal. To add value for shareholders we must grow operating revenues and earnings while managing Telecom's assets with increased efficiency. For revenue and earnings Growth we must provide Telecom services and products which are valuable to Customers today and into the future. To ensure our business has a strong growth orientation we must be committed to Innovation. In 1995-96 Telecom developed innovative services for an ever-changing marketplace, while achieving growth in revenues, earnings and shareholder value." (Telecom New Zealand, 1996, p. 1) All the innovations described in his statement refer to tolls and landlines.

Shirtcliffe noted that New Zealand shareholders had received a 21.5 percent gross return on their investment via imputed dividends and share price appreciation. For United States shareholders the gross return was 28.6 percent after incorporating favourable exchange rate movements. An investment in Telecom outperformed the top of the New Zealand 40 stocks index. Operating revenues and net earnings were growing by between 12 and 16 percent a year, allowing Shirtcliffe to describe Telecom as a world class company (Telecom New Zealand, 1996). The language reflects Telecom was engaged not only in the telecommunications market, but also in the international financial markets. Telecom was in New Zealand the largest firm by capital, but was not exceptional by international standards. Telecom was also a new organisation facing substantial technical challenges and associated costs. The report was thus specifically targeting international financial markets and investors. 
Telecom was also focusing on innovative technology as a competitive capability. In 1992, Telecom had been the first telecommunications provider in the southern hemisphere to offer digital cellular services, and by 1996 had digital coverage over 96 percent of New Zealand's populated area (Telecom New Zealand, 1996). Telecom expected substantial growth in digital cellular usage by the business sector, especially for data. New Zealand growth rates in using the internet were among the world's fastest, each month the number of internet connections grew by more than 15 percent (Telecom New Zealand, 1996).

\footnotetext{
Very early on in my tenure as CEO I realised that although we were going to spend a lot of time fighting the battle around tolls that wasn't going to be the future in terms of the long haul. I realised that mobile was indeed going to be the future. In fact, if anything I would have thought it would come faster than it did. And then, of course, within a year or two of that, I realised that the internet was going to become huge. (P1, 2016, p. 5)
}

\section{Internet}

The focus Telecom on the internet at this stage is a prelude to the merging of mobile and internet markets in later eras. Indeed, in the 1997 annual report, Shirtcliffe noted that if Telecom was to meet the needs of its customers the company had to provide more than a basic telephone service. "To ignore the convergence of communications, information and entertainment would be foolish....it would be like persisting with the horse and cart, while ignoring the motor car, aircraft and other modern forms of travel." (Telecom New Zealand, 1997, p. 3). Telecom launched XTRA as an internet provider (Telecom New Zealand, 1997). New Zealand's growth rate for internet connections had been rapid and reflected in a growth in landlines from 1.534 million in 1993 to 1.782 million in 1997. Most of the growth was domestic as second lines were installed in homes to enable internet capability (Telecom New Zealand, 1997) 


\section{Mobile growth}

By 1997 the number of mobile users had risen to 0.51 million $(510,000)$ or 14 percent of the population. This was a 608 percent increase since 1992 (Commerce Commission of New Zealand, 2008). The Telecom 1997 annual report noted that in New Zealand penetration levels of mobile telephones remained much lower than international measures and that there was a potential for the current numbers to double. Telecom had gathered its share of the growth in mobile numbers but noted that this did not necessarily result in correspondingly increased revenues - the expansion into mass markets meant newer customers were joining on cheaper, lower usage, plans. The company's response was to provide business consumers with increased technical services such as extension dialling where mobile telephones acted like an extension to the office landlines (Telecom New Zealand, 1997). The impetus for these developments was partly technically driven - what was possible - and partly competitive what had to be possible. Competition and technology were helping to drive down prices - prior to privatisation an off-peak telephone call between Wellington and Auckland cost $\$ 2.58$ minimum but in 1997 it was 29 cents. Overall toll prices were 82 percent less than a decade earlier with resulting expansion in usage - national call minutes were up around 13 percent and international outward calls up 12 percent over that period (Telecom New Zealand, 1997). These competitive movements highlight that the commercial priority for Telecom was still landlines and mobile was still an adjunct.

\section{Threat of regulation}

In the 1998 Telecom annual report Shirtcliffe noted the company faced competition internationally from 15 companies, some of whom had put hundreds of millions of dollars into creating businesses in New Zealand (Telecom New Zealand, 1998). P1 also reflected that the high levels of competition and low levels of regulation were essential drivers to innovation 
and customer benefit. New Zealand's dynamic competition in communications was producing substantial and rapid improvements in services and price structures. Shirtcliffe's statement reflects that regulation was a further Telecom priority, in part because of intense lobbying by its competitors for greater, and cheaper, access to Telecom's network assets. Shirtcliffe's response was to argue that competition in the telecommunications market was intense, driving down prices to consumers, and thus no further regulatory intervention was needed (Telecom New Zealand, 1998). Telecom's view was that intrusive regulation was not needed - that there was plainly competition, and benefits of competition to New Zealand consumers, without regulation. (Telecom New Zealand, 1998)

\section{Mobile through the Fundamental Era}

The mobile market was characterised by a large number of call plans designed for different usage patterns (Howell \& Obren, 2003). Between 1993 and 1994 mobile connections were sold on call plans with low handset prices and higher monthly connection and call charges. Monthly connection charges also varied, depending on the number of minutes per call and whether usage was during peak or off-peak hours. These plans were initially more appealing to business users and most of the initial purchases came from this sector. Prepay accounts with no monthly connection fee, but per minute call charges paid in advance of consumption, were introduced by BellSouth in 1997 and Telecom in 1998 (Howell \& Obren, 2003).

During the Fundamental Era the New Zealand telecommunications industry had substantially changed. In 1990 Telecom was the only provider of all telecommunications services but by the end of the era was competing in all its markets against much larger international firms. Telecom's mobile revenues in 1990 were $\$ 59.8$ million, or just 2.3 percent of the firm's total revenues of $\$ 2,568$ million. (Telecom New Zealand, 1992). Telecom's primary focus was growing the share price through growing landline usage and toll calls while 
cutting costs. Internet usage was minimal. By 1998, Telecom had operating revenues of $\$ 3,938$ million, of which mobile services provided $\$ 424$ million or 10.7 percent. There were 0.63 million $(630,000)$ mobile telephone users amounting to 16 percent of the population. Telecom was providing mobile services to 15 percent of the population, with the other 1 percent being serviced by BellSouth, mainly in Auckland. (Telecom New Zealand, 1992, 1993, 1994, $1995,1996,1997,1998)$

\subsubsection{Providers - parameters and institutional practices}

This section provides analysis of the practices of the primary mobile telecommunication provider in terms of the institutional practices and the movements in parameters during the Fundamental Era.

The priorities for the Telecom board and chief executive lay in growing shareholder value through the tolls market where competitors had appeared for the first time. The emphasis on shareholders and shareholder value reflected Telecom's competition in two distinct markets. In the first market, Telecom's customers for capital returns were global. Telecom's founding shareholders were also keen to maximise their returns prior to, and from, the required share sell-down. This reflects in the institutional practices where the commercial priorities were to grow shareholder value. P1 also had a fiduciary duty to the new owners of Telecom New Zealand to maximize the value of their assets (Balcombe, 1996; Eagles et al., 2001; Hossain, Prevost, \& Rao, 2001). Regardless of obligations, for P1 there was an ideological principle to maximize shareholder value. To grow shareholder value was an often-stated priority for P1 and transferred with him when he became chairman of other companies.

Telecom's second market was comprised of telecommunications customers. The tolls market provided the bulk of Telecom's revenues but for the first time in New Zealand's telecommunications history competitors were in play. Telecom's competitive actions included growing the landline business in tolls and local calls. There was no need, from Telecom's 
perspective, for any further regulation, but the threat of regulation was constant, and Telecom's position was made clear in the reports. The actions taken reflect movements in the Competitive Intensity parameter, but little or no movement in Legal and Economic Institutions parameter.

\section{Mobile competition}

Until 1994 there was no competition in mobile telecommunications. Mobile customers were few, and the growth in mobile users did not substantially effect Telecom's earnings, its share price, or consumer perceptions. The mobile market was still labelled in the company spreadsheets as 'other'. The mobile market was driven by Telecom recognising that businesses were beginning to see how the mobility offered by mobile telephones would meet critical needs. Businesses were, however, only becoming aware of the potential for mobility, as Telecom directly made its expensive value propositions available to them. The mobile market was thus defined by Information, Technology, Value Propositions, and Needs, but also by low Competitive Intensity amidst mobile providers.

BellSouth's arrival in 1994 increased the Competitive Intensity in the mobile market. BellSouth and Telecom thus became intent on growing the mobile market as rapidly as possible as well as competing for their share of new and existing users. Competition brought to users new Information, Technology and Value Propositions, in terms of cheaper and better products, and new groups of users emerged in rapidly increasing numbers.

\section{Missing practices}

Two categories of market-defining practices were not mentioned during the Fundamental Era, and are presented here to enable comparison with the later eras. Firstly, there was no mobile internet. Indeed in New Zealand in 1992 most businesses, and certainly most individuals, did not have landline internet. Secondly, pre-paid accounts had yet to be conceived. Mobile accounts were post-paid with monthly fees based on the number of minutes able to be used 
cheaply, the cost of mobile device purchased, and related terms of the 12- or 24- month contracts offered by the provider.

The movement in market parameters analysed from Provider performances and the market's institutional practices (accepted way of doing things) is summarised in Table 6-2.

Table 6-2 Provider Practices in the Fundamental Era

\section{PARAMETERS}

Spatial Matrix

Competitive Intensity

Responsiveness

Legal and Economic

Institutions

Competitive Intensity

Value Propositions

Competitive Intensity

Technology

Information

Social and Community

Meanings

Competitive Intensity
P1. We grew the share price 30 percent per annum compound. That was really the objective: to grow value in the company

P1. Growing toll use was a large part of the strategy because that was where the bulk of the revenue lay at that time. That's where the most intense competition was at that time.

P1. Although we were going to spend a lot of time fighting the battle around tolls, that wasn't going to be the future. Mobile was indeed going to be the future.

P3. (Telecom was) marketing the potential for mobility to change the way in which you do business.

P3. The corporate market was taking off at a great rate of knots, and the Telecom mobile business was growing very rapidly.

P3. It was larger businesses. Definitely businesses. There was nothing in the consumer market.

P3. It had very little competition and it had a very, very, dominant market position so it was making money.

P3. We had a pretty good understanding of what the global market was likely to do over the next ten years. You knew that this technology was going to start taking off. It was going to blossom

\section{INSTITUTIONAL PRACTICES}

\section{Commercial Priority}

Shareholder Value

Commercial Priority Grow

Telecom

\section{Competition Priority Tolls}

Commercial Priority Mobile potential becoming recognised

Mobile growing rapidly in Business

Multiple voice markets defined by provider

User buys mobile voice service

Future of mobile not recognised outside technical expert level

No Competition Mobile

No Mobile Internet 


\subsubsection{Users - performance of practice}

This section provides insights into the performances of Users in the New Zealand mobile market during the Fundamental Era.

\section{Status and Managing Business}

User AS, described his first mobile telephone:

I was driving a company car. I probably had about 14 staff. I was pleased, because it (the mobile telephone) brought with it a little bit of prestige. (AS, 2016, p. 1) It had an external aerial that I fitted on the car and it went in the centre at the top of the back window, and that was almost like a little bit of a badge of honour. There weren't many around. (AS, 2016, p. 3)

AS was the only person in his department who had a mobile telephone. This markedly changed the way he worked.

It gave me a lot of freedom and it also meant that I was available to the staff whenever they wanted me. (AS, 2016, p. 4)

It was not, however, a device to be used freely.

There was an in-built responsibility that you knew it was an expensive device and you... It was self-controlled. You just didn't pick it up and ring someone for a yarn about the weather or fishing or whatever. (AS, 2016, p. 5 )

User SS had been an early follower of mobile technology. He described his interest and first mobile telephone:

I'd been following the technology from when it was first being talked about in the 1970 s when you should carry these backpacks onto construction sites, and I was always ready for it to become small enough to be carried in the hand. And when it did I went out and bought one for myself. Shortly afterwards...about a couple of months after I bought my first one...the 
office gave us one. I joined Ernst and Young in 1990. I was a senior principal partner at the time. (SS, 2016, p. 1).

When I was overseas I would not get a lot of calls, but I would leave the phone lying around on the desk for people to see it. (SS, 2016, p. 5).

AS and SS were exposed early to mobile technology, and both had their mobile telephones provided by their corporate entities. Both were executives, and both felt heightened social status in owning the new device as if it were an insignia of office. They were among the 0.029 million $(29,000)$ users, or 0.8 percent of the New Zealand population, using a mobile telephone in 1990 (Statistics New Zealand, 2017; Telecom New Zealand, 1992).

The mobile telephone SS purchased in 1992 was a Nokia, chosen mainly because it was sleeker than other models and had a thin pull-out aerial.

I think it was the antenna mostly that convinced me. It was sort of a hidden pull out antenna you know? It had a two line data entry thing. It was easy to use from the point if you were dialling numbers, and such like, and it had a small memory for your contact list. But in those days you couldn't show more than one number for the same contact, so you had to show the same contact multiple times, you know, so it was ... it was a novelty. For the people's names it was easy to enter the person's name, so for example $A B C$ is on number 2, right? So if you pressed 2 once, it was A. You kept it pressed longer and it had B, C and then it would ... it would rotate through capitals and smalls, right? And then when you saw what you wanted you released the button. ... I became quite adept at it. (SS, 2016, pp. 2-3)

At the time SS was a BellSouth customer because, compared with Telecom, that company offered better roaming in South East Asia, where he often worked. Only a few of his colleagues had mobile telephones. 
Some of them did. But most of them had cellphones after our company gave them to all the senior people - not the juniors, only the senior people. A lot of my clients had cellphones. Because most of them were senior people - directors and senior Government people, so they used to have cellphones. (SS, 2016, p. 5)

SS and his family were early adopters of the new technologies. His children were the first in his social circle to have their own mobile telephones. His friends thought this was very indulgent, but within a year most of his children's friends also had mobile telephones (SS, 2016).

\section{Managing Connections}

ML was undertaking a film course in 1996 when she acquired her first mobile telephone.

It was purely functional. It would be because of other people - seeing that they were using them. I saw the benefit of having it. I didn't want to be in the bush without being able to contact anyone. (ML, 2016, p. 3)

Her first mobile telephone was a Nokia but not the most functional or trendiest model. Purchasing did not involve much research of options because there were so few.

It was not a big chunky block but the next one down. I'm on prepay now whereas back then as a poor student I chose the monthly payment. I signed in for it - locked in for a year. Free minutes ... yeah, so I had so many minutes a month. The main criteria for purchase was the cheapest plan. (ML, 2016, p. 3)

Her new mobile phone was not used a great deal because of the cost of each call. ML said that she monitored how many of her free minutes she was using, and if there were none left she would not call anyone. Often she would call only when off-peak cheaper rates were available. 
I had a pretty tight budget - which is why it was kind of a bit crazy me buying the phone, because I really couldn't afford it. I think I was kind of motivated by the fact that others in the school, they had phones and I thought "Yeah, so if I'm going to be in this in this industry I need to be contactable". Yeah...contactable...you know? At all times. (ML, 2016, p. 9)

Fitting in with the image of being a film student, and thus being ready for new and exciting things, was important to ML. The etiquette for using mobile telephones was, however, still being determined. ML was too shy to put her mobile telephone on the table at a café because she knew it was a status symbol. She even felt embarrassed when it rang. Other Users would tend to withdraw from a social space to have their conversation because they were unsure whether it was a private or public thing to do. Regardless of the socially accepted practice for mobile telephone use, the desire for the device to ring was strong. ML wanted to be seen as part of an exciting crowd and wanted to be constantly contactable because this was part of the film-making image and because of the career opportunities a call might represent. The need to be contactable has vanished over time and by 2014 ML strongly did not want people to contact her (ML, 2016). The appreciation of being part of an artistic and technical elite also faded.

\section{Managing Space}

AS had also enjoyed the prestige of being a mobile telephone user.

I used to feel quite proud to have that phone on my shoulder, because it was a mark of being...or doing an important job. (AS, 2016, p. 5) I felt enabled. If we were sitting there and it rang.... You almost wanted it to ring. (AS, 2016, p. 6)

Restructuring found AS first working for a radio station in Timaru, and then as a car dealer. Motor vehicle dealers did not have mobile telephones. 
We didn't get one from work and I didn't buy one. Expensive. I didn't feel I had the need for it. (AS, 2016, p. 9)

In 1994 he joined the Toyota franchise in Timaru.

The owner of South Canterbury Toyota wanted someone to go out and talk to the farmers. And that's when I got my next brick (large mobile telephone), and that was a superb phone. (AS, 2016, p. 9)

Instead of cold-calling farmers from his office, AS could drive to them on their farms and demonstrate the latest Hilux (AS, 2016).

When I first started being on the road I guess that's when they (farmers) must have realised how helpful it (the mobile telephone) was. I think some of them probably were surprised if my phone went off. And you could almost sense that they were surprised that it worked out there. So I probably did a little bit in promoting mobile phones to the farming community. (AS, 2016, p. 13)

\section{Managing constant connectivity}

A key difference for AS was that the mobile telephone made him constantly contactable by his most important clients - the farmers and the elderly.

I wanted to be contacted and I didn't care if it was day time, night time, weekends, holiday, any time. The only way to do that was to have a cellphone, and I actually worked two cellphones. I had the one that lived in the vehicle that had been my mobile phone for a couple of years, and then when I got a (more) portable phone. I always had it on my belt. It wasn't important to me any more in a social sense. It was important to me because it meant dollars and cents. (AS, 2016, p. 10)

I used to get calls, you know, and usually I was able to sort them out on the phone. So having the mobile phone made me accessible and available. I insisted, when I started working for 
Toyota and I had a mobile phone, that my mobile phone number was listed alongside my home number in all their advertising. And l'd never had anything like that before in my Post Office or Telecom days. (AS, 2016, p. 11)

\section{Status}

Who else in Timaru had mobile telephones?

Most of the movers and shakers in town. The real estate guys. Because, again, it was a bread and butter item. (AS, 2016, p. 13)

\section{Managing Mobility}

RG bought her first mobile phone because she was starting her own business, while looking after a new baby, and she and her husband were commuting between cities (RG, 2016).

The coverage was terrible, so there would be whole chunks of the drive where you didn't have coverage. And one of the reasons (I bought the telephone ) was I was living at Christchurch and because I was driving up to Blenheim by myself with (her son), and if something happened...if I had a phone then I could ring. (RG, 2016, p. 7)

Her first mobile telephone had no memory for contact lists or any other capabilities, but the immediacy of contact and convenience were immediate benefits.

If you were out somewhere you'd have to go and find a phone box and go and put money in. It was messy. Whereas having the phone on you was just - it was immediate, so it served an immediate need at that point. No delayed gratification waiting for your phone messages. (RG, 2016, p. 6)

Mobile telephones were not widely accepted, or even welcomed, by the community.

They were these alien things that gave us cancer, weren't they? So people used to say “Oh, don't use them. Don't talk too much on that because you'll get brain tumours" and things like 
that. I remember childcare centres not wanting cellphone towers anywhere near. (RG, 2016, pp. 4-7)

A change in her own behaviour was the amount of time not spent talking on the telephone. On her landline she had delighted in "yakking away" but not on her mobile because of the expense per minute and because the battery life was so short.

You Used to think "I'm not going to use my phone now because I need it for later on in the day". I don't think they actually went a full day. (RG, 2016, p. 8)

\section{Managing personal life}

AF was given his first mobile telephone in 1997 while still at high school. He is far younger than others interviewed about this era. Most importantly, in terms of the shift in perception of mobile telephones in the cusp of eras, the purchase was for personal use.

AF was living in the Hutt Valley and attending a high school with students drawn from a low socio-economic community. There were very few other students with mobile telephones and at school the telephone stayed in his bag. This was not a place to flaunt novelty or status (AF, 2016).

I had a lot of friends who went to Wellington city schools and a lot more of them had mobiles, and so I guess I was using it a lot more to communicate with my friends. That was about the time we were starting to meet at cafés, like at Tree House on Cuba and Fidel's and Toast on The Terrace and stuff, and so we were using it as a means to organise after-school activities. (AF, 2016, p. 2)

I remember being really excited to have a cellphone and feeling kind of privileged or lucky. We didn't have a lot of money. It was expensive. I remember it being expensive to use. My parents bought it for me, but I had to pay the bills. I was working at two part time jobs and 
I'm sure that a large portion of the income derived from those two jobs was going to pay the cellphone bills. (AF, 2016, p. 2)

The mobile telephone had an enabling impact integral to AF's personal relationships. The mobile telephone provided a bridge between one social context and another that otherwise may not have been attainable, enabling inclusivity with a social group very different to his high school.

It was kind of a catalyst in my changing lifestyle. Prior to that l'd been quite isolated in the Hutt. , like ... me sort of moving more into town (Wellington) and socialising more into town definitely coincided with cellphone use, and closing that time and space gap. By the time 2000 came around I had very little to do in the Hutt Valley. Even though I was living out there I was spending a lot more of my time in the city. (AF, 2016, p. 5)

And how did he feel about using a mobile phone?

I felt pretty boss (feeling socially superior about having a mobile phone). (AF, 2016, p. 5)

The following section provides analysis of the practices of the users of mobile telephones in terms of the institutional practices, or market paradigm, and the apparent movements in market boundaries, or parameters, during the Fundamental Era.

\subsubsection{Users - parameters and institutional practices}

The mobile telephone was seen by the broader New Zealand public as a commodity not for themselves or 'us' but for an elite or substantially different 'other'. Mobile telephone users also saw themselves as 'other' who in some way were substantially different to those without mobile phones - that, in a stratified professional, innovative, or social way, they were superior to the 'us'. 
Mobile telephones were seen by Users as an extension to, or substitute for, a landline in the management of productivity and their mobility - the mobile telephone was primarily used to manage space, time, connections and resources for businesspeople when away from their desks. Until the end of the era personal use was limited.

AS provides an example. His first mobile telephone was an emblem of his status, and was also indicative of the changed Spatial Matrix boundary whereby his effective managerial reach was extended well beyond his landline or office. But when he left Telecom, he left behind the mobile telephone. His occupational status also changed - he was no longer a manager. His new employer did not provide a mobile telephone. AS did not buy his own mobile telephone not only due of the expense but also because he was no longer part of the managerial elite and no longer saw himself as someone who used mobile telephones.

When AS re-entered the market having been was provided with a telephone, he saw himself again as being someone important. The other users of mobile telephones were the town's "movers and shakers", implying that he had become again an 'other' outside the normal society.

SS was very much an elite, or 'other' outside normal society. His mobile telephone as befitting his senior partner role in a large multi-national consultancy operating at director and senior Government level. His clients were similarly elite and 'other' and so had mobile telephones. SS and his colleagues thus had high Responsiveness to mobile telephones and the opportunities the devices provided for affirmation of their elevated social status, and also for the life-changing abilities to manage their time, their space, their connectedness and resources.

ML saw the mobile telephone as a means of joining a different kind of elite - that of the art-ocracy making movies. AF described his socially elevated feelings at having a mobile telephone - something so elitist he would not take it out of his bag at school but which enabled 
him to associate with 'others' in a different city with substantially different lifestyles and appreciations to those in his hometown. The mobile telephone was a life-changing social catalyst that expanded AF's Spatial Matrix.

By the late Fundamental Era, new Value Propositions had stretched the market boundary, providing to non-executives, that is, people on relatively lower incomes, with an entry into a socially sophisticated, artistically superior, and innovative, 'other'. In this way, more market parameters were impacted - stretched not only by Social and Community Meanings as to the acceptability of mobile telephones, or by the new Value Propositions on offer as the options were still few and a new slinky aerial was enough to effect a sale, or by the Social Matrix whereby social and professional spheres were expanded, but also by Competitive Intensity between users and between 'us' and 'other'.

The Social and Community Meanings distinction between 'us' and 'other' continued towards the end of the Fundamental Era, by which time the number of 'others' had grown since 1990 by 800 percent to 0.633 million $(633,000)$. The Spatial Matrix expansion enabled AS to go where no other car seller had gone before - directly into farmyards to demonstrate the latest Hilux. RG, as a young mother and new businesswoman, with a husband working in a different city several hours drive away, felt confident enough to make the commute with her baby because she now had a mobile telephone.

The constraints of the Technology and the Value Propositions that encapsulated the technology, were still apparent - coverage outside the main centres, range, and battery life, and device options and usage mechanisms, were very limited. The consumer was buying a mobile voice service with value propositions and options devised and configured entirely by providers.

Furthermore, the 'us', being outside the market - between 99 percent of the population in 1990 and 83 percent in 1998 - did not understand the practices associated with using mobile 
telephones in public by the 'other' within the market. New Zealanders had not only yet to recognise mobile phones as a useful aspect of their lives but also they believed that these mobile devices did not form part of their world. In general, mobile telephones were discounted as a toy for 'yuppies', in other words, for the pretentious 'others' with aspirations of importance, and not for 'us' as ordinary or 'real' people (Goggin, 2006). The 'us' were at best were sceptical, even paranoid about mobile telephones. Few 'us' were accepting of mobile telephone towers in their vicinity, feeling the perceived risks were not worth the nonunderstood benefits to the 'other'. Mobile phones and their related technologies were thus socially disruptive - positive for the using 'other' and negative for the non-using 'us'. Table 6-3 describes the parameters, performances and institutional practices for users in the Fundamental Era.

Table 6-3 User practices in the Fundamental Era

PARAMETERS PERFORMANCES

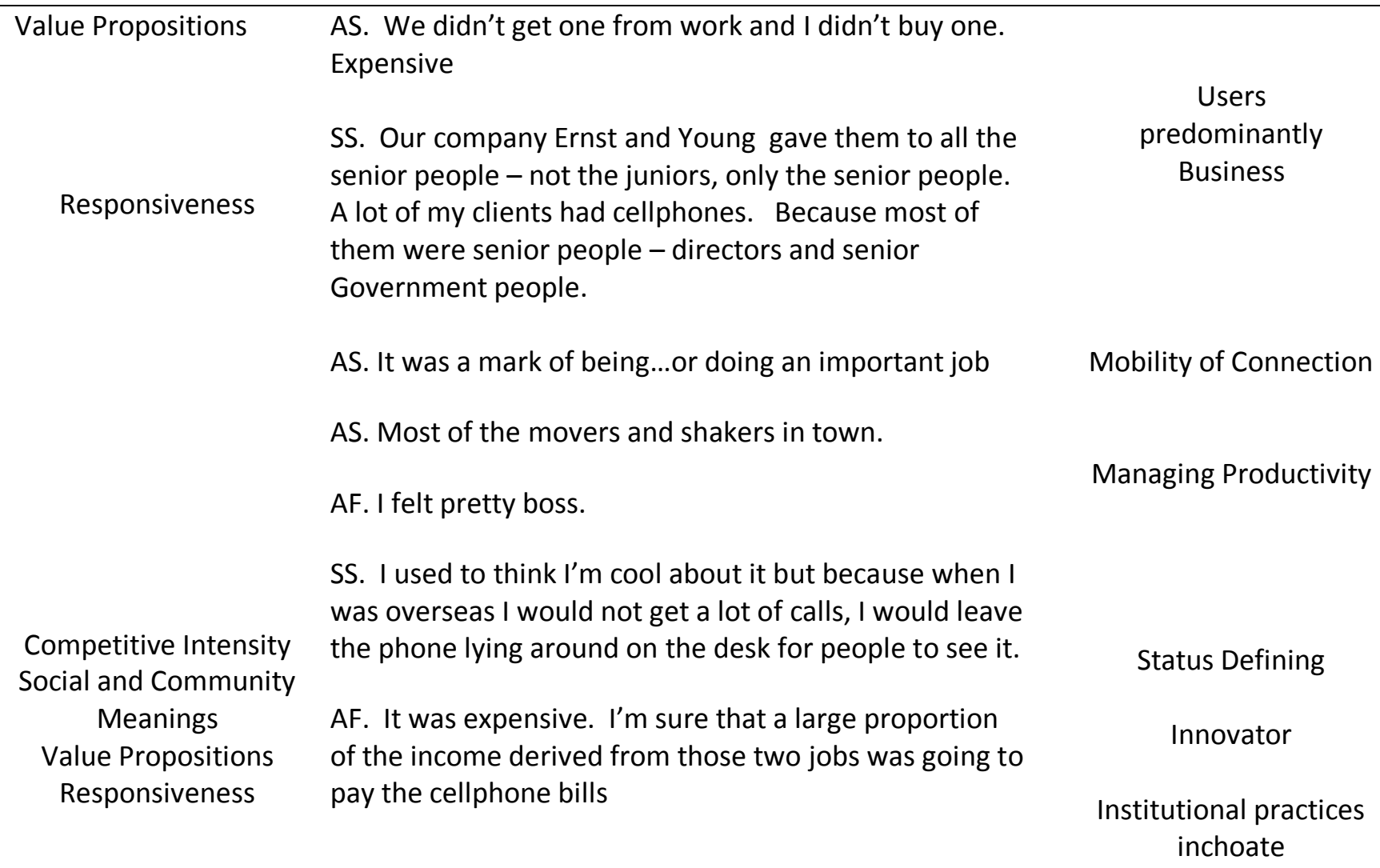


ML. It was kind of a bit crazy me buying the phone, because I really couldn't afford it

AS.I was a manager...I probably had 14 staff.

AS. It gave me a lot of freedom and it meant I was available to staff whenever they wanted me.

AS. There was an in-built responsibility that knew it was an expensive device and you... It was self controlled. You just didn't pick it up and ring someone for a yarn about the weather or fishing or whatever.ML. I was

Social and Community Meanings

Value Propositions

Spatial Matrix

Needs

Social and Community Meanings

Spatial Matrix

Technology

Value Propositions kind of motivated by the fact that others in the school, they had phones and I thought 'Yeah, so if I'm going to be in this in this industry I need to be contactable'. Yeah. Contactable. You know?

RG. It served an immediate need at that point. No delayed gratification waiting for your phone messages.

ML. I didn't want to be in the bush without being able to contact anyone.

AF. Socialising more into town definitely coincided with cellphone use, and closing that sort of time and space gap. It was an important catalyst. .

AS. If we were sitting there and it rang. You almost wanted it to ring

RG They were these alien things that gave us cancer, weren't they?

RG. The coverage was terrible, so there would be whole chunks of the drive where you didn't have coverage.

AS. Some of them probably were surprised if my phone went off. You could almost sense that they were surprised that it worked out there.

SS I think it was the antenna mostly that convinced me.

SS. If you pressed 2 once, it was $A$. You kept it pressed longer and it had B, C and then it would rotate through capitals and smalls, right? And then when you saw what you wanted you released the button.

RG I don't think they actually went a full day
Status Defining

Mobility of Connection

Managing Productivity

Managing Space

Managing Personal Life

Life Disruptive

Users of mobile phones are 'other'

Practices for users in this market are not yet understood

Mobile Network Geographic Coverage Limited

$$
\text { Post-paid only }
$$

Mobile Technology Limited

Options - Few 
This section described the performances of providers, users and regulators in the Fundamental Era and then described the relationships of these performances to institutional practices. An indication of applicable parameters was provided. The next section discusses the performances, parameters, and institutional practices of the Feature Era.

\subsection{9-2007: Feature Era - from Other to Us}

\subsubsection{Introduction}

This section discusses the performances of market actors in the New Zealand mobile telecommunications market during the Feature Era - from 1999 to 2007. The Feature Era was marked by the rapid diffusion of mobile telephones through the New Zealand community brought about by competition, by regulatory intervention, and the advent of technologies enabling new forms of communication and social change whereby mobile telephones were legitimated across the broader population. At the start of the era the mobile telephone was still primarily a status-giving tool for executives for as-required calls. By the end of the era school children were routinely and continuously texting each other as part of their social exchange. This section thus describes the expansion of the mobile market boundaries whereby mobile telephones transformed from being status-giving emblems and professional tools of the 'other' to becoming a social necessity for 'us'.

\subsubsection{Market size}

In 1999 there were 0.91 million $(910,000)$ mobile telephone users, equivalent to about 24 percent of the New Zealand population. By the end of the era in 2007 users numbers had increased to 4.25 million, equivalent to 103 percent of New Zealand's population. Of these users, 1.98 million were Telecom customers (Commerce Commission of New Zealand, 2008, 2015). The revenues from Telecom provide economic evidence of movements within the telecommunications market. In 1999 Telecom had total revenues of $\$ 3,450$ million - a 12 percent decrease on the previous year. Telecom's mobile revenues, however, had increased 
by 21 percent. Telecom's revenues grew substantially in 2000 and 2001 to $\$ 5,648$ million but thereafter there was negative or very low growth. Mobile revenues, however, continued to rise in parallel with user numbers. By 2000 Vodafone had captured about 35 percent of the mobile market, and was similarly competing on internet services. By June 2001 Vodafone had achieved a mobile market share of over 40 percent, and had captured 51 percent by May 2003 (Howell \& Obren, 2003). Figure 6-6 depicts the number of users and the percentage of population using mobile telephones during the Feature Era (Commerce Commission of New Zealand, 2008, 2015)

Figure 6-3 Feature Era: Mobile subscriptions in millions and as a percentage of the population

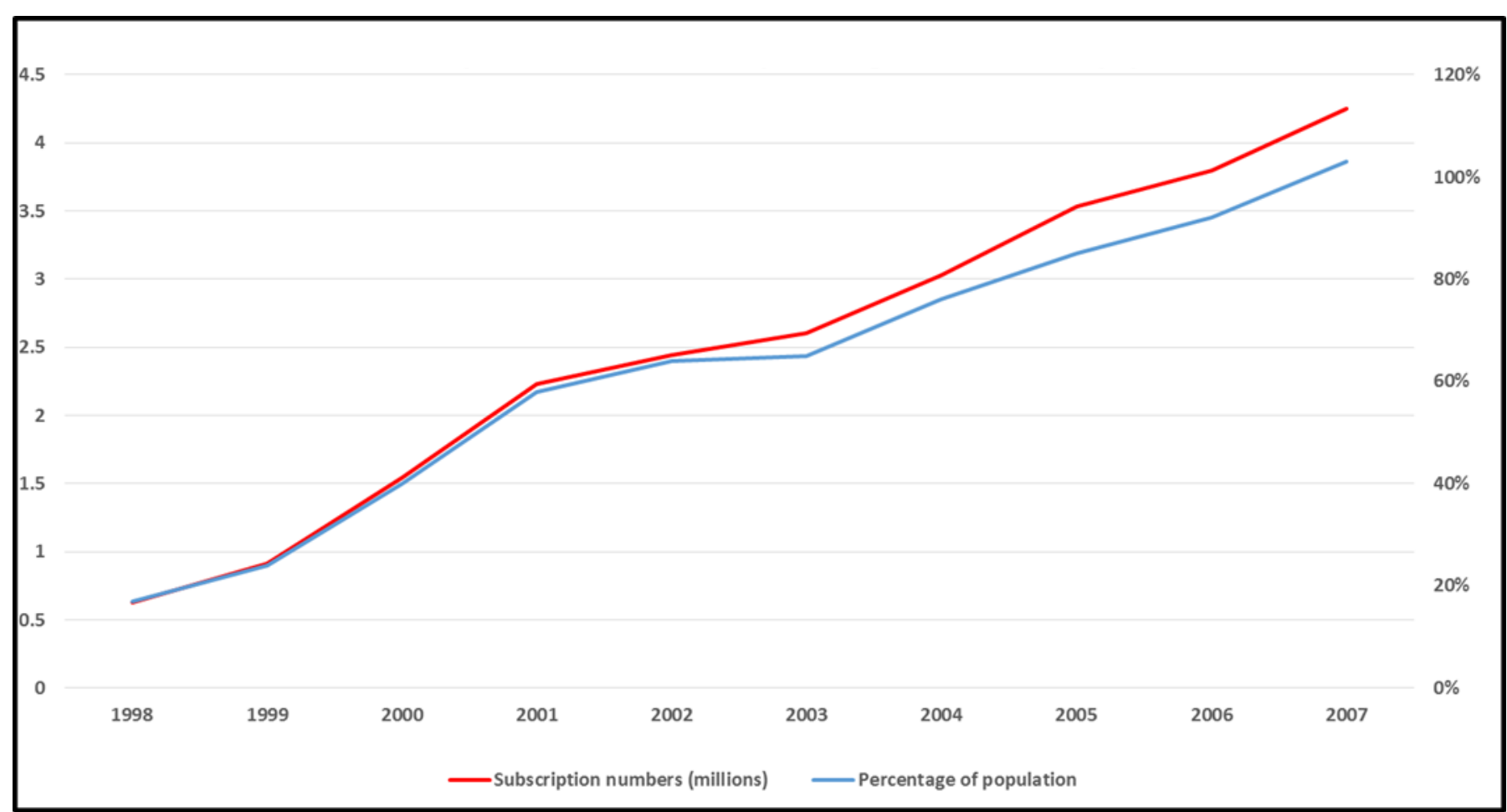

\section{Influences}

Multiple influences transfigured the mobile telephone market during the Feature Era. The first was the introduction of services by Vodafone of the United Kingdom which brought with it nation-wide competitive capabilities and value propositions previously absent. For the first time, consumers had choice not only in provider and contractual packages, but also in new 
value propositions particularly involving new technologies allowing for mobile telephones that were smaller, lighter, and more efficient than before, and which were available in far more models, each with different and defining capabilities or features.

A further influence was the introduction and rapid diffusion of Short Messaging System (SMS) technology. SMS was not common in the United States but New Zealand's providers and consumers rapidly followed the Japanese-European lead in adopting what became known as texting.

There was a further substantial disruptive influence: invasive, disruptive, or 'hard' regulatory practice intent on reconfiguring the telecommunications market. M1's term as Minister ended when the National government lost power to Labour in the December 1999 general election. The new Labour government assumed a very different ideological approach to regulation than had previously been the case. The change was driven at least in part by Communications and Information Technology Minister, M2. M2 held the view that Telecom was a monopoly deriving economic super-rentals which deprived consumers of fair benefit. The Labour Government's intervention forcefully opened Telecom's landline infrastructural assets to its competitors, and culminated in the legislated structural separation of Telecom into component companies of which only the wholesale and retail firm retained the name Telecom New Zealand.

\subsubsection{Regulators - performance of practice}

This section provides insights into the performances of New Zealand telecommunications regulators during the Feature Era. In this era regulatory interventions were introduced into a market structure that providers, particularly Telecom, saw as a highly competitive but which the regulators, particularly Minister M2, perceived as untenably favouring market incumbents over new entrants and consumers. The interventions ultimately led to the legislated structural 
separation of Telecom. While the regulatory interventions were directed at the New Zealand telecommunications structure as a whole, the mobile market was inextricably included.

In 1998, concurrent with the end of the Fundamental Era, American-based BellSouth announced it was abandoning the New Zealand mobile market and sold its network to Britain's Vodafone. In his interview for this thesis, M1 described meeting the chief executive of Vodafone UK, Sir Christopher Gent. The British firm was concerned that with the failure of BellSouth the Government, to that point leading a regime of 'soft' non-invasive regulation, might feel compelled to regulate the mobile industry, particularly pricing (M1, 2016).

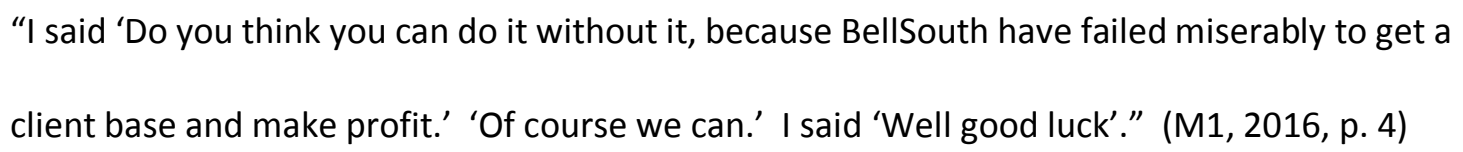

M1 recalled that the first target for Vodafone were potential users who were far younger and more independent than the corporate users focused upon by Telecom. To M1, Vodafone's success indicated that the market was working successfully and thus justified his position to neither regulate nor acquire and compensate (M1, 2016). M1 was not, however, surprised by the shift by a new Government to harder regulatory policy Telecom was strongly intent on maintaining the regulatory status quo while aggressively preventing access to its network facilities and number system (M1, 2016).

\footnotetext{
They ended up becoming their own worst enemy. By just taking too harsh a line. They would have been way better to have been a little bit more conciliatory, even though they had a right. (M1, 2016, p. 6)

They played big kid on the block. (M1, 2016, p. 8)
}

\section{The first Telecommunications Commissioner}

The general election of 1999 brought in a Labour Government with very different ideology to the one that nine years earlier had privatised or corporatised state assets, and also different to 
that of the National Government of which M1 had been part. Considerable public commentary and lobbying by internet service providers voicing discontent of, in particular, Telecom's monopoly of copper cable services to homes, was aimed immediately at the incoming Minister, Paul Swain (R1, 2016). The new Government announced an inquiry into whether regulation was required to allow access to Telecom's copper network - a process known as 'unbundling the local loop'. The Commerce Act was amended changing provisions that prohibited unilateral anti-competitive behaviour definitions from "dominant position" to "substantial market power". These provisions were reflected in the Telecommunications Act which came into force in December 2001 creating a new position of Telecommunications Commissioner, as an office within the Commerce Commission. The Commissioner had specific responsibility for the oversight of competition and consumer protection within the telecommunications industry. At its core, the new legislation signalled a firmer approach to regulation with a primary focus being Telecom ("Telecommunications Act," 2001).

R1 took office in March 2002. At the time, public perceptions were that more internet access was needed that was both cheaper and more efficient. Perceptions of the mobile telephone market were inchoate. Vodafone and Telecom were working to grow the total mobile market and there was excitement as to the possibilities of mobile despite the comparatively high costs at the time $(\mathrm{R} 1,2016)$.

Vodafone was, I think, feeling very comfortable about their position at that stage. The political and regulatory priorities, as they saw it, were very much concerning the fixed network and the primary issues around the interconnection and later unbundling. Telecom was in a somewhat different position because obviously they wanted both the fixed and mobile markets. They were very much focused on the fixed market in terms of the regulatory interventions that they saw as likely to come. They saw themselves as the underdog in the mobile services market so their focus in that area was very much about building up scale and 
building up the consumer base. They were aware of some of the regulatory issues but they were not particularly focused on them. (R1, 2016, pp. 1-2)

\section{Perceptions of competition}

Until well into the Feature Era, the data market was still seen as a fixed line product for businesses. Indeed, the Chief Executive of TelstraClear in early 2003, when giving evidence to the Commissioner on local loop unbundling, said she saw no valid business case for residential broadband. In New Zealand the $2 \mathrm{G}$ mobile network was still in place and the $3 \mathrm{G}$ network required for larger scale data transfer, while available in Europe, was still some distance from introduction in New Zealand (R1, 2016).

While provision of mobile data - such as emails and internet - was not seen as a regulatory issue during the early Feature Era, there was a consistent theme that compared with other OECD nations retail mobile calling prices in New Zealand were very high. Furthermore, a third competitive entrant, ECONET, later known as 2Degrees, was pointing at barriers to entry including the costs of linking into the Vodafone network. ECONET had concerns also at the apparent high cost of interconnection between mobile and fixed line networks. By 2004 mobile competitiveness was on the regulators' table (R1, 2016).

The number of mobile users was increasingly exponentially. The issue of call charges from a landline to a mobile was becoming an issue. It was touching many more people and was representing a much bigger economic impact than it had in, let us say, 2002. So in 2004 , we decided to look at the issue for termination charges on mobile networks, from landline calls to mobile networks. That was really the first occasion, from a regulatory perspective, we looked at the mobile market and said, well what is this market then? How should we think about it? (R1, 2016, p. 5) 
The Telecommunications Commissioner concluded that mobile termination rates - the charges a telecommunications provider charges another provider for calls entering its network - were so high as to favour the incumbent providers, presented a barrier to market entry, and that the rates should be regulated. ECONET pushed for even more regulation while Telecom and Vodafone pushed back saying no further regulation was needed, pointing to market indicators of competitive intensity, and that they would negotiate further with new entrants (R1, 2016).

We were sitting there with a set of regulatory instruments that were quite limited. We had a putative entrant, ECONET, which was negotiating with Vodafone about getting access...and not having much success. And a degree of public disquiet about market pricing, and not really much political interest in this whole issue. We could have just sat there and said, well these guys are negotiating, something may come of it, you know. Market penetration was going through the roof. With competitive intensity, pricing was likely to come down. So why worry? It was quite a seductive environment. (R1, 2016, pp. 5-6)

One option was to use a 'soft' approach to push the market players into positions more favourable to competition and consumer benefit (R1, 2016). By publicly messaging concerns, and by meeting with providers, R1 hoped to encourage negotiated solutions providing greater competition. R1 also used the Commerce Act that allowed him power to recommend to the Minister expansions to the list of regulated services. By aggressively using these sections R1 could provoke market reactions $(\mathrm{R} 1,2016)$.

We were saying, look there is competitive intensity in the market but there appear to be high prices which implies that the market is not fully competitive. (R1, 2016, p. 7)

A national network, reflecting the nature of mobile telephone to be used anywhere in the country, was fundamental to success, but it was unrealistic for a third national network to 
be rolled out behind those of Telecom and Vodafone $(\mathrm{R} 1,2016)$. The regulator had no powers to ameliorate that barrier to any third provider such as ECONET.

\title{
Perceptions of space
}

Further barriers included the co-location of equipment and the ability of Telecom and Vodafone to offer groups of high value users at substantially lower prices. Any new entrant lacked the scale that enabled cross-subsidising across the less-attractive customer base.

\begin{abstract}
The mobile services market, which was relatively easy to define at that point of course, was geographically constrained by being one country. If we had been in Europe it might have been different. We looked at the barriers to entry, we concluded that these were genuine barriers to entry, there were structural barriers, there were strategic barriers representing the behaviours of the industry, and there were also regulatory barriers because of our lack of regulatory powers. And we therefore recommended that the Minister should give us expanded powers to intervene actively in the mobile market. (R1, 2016, p. 9)
\end{abstract}

Faced with what amounted to an ultimatum of greater regulation, Vodafone and ECONET shifted negotiation stance and by 2006 had reached an agreement for an expanded range of nation-wide services. New Zealand had its third provider - now named 2Degrees (R1, 2016).

\section{Regulator ideology}

Concurrently with the movements in the telecommunications industry, the Commerce Commission chairwoman Paula Rebstock was signalling strongly a harder line on any anticompetitive practice. In the Commission's 2006 annual report she said the commission was unashamedly pro-market because of the benefits competition brings (Commerce Commission of New Zealand, 2006a). New Zealand, Rebstock said, was still coming to grips with regulation of network industries but while successful infrastructure companies were essential 
to New Zealand's economic success these firms must also be held to account (Commerce Commission of New Zealand, 2006a). The Commission was concerned that mobile termination charges were well above cost and was recommending regulation of these charges. On 10 October $2006 \mathrm{R} 1$ announced an investigation into the mobile market competitiveness as the market was typified by high prices and limited competition.

We haven't seen significant new entry into the mobile market. The Commission considers the current regulatory settings may not be creating sufficient incentives for that entry to occur. (Commerce Commission of New Zealand, 2006b)

Telecom and Vodafone were prioritising growing the market $(\mathrm{R} 1,2016)$. A further constraint to potential providers was the very rapid technological changes whereby $3 \mathrm{G}$ mobile phones were being introduced but where fourth-generation (4G) was a likely prospect in a redefined market based not on voice, but on data $(\mathrm{R} 1,2016)$.

The product had become ubiquitous, so there was enormous consumer interest in the whole issue, and finally, it was extraordinarily profitable, very profitable. At a period late in the 2000's New Zealand was one of the most profitable businesses in the whole Vodafone empire, worldwide, which is extraordinary. The industry was prepared, and able, to shift quite rapidly. Vodafone was still in this intense struggle with Telecom, and that was their major focus, but they were really competing for preferred slices of what was a rapidly growing market. They were both doing extremely well out of it, and they wanted to protect that. Indeed, the two giants were fighting each other so hard it was not unrealistic that they would hardly notice any other competitor, or care about them. (R1, 2016, p. 10)

The regulatory ideology changed, however, when a new Minister, M2, arose with interventionist perspectives on Telecom and the telecommunications market. In his interview R1 said M2 took not regulatory but legislative steps through Parliament, creating law giving the Minister sway over a broad range of real regulatory power. Whereas the commission was 
an economic regulator and unswayed by public perceptions, a Minister had new power and was expected to use it, based not only on economics, but also on political factors (R1, 2016).

The substantial movements in regulatory ideology are now described.

New Minister - new ideology

M2 was appointed Associate Minister of Communications and Information Technology in May 2003, and became Minister in December 2004. He held the post until Labour lost the November 2008 election. In the interview for this thesis, M2 noted that his elevation to Minister was not welcomed by Telecom who lobbied the Prime Minister against his appointment (M2, 2016), a prelude to the intense personal and political schisms that followed. M2 said M1's 'soft' regulatory stance had not succeeded in creating a competitive environment.

And it was, of course, just coincidental that Telecom New Zealand was by far the largest company on the New Zealand Stock Exchange. I think at one point responsible for nearly a quarter of the value of the exchange and had what was clearly the country's most effective and powerful lobbying operation. (M2, 2016, p. 1)

M2 began the process of interventionist 'hard' regulation of the telecommunications market. He deemed the Telecommunications Act 2001, insufficient to achieve the desired competitive outcomes. One of M2's first steps was to commission a review benchmarking New Zealand against OECD telecommunications policies, and which included M2 personally interviewing all the chief executives of telecommunications firms in New Zealand where he asked for their view of the state of competition. The review reinforced M2's view that Telecom had high levels of dominance, the regulatory framework was too weak, and New Zealand was at odds with the mainstream practice of dynamic, technology-driven competitive markets, with many providers (M2, 2016). 
We were well behind in national best practice. We beefed up the role of Telecommunications Commission. We gave them proactive powers. We unbundled the local loop. We started a process of reviewing separation options for Telecom, and we mandated access to cell sites on the towers and also DSLAMS ${ }^{1}$ in the cabinets. And in the review process, Telecom had been very clear that if anything like that were to occur, that there would be a capital strike, they wouldn't invest and I thought, well, everyone else will invest. I think they'll probably invest because everyone else is. And yet, at the time, the moves were seen as quite courageous and highly risky. (M2, 2016, p. 2)

Notwithstanding the thorough and deliberative process, it was still in a sense radical, and it was done against the most extensive and vigorous corporate lobbying and corporate intelligence really to the point where people were handing over highly classified cabinet documents at cycle meets. (M2, 2016, p. 2)

\section{Ideological clash}

M2's Cabinet paper was leaked to Telecom. Telecom's chief executive, Theresa Gattung, called M2 and described the ramifications if interventionist regulations went ahead. The decision was made, however, and announced by the Government that a 2006 amendment to Telecommunications Act would culminate in the structural dismantling of Telecom (M2, 2016).

\footnotetext{
“The next day the Telecom share price went into freefall. I can't remember the amount exactly, but at least several billion dollars were subtracted from Telecom's market cap over the successive couple of weeks. It was a front page story and that was the market basically putting a valuation on the loss of economic rent. There was an argument that this was an expropriation of private property rights. In my view, nobody has a property right to economic
}

\footnotetext{
${ }^{1}$ Digital Subscriber Line Access Multiplexer - the connection at a telephone exchange or roadside cabinet between multiple customers and the high speed digital communications channel.
} 
rent, and that was the view the Cabinet took. And so there was a repricing of the asset." (M2, 2016, p. 3)

The clash of ideology and personality between P1 and M2 was clear. P1 saw it as his duty to increase the value of Telecom whereas M2 had, as his starting point, that the value of Telecom was evidence of monopolistic power where there were high levels of market dominance and high probability of excessive economic rents being extracted. M2 said in the interview that he used Telecom versus Clear Communications litigation as a case study for his MBA dissertation at Harvard, and that the ignition point for intervention had been his academic study and his experiences as a diplomat in Washington observing the activities of corporate lobbyists and the breakup of AT\&T (M2, 2016; P1, 2016).

I (have) a clear value base which is that of fairness and equity, a participatory democracy, and economic rules which give everyone a fair chance to play. I'm not a big fan of extreme social inequality, and I'm not a great fan of market dominance. (M2, 2016, p. 5)

I was now a game keeper and my job was to make the rules so that businesses, following their enlightened self-interest, within these rules, would lead to a value maximising outcome for society which then fulfilled my ethical drive, that everybody is worth the same, and we need to maximise wellbeing for the whole community. (M2, 2016, p. 5)

Telecom could have prevented the legislative shift if they had dropped prices more rapidly to levels that were internationally competitive and if the market had then delivered at least a proxy of a perfectly competitive market. M2 conceded that it would have been very difficult for Telecom to have voluntarily abandoned value, and at the time leading up to the regulatory interventions he did not expect any change from the firm (M2, 2016). 


\section{The Social Sphere}

A question outstanding is the influence the social sphere on policy and regulation. M2 said he was not influenced by public opinion, but this did impact on the timing. Indeed, the February 2006 Government announcements of reviews of the telecommunication market coincided with media commentary. Editorials and Letters to the Editor, selected from The Dominion Post and New Zealand Herald newspapers files for that month, declared that regulatory intervention against Telecom was long overdue to provide improvements to broadband performance and price that were essential for New Zealand to be internationally competitive and to prevent living standards from further languishing (for example: "Broadband essential for delivering future growth," 2006; Dobson, 2006; Elvey, 2006; "Real competition needed to broaden horizons," 2006; "Ringing the changes," 2006).

The National Business Review did a front page story on businesses complaining at their telco costs. The business community was turning against the incumbent telco. They were identifying economic rents and saying, "look we don't think we should be paying these, it's inhibiting growth". I was out fishing on the Waitemata Harbour on the Saturday morning, and my mobile phone went and it was the Prime Minister (Helen Clark) and she said, "did you read the NBR yesterday?" And I said, "yes, I did actually Prime Minister". And she said "Oh good. You're off the leash". So I pulled up my line, literally reeled up my snapper line, turned the boat around, drove it to the dock, and got to work. And the other thing was that Chief Executive Gattung made some very unfortunate comments to some training seminar, I think it was, about how Telecom pricing was deliberately set in a way that would confuse the public because confusion was basically an effective weapon of competition. (M2, 2016, p. 6)

The 2006 legislative process initiated by M2 enabled access by rival firms to Telecom assets and culminated in the structural separation of Telecom, in much the same pattern at British 
Telecom and AT\&T, where the network is owned and maintained by a company separate from the wholesaling and retailing firms providing services to industry and the public.

\section{The second Telecommunications Commissioner}

R1 retired in 2007, by which time legislation had been passed that determined the structural fate of Telecom. To drive the changes M2 persuaded R2 to return from Australia to take up the position of Telecommunications Commissioner (R2, 2016). The biggest driver for R2 was the lack of competition he perceived in the New Zealand telecommunications market. The negotiate-arbitrate model worked for the incumbents Telecom and Vodafone, but not for newer entrants who needed access to networks.

Telecom had played that incumbent's game - looking as if it was trying to do things that needed to be done when in fact it just simply wouldn't, and made commitments that it didn't follow through on. And basically the 2006 Amendment was really only needed because of their failure to do what certainly the Government thought they had agreed to do. (R2, 2016, p. 1)

Telecom could have made the changes itself without regulatory intervention.

But it's hard, and you've got to be visionary and guys who run incumbent monopolies aren't visionaries. (R2, 2016, p. 2)

Look, (US investors) couldn't believe it, that there could be an unregulated telco anywhere in the world that they could rip all this money out, and no-one could do anything about it. So therefore, it was all about competition, and it was all about getting competition. Unbundling was about getting competition to fixed line, and getting a third entry into mobile. (R2, 2016, p. 3)

R2 dismissed the researcher's suggestion that the Commission's chart (Figure 6-6) showing Vodafone had passed Telecom in mobile market share could be interpreted as there being high competitive intensity (Commerce Commission of New Zealand, 2008). 
It looks like a duopoly to me because the two lines look the same. I mean that's what a monopoly is, a duopoly is. Around about fifty-fifty and that would have gone on forever. (R2, 2016, p. 3)

R2 argued a duopoly was insufficient competition in the market, as evidenced by the absence of a third provider despite prices that were high in comparison with other OECD nations, and which, by an economics interpretation, should have attracted more competitors.

Figure 6-4Mobile market share $1994-2007$

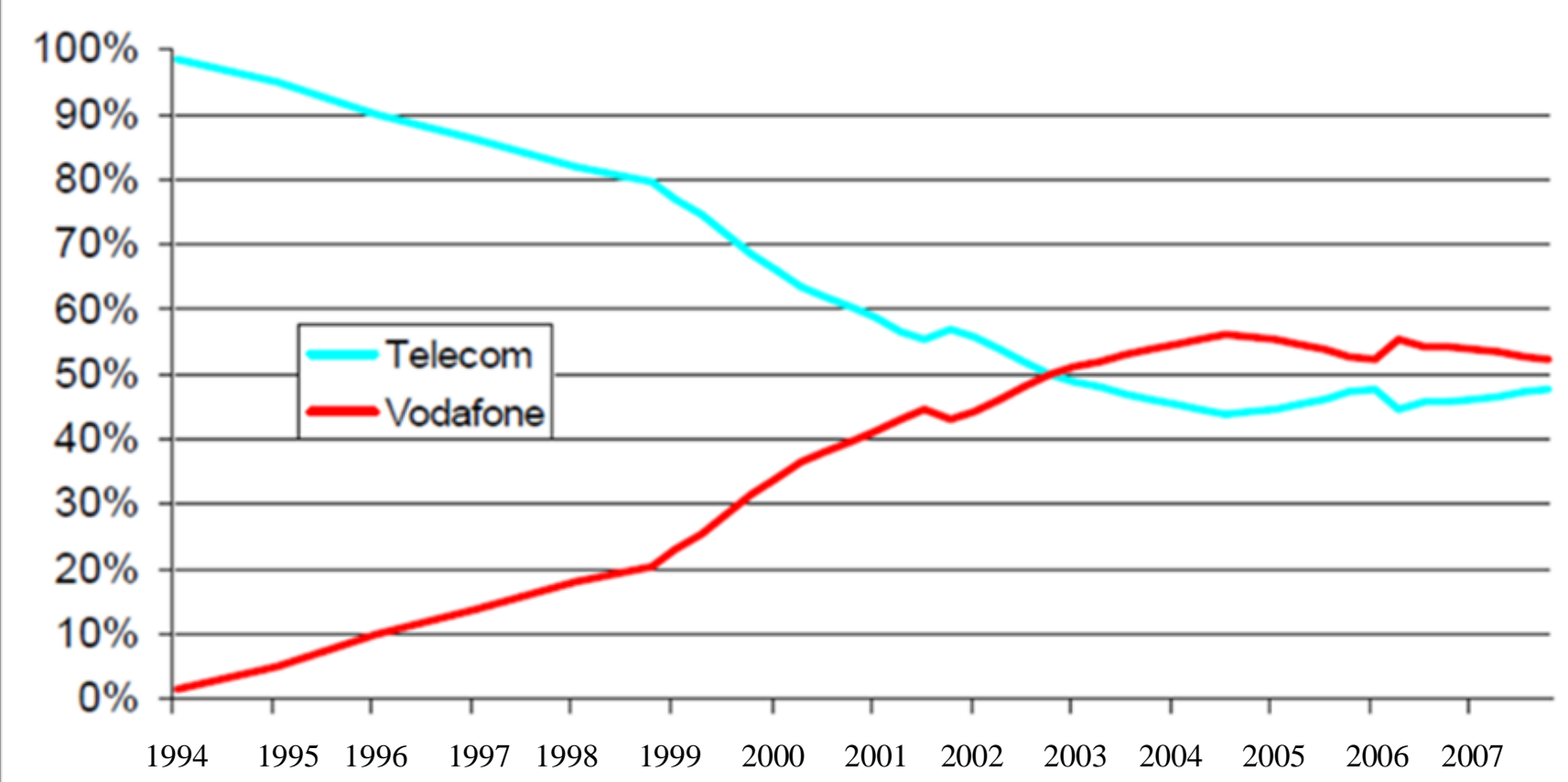

\subsubsection{Regulators - parameters and institutional practices}

The Feature Era was marked by an ideological disconnect: the regulating Minister M2 had a personal and moral standing that was irreconcilable with the beliefs of the Telecom chair P1. The Minister said that Telecom was earning undue economic rentals and that the bounty the rentals represented should be shared with consumers through competition, and by law structurally separating Telecom into network and service provider arms. He was unshakeable 
in this ideological standpoint. The chairman was similarly unshakeable that consumers were already being properly served in a fiercely competitive market, and that it was his duty to provide the best returns for his shareholders. The regulatory stance that Telecom should voluntarily provide its assets to its competitors was an anathema to P1 who believed there were no moral grounds for giving value away.

Telecom could point to the substantial increase in user numbers from 0.8 million to 4.58 million in just 10 years, and price reductions for all services, as evidence of competition resulting in large benefits to consumers. The regulatory argument was that the rentals were real because there should in New Zealand be prices not higher than the OECD average, and the lack of further competitors suggested that anti-competitive behaviour was keeping potential competitors from the field to the detriment of consumers.

To P1, as is described in the following section, the loss of billions of dollars of value due to regulatory action was evidence of regulatory and economic mismanagement. To M2 the loss was evidence that the market had valued Telecom based on the economic rentals and had adjusted value when these were removed. M2 was unmoved that Telecom was second in mobile to Vodafone - the mobile market was in this era still seen as secondary to a telecommunications market for voice and internet dominated by landlines.

R1 and M1 had attempted, because of their ideology of fair play where everyone is reasonable, to convince the market actors to change their practices. They were only partly successful. Their frustrations towards the end of their terms were evident and signalled the end of soft regulation. However, from R1's perspective, M2 went too far in pulling the regulatory activities into the legislative and political arena. The subsequent swinging of the regulatory pendulum away from legislation powered by politicians and back towards economic regulation administered by the Telecommunications Commissioner is covered in the Flexible Era. 


\section{Social and Community Meanings}

Ideology is reflective of Social and Community Meanings. M2's insights into market economics during his time in the United States, particularly when studying at Harvard, reinforced his ingrained ethical position of social fairness. By the time of his return to New Zealand and his elevation in the Labour Government to Minister he was convinced that Telecom, through an unethical exclusion of competitors, was taking unjustified economic rentals at the expense of consumers. When public opinion began to sway convincingly against Telecom, M2 had his opportunity. M2 cited an article in a business newspaper as the catalyst, resulting in a directive from the Prime Minister to bring Telecom to book. The timing was right for regulatory changes that previously may not have been politically possible. Movements in the public sphere, and the political moves these shifts enabled, are substantial evidence of change in the Social and Community Meanings parameter. In turn, the movement in the Social and Community Meanings parameter was reflected in subsequent displacement of the Legal and Economic Institutions parameter.

\section{Legal and Economic Institutions}

The outcomes of the Ministerial review were predictable and the 2006 amendments to the Telecommunications Act - with subsequent amendments in 2011 - were, despite their unprecedented reach and approach, also predetermined. As M2 noted in his interview, the legislative moves were "quite courageous and highly risky" and "radical". From a politician these are euphemisms for extraordinary political gambling and fundamental restructuring. Although restructuring was aimed at the telecommunications market as a whole, the Legal and Economics Institutions parameter of the mobile market was unavoidably substantially impacted. The effects of regulatory change are discussed in the Flexible Era. 


\section{Spatial Matrix}

Market regulators were limited in their perceptions of market boundaries. R1 argued the mobile market was easy to define, by being geographically constrained and being one country. R2 argued market definitions made no difference, and boundaries were determined by conventional competition tests based on price substitution. There was, R2 said, a market for mobile and a market for fixed defined by a rigid boundary determined by a coastline and price (R2, 2016). In the Flexible Era section the limitations of geographic-price market boundary definitions are made clear.

\section{Regulator practices in the Feature Era}

Table 6-4 describes the parameters, performances and institutional practices for regulators in the Feature Era and focuses the movements in the Social and Community Meanings parameter, which reflected in the Legal and Economic Institutions parameter whereby regulation was introduced. Through the Feature Era there was a hardening ideology held by regulators and the public that competition was not taking place. Even the proponents of 'soft' regulation, such as $\mathrm{M} 1$ and $\mathrm{R} 1$, adopted the view that a harder, more invasive, regulatory pattern was needed. For M2 the opportunity for intervention was provided by the public perception (Social and Community Meanings) that Telecom, in particular, needed to be brought to book (Legal and Economic Institutions).

Table 6-4 Regulator practices in the Feature Era

\begin{tabular}{llc}
\hline \multicolumn{1}{c}{ PARAMETERS } & \multicolumn{1}{c}{ PERFORMANCES } & INSTITUTIONAL PRACTICES \\
\hline & $\begin{array}{l}\text { M1: They ended up becoming their own worst enemy. } \\
\text { By just taking too harsh a line. They would have been } \\
\text { way better to have been a little bit more conciliatory, } \\
\text { even though they had a right. They played big kid on } \\
\text { the block. }\end{array}$ & $\begin{array}{c}\text { Ideology: Fair Play through } \\
\text { "playing the game" }\end{array}$
\end{tabular}


Social and Community Meanings

Legal and Economic Institutions
Social and Community Meanings

Legal and Economic Institutions
R1: My view was that I could influence this environment through messaging, and so I followed the conscious strategy of message through talking publicly at every opportunity about concerns around the way in which the mobile market was evolving, encouraging parties to negotiate, meeting with industry leaders, particularly Vodafone and Telecom. I was expressing a desire to see a negotiated solution emerge.

R1: So they were now on a treadmill of effectively taking over a broad sway of the real regulatory power, whereas they could have, and in my view should have, kept well away and left it to the regulator. They ultimately ended up in a very complex regulatory matrix where they were imposing functional separation on Telecom.

Commerce Commission: We haven't seen significant new entry into the mobile market. The Commission considers the current regulatory settings may not be creating sufficient incentives for that entry to occur.

M2: Telecom had high levels of dominance, and that the regulatory framework was still too weak and it left New Zealand at odds with evolving mainstream practice, which was dynamic, competitive technology markets, with lots of players.

M2: We beefed up the role of the Telecommunications Commission. We gave them proactive powers. We started a process of reviewing separation for Telecom.

M2: The next day the Telecom share price went into freefall. In my view, nobody has a property right to economic rent.

M2: I have a clear value base which is that of fairness and equity, a participatory democracy, and economic rules which give everyone a fair chance to play. I'm not a big fan of extreme social inequality, and I'm not a great fan of market dominance.

R2: It looks like a duopoly to me.
Ideology: non-invasive (soft) regulation

Ideology: invasive (hard) regulation

Ideology: invasive (hard) regulation

Property rights secondary to public outcomes

Ideology: Fair play through hard rules

Ideology: invasive (hard) regulation

\subsubsection{Providers - performance of practice}

Technology - the Japanese-European view

BellSouth entered the New Zealand mobile market in 1994 with GSM technology. An advantages of GSM over the AMPS technology of Telecom was roaming whereby BellSouth 
mobile telephones could be more effectively used by international travellers. A further advantage was that it allowed for better SMS capability. SMS, used for texting, had been a core technical expectation when the international standards for second generation mobile telephones were developed in late 1980s to early 1990s. Texting was a key feature of thirdgeneration (3G) mobile devices (P3, 2016). The predominant use of AMPS technology in the United States, however, meant that neither BellSouth nor Telecom, in sharing the US-centric view of mobile communications, had recognised the potential of texting. Although Telecom dropped AMPS in favour of the CDMA technology, it was because of CDMA's compatibility with $3 \mathrm{G})$ mobile telephones that were starting to be introduced and not because of texting (P3, 2016). P3 had tried, unsuccessfully to encourage Telecom towards text as a market driver, particularly in the consumer market.

People couldn't get their heads around it. Why would anyone want to do texting? (P3, 2016, p. 5)

The Europeans, including Vodafone, were, however, well advanced in text use. In 1998 Vodafone bought out BellSouth's network and entered the New Zealand mobile market. The ability to send text messages rather than use comparatively expensive talk minutes, and cheaper arrangements of pre-paid rather than post-paid term contracts, made Vodafone's Feature telephones more attractive to a broader, and much younger, market segment (P3, 2016).

(There was) now a shift from just the corporate enterprise market into the consumer market and that was driven as much as anything by two things, pre-paid and SMS texting. (P3, 2016, pp. 2-3)

User growth

In 1999, at the start of the Feature Era, the New Zealand mobile market was still dominated by Telecom. Telecom had 0.609 million $(608,900)$ users - amounting to 80 percent of mobile 
customers - using their mobile devices predominantly for business (Telecom New Zealand, 1999). The rest of users had either moved to Vodafone, or had adopted the British firm as their first provider. Between them Vodafone and Telecom were growing the market - despite the inroads of Vodafone, Telecom's user numbers had increased by 27.9 percent between 1998 and 1999 and had quadrupled in just five years. The number of mobile caller minutes had doubled in just two years to 200 million. The increase in users did not directly relate to increased earnings. In March 1998 Telecom had cut call prices and introduced five new call pricing plans based on amount of usage for mobile phone business customers in response to similar moves firstly by BellSouth and then by Vodafone. While average revenue for customer had increased by 16 percent between 1997 and 1998, the average revenue per customer in 1999 fell by 2 percent due the higher numbers of pre-paid accounts. It was clear that mobile now had Telecom's attention. In the 1999 Telecom annual report, Sutcliffe, in his last letter to shareholders, noted that the increased number of users across the two providers suggested scope for continued expansion in the mobile market (Telecom New Zealand, 1999).

\section{Competitive intensity}

From Telecom's perspective, the mobile market had become intensely competitive because they were caught in a technology deficit where their view of mobile was outdated.

Anything that was bigger than 20 people was typically a Telecom customer because we influenced it from the top right back in the 1990s and Vodafone struggled to catch on to that. But they bought in their pre-paid market much better. They attracted the youth market much better because of the texting and the features of the GSM phones and it just became a fad. Then that spread. The youth moving into the businesses sucked it with them, and so the whole market started to transition from being Telecom dominant in the enterprise market to having to really have to compete strongly in the enterprise market. And, more importantly, attract the youth market. (P3, 2016, p. 6) 
P1 moved to the chairmanship and Theresa Gattung became chief executive. Telecom's 2000 annual report noted a 44.8 percent growth in Telecom's cellular connections over the previous year, bringing the company's users to 0.998 million $(998,000)$ (Telecom New Zealand, 2000). The total number of mobile telephone users in New Zealand now stood at 1.54 million meaning 40 percent of the New Zealand population were connected to the mobile network. By August 2000, Telecom had more than 1 million mobile users, including 310,000 using 3G digital telephones, up from 495,000 users including 16,000 digital in August 1998. The diffusion of mobile telephones and devices with digital capability was rapid, but the penetration level, when compared with other countries, suggested further scope for expansion (Commerce Commission of New Zealand, 2008; Telecom New Zealand, 2000). During the year Telecom began rolling out its new CDMA mobile telephone network as well as a new broadband system.

\section{Mobile-internet convergence}

The convergence of mobile and internet was acknowledged both at Telecom and within its customer base. In his first letter to shareholders as chairman, P1 stated that telephone network operations including fixed cable and mobile remained Telecom's core business. "But no matter how excellent we make this business, we must develop beyond old boundaries if we are to sustain superior growth in value for shareholders. Thus Telecom is now becoming a more diversified online and communications company. Our transition has several dimensions. Telecom will retain a strong focus on delivering value to customers. Only on this basis can we sustain an unswerving commitment to growth in value for shareholders." (Telecom New Zealand, 2000, p. 3) This was the only reference to customers in the letter.

In the report Gattung noted New Zealanders were quick to adopt new services. "In more traditional telecommunications markets, competition between service providers is 
becoming more intense and prices are in decline." (Telecom New Zealand, 2000, p. 4) Traditional voice calling, that in 1994 had provided about 90 percent of operational revenues, were now providing only 60 percent (Telecom New Zealand, 1994, 2000). Mobile was now Telecom's biggest revenue stream after traditional fixed line calling. The CDMA network would enable users with $3 \mathrm{G}$ telephones to access mobile internet access and speeds similar to the standard dial-up connections on the fixed-line network. The \$200 million CDMA network would be functioning by July 2001 .

"The jump in data speed achievable through CDMA is particularly important given that, within a few years, mobile phones are expected to become the main means by which people access the internet.... Telecom expects wireless data to account for at least a quarter of total mobile revenues within four years, compared to about 1\% now," Gattung reported. "Just a few years ago mobile phones were the domain of business people. Today their popularity extends to people in all areas of life, as a tool for staying in touch and for personal safety." (Telecom New Zealand, 2000, pp. 8-9)

Telecom's 2001 annual report emphasised mobile and the mobile-internet interface where the provision of wireless data was propelling the mobile telecommunications market. (Telecom New Zealand, 2001).

From 'other' to 'us'

By 2001 there were 2.23 million mobile users in New Zealand, an increase over the year of 11.2 percent. However, Telecom's mobile revenues for the year grew by only 0.2 percent to $\$ 547$ million. The number of minutes of mobile talk increased by only 9.6 percent as an increasing proportion of users - particularly new users - spent more of their time not talking but texting. Furthermore, 61 percent of Telecom connections were pre-paid. The result was that the average monthly spend by Telecom users decreased by 27.3 percent (Commerce 
Commission of New Zealand, 2008; Telecom New Zealand, 2001). By the following year, 2002, the number of Telecom post-paid contracts had risen a further 1.6 percent to 0.514 million $(514,000)$, but for the first time were surpassed by the number of pre-paid users which risen by 9.3 percent to 0.562 million $(562,000)$. Combined with third-party pre-paid the number pre-paid stood in 2002 at 0.794 million $(794,000)$ out of a total of 1.308 million Telecom mobile customers. The amount of revenue per customer in 2002 declined by 2.8 percent for post-paid, but by 36.8 percent for pre-paid (Telecom New Zealand, 2002). These data are indicators of a key movement in the mobile market, that younger users were engaging with mobile in innovative ways involving text and pre-paid arrangements. Most of this emerging segment were not using Telecom but Vodafone. Most importantly, some 64 percent of the New Zealand population now used a mobile telephone for personal purposes. Users were no longer a professional elite. The 'other' had become 'us'.

\section{The end of growth}

The numbers of users grew by 0.21 million $(210,000)$ during the 2001-2002 year - a growth of 9 percent, and equivalent to a further 6 percent of the New Zealand population (Commerce Commission of New Zealand, 2008; Statistics New Zealand, 2017). Since 1992, however, the total number of users had grown on average by 32 percent a year. In 2002, for example, the total number of users had grown by 41 percent, and in 2001 the market had grown by 31 percent. In the 2002 report, however, Gattung noted that the growth in Telecom mobile connections had moderated - a growth of just 0.8 percent. While the slowing of growth for Telecom mobile was also due to the competitive inroads of Vodafone, the era of rapid growth in the New Zealand mobile market was effectively over (Commerce Commission of New Zealand, 2008, 2015; Telecom New Zealand, 2002). 
Instead of collectively growing the market, providers were now locked in combat for market share. "Success means constantly innovating and anticipating the next bend in the road - the next technological wave, the next shift in customer demand," Telecom's chief executive Gattung said in Telecom's 2002 annual report. For mobile, innovation involved moving to an Internet Protocol technology providing capable of carrying all types of traffic whether voice, video or data (Telecom New Zealand, 2002). Concurrently, Telecom created partnerships to develop applications and content for $3 \mathrm{G}$ Feature phones. Telecom had recognised that the future of mobile telecommunications would not be the mobile device itself, nor even mobile communication one-to-one. The device would be a vehicle for accessing communications and computing alternatives based on the users' personal requirements. For providers, the imperative would be providing access to data - the material, or content, viewed on the device. The content would be as competitively and commercially important as the device itself.

P1 said in Telecom's 2003 annual report that the launch of the CDMA network had meant data revenue had increased by 118 percent, driven by Telecom's new mobile JetStream internet services. P1 said new agreements with Sky Network Television would see Telecom launch new entertainment and communications packages. Gattung also pushed that Telecom was now a data business as much as a voice business, such as with mobile broadband. Telecom's mobile JetStream was New Zealand's fastest mobile data network, and more than 0.5 million $(500,000)$ users had Xtra email addresses accessible from their Telecom mobile telephone. Xtra's mobile services included weather forecasts, news and sports information, and games. "The services we deliver may be increasingly sophisticated, but customers want them to be simple and effective to use. Whether they are corporates or people at home, customers want to access their telecommunications information and entertainment needs on any platform, from any device, anytime and anywhere.” (Telecom New Zealand, 2003, p. 9) 
Despite the advantages of the new CDMA network Telecom was losing its battle against Vodafone. Telecom had 1.125 million mobile users, down from 1.308 million in 2002. Wireless and internet providers were increasingly competing for internet and voice calling market, P1 said in his 2004 letter to shareholders. "In turn, technology change - along with the need for integrated answers for customers - is seeing us move into areas that were not traditionally ours. In IT we are going head-to-head with the established global brand leaders. In fact the line between IT providers and telcos is now so blurred it's almost unrecognisable. Mobile customers can choose the best technologies in the world, particularly from global mobile giant Vodafone with its access to international products and services. It's never been more inviting for a disgruntled customer to vote with their feet." (Telecom New Zealand, 2004, p. 5) P1 was signalling that competition and technology (and user and provider responsiveness to these market-changing factors) was bringing about the end of traditional telecommunications companies, and the emergence of new cross-service integrating providers of internet and mobile services competing across borders (Telecom New Zealand, 2004, 2005).

\section{Regulatory intervention}

By 2005 a divergence of understanding between providers and regulators became apparent. Whereas M1 and the first Telecommunications Commissioner, R1, had tried to push Telecom to accommodate its competitors in terms of access to facilities and in interconnection charges, a new Minister, M2, was moving to break what he saw as Telecom's land-based network monopoly. Telecom had not moved fast enough to encourage internet usage - a key metric both for the Labour Government's economic platform labelled "the knowledge economy" and also an indicator of Telecom's willingness to share access and thus economic benefit.

The great fear I had in the mobile market was regulation. (P1, 2016, p. 10) 
It's not just attention. Regulation has so many unintended side effects, and unintended consequences. There is a serious lack of understanding of the market place and the pressures that were actually within that market place....and when you run those ideas past Government Ministers they don't show any concern or understanding. They don't even seem to understand what you're talking about and just think you're a right wing capitalist." (P1, 2016, p. 3)

$\mathrm{P} 3$ recounted constant frustration at the regulatory approach to the mobile market.

You ended up with this dichotomy. So often the regulator would look at what we were trying to do in the mobile business, and then shift the definition of the market such that it would be very hard, such that we'd look like we were still dominant. Even though, on a definition related to pure cellar mobile, we were not dominant at that stage, Vodafone was. (P3, 2016, p. 7)

It was against a backdrop of regulatory uncertainty that P1 in his 2005 annual letter pushed strongly the extent of Telecom's investment commitment. Telecom, P1 said, was at the midpoint of a most profound transition from a digital-switched platform to an all Internet Protocol network with seamless services across all technologies, whether fixed or mobile. It was one of the biggest infrastructure projects in New Zealand history and would extend the mobile $3 \mathrm{G}$ network to more than 80 percent of the population. The project, and new partnerships bringing in new mobile handsets, and content and services delivery, would not only rejuvenate Telecom's market presence and business growth, but also provide the first steps to broadband ubiquity for all customers be they business or residential (Telecom New Zealand, 2005). Competition, P1 said, was driving Telecom's investment in alternative technologies and networks. The 2005 Telecom annual report also noted that 1.8 million video clips had been accessed by mobile users in just three months from the firm's 3G service launch. (Telecom New Zealand, 2005, pp. 14-15) 
The Government remain unconvinced, and as will be shown later in the chapter, moved to regulate broadband services, provide competitor access to Telecom's copper network, establish regulation for the mobile network, and signalled that it would legislate the structural and operational separation of Telecom based on the British Telecom model. Allowing access to Telecom's copper network was known as unbundling the local loop. (Commerce Commission of New Zealand, 2006b; Telecom New Zealand, 2006)

A day or two after the unbundling announcement, three billion dollars was written off the value of Telecom overnight. And the Government was quite unconcerned. It was seriously inadequate economics. (P1, 2016, pp. 4-5)

P1 said the regulatory moves had more to do with punishment for Telecom than any technological or competitive purpose.

We had been allowed too much rope for too long. It was politically popular to have a crack at us. $(P 1,2016$, p. 4)

P1's position as chairman was thus untenable.

It led to my resignation, of course. I decided that I was not the right person to continue to lead Telecom. I think it was announced in March, and I'd gone by May. (P1, 2016, p. 5)

\section{Converging markets}

The 2006 annual report noted that in 2000 traditional revenue of local access and calling had made up 61 percent of Telecom's total revenue. By 2005, this had reduced to 44 percent. "In the past, telecommunications were essentially about customers using a fixed line to make a one-to-one contact with another person," Chief Operating Officers Kevin Kenrick (consumer) and Simon Moutter (business) stated in their joint report. "Now it is about using an evergrowing array of services - world-wide data networking such as mobile calls, websites, blogs, 
text messages, software applications, videoconferencing, music downloads - to communicate, inform, entertain, share data or deliver IT solutions to one person or a million people. Voice calling will remain a core service but it will be one application among many, delivered over an Internet Protocol network offering new options and flexibility for customers." (Telecom New Zealand, 2006, p. 3)

Technological changes were increasingly forcing the convergence of telecommunications markets. "The traditional fixed line business now expects aggressive competition from Vodafone with a range of fixed line substitute products, and the business market is converging with the IT industry. New wireless technologies such as $3 \mathrm{G}$ mobile, WiMax and WiFi will introduce new infrastructure competition and will be credible alternatives to traditional fixed networks for the provision of both high quality voice and fast data services." (Telecom New Zealand, 2006, p. 19) The strategic imperative had evolved from growing the number of users towards capturing market share while extracting more revenue from each user through the provision of more services. "Market penetration of mobile connections is trending towards 100 percent and the rate of penetration growth is expected to slow in the near to medium term. Future mobile data revenue growth is expected to be driven more by applications and content than by text messaging (which is currently the most significant driver). Future mobile voice revenues will be driven by share of connections and rate of substitution from fixed line services. As an integrated operator, Telecom also has a focus on the convergence of fixed and mobile services, which is expected to gain momentum in future periods." (Telecom New Zealand, 2006, p. 49 Material in parenthesis is the original text emphasis)

The New Zealand mobile telecommunications market by 2006 had 3.8 million users, equivalent to 92 percent of the population of 4,143,279. (Commerce Commission of New Zealand, 2015; Statistics New Zealand, 2017) 
By June 2007 Gattung had left Telecom. The operational separation of Telecom into new network, wholesale and retail businesses was underway. $\mathrm{R} 2$ became the new Telecommunications Commissioner and the Commerce Commission argued that not only were mobile prices too high, but also that there was limited competition in the market.

In the 2007 Telecom annual report, Telecom's chairman Wayne Boyd noted Telecom was spending a further $\$ 300$ million to complement its existing $\$ 1$ billion CDMA to the next level of WCDMA. The WCDMA mobile upgrade would allow faster mobile data speeds, access to better handsets, and opportunities for new revenues. "The telecommunications market in New Zealand is a vastly different place in 2007 to what it was 18 months ago. Aggressive retail competition and market consolidation, major technological change and the continued impact of regulatory reform are all major forces shaping our industry." (Telecom New Zealand, 2007, p. 12) By 2007, mobile growth revenues were being driven primarily by data traffic while other mobile revenues were stable. Revenues per user were continuing to decline as an impact of competition on pricing and integrated calling plans. Telecom's total connections grew during 2007 by 0.274 million (274,000), or 16 percent, to reach 1.977 million. Of those user connections, 40.7 percent were post-paid and 59.3 percent were prepaid.

These statistics add weight to how the mobile telecommunications market had changed during the Feature Era. At the start of the era the total number of mobile connections stood at 0.91 million $(910,000)$ of which 0.608 million $(608,900)$ were Telecom customers. The total number of users was equivalent to 24 percent of the New Zealand population. By the end of the era in 2007 , there were 4.25 million connections, equivalent to 103 percent of the New Zealand population. In 1999, the number of prepaid users was not even mentioned in the Telecom annual report. By 2007 the number of prepaid users far exceeded the number of users 
on post-paid contracts. Such shifts between tolls and mobile, and between post- and pre-paid reflected the changing nature of users from primarily corporate to primarily personal, and from primarily older people, to primarily younger. At the end of the Fundamental Era, the users had been 'other' - the general population did not use mobile telephones. By the end of the Feature Era, the general population were mobile telephone users - the 'other' had become 'us'.

\subsubsection{Providers - parameters and institutional practices}

This section provides analysis of the practices of Telecom in terms of the institutional practices and the apparent movements in parameters during the Feature Era.

\section{Social and Community Meanings and Legal and Economic Institutions}

In 1999 Telecom had a dominant position in the New Zealand mobile telecommunications market. BellSouth had failed to make any substantial inroads. Despite 24 percent of the New Zealand population being mobile users in 1999 , the mobile market was still an appendage to Telecom's business. The mobile telephone, as seen through the annual reports, was for 'other'. The priorities for Telecom lay in growing shareholder value, as be gauged not only in P1's letters to shareholders, but also in the response to the regulatory intervention that substantially reduced the value he and his team had so created. Furthermore, P1 took this priority into other companies of which he became chair, encouraging a rivalry between firms as to who would be the highest valued company on the New Zealand stock exchange (P1, 2016).

Telecom's ideologically-held primary priority of growing shareholder value thus remained unchanged throughout the era, indeed remaining unchanged from Telecom's formation through to structural separation. The Social and Community Meanings, and thus Legal and Economic Institutions, parameters, were changing regardless of Telecom's view. As seen from the interviews with M1, M2, R1, and R2, and documentary material, Telecom's unchanging ideology made regulatory intervention almost inevitable. 


\section{Competitive Intensity}

Vodafone bought out the BellSouth primarily Auckland network in 1998 and rapidly moved to develop the mobile market. The commercial priority for Vodafone was younger people who were outside the mobile telecommunications market. Vodafone's competitive strategy focused on providing cheaper value propositions such as text. Text had not been fully understood or utilised by either the American-influenced Telecom or its traditional business customers. The user connection with text were mobile telephones substantially different to their predecessors in the technological features of each model. The features enhanced communications capability and thus provided greater capacity for the management of business and personal life through the management of time, connections, mobility, and constant connectivity, while also allowing for managing entertainment in the form of basic games. Vodafone's competitive movement highlighted to consumers how technologies would meet needs not previously identified or understood by user or provider.

The commercial priorities for Telecom and Vodafone were to grow the mobile market, and mobile revenues, as rapidly as possible where the provision of voice services was just one capability amongst many. In 1999, mobile occupied only a small part of Telecom's perspective, as evidenced by meagre the space and placement devoted to mobile in its annual reports. In 2000, traditional revenues - local access and tolls - comprised 61 percent of Telecom's total revenues. By 2005, however, mobile was a primary priority and traditional revenues made up only 44 percent of revenues. From the provider perspective, priorities had substantially changed, reflecting substantial changes in the Competitive Intensity, Responsiveness, Technology, Value Propositions, Needs and Information parameters. 


\section{Social and Community Meanings and Social Matrix}

Telecom transitioned from analogue to a digital switched platform and then to an all internet protocol (IP) technologies across mobile and fixed networks. Telecom had evolved from being a provider of tolls to being a provider of landlines, broadband internet connections, and mobile, and the means of merging these capabilities into a single handheld device. Content and services were being developed to run across fixed and mobile broadband. Telecom was no longer just competing domestically for tolls, but was in a market where competitive effort was increasingly focusing on data, and where there was now global competition in terms of devices, connectivity and content. The changes in telecommunications market boundaries meant boundaries in other markets were being redrawn - banking, for example, could now be undertaken without having to visit a bank branch thus changing the relationships between banks and their clients, the services demanded, and the field of competition - different things were becoming important to customers. The location of a branch, and attentiveness of tellers, was becoming secondary to the functionality of the bank's website.

The common thread was that from the perspective of communications technologies and priorities, New Zealand was no longer isolated. Global trends in the value propositions offered by mobile technologies and applications were rapidly incorporated into the priorities of New Zealand providers and users. New Zealanders could see what value propositions were offered in internationally and the expectations were raised among users that similar value propositions should be available from their domestic providers.

Outcomes of market parameter movements included a four-fold increase in New Zealand user numbers from less than a million ( 24 percent of the population) to more than 4.25 million (103 percent of the population) in just seven years. By the end of Feature Era, however, providers were no longer striving to grow the mobile market but were increasingly aggressive 
in competing for their share of what had become a mature market, where growth was expected to be minimal, and where users were fully aware of mobile and its use. The mobile phone was now a tool whereby users managed productivity, entertainment, and the mobility of their connections and social acceptance regardless of location or social status. The market boundaries were thus impacted not just by the internationalisation of Responsiveness, Information, Value Propositions, Technology, and Needs parameters, but primarily by changes within the parameters of Social and Community Meanings and the Spatial Matrix.

There was, however, a divergence of ideology, as reflected in the Legal and Economic Institutions parameter, that took Telecom, and perhaps Vodafone, by surprise, the outcome of which made regulation a primary commercial priority. The relationships between the Legal and Economic Institutions and Social and Community Meanings parameters remained unchanged under M1 but markedly altered when M2 enforced structural separation on Telecom in 2006. Table 3 summarises the parameters, performances and institutional practices of providers during the Feature Era.

Table 6-5 Provider practices in the Feature Era

\begin{tabular}{clc}
\hline PARAMETERS & \multicolumn{1}{c}{ PERFORMANCES } & INSTITUTIONAL PRACTICES \\
\hline $\begin{array}{c}\text { Legal and Economic } \\
\text { Institutions }\end{array}$ & $\begin{array}{l}\text { P1: A day or two after the unbundling announcement, } \\
\text { three billion dollars, three billion, was written off the } \\
\text { vocial and Community } \\
\text { veanings }\end{array}$ & $\begin{array}{c}\text { Commercial Priority } \\
\text { quite unconcerned. It was seriously inadequate } \\
\text { economics. }\end{array}$ \\
& $\begin{array}{l}\text { Gattung: In 2000, mobile communication has really } \\
\text { come of age. Telecom has extended choice to people in } \\
\text { all walks of life through new packages of services and }\end{array}$ & Grow the Mobile Market \\
& features that add value to using a mobile phone: & Commercial Priority \\
competition has spurred growth in the market overall & Mobile revenues \\
Responsiveness & Kenrick and Moutter: Voice calling will remain a core & Commercial Priority \\
Technology & service but it will be one application among many, \\
delivered over an Internet Protocol network offering & voice one service among \\
Information & new options and flexibility for customers. & many
\end{tabular}


Information

Value Propositions

Technology

Needs

Social and Community

Meanings

Spatial Matrix
P3: The Americans didn't think that texts would supersede speech in any way shape or form... Then Vodafone came into the New Zealand market. And they started to put the European view. It had a different view of the world.

P3: The issue then was, how in the 3rd generation mobile standards, we could actually leverage a more mainstream global position, because it was obvious that the American perspective was not going to survive. P3: Vodafone had a European-centric view of how mobility was to develop, which was all about roaming internationally, was all about text and speech, and evolution into data, a lot of data. So Vodafone changed the whole scene in New Zealand because it had a different view of the world.

P1: This was an amazing future. I just felt the customers had such hugely exciting opportunities in front of them, and the trick was how do we convey that to them

Gattung: Just a few years ago mobile phones were the domain of business people. Today their popularity extends to people in all areas of life, as a tool for staying in touch and for personal safety

Gattung: Success means constantly innovating and anticipating the next bend in the road - the next

Competitive Intensity Information

Value Propositions Needs

Social and Community Meanings

Spatial Matrix Technology technological wave, the next shift in customer demand. All the while, a company such as Telecom must keep the business in order today, under the steady watch of customers, shareholders and institutional investors P3: Anything that was bigger than 20 people was typically a Telecom customer. Because we influenced it from the top right back in the 1990s and Vodafone struggled to catch on to that. But they bought in their pre-paid market much better. They attracted the youth market much better because of the texting and the features of the GSM phones and it just became a fad. And we started to lose it.

Gattung: Market penetration of mobile connections is trending towards 100 percent and the rate of penetration growth is expected to slow in the near to medium term.

Kenrick and Moutter: Now it is about using an evergrowing array of services - world-wide data networking such as mobile calls, websites, blogs, text messages,
Competition Priority Text

Internationalisation of value propositions and services

Japanese-European approach supplants US view of mobile communications

Opportunities provided by mobile technology recognised

Mobile diffusion across populations

Competition Priority

Pre-paid dominant over post-paid.

Competition Priority Market share.

Intense Competition Mobile

Market penetration 100 percent and over Average revenue per user declines

Internet growth 


\begin{tabular}{|c|c|c|}
\hline \multirow[t]{3}{*}{$\begin{array}{l}\text { Needs } \\
\text { Social and Community } \\
\text { Meanings } \\
\text { Spatial Matrix } \\
\text { Technology }\end{array}$} & $\begin{array}{l}\text { software applications, videoconferencing, music } \\
\text { downloads - to communicate, inform, entertain, share } \\
\text { data or deliver IT solutions to one person or a million } \\
\text { people }\end{array}$ & $\begin{array}{l}\text { Internet-mobile } \\
\text { convergence }\end{array}$ \\
\hline & $\begin{array}{l}\text { Gattung: Future mobile data revenue growth is } \\
\text { expected to be driven more by applications and content } \\
\text { than by text messaging }\end{array}$ & $\begin{array}{l}\text { User Buys } \\
\text { Multi-modal services } \\
\text { mobile and internet }\end{array}$ \\
\hline & $\begin{array}{l}\text { P1: I had that view about the media side. That we really } \\
\text { needed to have that interface with the media, and so } \\
\text { that was why we tried to make those acquisitions. If } \\
\text { you look back now, in principle that was the right call. } \\
\text { Because that is the way the industry has gone. Content } \\
\text { matters hugely. }\end{array}$ & Content importance \\
\hline \multirow[t]{2}{*}{$\begin{array}{l}\text { Legal and Economic } \\
\text { Institutions } \\
\text { Social and Community } \\
\text { Meanings }\end{array}$} & $\begin{array}{l}\text { P1: I think the great fear I had in the mobile market was } \\
\text { regulation. It's not just attention. You see the trouble } \\
\text { is that regulation has so many unintended side effects, } \\
\text { and unintended consequences. }\end{array}$ & $\begin{array}{l}\text { Commercial priority } \\
\text { regulation }\end{array}$ \\
\hline & $\begin{array}{l}\text { P1: There is a serious lack of understanding of the } \\
\text { market place and the pressures that were actually } \\
\text { within that market place.... }\end{array}$ & $\begin{array}{c}\text { Regulation } \\
\text { divergence of ideology }\end{array}$ \\
\hline
\end{tabular}

\subsubsection{Users - performance of practice}

This section provides insights into the performances of mobile telephone users during the Feature Era. In particular, the performances reveal the process of legitimation (Humphreys, 2010) whereby mobile telephones became accepted by a broad population, and provides insights into how users, as market actors, are motivated to change behaviour.

\section{Features take priority}

For car salesman AS the biggest frustration of using mobile telephones was the lack of coverage in rural areas. For all the proclamations by Telecom and Vodafone that they had the country covered, AS could too frequently find himself with no coverage at all. On the other hand, while the mobile telephones in the Fundamental Era had revolutionised his ability to work away from his office and to sell farmers new vehicles, in the Feature Era, his mobile telephone provided him instantly with a national network of advisers and buyers. A key component in selling a 
car is the value of the trade-in, for which AS often needed a second opinion, or a decision on a price. At times AS needed to secure a buyer for the trade-in vehicle.

You can't beat a photograph. I would look at vehicles and I think “We don't want that. There's no-one that I know in the South Island who wants that, but I know Miles Gazley in Wellington would love it". So I could then ring Miles from in the car...I could describe everything, the colour and everything. "And here's a photograph of it." And he would buy over the phone. So we'd put a deal together because time is the essence. Once you front up to someone and put something better in front of them you've got to be able to put the whole deal together. The mobile phone with the camera was just out on its own. (AS, 2016, pp. 23-24)

\section{Status diminished - the influence of text}

SS enjoyed the executive status of being one of the first people in New Zealand to use a mobile telephone. By the Feature Era, the status imbued by having a mobile telephone had disappeared. Initially, SS began texting because everybody was texting, he found texting to be convenient, it saved the price of a call, and was useful for setting up meetings.

It wasn't social communication. It wasn't “Oh hi, how are you?" kind of stuff. (SS, 2016, p. 16)

Status diminished - texting and price

ML had moved on from being a film student, but the mobile telephone remained essential. She upgraded her device from time to time but never with a top model and always focused purchase decisions on functionality. A primary use of the telephone was texting due to convenience and the lower price.

Texting friends, family. I'd use it to make toll calls because you had cheaper rates than if I was using my landline. I would phone people in the evenings or weekends. But not being a great talker on the phone, if I was making those toll calls they would be monthly. I did text a lot 
though because that's replaced me having to send emails at that stage, so shorter, quicker, you can... you know...more convenient. (ML, 2016, p. 15)

It (text) was one way to say 'How's it going? Hope everything's going well'. So it's like a reminder to them that you're thinking of them. Whereas before I used to be a letter writer. Then I became an emailer. And then I stopped writing emails. (ML, 2016, p. 18)

The elevated status ML had gained from using a mobile telephone when film-making had diminished as mobile devices became increasing popular across a wider public and behaviours changed.

I seemed like everyone had their phones, so I didn't feel any cooler. Texting was a big thing. I think texting was the main function that was used. Yeah, and then you started noticing the texts ... the behaviour in groups when people were responding to texts. It started to get worse when people were just interrupting conversations just to check their phone, check the texts, you know. (ML, 2016, p. 20)

ML's first mobile telephones were bought through Telecom and were run on long term plans, but in the Feature Era she switched to Vodafone.

They (Vodafone) were very aggressive in their marketing and they really tried to appeal to different segments, you know. Their plans appealed to me more because they realised that people had different budgets. Also different phone usage. I think Telecom were a little bit ... I think they were just too locked in to the early days, whereas, you know, I wasn't someone who used my phone a lot to phone people and that, and so therefore I wouldn't want to be paying a lot more for something that I wasn't getting. (ML, 2016, p. 19)

\section{Legitimation - social acceptance via competitive influences}

AF and his friends were acutely conscious of the social signals sent by using their mobile device. He and his friends would pay attention to each other's mobile telephones the same way 
as their shoes, watch, or other status statement of fashion or social mobility. The legitimation of mobile devices, where mobile telephones became ubiquitous across the New Zealand population, came so suddenly as to take him by surprise.

It was like it wasn't there one day and the next day it was. It was like the social context that I was in at the time changed, and corresponding with that was people's usage of the new technology and adoption. It was just on this massive sort up upswing. (AF, 2016, p. 9)

Legitimation resulted from the intensified competition and the cheaper plans that emerged (AF, 2016). AF found pre-pay too restrictive, in that he preferred to call rather than text, and calling too rapidly ate through the available credit.

I became aware of this new kid on the block, Vodafone, and the competitiveness, or my perceived competitiveness, in their plans. I saw that as a better fit for me who was still calling a lot. I felt that I could actually support that financially at the time. (AF, 2016, p. 14)

\section{Legitimation - the changing nature of business and social use}

Consulting engineer AR often drove between his home in Christchurch and the inland towns associated with electricity generation such as Manapouri or Twizel. His early Feature Era mobile telephone enabled him to text and make calls while working on-site. He could stay in touch with his wife, and his colleagues, and clients could contact him. AR said coverage was the most important capability a provider could offer. AR had a Telecom contract because Vodafone coverage faded quickly beyond urban boundaries, but heading well into the South Island hinterland meant there was often no coverage at all. He had bought his own mobile for about $\$ 500$ (AR, 2016).

There was no status attached to it. You could just make a phone call, or text, or play Snake. They weren't all singing, all dancing. I wouldn't say they were widespread. Not every 
professional had a cellphone, and not everybody on the street had a cellphone. Certainly students didn't have cellphones. (AR, 2016, p. 1)

You were well past early adopters because all the bankers, or whoever it was, would have cellphones, but you're into the start of the mainstreaming. So it was consultants, and everybody else in that space. And businesses were starting to grapple with "do I need my staff to be contactable all of the time" because at that point in time businesses weren't expecting to get you if you were mobile (away from your office). Your business expectation was not "I can get you at any time". You'd send an email and if you got a response in the next couple of days that was fine. (AR, 2016, p. 2)

Socially, AR's mobile telephone was used very infrequently. The device was purely a work tool. The price of mobile telephones and their usage was too high for family.

There were a few work colleagues who started to have phones. If you were a general manager you got quite a small phone. (AR, 2016, pp. 3-4)

Social practices around mobile telephones changed as more people began using the developing technologies.

Having some yob yelling down the phone was much more prevalent then, trying to show off. The thing that was most prevalent though, that everyone was interested in, was how much smaller and lighter they were getting. So the next one came along and it was smaller, and it was lighter, and a better email system, so lots of people would have a Blackberry or something, that was a much better email-driven phone. Those were probably the big two things. The smaller and lighter, and the better email functionality. (AR, 2016, p. 6)

\section{Legitimation - managing personal life}

Academic PT had his first encounter with a mobile telephone at a meeting with his Dean in the late 1990s. 
He'd just got this phone, and rather importantly placed it on the table. It had a bit of an impact on me, and I thought "Oh wow, I'd like one of those", and then part of me thought "Ah, he looks very pleased with it. Almost self-important". It might sound an odd reaction, but it slightly put me off, you know? I don't feel I'm important just because I've got a phone. (PT, 2016, p. 4)

Although an innovator in terms of computers, PT delayed owning a mobile telephone until 2002. The purchase stimulus was that his father took seriously ill and a mobile telephone was a pragmatic approach to staying in touch with the broader family. He discussed the purchase with his wife.

It was definitely around the need for it. That was the question. Not can we afford it but do I need it? We both went to the shop and bought the phone. (PT, 2016, pp. 13-14)

It was a difficult choice because there was too much choice almost. Hundreds of little mockup phones. And you couldn't really try them out because they were little plastic - literally mock-ups - and they'd either go out to the back room or say "We have to order it in" depending on the model. So you couldn't actually try it. It was a funny process. (PT, 2016, p. 5)

It was a Nokia basic phone but it did what phones did in those days. It rang. And it actually worked very nicely. It was very robust. And you could sent texts on it...and receive them! (PT, 2016, p. 2)

His mobile telephone had a far greater impact on his life than he anticipated. More people, particularly young people, were using mobile telephones and he recognised that being able to make or receive a call from anywhere was shifting social attitudes and the ways people behaved. 
I was amazed, and I still get amazed, at this texting phenomenon when young people talk about hundreds of texts, and I'm like, how could that be? But the phone ... you realised that you could organise your day a little bit differently, and it made you more flexible. You didn't have to plan ahead quite so much or think about where's the phone box? And it was liberating in the sense that you could be a bit more relaxed about this notion of staying in touch. (PT, 2016, p. 3)

\section{Legitimation - digital natives}

RV was the first of the digital natives interviewed for this thesis to use a mobile telephone. Digital natives have spent most, or all, of their lives using the tools of the digital age such as mobile telephones, and think and process information in ways fundamentally different from their predecessors (Prensky, 2001). RV received his first mobile telephone from his parents in 2005 when he was in Year 9 at high school. Many of his colleagues had received their first mobile telephone while still in primary school or at intermediate, others were yet to do so, however by the end of his first year at high school almost everyone had a mobile telephone (RV, 2016).

The decision wasn't made by me, it was my Mum or Dad. They wanted me to have some form of communication, so they had an upgraded device and there was an old one lying around, so I got that. It could text, it could call, and it could play Snake. The most noticeable thing was that you could drop it, and it wouldn't break. The ability to text was the most notable change from not having a mobile phone. Calls were not that interesting, were expensive, and required having money on the phone. I didn't have much money at the time. But you could text." (RV, 2016, pp. 1-2)

Digital natives placed no status on mobile telephones primarily because features were few, and the devices were not particularly interesting compared with other digital equipment they might 
be using. The rapid increase in numbers of students who became users in those twelve to eighteen months of 2005 to 2006 created the first element of what RV described as a tipping point whereby "everyone" had a mobile device and "everyone" started texting. Unlike older users the digital natives did not have sufficient money to enable either talk or text until intense provider competition created affordability leading to widespread and intensive usage (RV, 2016).

It wasn't normal to be always to be on your phone back then texting. It was not exactly cheap. This was at a time when you were paying 20 cents a message, before Boost Mobile did unlimited texts and everyone suddenly bought a Boost Mobile phone and picked up unlimited texting and it became ten dollars for two thousand texts, and suddenly...that became more normal to text a lot then. You'd trade numbers and then occasionally text, but there wasn't this big in-touch-with-everyone constantly engaging with everyone the way it is now. It took effort, it took money, it was normally a specific task-oriented thing. Probably a year or two after that it started becoming more you were texting someone, you were having a chat, and then it's grown exponentially since then. (RV, 2016, pp. 6-7)

\section{Legitimation - the older new user}

Engineering draughtswoman DS had no mobile device until she retired. Her husband had a mobile telephone but DS felt no need for a mobile telephone until one day when she arranged to meet him in a small rural town at midday. Midday came and went and by $2 \mathrm{pm}$ she was worried about his state of health. He was perfectly fine, but the scare led DS and her husband to conclude that as they both got older she needed a mobile telephone. Having the mobile telephone was very reassuring. When interviewed in 2016 , she was still using the same mobile telephone that she bought in 2006, mainly using text to contact family for arranging picking up her grandchildren, and to connect with old friends (DS, 2016). 


\section{The negatives of ubiquity}

For businesswoman RG, the Feature Era meant she could now buy a "sexy" mobile phone small enough to fit in her handbag and which she could use for texting. Social attitudes towards mobile telephones, and expectations in the business world, had changed (RG, 2016).

Everybody thought mobile phones were awesome, didn't they? It was just one of those things that you had to have. And everybody used to say "Have you got a mobile number?" as if was something like, you know, you're not a business unless you've got a mobile number. (RG, 2016, p. 14)

Some changes, however, were not always for the better. In the late 1990s and early 2000s, RG was working in road safety and became concerned at the distractions mobile telephones caused drivers, the effects of which were starting to emerge in scientific journals. She was moved particularly by an experiment with expert pursuit drivers in the British police that showed talking on a mobile telephone reduced the expert drivers' cognitive and driving ability to that of a learner driver.

I remember a woman being killed. She was on the Auckland motorway just talking on the cellphone and she crossed the median strip and was killed. That was kind of like a big... where you were just starting to see the negative things coming out of cellphones. (RG, 2016, pp. 1819)

As vice chairperson of the Automobile Association, RG's view was that handheld mobile telephones should not be allowed for drivers. Association members were strongly opposed to any safety regulatory intervention. Laws prohibiting the use of mobile devices by drivers came into force in New Zealand on November 1, 2009 - well into the Flexible era - by which time 76 percent of Association members had changed their perspectives and were strongly in support of a ban (Automobile Association, 2017; "Land Transport (Road User) Rule 2004," 2004). 
While mobile telephones were used to manage connectivity, by the end of the Feature Era the devices enabled what this thesis describes as proximity disconnect. Proximity disconnect occurs when the user employs their mobile device in a pervasive, often addictive, desire for constant connectivity with someone or something at a distance while simultaneously actively and determinedly using their device to disconnect with people at close proximity (Walsh, White, \& Young, 2008). RV was one of the new group of users who connected with their device to disconnect from other people.

It was always a good way of avoiding interaction with someone you didn't want to have an interaction with. So if you were walking past a group of people you just couldn't be bothered talking to you could just pretend to be texting and no-one would know. I'm otherwise engaged, I will keep on moving and we will smile and nod. (RV, 2016, p. 6)

This section highlighted the performances of users during the Feature Era. The following section provides analysis of the practices of users in terms of the institutional practices, and the apparent movements in parameters.

\subsubsection{Users - parameters and institutional practices}

\section{Social and Community Meanings}

For the mobile market to expand users had to be responsive to the value propositions offered by the providers. At the start of the Feature Era, the mobile telephone was used by 24 percent of the New Zealand population, thus the device was still a status object associated with 'other'. The legitimation process for mobile telephones occurred through the advent of value propositions of particular utility and accessibility to potential users. Smaller and shinier was preferable in the early years of the era, but a distinction of the Feature Era was that texting, 
gaming, and eventually basic internet capabilities, became desirable and also accessible to more users.

By the end of the Feature Era 103 percent of the population were users. More than three million New Zealanders previously outside the market were now inside. Legitimation of the mobile telephone - the shift from 'other' to 'us' was complete. Legitimation brought egalitarianism where competitive intensity between users was reduced or even erased. The mobile telephone no longer afforded social status to 'other' but afforded socially accepted abilities for managing mobility and connections for 'us' of all ages and backgrounds. Legitimation, whereby telephones were accepted as part of the social, reflects changes to market boundaries, primarily to the Social and Community Meanings parameter but also to the Competitive Intensity, Needs, Information and Value Propositions parameters.

\section{Spatial Matrix}

Older potential users debated whether they had a need to buy a mobile telephone and fretted about what social signals the devices gave. AS, DS and PT needed to see a demonstrable need before they would engage with a mobile device. To them, at least at first, texting made little sense. Texting, however, made great sense to digital natives who saw the potential as a tool for managing connectability while also allowing for proximity disconnect. The social aspect of mobile telephones thus moved from "why text?" to "always text" and from the exchange of talk to the exchange of data such as photographs. Furthermore, data exchange, while at first being the arcane province of business users, later became the mundane practice of 'us'. This reflects a substantial change in the Spatial Matrix. Alongside Social and Community Meanings and Competitive Intensity, the Spatial Matrix was the key parameter in the expansion of the mobile market. With mobile devices the available social boundary of the user could be expanded at will. The user could call, text, send data while mobile to anyone else, almost 
anywhere, whether they were mobile or not, at any time, and an immediate response was expected. Conversely, the ability to receive data at any time and in any place had a secondary function - the user could exclude those in close proximity. The Spatial Matrix for mobile users can thus be said to have two boundaries much like a bubble within a bubble. Firstly, there is the public boundary marked by the largest bubble delineated by the furthest reaches of the market. Secondly, there is a flexible but much smaller private boundary that expands and recedes as the user includes or excludes those in proximity.

\section{Mobile - Life Changing}

Feature Era mobile telephones enabled users to manage their lives, their mobility, their connectedness, and resources for both business and personal reasons. Every person interviewed for this research said mobile telephones were not just a communications platform, but for them were substantially life changing. The processes whereby mobile telephones became accepted by a large number of people served to bring their use under scrutiny. Phobias of direct health risk were replaced by real evidence of negative social impacts such as death and injury through vehicle collisions caused by drivers' inattention.

Table 6-6 User practices in the Feature Era

\begin{tabular}{|c|c|c|}
\hline $\begin{array}{l}\text { Social and Community } \\
\text { Meanings } \\
\text { Needs } \\
\text { Responsiveness }\end{array}$ & $\begin{array}{l}\text { PT: I thought 'Oh wow, I'd like one of those', and then } \\
\text { part of me thought 'Ah, he looks very pleased with it. } \\
\text { Almost self-important'. It might sound an odd reaction, } \\
\text { but it slightly put me off, you know? } \\
\text { PT: That was the question. 'Do I need this phone?' Not } \\
\text { 'Can we afford it?' but 'Do I need it?' We both went to } \\
\text { the shop and bought the phone. } \\
\text { PT: I was amazed, and I still get amazed at this texting } \\
\text { phenomenon when young people talk about hundreds } \\
\text { of texts, and I'm like 'How could that be?' }\end{array}$ & $\begin{array}{l}\text { Social Acceptance } \\
\text { determinant in purchase } \\
\text { and use decisions }\end{array}$ \\
\hline
\end{tabular}




\begin{tabular}{|c|c|c|}
\hline $\begin{array}{l}\text { Value Propositions } \\
\text { Technology } \\
\text { Needs } \\
\text { Responsiveness } \\
\text { Competitive Intensity } \\
\text { Information }\end{array}$ & $\begin{array}{l}\text { AS: He would buy over the phone. So we'd put a deal } \\
\text { together because time is the essence. Once you front } \\
\text { up to someone and put something better in front of } \\
\text { them you've got to be able to put the whole deal } \\
\text { together - and the mobile phone with the camera was } \\
\text { just out on its own. } \\
\text { AR: The thing that was most prevalent though, that } \\
\text { everyone was interested in, was how much smaller and } \\
\text { lighter they were getting. So the next one came along } \\
\text { and it was smaller, and it was lighter, and a better email } \\
\text { system, so lots of people would have a Blackberry or } \\
\text { something, that was a much better email-driven phone. } \\
\text { So all of this was...those were probably the big two } \\
\text { things. The smaller and lighter, and the better email } \\
\text { functionality. }\end{array}$ & $\begin{array}{l}\text { Features determinant in } \\
\text { purchase and use decisions } \\
\text { Use accepted widely in } \\
\text { business } \\
\text { Data transfer a priority } \\
\text { Internet-Mobile } \\
\text { convergence }\end{array}$ \\
\hline $\begin{array}{l}\text { Social and Community } \\
\text { Meanings } \\
\text { Spatial Matrix } \\
\text { Technology } \\
\text { Value Propositions }\end{array}$ & $\begin{array}{l}\text { SS: By that time because it was very acceptable - } \\
\text { cellphones were acceptable. Having multiple } \\
\text { cellphones was acceptable. } \\
\text { ML: Everyone pretty much had a phone by then, didn't } \\
\text { they? Well, it seems like everyone had their phones, so } \\
\text { I didn't feel any cooler. } \\
\text { AF: Honestly, it was like it wasn't there one day and the } \\
\text { next day it was. It was like the social context that I was } \\
\text { in at the time changed and corresponding with that it } \\
\text { was like people's usage of the new technology and } \\
\text { adoption - it was just on this massive sort up upswing. } \\
\text { AR: It was new and it let you do stuff that you couldn't } \\
\text { otherwise do, so that was quite good. It was useful. } \\
\text { But it was just useful. There was no status kind of } \\
\text { attached to it. At the end of the day you could just } \\
\text { make a phone call, or text or play Snake. }\end{array}$ & $\begin{array}{c}\text { Status diminished } \\
\text { Ubiquity of mobile } \\
\text { Legitimation } \\
\text { Social Perception Positive }\end{array}$ \\
\hline $\begin{array}{l}\text { Social and Community } \\
\text { Meanings } \\
\text { Technology } \\
\text { Value Propositions } \\
\text { Needs } \\
\text { Spatial Matrix }\end{array}$ & $\begin{array}{l}\text { ML: I do text a lot though because that's replaced me } \\
\text { having to send emails at that stage, so shorter, quicker, } \\
\text { you can, you know...more convenient } \\
\text { DS: And I kept thinking 'If only I had a cellphone.' }\end{array}$ & $\begin{array}{c}\text { Mobile a means to manage } \\
\text { personal life } \\
\text { User buys text and calls } \\
\text { One-to-one contact }\end{array}$ \\
\hline $\begin{array}{l}\text { Social and Community } \\
\text { Meanings } \\
\text { Spatial Matrix }\end{array}$ & $\begin{array}{l}\text { ML: You started noticing the texts ... the behaviour in } \\
\text { groups when people were responding to texts. Like it's } \\
\text { starting to get worse when people were just } \\
\text { interrupting conversations just to check their phone, } \\
\text { check the texts, you know. }\end{array}$ & $\begin{array}{l}\text { Texts determine mobile } \\
\text { value } \\
\text { Proximity disconnect }\end{array}$ \\
\hline
\end{tabular}




\begin{tabular}{|c|c|c|}
\hline $\begin{array}{l}\text { Competitive Intensity } \\
\text { Value Propositions } \\
\text { Responsiveness }\end{array}$ & $\begin{array}{l}\text { ML: They (Vodafone) were very aggressive in their } \\
\text { marketing and they really tried to appeal to different } \\
\text { segments, you know. They thought about their plans, } \\
\text { so of course their plans appealed to me more because } \\
\text { they realised that people had different budgets. I } \\
\text { wasn't someone who used my phone a lot to phone } \\
\text { people and that, and so therefore I wouldn't want to be } \\
\text { paying a lot more for something that I wasn't getting. } \\
\text { AF: This new kid on the block, Vodafone, and the } \\
\text { competitiveness, or my perceived competitiveness, in } \\
\text { their plans. I saw that as a better fit for me who was } \\
\text { still calling a lot. I felt that I could actually support that } \\
\text { financially at the time }\end{array}$ & $\begin{array}{c}\text { Price determinant in } \\
\text { purchase and use decisions }\end{array}$ \\
\hline $\begin{array}{l}\text { Competitive Intensity } \\
\text { Value Propositions } \\
\text { Responsiveness } \\
\text { Social and Community } \\
\text { Meanings } \\
\text { Needs. } \\
\text { Information }\end{array}$ & $\begin{array}{l}\text { AR: Businesses were starting to grapple with 'do I need } \\
\text { my staff to be contactable all of the time' because at } \\
\text { that point in time businesses weren't expecting to get } \\
\text { you if you were mobile } \\
\text { RG: Everybody thought mobile phones were awesome, } \\
\text { didn't they? I mean it was just one of those things that } \\
\text { you had to have a mobile. And if you were in a business } \\
\text { you definitely had to have a mobile phone. I couldn't } \\
\text { be in business without a mobile. And everybody used } \\
\text { to say 'Have you got a mobile number?' and as if was } \\
\text { something like, you know, you're not a business unless } \\
\text { you've got a mobile number. }\end{array}$ & $\begin{array}{l}\text { Mobile creates new } \\
\text { management practices }\end{array}$ \\
\hline $\begin{array}{l}\text { Social and Community } \\
\text { Meanings } \\
\text { Legal and Economic } \\
\text { Institutions }\end{array}$ & $\begin{array}{l}\text { RG: I don't think she killed the other person but she } \\
\text { herself was killed, and I remember that was kind of like } \\
\text { a big... where you were just starting to see the negative } \\
\text { things coming out of cellphones. }\end{array}$ & Social Perception Negative \\
\hline $\begin{array}{l}\text { Social and Community } \\
\text { Meanings } \\
\text { Technology } \\
\text { Needs } \\
\text { Spatial Matrix }\end{array}$ & $\begin{array}{l}\text { RV: The ability to text was the most notable change } \\
\text { from not having a mobile phone. Calls were not that } \\
\text { interesting, were expensive, and required having } \\
\text { money on the phone. I didn't have much money at the } \\
\text { time. But you could text. } \\
\text { RV: It took effort, it took money, it was normally a } \\
\text { specific task-oriented thing. Probably a year or two } \\
\text { after that it started becoming more you were you } \\
\text { texting someone, you were having a chat, and then it's } \\
\text { grown exponentially since then }\end{array}$ & $\begin{array}{l}\text { Market expansion - digital } \\
\text { natives } \\
\text { Text becoming priority } \\
\text { No social status } \\
\text { Entertainment priority } \\
\text { Social connection priority } \\
\text { Proximity disconnect } \\
\text { Managing Space }\end{array}$ \\
\hline
\end{tabular}




\subsection{8 - 2014: Flexible Era - the Data Pipeline}

\subsubsection{Introduction}

This section analyses the performances of market actors in the New Zealand mobile telecommunications market during the Flexible Era. The Flexible Era is typified firstly by the convergence of technologies bringing communication and internet into a single mobile computing device, and secondly that these devices were Flexible whereby users could themselves readily modify their mobile telephones to suit specific needs beyond one-to-one communication. A further distinctive factor is the enhancement of co-creation of value whereby providers supply a data pipeline connecting users to content accessed through applications.

Competitive intensity amidst providers of devices led to the unveiling in 2007 of the iPhone by Apple, a manufacturer not of mobile telephones but of computers. The technological disruption of the iPhone, and the 'smart' phones developed by other manufacturers from within and without the traditional telephone construction industry, brought to mobile devices process capabilities, and hence functionality, previously associated with computers thus presenting a merging of telephone and computing market boundaries. The Flexible Era is thus marked by the user's purchase decision based not so much on the internal features of the device but on the devices's data processing capability and the user's ability to modify the device externally through installation of data-driven applications chosen to suit each user's specific and flexible needs. Indeed, otherwise identical mobile telephones could have very different functionality. The Flexible Era is thus epitomised by user purchases being measured by the quantity of data. Furthermore, one-to-one discrete as-required conversation became only one function of the Flexible Era mobile telephone: the mobile telephone had become a device for one-to-one, oneto-many, many-to-one and many-to-many communication via the internet. 


\subsubsection{The Market in the Flexible Era}

In 2008 there were 4.58 million mobile telephone users in New Zealand, representing 111 percent of the population. By 2014, this had risen to 5.3 million, or 122 percent of the population. The trends, as depicted in Figure 6-5, suggest total saturation of a mature market where new users were only a small percentage of the population, and that most purchases were replacement or additional devices for current users.

Figure 6-5Flexible Era: Mobile subscriptions in millions and as a percentage of the population

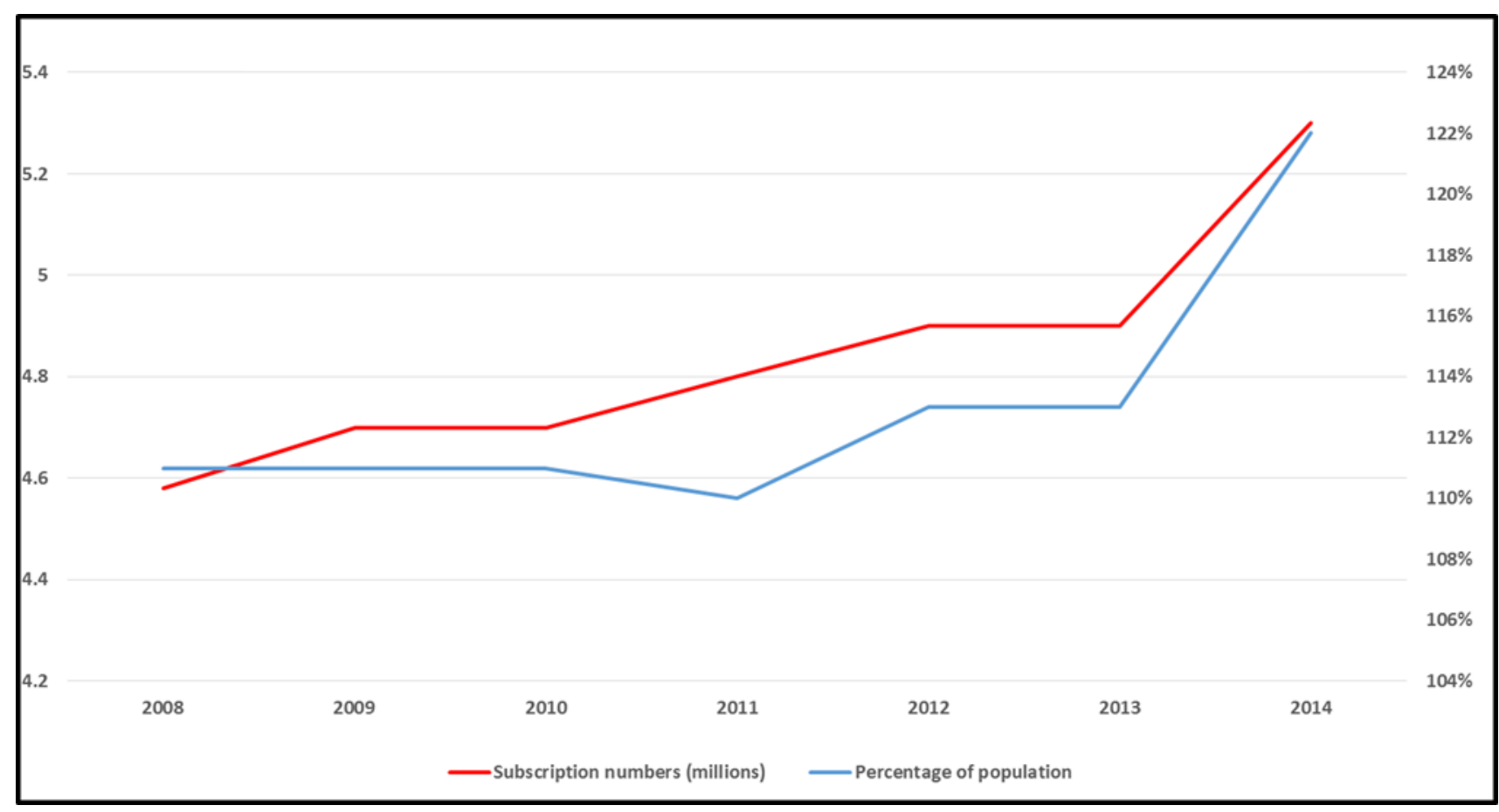

Except for 2008, Telecom total revenues fell every year from 2006 to 2015 . In part, reduction reflects the structural separation of Telecom's network, wholesale and retail arms which began in 2008 and was completed in 2012. Telecom's cellular revenues, however, continued to steadily rise from $\$ 875$ million in 2008 to $\$ 976$ million in 2014 . Of the 4.58 million users in New Zealand in 2008, 2.176 million were Telecom customers. The number of Telecom mobile customers fell during the Flexible Era to as low as 1.815 million in 2013 and rose to 2.178 million again only in 2015. The decline in user numbers, while revenues increased, reflects firstly the intensity of competition in the mobile market, and secondly the importance of mobile 
data whereby revenues per customer were increasing as mobile telephones were used across an array of applications (Commerce Commission of New Zealand, 2008, 2015; Spark New Zealand, 2014; Telecom New Zealand, 2008).

A further competitive influence was the launch in September 2009 of a third provider, 2Degrees using the Vodafone network. Primarily to compete against the low-cost offerings of 2Degrees, Spark launched its Skinny brand. Telecom was renamed as Spark New Zealand in 2014. The competitive impacts of 2Degrees on market share can be seen in Figure 6-6 (Commerce Commission of New Zealand, 2015).

Figure 6-6 Market share across the Flexible Era

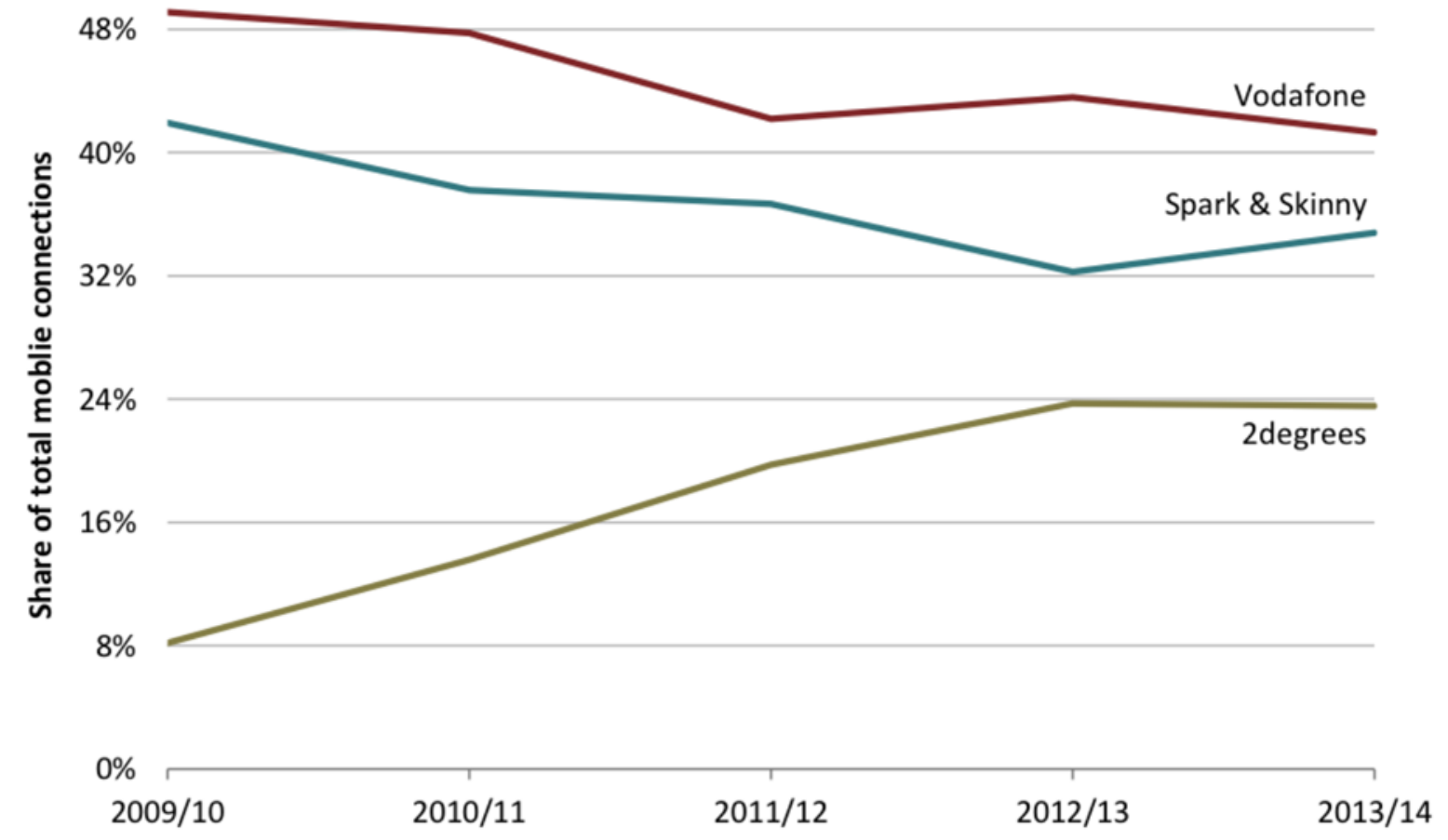

Having provided a background of the Flexible Era market, the next section provides a narrative outlining the performance of practice by regulators.

\subsubsection{Regulators - performance of practice}

The start of the Flexible Era coincided with the structural and operational separation of Telecom, reflecting ideologies of 'hard' regulatory intervention for political and economic 
purposes. As the new market structure embedded, and ideologues departed, the regulatory pendulum returned to the centre.

\section{Market shaping - the regulator}

M2 lost his role as Minister when in the November 2008 general election the Labour Government was ousted by National. In the interview, M2 remained convinced of the appropriateness of interventionist regulation.

We changed the game. The economic consequences were frankly exactly as we had hoped and predicted, which were the investment levels in the industry roughly doubled. Market entrants dropped the price and increased the output. All of these measures had the same objective which was to increase effective competition in the marketplace. Yet because of the high levels of dominance, it required a public policy input to achieve that market proxy. So it's a very classic example of pro-competitive regulation. (M2, 2016, p. 3)

From 2011, discussion about telecommunications declined substantially in the Commerce Commission's annual reports. Of note, is that the regulation of telecommunications had simultaneously disappeared from the public sphere.

The political centre of gravity had moved because the public got what they wanted broadband. It became an assumption. (M2, 2016, p. 4)

The era of hard regulation did not end with M2's departure - the legislated structural and operational separation of Telecom and other initiatives continued and R2 remained in office until he retired in 2011. R2 also argued of the necessity for intervention.

We got unbundling, we got separation. Who would have thought that we would have achieved that much so quickly? The change is going to be even faster because we are leading the convergence challenges because we will be right up there with availability of very fast broadband. By 2020, the gigabyte will be standard service and probably 70 percent to 80 
percent of broadband will be over fibre plus $4 \mathrm{G}$, probably $5 \mathrm{G}$ by then, and these blur the market distinctions. (R2, 2016, p. 7)

Regulation is falling away because we've broken that vertical integration. We've got the separation. That's what regulators internationally have said, that we've solved the access problems. (R2, 2016, p. 8)

The 2008 to 2011 period was marked by the Telecommunications Commission evolving from interventionism to questioning the requirement for regulation in the mobile market, and in 2011 the Commission noted that increased competition, and continued substantial growth of user uptake of core regulated services, meant regulation could be removed in relation to resale services (Commerce Commission of New Zealand, 2011, 2012, 2013, 2014a).

\section{Neo-regulation}

R3 was appointed Telecommunications Commissioner in 2011. The regulatory questions now centred whether telecommunications should be regulated as a network in the same manner as electricity supply, while monitoring for future competitive bottlenecks. The regulatory dilemma was how to determine whether poor performance by new actors was due to anticompetitive practices or to internal factors such as poor management, and further how to control competition while not damaging investment incentives (R3, 2016).

International standards as a measure of competitive performance in New Zealand had been used to justify intervention, but were in the later Flexible Era under scrutiny. In 2011, for example, the Commission reported that the level of competition in the mobile market had increased with the launch of 2 Degrees but that mobile voice usage remained low by international standards. The Commission had, however, offered no internationally comparative data regarding the extent of use of other mobile applications such as data use or text (Commerce Commission of New Zealand, 2011). By 2014, however, the problem with 
international comparisons had been recognised in that metrics, such as call minutes, may not accurately reflect usage driven by national peculiarities - New Zealanders tend to talk about a quarter of the time per person on their mobile telephones than Americans but instead use their mobile more for banking and online purchasing. That the United States model, with its emphasis on talking, was no longer appropriate was noted by R3 (R3, 2016).

It's not the right measure where the market's going, it's just a quirky thing that people are using their fixed line at home less and less for talking. They're talking more on their mobile but the total amount of talking is still tiny. And all the traffic, the data traffic, is now nothing to do with voice. $(\mathrm{R} 3,2016, \mathrm{p} .4)$

Fresh regulatory challenges may emerge, however, if virtual global actors further developed remotely controlled mobile hardware that matched their specific artificial intelligence software to the exclusion firstly of other manufacturers of computer materials, but then to the exclusion of the retail capabilities of network providers. The market power of global actors would be such that networks, such as Telecom or Vodafone, would have little choice but to comply with the prices and conditions offered. The competitive challenges in mobile that arise suggest new era of neo-regulation - that is, regulation across virtual space.

The things that worry me the most are things like the loss of competition that you have. Some of it is the scale effect, where it doesn't need to be bad behaviour on someone's part, it's just that if the whole of future network design is software, it might just slip through your fingers, and it's not Spark and Vodafone anymore it's Google or somebody else who's running the network. (R3, 2016, p. 11)

\section{Market convergence}

The convergence of mobile and the internet and the blurring of lines between fixed and mobile concerned all three Telecommunications Commissioners. In the interview for this thesis R1 
pondered whether there was by 2014 any significant difference between the mobile and fixed data market (R1, 2016).

There's been a significant coming together, convergence, and I think potentially there's a single data services market. There is potentially a single calling market as distinct from a mobile calling market. So the question is, is there a mobile services market at all in New Zealand today? I think it's arguable there is not, that there is simply a series of functional markets, which can be described by the user experience. (R1, 2016, p. 13)

This section highlighted the practices of regulators during the Flexible Era. The following section provides analysis of the practices of providers in terms of the institutional practices and the apparent movements in parameters.

\subsubsection{Regulators - parameters and institutional practices}

The Feature Era was notable for the ideological movement towards interventionist regulation. The Flexible Era was marked by a transition to a more moderate regulatory approach, where regulation was withdrawn where possible, where suggestions surfaced that international metrics might not always be relevant, and that regulators needed to examine not just the extent of use, but the type of use, when designing regulatory interventions for mobile. Furthermore, regulators had in the Flexible Era to consider more than competition whereby regulation had also to encourage investment. This reflects substantial changes in the Legal and Economic Institutions, and Social and Community Meanings, parameters.

The Flexible Era was marked also by the recognition by regulators that future challenges may be rooted in disruptions from global content providers possibly not currently in the mobile market. R1 and R3 noted that international actors were developing sufficient power to dictate markets and yet may be outside the ambit of any particular market regulator, and which might stymie competition to the detriment of consumers. A neo-regulatory era may thus be emerging with providers and regulators not only co-operating but also exploring 
regulation beyond traditional geographic market boundaries and preparing instead for engaging in a purely virtual space. This is a distinct shift in in the Spatial Matrix parameter in terms of conceptualisation of market boundaries.

The neo-regulatory phenomenon can also be drawn from what disappeared from market dialogue. Previous eras, particularly the Feature Era, were in part defined by the substantial interest shown by the public and hence by regulators. Media editorials and correspondents who, in stridently calling for more regulation to reduce prices while simultaneously demanding more access at greater speeds, helped interventionist regulation become socially and politically legitimated, have since 2011 been silent. The Commerce Commission annual reports say little of substance about the telecommunications sector. Parliament no longer devotes energy to legislation on telecommunications. The reasons for silence were not explored in this thesis, but may have occurred because of perceptions that the regulatory job is done and that sound competition exists, or it could be because those of strong ideological persuasion, at either end of the spectrum, have moved on. It could also be that the regulatory and commercial challenges thrown out by globally disruptive actors are not yet seen as negative in the public sphere (Blanning, 2015; Eder, 2006; Eisenstadt \& Schluchter, 2001; Morley \& Robins, 1995) and that new regulatory interventions are thus not yet desired. Table 6-7 describes the parameters, performances and institutional practices for Regulators in the Flexible Era.

Table 6-7 Regulator practices in the Flexible Era

Legal and Economic Institutions
R2: Who would have thought that we would have achieved that much so quickly?
Markets shaped by the

regulator

(hard regulation) 
Legal and Economic Institutions Social and Community Meanings
R3: The legislation...says we want you to promote competition as much as possible in the sector... but when you do that, think about what you might be doing to people's incentives to invest the hardware in the first place if they know that tomorrow you're going to give it away to somebody else, or at least force them to wholesale it so they only ever have half the traffic or something, and they were counting on some of the downstream profits.

R3: The things that worry me the most are things like that, the loss of competition that you have. Some of it is the scale effect, where it doesn't need to be bad behaviour on someone's part, it's just that if the whole of future network design is software, it might just slip through your fingers, and it's not Spark and Vodafone anymore it's Google or somebody else who's running the network
Regulation to encourage investment as well as competition. (soft regulation)
Legal and Economic Institutions

Social and Community Meanings

Technology Spatial Matrix
Markets disrupted by virtual forces. Neo-regulatory era

This section described the practices of regulators in the Flexible Era. The Flexible Era began with regulatory interventions that shaped what regulators perceived as a single market bounded by a rigid national border. By the end of the research period, the regulator was exploring a neo-regulatory phenomenon, driven by the emergence of global actors likely to shape markets and competition in future irrespective of national boundaries. The section now turns to the performance of practice by providers in the Flexible Era.

\subsubsection{Providers - performance of practice}

This section provides a narrative outlining practices by providers in the Flexible Era. Of particular interest are the emerging commercial priorities for Telecom. Telecom annual reports, for example, no longer referred to a "letter to shareholders" but instead reflected new understandings placing consumer value as the priority in protecting market share in an era of low numerical growth; where competitors were no longer predominantly local but global; where tolls (national and international) no longer provided the bulk of revenues; and where the primary value propositions became access to a data market defined by consumers. 


\section{Structural separation}

The structural separation of Telecom into two companies - Telecom and Chorus - was completed in March 2008 and structural separation was finalised in 2011. The separation was estimated to cost Telecom more than $\$ 200$ million over four years with ongoing costs of $\$ 40$ million a year. Local loop unbundling and co-access would further negatively impact on company performance (Telecom New Zealand, 2007). In 2008, Telecom engaged Dr Paul Reynolds as chief executive, a decision based in part on his involvement with British Telecom during its similar deconstruction, and through whom relationships with the Government could be improved. In the interview for this thesis, M2 described where Telecom's previous chief executives and chairman had been adversaries at a personal level but chairman Wayne Boyd and Dr Reynolds had been helpful in negotiating and then managing separation (M2, 2016).

\section{Market merger}

Simultaneously with legislated structural changes, Telecom moved to improve competitive performance through a third-generation WCDMA mobile network entitled XT Mobile. The existing telephone network was replaced and all services provided over Internet Protocol (IP). The XT Mobile network was in place by May 2009. In September 2009 2Degrees entered the market (Telecom New Zealand, 2009, 2010). Further evidence of the dynamic nature of the market was that by 2011 all Telecom mobile post-paid plans included an allocation of data per month. Moreover a new phenomenon was developing whereby internet content providers such as Amazon, Apple, YouTube, Google and Facebook were using the networks of Telecom and others to connect directly with users.

The impacts of technological change since the iPhone unveiling in 2007 were reflected in New Zealand where of the 4.9 million connections in 2013, some 2.5 million were smartphones and the average user was reaching for their device 150 times a day. By 2013, the 
number of cellular connections declined, in part due to the closure of the old CDMA network, but revenues grew due to increased smartphone penetration and data use. Telecom predicted that by 2017 mobile data traffic would grow eight-fold - equivalent to 32 million texts being sent each second (Commerce Commission of New Zealand, 2015; Telecom New Zealand, 2010, 2011, 2012, 2013). In a further merging of previously distinct markets and industries, such as entertainment, IT services, and information services, and the changing nature of the underlying technology, Telecom's 2009 annual report highlighted the firm's movement from being solely a provider of communications to also being a provider of information technology and data services (Telecom New Zealand, 2009)

\section{Global competitors}

The 2009 Telecom annual report also noted the telecommunications industry in New Zealand shared challenges faced by telecommunications companies globally. The most significant trends were firstly the adoption of the IP standard for all communications including voice and data over internet networks rather than having separate network methods, secondly high-speed broadband networks would be available across mobile and fixed lines, in turn fuelling the growth in applications and services requiring high-speed connectivity and management systems, and thirdly that all of these capabilities were now available to mobile, and with mobile-landline interface. A fourth trend was also noted: that value in the consumer and business sectors of the telecommunications industry would shift away from integrated networkdelivered services towards internet-based global content and applications where international actors, such as Amazon, Apple, Google, YouTube and Facebook, would use their global scope and scale advantages to win customer preference. In response, providers such as Telecom, were developing as content and application aggregators that allowed exclusive supply relationships with the global content providers, also known as "over-the-top" providers. 
(Telecom New Zealand, 2009). Meanwhile users were evolving higher expectations of mobile and the internet.

In 2014, Telecom signalled its changing strategic direction by changing its name to Spark New Zealand. Telecom had been formed 27 years earlier when mobile phones and the internet did not exist (Spark New Zealand, 2014).

The architect behind the changes of name, brand, and direction was P2, who returned to the company in 2012 as chief executive with a mandate for change in an environment where technologies were fast changing, where customers were struggling to understand their options and opportunities, and where competitive forces were emerging on a global scale. While regulators perceived the telecommunications market as bounded by New Zealand's coastline and price, those within the industry, however, saw no such parochial constraints as new value propositions arose from international providers of new services and applications. The mobile market in New Zealand, from a provider perspective, is thus substantially larger, more competitive, and more complex, than regulators such as M2 and R2 perceived. The regulatory impacts on providers thus extend beyond the intended large scale change of separation, as will be discussed next.

\section{Market shaping - users}

In the Flexible Era data technology, and its applications by users, had taken over from the regulator as the shaper of the mobile market. From 2000 onwards there were essentially two markets - larger businesses and the rest - and the rise of mobile had been founded on managing connections and managing productivity. The early internet was about email and not much more. The value propositions for Telecom and its competitor providers were very much about communication and little else. By the Flexible Era, business and private users were keenly exploring the new service concepts (P2, 2016). 
From 2010, you were starting to see more of a view of services enablement. Now it's very clear. It's entertain me, it's provide me music, video, help me run my home or my business more efficiently, lower my cost, get me more flexible with software in the cloud. It's moved more into make my life better, make my business more effective. Technology's definitely driven all this. It's always been you don't know what you don't know until someone turns up and shows you. (P2, 2016, p. 5)

A further actor in reshaping Telecom was its former chief financial officer, Mark Verbiest, who returned to the firm as chairman in 2012. The first, joint, statement Verbiest and P2 made in an annual report prioritised not tolls, nor shareholders, but mobile. They provided a description that reflected the new understanding of mobile as "voice services, text and multimedia messages, wireless application services, wireless data services, paging, cellular equipment sales and other related mobile network services" (Telecom New Zealand, 2012, p. $3)$.

In the report, P2 said of his taking up of the role of chief executive: "I am very ambitious for New Zealand and I believe Telecom will play a vital role in New Zealand's success on the global stage. I will be working hard to ensure we deliver both for you, our shareholders, and for the country." (Telecom New Zealand, 2012, p. 4) Important in his statement is the reflection for the first time of Telecom prioritising the user as the focus of corporate effort.

In the 2013 annual report, P2 and Verbiest signalled Telecom's core strategy in markets subject to perpetual change. Telecom would focus on growing mobile share and holding share in the broadband market. The strategy would require not only being cost-competitive, but retaining customers through value propositions beyond price. (Telecom New Zealand, 2013). The key, in what P2 and Verbiest described as a data and mobility revolution, was delivery of data access and data connectivity while meeting the "anywhere, anytime" user expectation. In a world where demand for information was measured in gigabytes, data - and not mobile or 
landline connection - was now central to Telecom's business and revenue structure (Telecom New Zealand, 2013).

The 2014 annual report was the first for the newly renamed Spark New Zealand. The report began with "Inspired by customers". The chairman and chief executive, in their joint statement, first mention shareholders on page 12 where they note that the focus on users will grow shareholder value - the inverse of the 1990s reports and priorities. The 2015 annual report focused the growing demand for mobile and broadband data as fixed line revenues continued to decline, and mobile revenues increased by 4.4 percent, equivalent to $\$ 43$ million. The revenue growth reflected an increase of 172,000 connections. Indeed, for the first time since 2003, Spark became the market leader in mobile in New Zealand.

Regulation was barely mentioned in the Spark reports. At the start of the research period in 1992, Telecom focused on shareholder value as a provider of fixed line local and tolls services. By the end of the research period in 2014, Spark focused on consumer value as a provider of a data pipeline, where users bought access to the pipe for whatever purposes they opt for (P2, 2016). The user was now the shaper of the mobile market, as $\mathrm{P} 2$ described in his interview:

We're the intermediary. We're the bundler, the carrier. We don't create the stuff, we just present it. Our view is shaped by how a customer wants to consume it, to pay for it. The terms to service and manage it are changing rapidly. To make it accessible, and to get a large scale uptake, you have to listen to your audience and say, well how is that going to work? How does it have to be delivered? How do you manage it? We help those firms in the centre to get consumers to take it.

Apple phones wouldn't be very successful if we hadn't changed the way plans and mobile work. Today we're rapidly shifting from plans which were minute, text, and megabyte based 
to plans which are just price points where you get an amorphous bundle. If we hadn't done that, most of the iPhones would sit there and people would be afraid to use the data. They would turn it off. Whereas today you can solve that. (P2, 2016, p. 5)

The world has been surprised by how much more capable these services get and how quickly. You tend to underestimate impact and demand for it. So we now just believe without knowing why...(P2, 2016, p. 6)

This section highlighted the practices of providers during the Flexible Era. The following section provides analysis of the practices of providers in terms of the institutional practices and the apparent movements in parameters.

\subsubsection{Providers - parameters and institutional practices}

The early Flexible Era was marked by the structural separation of Telecom, where the mobile telecommunication was shaped not by competitive efforts but by regulatory intervention. The end of the Flexible Era was marked by neo-regulation where domestic regulatory interventions dropped out of provider and user priorities but where new international challenges emerged. The Flexible Era was also marked by the substantial amendment of commercial priorities for Telecom and its successor, Spark. By the end of the Flexible Era Spark annual reports no longer prioritised a "letter to shareholders" but instead reflected new understandings that placed consumer value as the priority, and as a means of protecting mobile market share in an era of low numerical growth; where competitors were no longer predominantly local but global; where tolls (national and international) no longer provided the revenues of primary importance; and where the primary value propositions focused on access to a data market defined not by providers, or regulators, but by users. Indeed, the merger between mobile and internet markets appeared complete. Providers like Spark were thus focused on meeting user needs via a data pipeline of sufficient size to manage an unknown level of demand for value propositions that do not yet exist. 
Table 6-8 describes the parameters, performances and institutional practices for providers in the Flexible Era. Increased Competitive Intensity in mobile and internet provision through domestic and international competition is reflected in Value Propositions, and Social and Community Meanings, which combined have impact on Spatial Matrix. On the one hand, Spark's market rivals and influencers are international organisations from outside traditional telecommunications who cross the merged boundaries of mobile and internet. On the other, Spark's is providing highly specific services to micro-markets comprised of business and consumer segments irrespective of any physical barrier, and where receiving a podcast from New York through a hand-held device while walking down a Wellington street is not only normal, but socially acceptable and desirable in a constantly connected world. In the Flexible Era, mobile market boundaries are defined neither by geography nor price but are determined by the Spatial Matrix of users.

Table 6-8 Provider practices in the Flexible Era

Legal and Economic Institutions

Legal and Economic Institutions

Technology

Needs

Value Propositions

Information
P2: The interventions of the regulator became the dominant factor.

P2: There was so much value at stake as the incumbent, we didn't have any choice but to dedicate the majority of our mind share to managing the regulators. Decisions, choices, pathways

P2: This is all just going to keep going at these sort of rates for a long time yet. Look, every home's got between 10 and 50 megabits a second now. That's all you need because a HD video stream only needs 6 , so it's obvious you don't need any more. That's how we would have thought it through a few years ago. Today, no one would say that because we would just know that's probably going to be wrong. There will be things that need hundreds of megabits for the way the households will develop and the multiple things going on at once.

\author{
Markets shaped by the \\ regulator \\ (hard regulation)
}

\author{
Markets shaped by \\ technology and Users \\ Post interventionist era \\ (soft regulation)
}


Competitive Intensity

Technology

Needs

Value Propositions

Technology

Social and Community

Meanings

Competitive Intensity

Competitive Intensity

Spatial Matrix

Competitive Intensity

Value Propositions

Technology
P2: We're the intermediary. We're the bundler, the carrier. We don't create the stuff, we just present it. Our view is shaped by how a customer wants to consume it, to pay for it.

P2: I will be working hard to ensure we deliver both for you, our shareholders, and for the country.

P2: It's 'entertain me', it's 'provide me music, video, help me run my home or my business more efficiently, lower my cost, get me more flexible with software in the cloud'. It's moved more into 'make my life better, make my business more effective'. Technology's definitely driven all this.

P2: It was a year in which Telecom made some deliberate calls: to grow share in the mobile market, hold share in the broadband market...
Markets Shaped by Users

Users buy

access to a data pipeline

\author{
Commercial Priority \\ Consumer Value/User \\ Needs
} that are delivered across a variety of access,

transportation and service management platforms.

Value Propositions

Spark: The global and local operating environment provides context for our results. In recent years, we've seen extraordinary growth in the demand for, creation of, and accessibility to, information. This is changing consumer behaviour and disrupting commercial models at an unprecedented rate. There are a growing number of 'over-the-top' (OTT) players offering services and applications delivered over existing telecommunications networks and the internet.

P2: Today we're rapidly shifting from plans which were minute, text, and megabyte based to plans which are just price points where you get an amorphous bundle.

Mobile and Internet Merged

Telecom: "Telecom is a participant in the New Zealand and Australian communications and information technology industries. Broadly, the communications industry can be defined as fixed and mobile calling, messaging, and managed and unmanaged data services

Commercial Priority Competition Global

Commercial Priority Mobile Market Share

Commercial Priority Mobile/Data/Content

(Tolls no longer mentioned)

Spatial Matrix Information Competitive Intensity

Market Convergence 
Social and Community

Meanings

Value Propositions.
Owing to the changing nature of the underlying technology, the communications industry is developing significant overlaps with other previously distinct industries, such as entertainment, IT services, and information services (search, classifieds and online trading, and online display)."

P2: Telecom was Telecom, we didn't have anything else. Today we have to slice down to a lot of sub-markets, and increasingly today we use sub-brands, so we're a Micro Markets emergence multi brand company. We have multiple brands in all markets, and they face different markets.

\subsubsection{Users - performance of practice}

The Apple iPhone was not the first smartphone (Budd, Karidis, \& McVicker, 1999) but the iPhone's introduction in 2007 was remarkable for several reasons. Firstly, an actor from outside telecommunications substantially disrupted the mobile market with a device that could be adapted by the user through external applications to suit the user's changing and specific needs. Other manufacturers, including several from outside the mobile market such as LG and Samsung, were compelled to match Apple with their own flexible value propositions. Secondly, the Flexible Era mobile communications device had not only merged mobile telephones with computing devices, but also had fully merged mobile technology with the internet. There was a further profound affect - users were expecting, and expected, to be constantly connected through their flexible device. That is, be instantly available and responsive to anyone and everyone at any time. The merger of mobile and internet through specific applications therefore took communication beyond one-to-one to a new realm where many could connect with many instantaneously and continuously.

The Flexible Era focuses on constant connectivity, where the smartphone is an extension of the self and used continuously for communication between individuals and a broad range of constituents and communities by which individuals define themselves. Constant 
connectivity evolved to the extent of proximity disconnect where mobile telephone connection with people at a distance was at the expense of disconnection from people and things nearby. User performances also reveal concerns about pervasive social impacts of mobile telephones, particularly surrounding personal privacy being impinged upon by constant connectivity that is not always voluntary.

The section concludes with narrative from the two youngest users who were interviewed. Their practices provide deeper insights into mobile telephone use in the Flexible Era from the perspective of digital natives for whom a mobile device has been a constant companion since childhood. Their practices thus provide the strongest contrast with users of the Fundamental Era, AS and SS.

The merger of mobile telephone and mobile computer

The Flexible Era smartphone released users from their laptops, notebook computers and peripheral devices. Some users recognised early the potential of the Flexible Era mobile device.

It's just a small computer that makes phone calls. The smartphone had the slight sense of "The computer has come to the phone world and isn't that fun?". (PT, 2016, p. 4)

You could meaningfully access the web and aspects of its richness - not the same as a desktop experience, but way better than that crummy Windows phone that didn't really do anything useful. (PT, 2016, p. 27)

The technological difference for users was not just that a Flexible Era device had more computing and processing power.

The phone now had an operating system just like a computer on which you overlaid functionality including the phone feature. In effect it became just like a computer that was really small but you could talk on. You still bought it because the primary function was that 
you want to talk to somebody, but it now did all these other things at the same time. (AR, 2016, pp. 8-9)

RV opted not for an iPhone but instead bought a Nokia 5800 and in so doing learned a critical difference about Flexible devices.

I bought it over buying an iPhone because the numbers on paper were better, and it had a better camera and a faster processor where it supposedly was a better phone. It really wasn't. With computers, you bought the biggest numbers, because that made a big difference. With this it was so much more about the software than what was powering the software. And that was a big shift. (RV, 2016, p. 16)

\section{User competitive intensity}

The social attitude of mobile telephones being mundane had increasingly pervaded the Feature Era. For a short time in the Flexible Era an iPhone once again granted status to a mobile device user because of the cost, and because of multiplicity of new capabilities and applications. This status faded completely as competitive intensity among providers ensured increasingly capable and cheaper devices became available.

When I got the first iPhone, I remember that slight feeling of self importance. It was like Oh, wow, I'm one of the first guys around here to have a smartphone. I mean by today's standards it's laughable isn't it? I mean everybody's got one. (PT, 2016, p. 4)

I don't do brand communities in a big way, like I don't feel a strong compulsion to go out and get the brand new iPhone 6S just because everyone and his dog's got it - it's one gram lighter and it has like a high mega pixel for a camera. I really don't play that game. (AF, 2016, p. 16)

In the narrative later in this section, NL recalled that when she received the latest iPhone as a present, her friends with older devices hardly noticed. There was little or no status, or even interest, in whatever device was being carried. 


\section{Flexible mobile in-use}

The Flexible Era substantially changed the way users interacted with their mobile telephone and with each other. Uses that had never previously been available, or ever considered, suddenly became of critical importance either real or perceived.

It saves you carrying a whole lot of other stuff. I didn't have to carry a camera any more, and that was a really big step. As a road safety person you're always out there with the communities. I might see something and say "that's really bad" - click - I'll take photos, take it back to work and say "Hey guys, go and sort that". (RG, 2016, p. 23)

I still carry a street map because I like a street map, but if I am in trouble I can find where I am in here (holding her telephone), find how to get from A to B or whatever in that. (RG, 2016, p. 25)

$\mathrm{AR}$, as an engineer, instinctively planned ahead and in the past insisted that whenever his family separated in a city that there was a prescheduled rendezvous, with fall-back positions and times if necessary.

Pre everybody having cellphones it was "I'll see you here at such and such a time, and we'll work out what we're going to do." There was always a bit more forward planning and options. Whereas as soon as people became more contactable, you didn't worry about that. You just sorted it out on the fly. (AR, 2016, p. 7)

"And when I say "on the fly", instead of being just restricted to around the hotel or something, you could go "that's only three blocks away, we could go there". You could see things further. (AR, 2016, p. 11)

For AF, the Flexible Era mobile device opened a new vista of contacts and groups with whom he could communicate to share mutual interests. He was no longer by himself when out mountain biking but part of an instantly and constantly contactable community with whom he 
could share experiences. The participation with those communities - often comprised of people he had never met - made the experience far more meaningful.

I quickly cherry-picked apps that worked for me, or were a bit of a fit with my lifestyle. I starting used Instagram a lot and documenting things that (his wife) and I were doing. There was an app called Strata, which was for a time my probably heaviest use app. It mapped my run, you know, as a runner and a cyclist. I was using it to track my route. It's a social app as well, so people follow you and you follow people, and you can see similarly where they've run or ridden, and segments of the routes that they've taken. And so yeah, probably for two years I was a very heavy user of that, and it was quite an intensive app. Instagram, Facebook. Yeah, I'm sick to death of Facebook but I'm at a point now where it's a necessity, particularly considering what we're travelling overseas - for family to keep tabs on what we're doing. (AF, 2016, p. 18)

RV became a very heavy user of Flexible Era technology, particularly for communication beyond one-to-one.

The fact that I charge it twice a day says I use it a hell of a lot. It's normally on the charger by around lunchtime. Texting (his partner) because she's away. I'm staying in constant contact with a small group of friends. We've got group chats on Facebook, things like that, so there's always things happening. It's my mini-computer in my pocket. I deal with emails all the time, so with the majority of my emails I'll reply to them off that - I won't reply to my computer any more. I get all my news off it, so Facebook, Twitter, Newsreaders - I can flick through those, I can get breaking news, I get notified when something happens in the world. I do a large amount of my (academic) article reading on there, possibly even more so than my iPad now. I still use my iPad for sitting down and having a concerted "I'm going to do this" session, but the majority of my quick flicking through news is now my iPhone. That's been growing steadily over the last four years. It's increasingly becoming a consumption tool for much more than 
just messaging. Messaging is almost a side function of it now. And were I single it would probably be a complete side function. It would almost be unimportant. (RV, 2016, p. 20)

For many users the Feature Era mobile telephone became a device for sharing - constantly sending every last event in their lives to many people via Twitter, Facebook, Instagram, or similar, and receiving material from users within their group of connections. Group boundaries overlap, meaning shared material often was relayed well beyond what the originator may have intended, and responses may be received from users far removed from the anticipated audience. For some, the relay of content is welcomed. For others, less so. RV said he rarely shared content. He is careful to maintain his on-line image.

Once it's out there, it's out there. I probably used to share a lot more and the realisation that it's always there, and someone will always find that, has grown in me. My tolerance for that has fallen completely. The sheer amount of data tracking - big data - surveillance of data - I dislike. The commercial use of the data, Government use of the data, just sucking away at the data, I have objection to. So the easiest way of dealing with it is not to contribute the data. And I think it's narcissistic to a ridiculous level to want to fill the internet with photos of yourself, read comments that everyone makes and, the "likes", and count them. If I want to share something I won't share a status about an article. I will forward the article to a friend who I think it's relevant to, and offer my insight or my viewpoint, and then have a discussion that way rather than just shouting at this mass of people most of whom don't care. (RV, 2016, p. 22)

\section{Expectations}

As users evolved in step with technology and the value propositions on offer, user expectations also evolved. Users moved from the Fundamental Era delight in making telephone call when walking down the road to Flexible Era dissatisfaction with their mobile internet data speeds, and dissatisfaction with each other if constant connectivity was not maintained. 
The whole point of the thing was to have a browser and be connected and have email and so on. So speed was an issue. People somehow were dissatisfied. (PT, 2016, p. 22)

Things become far more real time. It's just far more expected that you can be got hold of if you need to be got hold of. You used to write a letter to a manufacturer somewhere in America or Europe. "Dear sir, l'd like my transformer painted green." And it would take three weeks for the letter to get there. And they'd do something with it. So seven weeks later, you're going "ah yes, he's agreed to the green transformer". Whereas today, if you haven't got a reply within four hours.... (AR, 2016, p. 11)

\section{The cost of constant connectivity}

Costs in real terms of mobile devices and their use declined during the Feature Era due to competitive intensity between providers. An aspect of the Flexible Era was the reversal of this trend, where users were prepared to pay the high cost of device purchase and the data pipeline access they needed for operation. RV purchased an iPhone 3GS at the time it was a highly desirable Flexible device.

" $\$ 1,350$ for a phone! That seemed at the time this massive, huge, expenditure. That was just the beginning of getting a new one every year at that same value. It's actually become normal, and that's become the benchmark for a large number of people buying phones. I mean half my friends have iPhones so they all spend $\$ 1,000$ on a phone as well. So it used to be you'd buy this $\$ 200$ Nokia and that was enough, and now it's all a race to see who gets the next $\$ 1,000$ iPhone the quickest. What happens if you don't get one? I don't know. I haven't found out. (RV, 2016, p. 18)

\section{Constant connectivity}

Constant connectivity appeared to users as both negative and positive. The full implications may not emerge until users become fully aware of the potential of the technologies embedded 
in a Flexible Era device. For many of the users interviewed, however, constant connectivity was almost like an addiction, a compulsion to be engaged with someone or something.

I feel more accessible. I feel I need to be accessible. I don't want to drop off the grid. (PT, 2016 appendix p1)

I travel with my laptop, my Kindle, my iPad and of course my phone. (ML, 2016, p. 30)

By 2009 RV had a Flexible telephone and found connectivity substantially increased. For the first time he had email capability on his mobile device. The camera was of sufficient quality that taking and sharing photographs was feasible and enjoyable.

It evolved to where I suddenly became always contactable. The phone was always charged, it was always on me. I wouldn't leave it behind. I would notice when it wasn't there. Was that good? It felt good at the time. The fact that I'm always contactable to everyone can be a pain, but at the same time I think the point where expectations have always been contactable has diminished again. Everyone is at that hump of "Oh my God, everyone can email me at any time of the day or night. It's on my phone, I'll see it. They'll know l'll see it" to "Actually I can ignore that email. I can deal with it tomorrow or I can leave it for a bit. I can respond to it later". Text messages...it used to be if someone hadn't replied within five minutes you'd call the police and wonder why they hadn't responded. Now if someone doesn't reply for five minutes that's normal. You filter your text messages. You say “Okay, this is from someone else. I'll leave it for now - I'll talk to them later". (RV, 2016, p. 17)

Not every aspect of constant connectivity was welcomed. For some uses it was intrusive, for others annoying, and for some pointless. Everyone interviewed felt they were engaged in the connectivity process whether they liked it or not.

I am connected to people for the sake of being connected to them. I'd have friends on Facebook that I probably wouldn't even look twice at on the street. I have 400 and something 
of them. I probably don't know what half of them look like any more, but that's connected for the sake of being connected. (RV, 2016, p. 24)

RV said the problem of constant connectivity was not the process itself, but that his device snaps him out of his physical space into another place where he has to deal with a problem. (RV, 2016). SS grieved that the quantity of communication had increased but not the quality. It was communicating for the sake of communicating and not because anyone had anything worthwhile to say, partly because connection was expected to be instantaneous.

The communication is not satisfying. It's voluminous. But it is surface, you know? It is not serious. (SS, 2016, p. 13)

SS maintained contact with three or four sets of old school and university friends, not because they were close to him, but because someone thought to create a WhatsApp group.

Mostly it's about drinking and partying. Do I need to be in touch with all of them? No. Do I extract myself from the group? No. Why? Because I have a vicarious desire of seeing what is happening, but I'm not participating. I've got all these groups. But the ones that I want to be in touch with I'm not in touch with. (SS, 2016, p. 27)

Because of this technology people know each other's birthdays, and then you will start wishing somebody “Happy Birthday". I can't even remember the fellow's face. (SS, 2016, p. 29)

Just as the user was looking into the lives of others, others were looking into their life, and sometimes without the user's awareness. It was becoming impossible to manage the extent of engagement.

As long as I exist in society now I have to give up my anonymity. My personality is no longer my own, it is for everybody to see. It is no longer that you have to experience me personally to know me, now everybody can know me. I actually don't want anything (from the 
technology), I would rather have it go back into its worm-hole and not come out again. (SS, 2016, p. 30)

Other users, such as AF, made conscious moves to reduce their connectivity.

I just move my phone, and I have no issues, you know, when I'm at work or in business, I'm turning my phone upside down and effectively blanking people or screening people. I do that quite easily. (AF, 2016, p. 16)

I was involved in a lot of ongoing conversations around the different communities that I'm involved in, the little cliques and stuff, and so I was really engaged in conversation at any given time in all of those groups. I've shrunk those cliques considerably and I'm much more pragmatic with the conversation, much more discerning with the conversations that I get involved in. There are a lot of conversations I walk away from. (AF, 2016, p. 18)

Life is really simple when you can just switch off at home. What is so important that I need to know? That I really need to know? Who would have called me? Some new revelation? Superfluous usage I think has dropped right off. (AF, 2016, p. 21)

\section{Proximity disconnect}

Some users interviewed were concerned at the extent that friends, colleagues and others found their telephone more attractive than the people they were supposed to be engaged with.

I find it's become very anti-social. That's one thing I've really disliked about this technology when you're in a social setting and people, you are there having a coffee or whatever, and then people all of a sudden are distracted from that. You've organised to meet at a certain time but they can't help but check their messages. Like do you really need to check your message in that 40-minute timeframe? Or sending messages! I just find it's a real shame that people can't connect with the people that they're in contact with. That they're not present in the moment. They're present on this hyper-reality. (ML, 2016, p. 27) 
He'll be doing something on his IPad and I'Il be doing something on mine. I'm reading my book and he's reading something that he's interested in, and you're doing it because you're in a relaxation space. But you could also be doing it because you're talking to someone else on your texts, and he's talking to someone else, and you're actually not there. You're not there with each other. (RG, 2016, p. 31)

\section{Social rules}

Proximity disconnect has its corollary in new social rules for the use of mobile telephones. Some companies introduced protocols for mobile telephone use in the workplace.

You can have it out on the desk, because a lot of people don't wear watches anymore. But everyone should turn them off. And if it's just an informal catch-up, a phone goes off, that's fine. If it's a formal meeting, because you are there for a formal thing, unless it's in an operational capacity, you don't answer the phone. People expect that if we're here for something serious that you don't have any disruptions and you stay put, unless it's an operational thing. However, because some people may not have been brought up in that way, the business has had to make that an expectation. Like little things we stick on the wall...'Be present. Turn off your mobile phone.' And that's just trying to have a bit of respect for the people you're there with. They've asked you to be there. Or you've wanted to be there. So damn well be there. Elsewhere? The phones are going to be off. If it's a formal, serious, meeting. Yes. If it's just a friendly catch-up in the coffee shop down below...don't care. (AR, 2016, p. 10)

RG's organisation has yet to impose such strictures.

Having a phone for your work all the time drives business into a whole different space, and it stops the respect of people in terms of understanding that people are in meetings and acknowledging that they should be 100 percent in where they are. I see it when I'm sitting 
with people around a table and there's someone over there on their IPad working, which is the same as texting or whatever. I find that rude (RG, 2016, p. 30)

I don't believe people can split their brain in two of these spaces, because I've studied it. And I think if someone's working on their iPhone or whatever, then they're not in your meeting, and they should just go away. (RG, 2016, p. 30)

Society also developed new rules to compensate for the negative impacts of mobile telephone use. As mentioned above, RG had campaigned for a ban on mobile telephone use while driving but at that time prohibition was unpopular. By the Flexible Era, social attitudes had hardened and legislation was passed banning handheld mobile telephone use in travelling vehicles ("Land Transport (Road User) Rule 2004," 2004). The law is often ignored and in 12 months to June 2017 some 27,681 people were caught by New Zealand police for using cellphones while driving. This is greater than the number of people caught drink-driving ("Call to penalise drivers harder for using cellphones while driving as road toll soars," 2017). For some, the law and changing social attitudes altered the way they lived.

That's something I really really missed...was when they changed the laws about talking on the phone, because I used to basically spend hours on the phone while I was driving. (AS, 2016, p. 16)

\section{Business ubiquity}

Flexible Era telephones created new opportunities for businesses. AR's company had introduced Blackberries for senior managers but with the advent of Flexible phones could see value in pushing the devices further down through staff levels to aid integration. The firm purchases between three hundred and four hundred mobile telephones a year for staff. 
It's gone from being senior managers, next level down, next level down, to being almost every staff member. New graduate engineers don't get provided ones automatically. Admin staff...anybody you need to get, has got one. (AR, 2016, p. 7)

Others doubted the value of mobile telephones which thrust communication and comparatively menial tasks on to staff who could be better engaged (SS, 2016)

\section{Users NL and AM - exemplars of Flexible Era social practice}

The following section describes the use of mobile telephones by two users, NL and AM, both of whom were given their first devices for their $11^{\text {th }}$ birthday. As children neither had felt out of place having a mobile device as mobile telephones were in general use. These two women are markedly younger than other users interviewed. Their experiences of provide comparison with those of AS and SS during the early Fundamental Era. Furthermore, their experiences illustrate the diffusion of mobile technologies across the New Zealand population and also illuminate the divergence of social practice in the use of mobile telephones.

NL grew up in Miramar, a middle-of-the-road suburb of Wellington, and AM grew up in Remuera, an upmarket area of Auckland. Each had parents who felt that as their daughters gained greater mobility they would need to keep in contact. This reflects changes in Social and Community Meanings in that while children have always wandered, these days the world is seen as unfriendly and possibly dangerous to children, particularly girls. Changes in Spatial Matrix are also evident, in that parents feel the mobile device extends the limits of their control and protection beyond visual range.

NL's story

NL recalled receiving her first Nokia from her parents.

"I felt excited that I had a phone, and that I could now keep in touch with my friends. Just texting and calling, asking where my friends were, and calling parents or having my parents 
call me. I could talk to my friends more than just calling them, like on the landline, hoping that they're home. (NL, 2016, pp. 2-3)

Eight years later, at the time of the interview for this thesis, NL had an iPhone 5, also given as a present by her parents.

"It's quite fast, so you can like use things quite fast. It's like with some phones, it's like they're slow and it takes forever, but iPhones are quite quick and easy to use. Social networking, texting, calling, playing games. Just an easier way to get in contact with people if like ... say you need to be on Facebook and you're like in town and you have no laptop it's just better to use. (NL, 2016, p. 6)

NL was asked about the responses of her friends to her having a latest model iPhone. Most people kind of had like iPhone $4 \mathrm{~s}$ and iPhone $3 \mathrm{~s}$ and everything, so... It didn't make much of an impact at all? Not really. (NL, 2016, p. 9)

NL sent at least 200 texts a day and received as many - her boyfriend alone received around 120 texts a day from her and she called him, somewhat angrily, if he did not respond promptly. She also communicated with friends on Snapchat, Instagram and Facebook.

Maybe something that I found funny or "How's your day?" if they want to hang out ... just stuff like that. (NL, 2016, p. 11)

She would make only two or three calls a day, generally to her parents because it was more productive than texting them. For her friends, the reverse was the case.

If you're texting someone that means you can go off and do something else while you're waiting for them to reply, but if you're calling someone you kind of have to put everything on hold. (NL, 2016, p. 19) 
NL spent 12 to 13 hours a day on her mobile telephone and never turns it off. She would normally put the device aside around 10.30pm, but if she was awake and bored at 3am she would check Facebook and other social pages. The first action every morning was to check her messages. (NL, 2016)

Due to the limited availability of data on her mobile plan NL spent less time using her mobile telephone than some of her friends whose plans included unlimited data and who placed even greater emphasis than she did on constant connectivity. NL said she was concerned at proximity disconnect even though she had been frequently observed by the researcher using her telephone while in a face-to-face social space, such as during the interview.

They have actually made us less sociable. If you're hanging with a group of friends you should just put your phone away and just talk to them. Because they're all like "Oh, look at my texts". So, it's just like "Why are you here?". (NL, 2016, p. 13)

\section{AM's story}

AM first mobile telephone was a pink Feature Era Nokia.

It was one of the latest models and it was pink and I remember thinking that was the best thing about it. And it could text and call but I didn't have any internet access. It had one game. I thought I was so cool. I just wanted to have it out all the time and kept flipping it so that everyone could see that I had a phone. Mine was cooler because it was flip and at the time that was the new trend into smaller, sleeker phones. So mine was one of the cooler ones at that stage, although it wasn't a Motorola which was the coolest one because it was more expensive. (AM, 2016, pp. 1-2)

Mum and Dad got me a phone for safety when I started bussing to and from school. The only purpose was to call them, so I only got money on it for that purpose. I just remember it being 
a massive thing about safety. So you were safe, you were classified as safe, if you had a phone with you. (AM, 2016, pp. 1-3)

Most of the schoolgirls who bussed alongside AM had their own mobile telephone. Conversely, those who were driven to and from school by their parents did not. At the time, there was some debate between parents about providing children with mobile telephones. Many people could not see why such young people would need them. Over time this perception markedly changed.

It was definitely cool to have, but it wasn't like one of those things where if you don't have a phone, you're not cool. It was just becoming very normalised. Like very normalised, like everybody started to get phones. Probably not in 2005 but from 3 years after that if you didn't have a phone, then it was weird. (AM, 2016, pp. 3-4)

More than changing her social life, the mobile telephone changed her relationship with her parents, making her, conversely, more dependent upon them. Missing a bus used to mean walking home, but with her mobile telephone, she would call for a ride. By the time she was 15, however, new plans and mobile telephone models permitted considerably more freedom to text in quantity.

It became like a competition to see who could send the most texts in a month. And if you had a boyfriend then you'd be texting your boyfriend all the time, but that was the sole purpose of the phone anyway. But no calling, you'd never call, these are for texting, because calling was expensive. You'd text Mum and Dad to "call me now", and then they'd call. But otherwise you wouldn't call anyone, ever. I probably didn't call anybody until I left high school. (AM, 2016, p. 6)

AM received her first Flexible Era telephone, an iPhone handed down from her father, when she turned 18 during her senior year at high school. 
It was so cool. I loved everything about it. You could go on the internet, you could go on Facebook, you could communicate on so many different levels with people. You could play games all the time, you could Google Maps places, you had data all of a sudden so you didn't need to be connected to Wi-Fi to be connected to the internet. And that was massive. I could Google which bus I'd need to catch to get home which was a massive thing as opposed to having to then rely on Mum and be like, "hey Mum can you please tell me how to get home". And it was when I was driving as well so I was able to Google Map everywhere I went, which was useful. I remember the photo component being really massive. Nobody bought cameras anymore because you had that on your phone. So it started becoming this multi-functional tool. (AM, 2016, pp. 6-7)

Multi-functionality extended into the social sphere when mobile telephones became the means for accessing new applications such as Facebook. Facebook gave AM and her friends a means of sharing messages and photographs and for organising events. The mobile device even enabled users to have personal relationships with other users without any personal connection. AM recalled her younger sister linking up with someone on Facebook. They texted each other frantically for about a month. And then it was over. They never actually met. One of the effects of mobile facilitated communication was that the need to socialise with friends personally faded.

When you were younger you'd make plans after school to go and hang out with people. You wouldn't necessarily do anything but you'd go and hang out. Whereas now that you have a phone, you don't actually have to get to their house because you feel like you're doing the same thing, but you're just not with them. It's almost compulsive to pick up your phone. You're not necessarily communicating with people. You'll be looking at social media instead. Like Instagram, you just look at photos. Facebook, you're looking to see what people are 
doing. Snapchat, people Snapchat a lot. I use all means of communication, I email quite a lot from my phone. A significant amount of emailing. (AM, 2016, p. 13)

Use of the Flexible Era mobile phone extended beyond communication.

I Google things a lot more often than I would have, so if there's anything I don't understand, or if there's anything I want, if I'm thinking about something and I don't know the answer to it, then I'll Google it straight away. Then I'll know the answer. I buy a lot of things on my phone. Like I purchased a birthday present for somebody today on my phone. It was like a book. I bought shoes. I purchased flights. I purchased something really big the other day and I thought, that's interesting that I purchased that on my phone. It was something really expensive. Anything that I purchased on my laptop I now purchase on my phone. (AM, 2016, p. 20)

Besides reducing face-to-face conversation, constant connectivity was paradoxically closing off the range of subjects discussed. What was happening on Snapchat, Instagram, Facebook, Pinterest, and blogs was becoming more important than anything else. AM and her flatmates met every night for dinner and introduced house rules for the use of mobile devices as a counter to proximity disconnect.

We weren't talking to each other. Everybody was just on their phones. We would talk about "have you seen this on Instagram today, or have you seen what so and so's posted?" It wouldn't actually be about what our days were. We only realised that it was bad when we went out to a flat BYO together. It was supposed to be drinking your bottle of wine and having dinner together and we were all just on our phones instead. I got very sick of it. I put my iPhone in the middle and said "I'm not touching that anymore". So we put them all into the middle, and we were like, "no more phones for tonight", and then we just made it a rule for always. (AM, 2016, p. 13) 
For AM and her friends constant connectivity was no longer seen as desirable. AM used Facebook and similar conduits less. However, turning away from her mobile telephone, and the constant connectivity it both represents and provides, was extremely difficult. For example, she cannot go to sleep without checking her mobile telephone first. She remains permanently contactable apart from when she is asleep.

As value propositions changed, so too did use of the device and the social signals of various means of communication, such as when to text and when to call.

As soon as you see unlimited text and unlimited minutes then they become the same thing. , The difference is that in a text conversation you can have it so much more drawn out, I guess, over the day. Whereas a phone conversation is three minutes and then you're done. You don't need to talk to them anymore that day, cause otherwise it's kind of weird.

But if someone was special calls?

I like it, yeah. A text message they could do while they're doing anything else, whereas with a call, they can't do anything else at the same time. So they're giving you their time. (AM, 2016, p. 18).

This section highlighted the practices of users during the Flexible Era. The following section provides analysis of the practices of users in terms of the institutional practices and the movements in parameters.

\subsubsection{Users - parameters and institutional practices}

In the Flexible Era the number of mobile users did not markedly increase, but purposes to which the mobile telephones were put substantially changed. Flexible mobile telephones merged the telephone with the computer and could be individualised whereby users added or deleted applications to suit their evolving needs and whims. The mobile phone was no longer a standalone communication device but a means to access software specific to the task desired 
by the user. The task of communication with another individual may be only one task amidst many. Furthermore, the Flexible device merged mobile and internet. In the Flexible Era users were able to communicate one-to-many or many-to-one or participate in many-to-many conversations. Users no longer purchased texts by numbers or calls by minutes but instead bought data - a rationed connection to the rest of world via an internet pipeline. At times, constant connectivity was strongly desired by the user, and at other times strongly resented or resisted.

These changes for users reflect changes in the Responsiveness, Value Propositions, Technology and Information parameters as users strongly migrated to Flexible Era devices. Knowledge as to the availability, capability, and use of the devices was based on formal and informal communication channels ranging from provider advertising through to blogs and internet product reviews. The social acceptance of the technologies that enabled constant connectivity where mobile devices became core to user management of productivity and management of entertainment reflected changes to Social and Community Meanings and Needs parameters whereby a device that enabled capabilities previously never known became a vital element in the lives of millions of New Zealanders.

Most importantly, the Flexible Era device changed the Information and Spatial Matrix parameters. With a Flexible Era telephone a user could connect with anyone, anywhere, and access and exchange any information whether it be through a search engine such as Google, or an organisation's intranet, with favoured blogs, podcasts or website, or with a myriad of any other users anywhere on earth. Regulators may have seen the New Zealand mobile market as being defined by a coastline, but the users were acting in a different, boundary-free, universe.

Constant connectivity, however, came with a price. RV described the cost in dollar terms of the constant cycle of upgrading of all his electronic communications and computing 
hardware. SS and RV, in particular, were concerned that their data was recoverable and useable by others unknown. SS, AR and RG were concerned that the mobile device was a source of interruption, and that the material on devices were seen by users as more important than the real people in close proximity. SS grieved that although constant, the connection with people had become superficial - there was breadth but no depth or meaning. He and RV said they felt bound to respond to people in internet groups they otherwise had no connection with and would walk past unknowing in the street. Some users, such as AF and AM, and the company of AR, made deliberate rules for behaviour to counter either intrusion from mobile devices, or the proximity disconnect that the devices encouraged. Broader society also perceived negatives in constant connectivity in developing regulation covering the usage of mobile devices such as banning them from being used by drivers - a shift in the Social and Community Meanings, and the Legal and Economic Institutions parameters.

NL and AM, as digital natives, had social interaction through their mobile devices completely contrary to the early users of mobile telephones such as AS and SS. Whereas AS and SS drew considerable social status from their mobile telephones, NL described her friends as hardly noticing she had the latest device. Whereas AS and SS were seen as innovators in adopting the mobile telephone, NL and AM were conformist - conforming to social expectations by using a Flexible Era mobile telephone. Whereas AS and SS were using their telephones for one-to-one communication on an as-required basis, with one eye on the cost, NL and AM were in constant connectivity with one person or many with little thought of the cost. Whereas AS and SS were constrained by the mobile network geographic limitations, NL and AM have no constraints. With their mobile in their hand, they can go anywhere. 
Table 6-9 User practices in the Flexible Era

PARAMETERS

PERFORMANCES

INSTITUTIONAL PRACTICES

$\begin{array}{cl}\text { Responsiveness } & \begin{array}{l}\text { PT: It's just a small computer that makes phone calls. } \\ \text { The smartphone had the slight sense of 'The computer } \\ \text { has come to the phone world and isn't that fun?'." }\end{array} \\ \text { Information } & \begin{array}{l}\text { AR: The phone now had an operating system just like a } \\ \text { computer on which you overlaid functionality including } \\ \text { the phone feature. In effect it became just like a } \\ \text { computer that was really small but you could talk on. } \\ \text { You still bought it because the primary function was } \\ \text { that you want to talk to somebody, but it now did all } \\ \text { these other things at the same time. }\end{array}\end{array}$

Technology

Value Propositions

PT: The whole point of the thing was to have a browser and be connected and have email and so on. So speed Information was an issue and I was very happy with the speed, you know?

Spatial Matrix

AF: I quickly cherry-picked apps that worked for me, or Responsiveness

Value Propositions

RV: It's increasingly becoming a consumption tool for much more than just messaging. Messaging is almost a side function of it now. And were I single it would

Needs probably be a complete side function. It would almost be unimportant.

Social and Community Meanings

PT. There's more cellphones than people on the planet. Ubiquitous, and that's of course connected to the whole association. The sharing of data is a big deal.

Spatial Matrix

Social and Community Meanings

RV: Twenty years ago my monthly costs would have been my power bill and my phone bill. Now it's my landline broadband, it's my mobile broadband, it's the mobile broadband for my iPad, it's the cost of Information upgrading the iPhone every year, it's the cost of upgrading the iPad every two, plus upgrading the Technology laptops every three. There's just all these different upgrade cycles, which are new costs which I don't think Responsiveness ever existed before. I have a pile of technology that goes obsolete every two years and needs replacing.

Value Propositions AM: As soon as you see unlimited text and unlimited Responsiveness minutes then they become the same thing, so it's like, well why don't I just call?

Market Convergence Data over Internet Protocol

Data Market defined by Users Buyers

Predominantly Consumers

User buys access to a data pipeline

Users Prepaid Cost not a determinant of Use 
Competitive Intensity

Social and Community Meanings

Technology

Technology

Needs

Responsiveness

Spatial Matrix

Social and Community Meanings

Needs

Responsiveness

Spatial Matrix

Social and Community Meanings
PT: When I got the first iPhone, the smartphone, I remember that slight feeling of self importance. It was like 'Oh, wow, I'm one of the first guys around here to have a smartphone.' I mean by today's standards it's laughable isn't it? I mean everybody's got one.

RG: Well it saves you carrying a whole lot of other stuff. I didn't have to carry a camera any more, and that was a really big step.

RG: I still carry a street map because I like a street map, but if I am in trouble I can find where I am in here, find how to get from $A$ to $B$ or whatever in that, and that's like, that's amazing

AM: Nobody bought cameras anymore because you had that on your phone. So it started becoming this multi-functional tool.

$\mathrm{RV}$ : I probably am connected to people for the sake of being connected to them. I'd have friends on Facebook that I probably wouldn't even look twice at on the street

NL: Most people kind of had like iPhone 4s and iPhone 3s and everything, so..."

M: It didn't make much of an impact at all?

NL: Not really

AR: That's been a change that has moved in over the past five or six years. It's gone from being senior managers, next level down, next level down, to being almost every staff member. New graduate engineers don't get provided ones automatically. Admin staff...anybody you need to get, has got one

AM: It became like a competition to see who could send the most texts in a month.

AM: I Google things a lot more often than I would have, so if there's anything I don't understand, or if there's anything I want, if I'm thinking about something and I don't know the answer to it, then I'll Google it straight away

AR: Pre everybody having cellphones and it being cheap enough to do it, it was 'I'll see you here at such and such a time, and we'll work out what we're going to do there'. There was always a bit more forward planning and options. Whereas as soon as people suddenly
Egalitarian

Multiple Use Flexibility

Conformist

Life Normative
Mobile devices enable management of All of Life 
Information became more contactable, you didn't worry about that. You just sorted it out on the fly

Technology

Needs

AM: I use Google Maps all the time, bus routes, things like that. I buy a lot of things on my phone. Like I purchased a birthday present for somebody today on my phone. I bought shoes. I purchased flights. I purchased something really big the other day and I thought, that's interesting that I purchased that on my phone. It was something really expensive. It was a birthday present for somebody. Anything that I purchased on my laptop I now purchase on my phone.

AM: I check all my notifications on all communications. I just never think to turn my phone off. I don't think I've deliberately turned my phone off in years. I don't know, I just don't. I don't know anybody who does either.

Spatial Matrix AR: Things become far more real time. It's just far more expected that you can be got hold of if you need to be

Information got hold of.

Social and Community Meanings

Needs

Spatial Matrix

Information

Social and Community Meanings

Legal and Economic Institutions
PT: I feel more accessible. I feel I need to be accessible. I don't want to drop off the grid.

ML: I travel with my laptop, my Kindle, my iPad and of course my phone.

RV: It evolved to where I suddenly became pretty ... always contactable. The phone was always charged, it was always on me. I wouldn't leave it behind. I would notice when it wasn't there.

RV: Once it's out there, it's out there. I probably used to share a lot more and the realisation that it's always there, and someone will always find that, has grown in me. My tolerance for that has fallen completely. The sheer amount of data tracking - big data - surveillance of data - I dislike. The commercial use of the data, Government use of the data, just sucking away at the data, I have objection to. So the easiest way of dealing with it is not to contribute the data.

SS: As long as I exist in society now I have to give up my anonymity. My personality is no longer my own, it is for everybody to see. It is no longer that you have to experience me personally to know me, now everybody can know me. I actually don't want anything (from the technology), I would rather have it go back into its worm-hole and not come out again.
Constant Connectivity Negative 
Needs

Social and Community Meanings

Spatial Matrix

Social and Community Meanings

Needs

Information
SS: We didn't improve or increase our productiveness, we just decreased our quality of life

NL: I feel they have actually made us less sociable, even when we're out in a group of friends. If you're hanging with a group of friends you should just put your phone away and just talk to them. If everyone was just on their phones I feel like that they don't actually want to be here. Because they're all like 'Oh, look at my texts'. So, it's just like 'Why are you here?'

AS: That's something I really really missed... was when they changed the laws about talking on the phone, because I used to basically spend hours on the phone while I was driving

ML: Like do you really need to check your message in that 40-minute timeframe? Or sending messages! I just find it's a real shame that people can't connect with the people that they're in contact with. That they're not present in the moment. They're present on this hyperreality, like this virtual reality

AR: Be present. Turn off your mobile phone.' And that's just trying to have a bit of respect for the people you're there with.

AM: Everybody could see what events you were going to. So that would relate back to your social life and how you were seen in your social standing at school and things like that, which probably wasn't that great but at the time we thought it was really cool. And I guess as well everybody was trying to contact with boys and stuff, and we weren't at a mixed school so to be able to then be able to contact these large groups of people, and just invite them all to an event without having it to be seemingly personal, was really good

AF: I'm sick to death of Facebook but I'm at a point now where it's a necessity, particularly considering what we're travelling overseas - for family to keep tabs on what we're doing.

RV: We've got group chats on Facebook, things like that, so there's always things happening. It's my mini computer in my pocket. I deal with emails all the time, so with the majority of my emails l'll reply to them off that - I won't reply to my computer any more. I get all my news off it, so Facebook, Twitter, Newsreaders - I can flick through those, I can get breaking news, I get notified when something happens in the world.
Proximity Disconnect

Communication one-to-one one-to-many many-to-one many-to-many

User Perception Global 
This section described the practices of users in the Flexible Era defined firstly by the merger of internet and mobile, secondly by the merger of the computer and the mobile device, and thirdly by the user having the flexibility to adapt their mobile telephone to suit their present and changing needs and who could also define the extent of service they wished to purchase from providers. The mobile market was user-defined.

A further profound change was the emergence of constant connectivity where users expect, and are expected, to be always available via their mobile devices. Furthermore, connectivity moved from being a one-to-one experience to possibly incorporate a multiplicity of connections some of whom may not be directly known to the user. A corollary was proximity disconnect whereby users become so integrated with their mobile device that they effectively blanket connection with people around them. The extent of proximity disconnect has hastened new social rules, both formal and regulatory, outlining the acceptable limits of mobile telephone use. A fundamental change in the market were user perspectives of their world - users were no longer confined to New Zealand geographical boundaries but could engage globally on their internet-capable mobile telephone.

The chapter now turns to the illumination of parameters through the comparison of actor performances of practice and institutional practices across the Fundamental, Feature, and Flexible Eras.

\subsection{Comparison of Practices Across Eras}

\subsubsection{Introduction}

This research strengthens the conceptual approach of market practice model through exploration of market parameters. The research thus explores, or makes clearer, those categories of practices that form the nine parameters describing market boundaries. Market parameters evolve according to endogenous and exogenous forces upon the market. Furthermore, the greater the change in parameters, the greater the change in performances by 
market actors and the institutional practices that embody the market paradigm. Exploration of parameters was achieved through the examination of actor performances by which institutional practices were highlighted. Thus, the existence, composition, and nature of market parameters could be abducted from the extent and nature of observed change in institutional practices over time.

Specific performances by regulatory, provider and user market actors across three distinct eras in the New Zealand mobile telecommunications market between 1990 and 2014 indicated the institutional practices typifying each market era. The chapter now provides a comparison between the institutional practices of the market eras to illuminate market parameters. The comparison is summarised in Table 6-10. The vertical columns show for each of the three distinct market eras the institutional practices and the characteristics of the mobile market in New Zealand. The characteristics are shown in terms of market size, as measured by the number of users and the percentage of New Zealand population, to indicate the importance of mobile to the general population and the diffusion of the mobile technologies, and the contribution of mobile revenues to the total revenues of Telecom/Spark as a further indication of market size and economic importance. Market characteristics also include the critical actors and technological capabilities that shaped the market in each era. The market characteristics are briefly explained in the following section.

The horizontal components provide comparison of institutional practices across eras. The analysis suggested five groupings of institutional practices predicated on their distinct and unique relationships with interlinked parameters. By comparing the material in each vertical line (within each era) across the relevant horizontal lines (between each era) the changes in institutional practices can be seen, and the changes to market boundaries in terms of parameters illuminated. 


\subsubsection{Market Characteristics}

Market characteristics are the metrics by which the boundaries of a market are made quantifiable and, further, the summary of institutional practices by which the shape of market, or market paradigm, is explained. The three market eras, Fundamental, Feature and Flexible are primarily defined by the prevalent technologies which changed between eras. The eras have been previously described. The size of the market in term of users at the beginning and end of each market phase, and the economic importance of mobile to providers, have also been previously described but are included for clarity and completion. The analysis of performances, however, revealed further market characteristics defining each era.

The Fundamental Era was shaped by providers who primarily supplied multiple voice markets defined by fixed-line local and toll call capabilities and a geographically limited mobile network.

The Feature Era was shaped firstly by providers who supplied multiple voice markets defined by fixed-line local and toll call capabilities and a geographically expanding mobile network in a market distinguished by increasing competition, and secondly by interventions by the regulator. By the end of the Feature Era and the early Flexible Era the providers were no longer shaping the telecommunications market. The mobile market, as part of the broader telecommunications market, was instead substantially reshaped by regulatory interventions.

The start of the Flexible Era was marked by technologies which placed in the hands of users not only new mobile capabilities and the ability to adapt and adopt content of their own choosing but also gave users the collective power to shape the market through the purchase of data.

Figure 6-7 summarises the development of the mobile market in New Zealand from 1990 to 2014 in terms of the number of users, percentage of population, and the correlation 
with market eras. (Commerce Commission of New Zealand, 2008, 2015; Telecom New Zealand, 1992, 1994, 1998).

Figure 6-7 The growth of the New Zealand mobile market

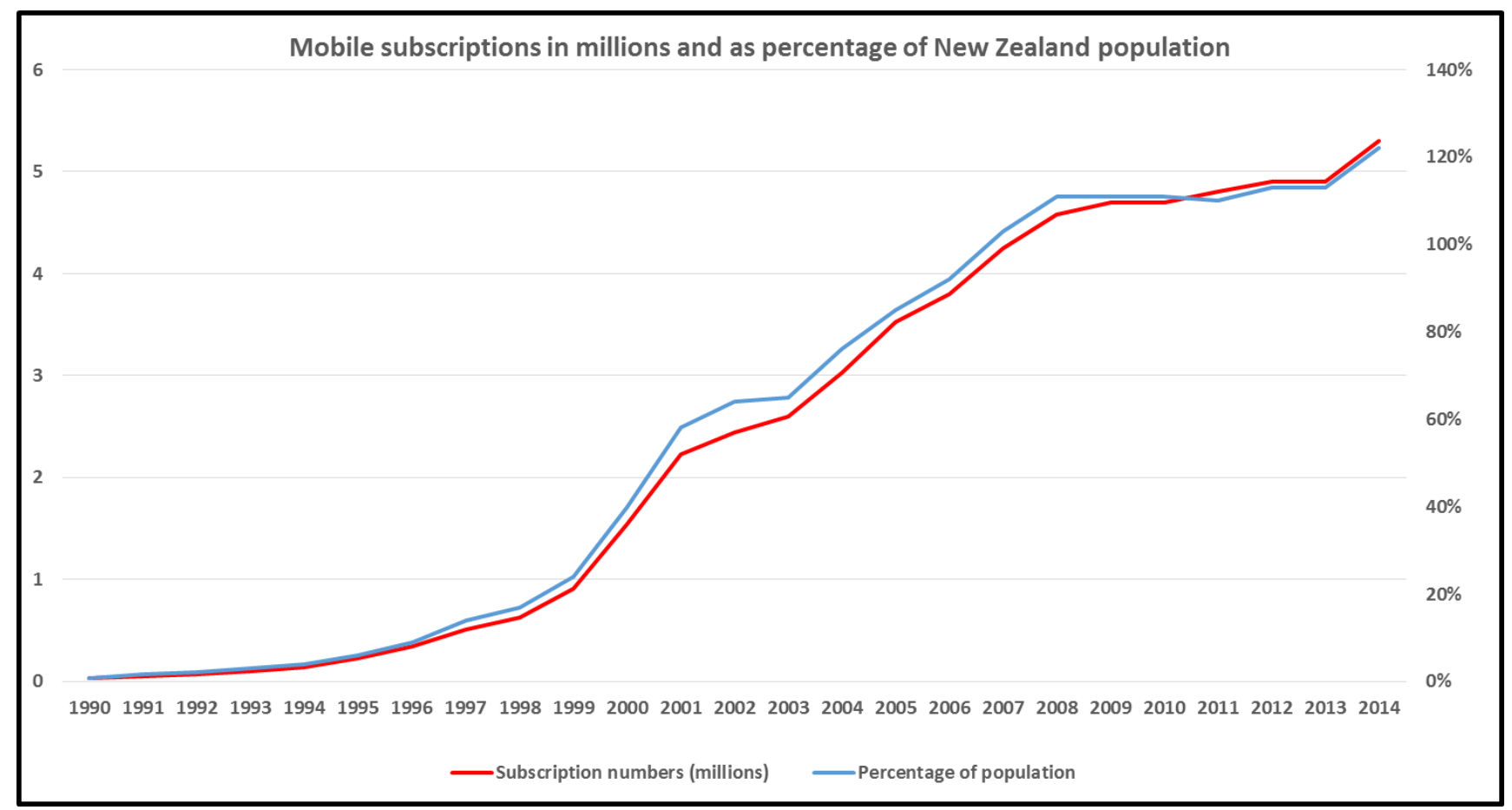

\subsubsection{Linking Parameters and Institutional Practices}

The chapter now turns to the comparison of practices from which emerge the identity and character of parameters. To assist discussion, five groups of institutional practices for the mobile telecommunications market in New Zealand are presented in turn. The groupings overlap, to a greater or lesser degree, due to the influence of parameters upon each other.

\section{Regulators}

During the Fundamental Era the market focus was on tolls and the emerging internet. The regulatory ideology was non-invasive and reflected the 'play the game fairly' attitude of the Minister, M1, and apparent within the public sphere. As the telecommunications market in New Zealand changed with advent of new technologies, new providers and a considerably increased numbers and types of users, the ideology changed to where 'hard' regulation was desired to shape the mobile market in face of the generally perceived dominance of Telecom 
primarily in the internet access market. This was reflected in the performances of Minister M2 and the Telecommunications Commissioner R2. Towards the end of the Flexible Era, discourse in the public sphere regarding telecommunications regulation faded away and the focus was instead on the availability of data enabling mobile access to content. The Flexible Era market was thus shaped not by the regulator nor by the providers, but by the users. The market in latter years of the Flexible Era showed signals of shaping by virtual providers of content heralding a neo-regulatory era whose form is inchoate. The changes to institutional practices in the regulatory group across market eras suggest changes within the Social and Economic Meanings and the Legal and Economic Institutions parameters.

\section{Providers}

In 1990 New Zealand had one provider of mobile services. The focus for Telecom New Zealand's chief executive and chairman was clearly the shareholders, and growing shareholder value through the provision of an expanding tolls service. Telecom followed strongly the United States approach to technology and the commercial potential of mobile was only just becoming recognised.

The Feature Era was notable for the internationalisation of mobile telephone value propositions. Vodafone introduced a Japanese-European understanding of mobile technologies that was superior to those of Telecom in terms of capability and adaptability, and thus user preference. In particular, the Vodafone model suited users from outside Telecom's understanding of a business-based market. Telecom was caught flatfooted by the movement of users into text. A feature of text was a rapid increase in the user population accompanied by a decrease in the average revenues per user as technology and competition developed in tandem. These changes reflect movement in the Competitive Intensity, Technology, Information, Value Propositions parameters, which combined reflect in the Responsiveness of the providers to user needs and to technological innovation. The movement of users to the 
Feature mobile telephones and texting reflected changes in Information and the Responsiveness of the users to the Value Propositions offered by providers, and the users own assessment of their Needs. The movement whereby texting diffused through a rapidly growing mobile users population reflects changes in the Social and Community Meanings parameter. A further movement in market boundaries in the Information and Social and Community Meanings parameters reflected the ideological divergence setting apart Telecom from its users and the regulator.

By the end of the Flexible Era the priority for providers was to provide mobile data and content, and to grow data use. Growing shareholder value as a competitive priority was subsumed by the need to compete by creating customer value. User needs were increasingly being met by international providers, particularly in content. The boundaries of the New Zealand market were no longer constrained by the coastline - competition was truly global. These movements primarily reflect changes in the Competitive Intensity and Spatial Matrix parameters. The greater the competitive forces, the more powerful the Responsiveness of providers in terms of Technology and Information that was translated into the Value Propositions on offer to meet the needs of users. The ability of users to select providers of data access and content, and the responsiveness of providers to these needs on a global scale reflects changes to the Social and Community Meanings and Spatial Matrix parameters.

The chapter now turns to the changes in institutional practices of users. The institutional practices are divided into three distinct, though overlapping, groups.

\section{Users}

The institutional practices of users are divided into three distinct, though overlapping, groups. Presentation through division into groups enables lucid depiction and explanation of the multiple facets of social practices defining market parameters. 
The first group involves institutional practices associated with the purchase and use of mobile telephones - thus, the practices associated with users entering and maintaining a presence in the New Zealand mobile market.

The second group involves institutional practices associated with the user as a member of society where a mobile market exists.

The third group involves the development and adoption of practices from a nascent or inchoate state to legitimation, and from legitimation of practices to a further state whereby actors question practices they perceive as negative or unwelcome, and which may manifest in the actor challenging or withdrawing from some practices.

\section{Users - purchase and use}

The Fundamental Era purchaser of mobile telephones was almost invariably buying for business. Purchase options were limited to a very few variations of handsets, battery size, and the contracted number of minutes available each month from the sole provider. The user thus purchased the ability to make one-to-one telephone calls when away from a landline. User spatial perceptions were constrained by the limited geographic coverage of the mobile network. User willingness to make calls was constrained by the perceived high cost of calling. Connectivity was thus constrained by place and cost, and calls were made only when essential for business purposes. The value of the mobile telephone was firstly determined by the ability to make voice calls when such communication was essential, or, secondly when obtaining other means of distance communication was otherwise inconvenient, difficult, or even impossible, and, thirdly, the sense of status the mobile telephone ascribed to the user. The constraints afforded by connectivity and value impacted upon the New Zealand population's perspectives of mobile telephones and the people who used them. Landline access to the internet was limited and for mobile non-existent. 
In the Fundamental Era the boundaries of the broader telecommunications market changed to incorporate Value Propositions afforded by mobile Technology. Movements in these two parameters may have been insufficient to create, and then expand the boundaries of, a new market for mobile communications. Creation of the market and expansion of its boundaries was assisted, however, by shifts in other parameters. Competitive Intensity in the New Zealand telecommunications market was very low, however between business people the normal high levels of Competitive Intensity existed. Information that practical and affordable (relatively) mobile telephones and a commensurate network was available, business organisations which had a Need for greater efficiency, and business people who had a Need for efficiency and status, led to mobile telephones being adopted in growing numbers. The growth in numbers of users was not unnoticed by providers, who moved to capture as many new users as possible, thus beginning new rivalries which further impacted the Responsiveness, Competitive Intensity, Value Propositions, Needs and Information parameters.

While price remained key in user decision-making, the specific capabilities of each handset became the principal determinant in purchase and use during the Feature Era. As prices fell, relatively, and features increased, due to increased Competitive Intensity and Responsiveness amongst providers, and while Competitive Intensity remained high amongst users, the number of users substantially grew. The Feature Era can be differentiated from other eras by the awakened social acceptance of mobile telephones whereby the mobile telephone was no longer regarded by the general population as a 'yuppie phone' but was legitimated as a capability. Users moved from 'other' to 'us' through the adoption by burgeoning numbers of users of practices associated with the mobile market. As the Feature Era progressed, the use of mobile telephones evolved from being one-to-one communications tool used as required (with a high need threshold to be surpassed prior to use) to a multi-modal device for talk and text. Texts in the Feature Era determined mobile value amongst users who opted for pre-paid 
contracts rather than post-paid, thus providing themselves with greater freedom to determine their own extent of usage. Towards the end of the era a user priority became data transfer due to Responsiveness by users to the Value Propositions, Technology and Information of providers, and the changes to Social and Community Meanings held by society.

Flexible Era users were predominantly individual consumers, and price was no longer a determinant in whether or not a mobile device would be used. Individual users no longer purchased text or talk minutes but bought access to a data pipeline for whatever purpose they decided upon on a device they adapted and re-adapted for their own specific use. User priority thus evolved from a high needs threshold where connectivity was enabled as required to a low needs threshold of constant connectivity. The mobile telephone had evolved from a one-toone communication device as determined by providers, to a communication device linking other devices and applications in ways determined by the user. User Spatial Matrix evolved from being constrained by geographic networks to having no geographic constraints with the complete merging of mobile and internet enabling global connectivity between users and with providers of services and content. The flexible nature of the device lends towards specific groups of users whereby there emerged micro-markets for specific connectivity as reflected in the Needs parameter.

The mobile telephone would not have become popularised without changes in the Responsiveness parameter whereby users responded to the Value Propositions on offer. Responsiveness, in terms of users, impacted on the Needs and Social and Community Meanings parameters. Similarly, changes within the Technology and Information parameters would not have occurred without changes in the Responsiveness parameter in respect of providers and users. 
In this section on user purchase and use of mobile devices, particular prominence was given to changes in the Competitive Intensity parameter. In the section that follows on the use of mobile telephones within society, the most important changes occurred within the Social and Community Meanings and Responsiveness parameters.

\section{Users - the mobile telephone in society}

A mobile telephone was an adventure for the Fundamental Era user. The mobile telephone conveyed status on its user as an innovator and of high importance to their organisation. For users the mobile telephone was life disruptive: to leave the office no longer meant disconnection from the business worries, but explicitly removed the boundaries between being at work and being elsewhere. It was a price the users were prepared to pay in return for their elevated status and mobility. The mobile telephone was an expensive commercial and economic tool enabling limited mobility of connection for managing productivity and managing space - attributes sufficient to create self-aggrandisement in users and dismay or disdain amongst the 80-90 percent of the social who were not users and thus dismissed mobile devices as 'yuppie phones'. The practices associated with mobile telephones were thus inchoate, and understood by neither users nor non-users. The emergence of practices not understood or accepted by the social positioned the users of mobile telephones as 'other' and the non-user population as 'us'. The non-acceptance by the social of mobile telephone practices reflects little or no movement in the Social and Community Meanings and Responsiveness parameters, and hence, despite disruptive changes to the Technology parameter, the mobile market, while expanding, remained relatively small.

The Feature Era involved the mass adoption of mobile technologies by the New Zealand population suggesting the legitimation of associated practices where mobile telephones became perceived as socially positive. By the end of the era 'other' had become 'us' where routinised 
practices were understood and performed by the social. The mobile telephone was ubiquitous, life normative, and conveyed no social or economic status on the user. Users, rather than just managing productivity, were also managing their personal lives and managing entertainment. Thus, in the Feature Era, non-users became users primarily due to the legitimation of the mobile telephone through substantial movements in the Social and Community Meanings and Responsiveness parameters. Legitimation would not occur without prior changes in the Information, Value Propositions and Technology parameters brought about by Competitive Intensity in both providers and users.

\section{Users - the adoption and transformation of practices}

The early years of the Fundamental Era were marked by inchoate practices whereby the users of mobile telephones and the community around them had few ideas of how to perform. The lack of practices accepted as legitimate by the social meant those who performed practices associated with mobile telephones were seen as 'other' and apart from the social. The Feature Era was marked by the legitimation of practice associated with mobile telephones whereby mobile telephone use in society became normalised. Practices during the Feature and Flexible Eras reflected societal views that mobile devices were simultaneously a legitimate means of communication and socialisation and while also a means of proximity disconnect. It was acceptable for the user to hide from those nearby by using their device intended for communication and connection with users at a distance.

Negatives emerged, however, and social perceptions regarding mobile devices questioned whether the devices should indeed be used constantly. Was it acceptable practice to use the mobile telephone while in a business meeting, at a social function, when in bed with someone, when in a lecture, or when driving? Is proximity disconnect a negatively perceived practice? By the end of the Flexible Era practices had transformed to the extent that in New 
Zealand mobile device use when driving is prohibited, and use in business meetings or social functions may not be acceptable.

This grouping of practices is important because it illustrates the influence and processes of legitimation - the social influence on practice development, adoption and transformation over time as reflected in the Social and Community Meanings parameter. A market boundary can thus be influenced powerfully by social perceptions regardless of any other influences.

\subsection{Conclusions}

Analysis of interview transcripts and documentary evidence explored parameters as catalogues of practices and the structural interrelationships of the nine parameters. The key finding is the conceptualisation of the Market Practices Model, in particular the continuous balancing and tension between, and among, the nine parameters, between parameters and the stabilising institutional practices, and the influence upon and by the performances by market actors. Secondly, the research suggested the nine categories of practices that form market parameters can be defined and distinguished: Competitive Intensity, Legal and Economic Institutions, Responsiveness, Information, Value Propositions, Technology, Needs, Social and Community Meanings, and Spatial Matrix. Nomenclature and definitions of the parameters, particularly Responsiveness, Spatial Matrix and Competitive Intensity, were amended upon reflection as the research progressed. Thirdly, the findings were congruent to conceptualisations that the individual and combined influences of parameters varies over time, and that change in one or more parameters may change the boundaries of a market. The research was also congruent to conceptualisations that the greater the destabilisation of, and by, parameters the greater the change in performances and institutional practices in a market. These findings reply to Research Questions 1, 2, and 3.

Furthermore, new understandings emerged that to be an actor in the mobile market - as user or provider - required changes to actor behaviour in step with the emerging and evolving 
social practices of the market as defined by market parameters. This finding replies to Research Question 4.

This chapter presented the empirical findings. The following chapter discusses in greater depth relationships between the findings and analysis to the literature, the research questions, and the broader purpose of the research. 
Table 6-10: Parameters: a comparison across market eras

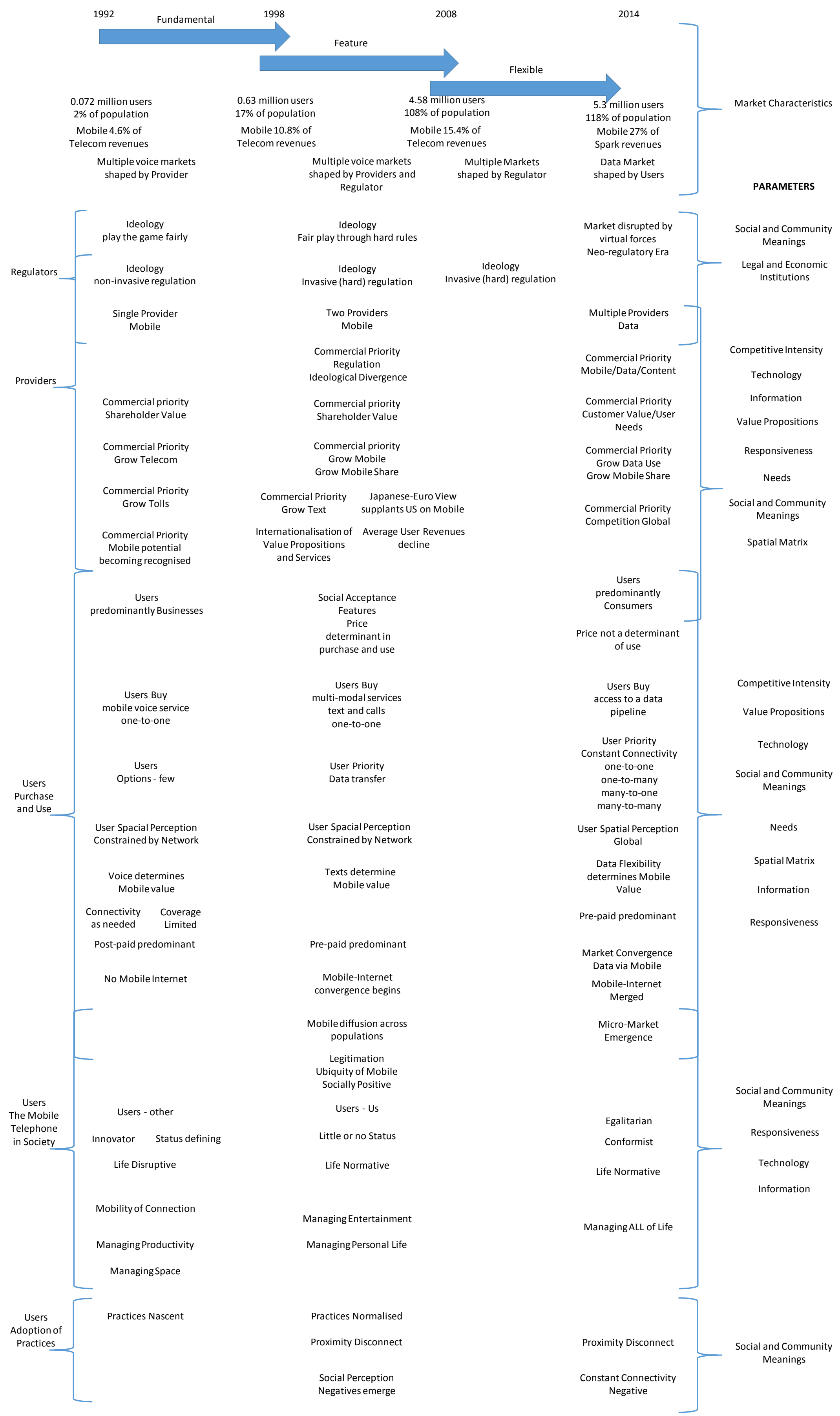




\section{DISCUSSION AND CONTRIBUTION}

\subsection{Introduction}

This final chapter discusses the relevance and importance of the research findings from this exploratory study that from a social practices theoretical perspective contributes towards the discussion of a general theory of markets. The Market Practice Model reflects contemporary social practices-based approaches to markets and marketing; advances new theory that extends academic understanding of market structure; provides a rational and dynamic approach as to how markets are created, how they evolve and how they cease to exist; how innovations shape markets; and how market actors are motivated to change to conform to market practices. The research advances theory that extends our understanding of markets, market boundaries, market functions, and the mechanisms of market change. The research furthermore provides a dynamic framework for future markets and marketing theorising. Development of the model was guided by four research questions:

1. How does a social practice theory-based Market Practice Model contribute to a dynamic general theory of markets?

2. What parameters forming market boundaries can be identified?

3. How do parameterising practices forming market boundaries influence how markets emerge and evolve?

4. How are market actors motivated to change their behaviour?

The research objectives and research questions were addressed through abductive analysis of the literature and data derived from the New Zealand mobile telecommunications market. The outcomes enabled development of the Market Practice Model conceptualisation, in particular the nine parameters that define market boundaries.

This chapter begins by summarising the theoretical contributions of the research. Strategy and management implications for marketers and for policy are then presented. A brief 
overview of potential limitations of the study follows. The chapter concludes with a more overarching discussion of the directions for future research including broader philosophical issues providing an ontological basis for further study of markets and marketing.

\subsection{Theoretical Contributions}

Orthodox neoclassical economics approaches to markets and market boundaries have been increasingly challenged since the 1980s. The neoclassical approach of markets in equilibrium, where exchange involves a buyer-seller dyad, and where boundaries are determined by price and geography, have been tested, firstly by the emergence of new types of markets accessed by different means, secondly by new understandings of markets as dynamic social spaces, and thirdly by the need for broader descriptions of market boundaries and who or what may influence these (Fourcade, 2007). The neoclassical model is described variously as unrealistic (Layton, 2008), under-socialised and separate from society (Granovetter, 1985), ignoring social, legal and cultural forces prevalent in society (Gummesson, 2002), making untenable assumptions about human behaviour (Brennan, 2006) or failing to account for market complexity (Mele et al., 2015). The marketing discipline has expressed a need for a market model that reflects and provides context for contemporary theorising of markets and marketing, and which is sufficiently compelling as to supersede those of neoclassical economics (Venkatesh \& Penaloza, 2006). The findings from this thesis thus fill a strategic theoretical gap in the literature by providing a compelling conceptualisation of a market model that both reflects and builds on current perceptions. The rest of this section describes the thesis theoretical contributions but begins by discussing the contribution to social practices theory as the theoretical basis for the market model.

\subsubsection{Social Practice Theory - a theoretical basis for markets}

Social practice theory highlights the significance of the shared symbolic structures of knowledge - social practices - and the dynamic processes inherent in the ordering of collective 
everyday life. A practice is a nexus of routinised behaviours - sayings and doings - which govern how people act and which are understandable not only to the actor who performed them but also to observers from the same culture (Schatzki, 1996; Shove et al., 2012). Practices do not exist unless recurrently enacted. If new practices are to take hold, they have to become embedded in the details of daily life and thus in the ordering of society. Both social order and individuality result from practices. Structures are embedded sets of long-lived, routinised and generalisable rules that provide a forum for the enactment and reproduction of social practices (Giddens, 1984; Schatzki, 1996; Shove et al., 2012)

\section{Society boundaries}

Social practice theory and structuration are important to theorisations of markets because they allow understanding of markets as social constructs. A market thus becomes a nexus of routinised practices of shared understandings that predate and surpass, constrain and enable, the actors who engage day-to-day in a market. A contribution of the thesis to both markets and social practice theorisation is that as a society has boundaries determined by the limit of their institutions that mark it off from other surrounding societies, then as social structures markets must also have boundaries determined by the limits of their institutions (Giddens, 1984). A further contribution, described in more detail below, is the identification of categories of practices, termed parameters, that define market boundaries.

\section{Societal change}

Practices are constituted of elements that are integrated when practices are enacted. Practices are defined by the interdependent relations between competences, materials and meanings (Shove et al., 2012). A contribution of this thesis is that if the changes to the interlinked elements of practices - competences, materials, and meanings - explain the changes within a society, then a similar change mechanism must apply to the markets. Furthermore, as 
paradigmic change occurs through episodes of conflict or intensified competition (Giddens, 1984; Perez, 2009), then competitive intensity thus drives the efforts of market actors to reshape market configurations. The thesis contributes to market and social practice theory by describing the influence of competitive intensity on market boundary change.

\section{Macro practice elements}

The interdependent relations of practice elements - competences, materials and meanings has previously been applied at the micro level of individual practices (Shove et al., 2012). A contribution of this thesis to social practice theory is the application of the practice elements at a macro level to describe market practices and define the categories of practices termed parameters.

\subsubsection{Towards a general theory of markets}

Scholars have been building a "causeway" from the neoclassical economics perspective of markets towards a general theory of markets founded in a social-practices paradigmic understanding. The causeway of contemporary conceptualisation perceives markets as social phenomena where markets are shaped by the performance of actors that are developed and reinforced over time and are specific to a market (Glynos, 2011; Rosa et al., 1999). Layton (2007), Venkatesh and Penaloza (2006), Storbacka and Nenonen (2011a), and Webster and Lusch (2013) perceive markets as a social mechanisms with market boundaries based on the linkages between market actors including those not involved directly in the exchange. Shove et al. (2012) broaden market perceptions by recognising the role of culture and cognition in forming institutions such as markets. An integral element of the social approach to markets is the understanding that markets are shaped by social and community collective understandings and that markets in one social context may be different, at fundamental levels, to markets for similar products but in different locations, and vice versa (Arnould \& Thompson, 2005; Humphreys, 2010; Kjellberg \& Helgesson, 2006, 2007; Lindeman, 2012; Morley \& Robins, 
1995; Thornton \& Ocasio, 2008). By suggesting a social practices-based market model, the thesis contributes material yardage on to the causeway towards a general model of markets.

\subsubsection{RQ1 - The Market Practice Model}

The Market Practice Model provides an alternative to neoclassical market models. Research Question 1 asks how a social practices theory-based Market Practice Model contributes to a dynamic theory of markets. Based on social practice theory, the Market Practice Model considers markets as dynamic social structures comprised of competing transvectional networks. Markets are a nexus of specific routinised performances of market practice, delineated by plastic boundaries defined by nine parameters of practice within which market actors perform differently to actors outside the market. The model further theorises market institutional practices are inherently stable and changed only when subjected to substantial reformation of parameters.

The Market Practice Model, defines a market: as a social structure for the exchange of value; the aggregation of market performances effecting transvections; the centre of integration of resources and relationships; the hub of practices that constrain and enable market activity; and, where promises are kept.

Market parameters are defined by nine inherently destabilising categories of practices: Competitive Intensity, Legal and Economic Institutions, Responsiveness, Information, Value Propositions, Technology, Needs, Social and Community Meanings, and Spatial Matrix.

Market performances are specific routinised practices by all the buyers, all the sellers, and all the collections of core competencies of all the organisations and networks of industries and all the facilitators of exchange.

The market's functions are defined and stabilised by institutional practices that give the market shape, meaning, function, and resilience. 
The model describes the interrelationships between market boundary parameters, and between the parameters and performances by market actors, and between performances and market institutional practices. By perceiving market boundaries as defined by nine parameters, the model provides a rational and dynamic approach to how markets emerge, evolve, and cease to exist, and why market actors are compelled to perform in compliance with market practices.

\subsubsection{RQ2 - Market Parameters}

Market parameters are categories of practice that provide within the market boundary essential differences from other markets (Giddens, 1984). In addressing Research Question 2, the thesis abducted from diverse schools of literature and from the empirical evidence the nine parameters.

Competitive Intensity: The practices of market actors amidst competing transvectional networks who have the capability and willingness to compete.

Legal and Economic Institutions: Competences in, and trustworthiness of, legal institutions such as laws, regulations, political and court processes, and in economic institutions such as capital markets, currency, banking and insurance.

Responsiveness: The capability, willingness and agility of market actors, whether providers, users, or regulators, to respond to the market practices of other actors. The market boundary thus occurs at the point where actors begin responding to the practices of other actors.

Information: The awareness and means of awareness by which market actors respond to each other and the value propositions presented.

Value Propositions. The core competencies, knowledge and skills promised by a provider whereby users integrate into their own practices perceived benefits to meet their specific needs. 
Technology: Specific tools, materials, and related competences that enable specific performances of practices.

Needs: Socially defined practices of acquisition and are reflective of the symbolism, ideas, understandings and aspirations acceptable and important within the practice space.

Socially defined practices of acquisition acceptable and important within the practice space.

Social and Community Meanings: Accepted understandings and symbolism of the social or community in which the market is situated.

Spatial Matrix: The equivocal and dynamic, physical and virtual, tangible and intangible, and symbolic limits of their space, by which market actors understand who are 'us', or those actors within a market, and who are 'other' on the outside of the market boundary. The Spatial Matrix includes non-human market actors, such as infrastructure.

That boundaries are formed from nine specific categories of practices termed parameters and that markets change as parameters emerge and evolve or dissipate, is an important finding from the research. Individual parameters, and combined influences of parameters, vary over time, and change in one or more parameters may not only change the boundaries of a market but also force changes to the embedded institutional practices describing the market paradigm (Kjellberg \& Helgesson, 2006, 2007).

By defining boundaries through interrelated parameters, the Market Practice Model contributes by accounting for how markets emerge, evolve, remain static or decline. The thesis further contributes by suggesting two distinct but related approaches to the willingness of market actors to perform in accordance with practices within a specific market delineated by 
specific market parameters. Market emergence and evolution, and market actor conformance, were the subject of Research Questions 3 and 4, to which the thesis now turns.

\subsubsection{RQ 3 - Parameter influence on market change}

In discussing theoretical developments of market model alternatives, Vargo et al. (2017) raises challenges that any new market model must account for how change in one aspect of a market would influence a corresponding change in other elements of the market. Giddens (1984) and (Perez, 2009) describe paradigmic change occurring due to substantial competitive forces that sequentially disrupt the incumbent paradigm and then coalesce into a new paradigm until further large scale, possibly violent, disruption. Leonardi (2011), however, describes the stepby-step incremental shuffle of change whereby evolutionary development in a practice first enables new actions and then constrains until the next step is taken. Humphreys (2010), Hargreaves (2011), and Lindeman (2012) argue change is unlikely until practice is legitimated as acceptable by the market actors.

In addressing Research Question 3, the Market Practice Model suggested that change in one parameter would directly bring about a corresponding change in other parameters, and that change would influence change in actor performances of market practice. If the change in parameters had sufficient impetus, then the substantial changes in performances of amended market practice would become embedded and the institutional practices - the market paradigm - would accordingly modify. Furthermore, the greater the destabilisation of, and by, parameters the greater the change in actor performances and thus the practices of a market.

As described by Shove et al. (2012) practices need aspects of competences, materials and meanings in order to form. This research suggests that for a market to emerge, at least one parameter from each of competencies, materials and meanings needs first to be present, and secondly must become sufficiently routinised that the practices become embedded as 
institutional practices. The research for this thesis showed, for example, how regardless of other elements in the market, mobile telephones were not adopted by the broader New Zealand population until meanings surrounding mobile usage became accepted. The Market Practice Model involves boundaries changing as parameterising practices emerge and evolve or dissipate. Change occurs first in at least one parameter due to exogenous or endogenous influence, but the parameters are themselves interwoven and influence each other.

By perceiving market boundaries defined by nine parameters of practices, the Market Practice Model provides a rational and dynamic approach to how markets are created, how they evolve, and how they cease to exist.

\subsubsection{RQ4 - Motivating Change in Actor Behaviour}

Schatzki (1996) argued that practices were normative and presented the rightness and acceptability of actions from a range of options. By normative, it is meant that market actors mutually understand what will be exchanged and how (Aspers, 2007, 2009; Kjellberg \& Helgesson, 2006, 2007). Market actors thus either followed the specific practices of a market or were subjected to corrective action by other actors. An example is the critical element of trust between market actors which enables market transvections both for the current exchange and in the future. Acting contrary to trust encourages exclusion of the actor (Layton, 2007; McLoughlin \& Horan, 2002). Furthermore, practices are social and cultural phenomena that are shared by members of the society, and incentives such as inclusion are provided such as the ability to participate in transvections, seek and share information, and so forth (Arnould, 2007; Arnould \& Thompson, 2005). To participate in a market, market actors adopt the collective cultural identity by participating in practices peculiar to a market, thus separating the "us" from the "other' (Lefebvre \& Nicholson-Smith, 1991; Morley \& Robins, 1995). The research for this thesis showed, for example, AS, who as a manager was proud to have a mobile telephone to the extent of hoping it would ring in public, when no longer a manager did not 
buy his own device because they were reserved for "movers and shakers". It was only when he saw the devices moving from "other" to "us" that he identified himself again with mobile telephone users. Furthermore, AS described using his mobile telephone extensively while driving, but now cannot do so because society has imposed restrictions on their use. Similarly, $\mathrm{AM}$ and $\mathrm{AR}$ showed how constant connectivity enabled by mobile telephones was at times to be rejected with social and business etiquette and rules established at a personal or corporate level.

Parameters thus answer Research Question 4, and contribute to our understanding of markets and market boundaries, by providing two distinct but related approaches to motivating market actors to perform in compliance with market practices. Parameters describe the behaviour expected of actors within a market compared with the "others" outside the market. Actors are thus compelled to perform in compliance with practices in order to gain access and participate within the market. The Market Practice Model describes a market being comprised of market performances by all the sellers and all the buyers, all the core competences, and all the networks of market actors, who are willing to conform to the practices delineated by market parameters. The model also supports conceptualisations that individual parameters and combined influences of parameters vary over time, and that change in one or more parameters may change the boundaries of a market. Therefore, the performances by market actors change in step in order to remain in the market.

\subsection{Managerial and Policy Implications}

\subsubsection{Strategy development}

The Market Practice Model has important implications for managers, beginning with an approach to strategy based on identifying cumulative parameter changes over time, and the likely impacts on market actors. 
Figure 7-1 Cumulative parameter change

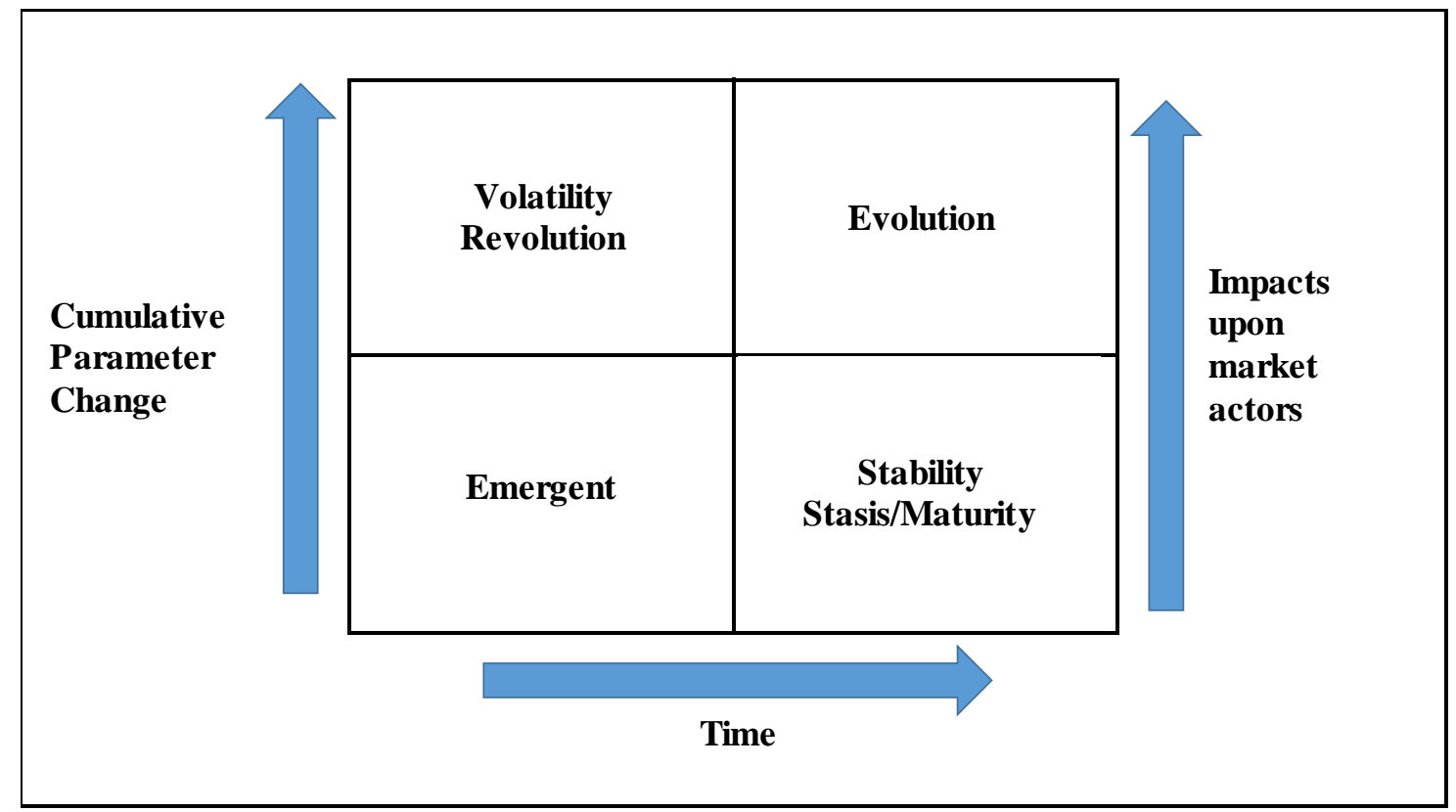

Analysis of markets and market changes at the parameter level would provide deeper understanding of transvections, consumers and socially-defined needs. Figure 7-1 depicts that cumulative change in parameters when measured against time and the likely extent of impacts on market actors. Firstly, low cumulative change in market practices over extended time frames is reflected in the stability of market maturity with few impacts on market actors. The emphasis in strategy development in this quadrant would be for managers to explore how the market parameters could be shaped endogenously to advantage, and to be alert for potential exogenous changes to market parameters. Substantial cumulative parameter change over a comparatively short time frame would suggest market volatility or revolution with substantial and sudden impacts on market actors. Cumulative changes over a longer timeframe suggest evolutionary developments but with no less effect on actors. Emergent markets' parameters are by contrast so markedly plastic as to challenge expectations and cumulative change and impacts cannot be conclusively predicted, for example on a macro scale such as electric cars where there are potential changes to the needs, value proposition, responsiveness, legal and economic institutions, social and community meanings, and spatial matrix parameters, or at the 
micro level where supermarkets in some New Zealand cities respond to the value proposition, information and social and community meanings parameters no longer provide plastic bags at checkout.

Strategy development would track and predict changes to parameters through deconstruction in the changes of competencies, materials, or the meanings attached to each. Market actors intending to shape a market would first identify parameters and then determine how parameters could be changed in their favour. Subsequent phases of strategy development would involve recognising and understanding the value proposition elements that define and enable the transvections being impacted by parameter change. A further phase would involve building in value through change-reflecting service definitions across transvectional networks. The research for the thesis provides the example where the payment process for mobile telephones shifted from traditional post-pay to pre-pay, thus creating a positive responsive action from private individuals previously not in the market.

\subsubsection{Policy Implications}

Market definition and market boundary definitions are critical for anti-competitive and mergeracquisition rules, and other policy considerations such as boundaries for health care and

education. To date, policies have centred on neoclassical economics-based approaches of geographical and price boundaries even where notably deficient (Baker, 2007; Commerce Commission of New Zealand, 2014b; Farmer, 2002; Geroski, 1998). A contribution of the Market Practice Model to policy development and implementation is that market boundaries and exchange processes may be more accurately and objectively described by consideration of all nine parameters of any particular market. 


\subsection{Limitations}

A key limitation to this research was that the exploration involved only one market. A further significant limitation involves the limited number of individuals describing that may have taken place some considerable time previous. Unavoidably, the research depended on the interview subjects' abilities to accurately describe and articulate their position or actions, and on the interviewer accurately comprehending these expressions of perception (Mason, 2002). These limitations were to a degree mitigated by the use of protocols to select multiple interview sources, substantial trustworthy documentary materials, and the triangulation of material (O'Driscoll, 2006). Triangulation involved the comparison between documentary material, matrices and interviews. At times the interview sources provided confidence through the congruency of the material from interview subjects. At times confidence was provided whereby interview subjects, from their different and often conflicted perspectives, collectively provided multi-dimensional and very real descriptions of an event, much like six people each describing a different side of a dice. Furthermore, while interview numbers were limited, they included all the relevant actors at provider and regulator level throughout the research period, and all eras were covered by multiple user interviewees and deep congruence established between them.

New Zealand's geographic isolation, which was a criteria favouring New Zealand's mobile telecommunication market as a research subject, created a further limitation as the hard geographic boundary often restricted the perceptual sets of market actors (Weiten, 2007).

A further limitation was that only constructionist methodologies were used. Abductive reflexive methodologies are founded on pre-structured understanding shaped by theory. To mitigate pre-understanding inappropriately dominating, whereby the interpretation of empirical data will tend to confirm the theory, the researcher remained alert to alternate theories, and was cautious in avoiding over-reliance on sources from a highly unified dominant 
paradigm (Alvesson \& Sköldberg, 2009). This research has drawn not only on literature directly supporting a social practice approach but also refers, for example, to neoclassical economics, new institutional economics, institutional logic, sociology, and military and political history. Furthermore, development of this thesis involved intense periods of metatheoretical reflection involving detached critique of the market practices model and its elements including parameter nomenclature and definitions (Alvesson \& Sköldberg, 2009).

\subsection{Future Research}

The research for this thesis involved a single rapidly evolving market. The changes in the parameters of the New Zealand mobile market were indeed so constant and emphatic during market emergence, that it was not readily possible to clearly determine which parameters first changed, nor all the influences between parameters, nor the sequencing of influences on performances and institutional practices. Further empirical evidence from situated investigations would refine theorisations of market parameters, provide insights into the interrelationships between parameters, and assist understanding of the influence of parameters on market performances and institutional practices as markets emerge and evolve.

The extent and impetus of change in parameters required to overcome the inherent inertia and stability of institutional practices may be market specific or may be dependent on the phase of the market life cycle. The current research brought to light some of these connections but further situated research would perhaps enable explication of the extent of forces required to effect market change. This would necessarily include further investigation into the processes whereby potential market actors learn and absorb the practices of a market and how they are motivated to do so. 
The applied managerial and policy implications also suggest further research, particularly in how an understanding of parameters could enable isolation of specific practices to allow for targeted market boundary definition and strategising of market shaping efforts.

Describing a market based on institutional practices - normative, representational and exchange - that define and stabilise, and that categories of parameterising practices define boundaries and provide elasticity and destabilisation, suggests a hierarchy of practices. Social practices research should continue to explore the hierarchy and specificity of the categories and subcategories of market practices, and furthermore isolate whether practices are marketspecific or generalisable.

\subsection{Renewing the Great Debate}

I conclude by referring to the quote used at the opening of this thesis, that for a profession that purports to be interested in markets, surprisingly few resources are devoted to defining our basic unit of analysis (Geroski, 1998, p. 678). His lamentation was directed at his fellow economists but could have readily been meant for marketing. Indeed, his comment was kindling for this research. There have been repeated calls for development of a market model that reflects contemporary marketing theorising and which could provide context for future efforts (Venkatesh \& Penaloza, 2006). The Market Practice Model based in social practice theory is one such attempt. The debate for a new basis for market and marketing conceptualisation has to date, however, been at an insufficiently theoretical level. The ontological basis for the neoclassical economics frame of markets being comprised of rational self-actualising actors in a science-oriented mathematically-described world was developed in the great philosophical debates in Germany in the mid to late $19^{\text {th }}$ century (Jones $\&$ Monieson, 1990; Lawson, 2010, 2013). If, as Reckwitz (2002) argues, we are neither homo economicus nor homo sociologicus, then how do we see ourselves? This research provides a fresh perspective for future market and marketing conceptualisation and exploration. The final 
contribution is the further impetus towards the ontological discussion on how we see humankind in the $21^{\text {st }}$ century. Service dominant logic, market ecosystems, consumer culture theory and market practice models (and economics) may collectively be parts of an answer but I suggest that a new general theory of markets and marketing cannot hope to emerge until at an ontological level the philosophical arguments are resurfaced and renewed. 


\section{REFERENCES}

Abernathy, W. J., \& Utterback, J. M. (1978). Patterns of industrial innovation. Technology Review, 80(7), 41-47.

AF. (2016) /Interviewer: M. J. Gosling.

Ager, A., \& Loughry, M. (2004). Psychology and humanitarian assistance. Journal of Humanitarian Assistance.

Ågerfalk, P., \& Fitzgerald, B. (2006). Exploring the concept of method rationale: A conceptual tool Advanced Topics in Database Research (Vol. 5, pp. 63-78).

Alderson, W., \& Martin, M. W. (1965). Toward a formal theory of transactions and transvections. Journal of Marketing Research, 2(2), 117-127.

Alvesson, M., \& Sköldberg, K. (2009). Reflexive Methodology: New Vistas for Qualitative Research. London: Sage.

AM. (2016) /Interviewer: M. J. Gosling.

Andersson, P., Aspenberg, K., \& Kjellberg, H. (2008). The configuration of actors in market practice. Marketing Theory, 8(1), 67-90.

AR. (2016) /Interviewer: M. J. Gosling.

Araujo, L. (2007). Markets, market-making and marketing. Marketing Theory, 7(3), 211-226.

Arnould, E. J. (2007). Service-dominant logic and consumer culture theory: Natural allies in an emerging paradigm Consumer Culture Theory (pp. 57-76): Emerald Group Publishing Limited.

Arnould, E. J., \& Thompson, C. (2007). Consumer culture theory (and we really mean theoretics): dilemmas and opportunities posed by an academic branding strategy. Research in Consumer Behavior, 11, 3.

Arnould, E. J., \& Thompson, C. J. (2005). Consumer culture theory (CCT): Twenty years of research. Journal of Consumer Research, 31(4), 868-882. 
Arrow, K. J. (1974). The Limits of Organization. New York: Norton.

AS. (2016) /Interviewer: M. J. Gosling.

Aspers, P. (2007). Theory, reality, and performativity in markets. American Journal of Economics and Sociology, 66(2), 379-398.

Aspers, P. (2009). How are markets made? Retrieved from Cologne, Germany:

Automobile Association. (2017). Mobile phones and driving. Retrieved from http://www.aa.co.nz/about/safety-on-the-roads/safer-drivers/staying-focussed-andalert/mobile-phones/

Baker, J. B. (2007). Market Definition: An Analytical Overview. Antitrust Law Journal, 74(1), 129-173.

Balcombe, J. (1996). Fiduciary relationships: dream or nightmare? New Zealand Law Journal, 1996(11), 402-404.

Baskerville, R. L. (1999). Investigating information systems with action research. Communications of the AIS, 2(3es), 4.

Beard, M. (2016). SPQR. London: Profile Books.

Berndt, C., \& Boeckler, M. (2009). Geographies of circulation and exchange: Constructions of markets. Progress in Human Geography, 33(4), 535-551.

Bhappu, A. D. (2000). The Japanese family: An institutional logic for Japanese corporate networks and Japanese management. Academy of Management Review, 25(2), 409415.

Blanning, T. (2015). Frederick the Great: King of Prussia. London: Penguin UK.

Boeckler, M., \& Berndt, C. (2013). Geographies of circulation and exchange III: The great crisis and marketization 'after markets'. Progress in Human Geography, 37(3), 424432. 
Brennan, R. (2006). Evolutionary economics and the markets-as-networks approach. Industrial Marketing Management, 35(7), 829-838.

Broadband essential for delivering future growth. (2006, 4 February). The New Zealand Herald.

Brooks, G. R. (1995). Defining market boundaries. Strategic Management Journal, 16(7), $535-549$.

Budd, R. A., Karidis, J. P., \& McVicker, G. (1999). Personal communicator including a handset phone with an integrated virtual image display: Google Patents.

Buzzell, R. D. (1999). Market Functions and Market Evolution. Journal of Marketing, 63(special), 61-64.

Call to penalise drivers harder for using cellphones while driving as road toll soars. (2017). The Dominion Post.

Callon, M., \& Muniesa, F. (2005). Peripheral vision economic markets as calculative collective devices. Organization Studies, 26(8), 1229-1250.

Casson, M., \& Lee, J. S. (2011). The origin and development of markets: A business history perspective. Business History Review, 85(1), 9-37.

Cavana, R. Y., Delahaye, B. L., \& Sekaran, U. (2001). Applied Business Research: Qualitative and Quantitative Methods. Sydney: John Wiley and Sons.

Cayla, J., \& Eckhardt, G. M. (2008). Asian brands and the shaping of a transnational imagined community. Journal of Consumer Research, 35(2), 216-230.

Clark, G. (2001). Markets and economic growth: The grain market of medieval England. Davis: University of California.

Coase, R. H. (1988). The Firm, the Market, and the Law. Chicago: University of Chicago Press. 
Coase, R. H. (2005). The Institutional Structure of Production. In C. Menard \& M. M. Shirley (Eds.), Handbook of New Institutional Economics: Springer.

Commerce Commission of New Zealand. (1994). Annual Report 1994. Wellington, New Zealand.

Commerce Commission of New Zealand. (1996). Annual Report 1996. Wellington, New Zealand.

Commerce Commission of New Zealand. (1997). Annual Report 1997. Wellington, New Zealand.

Commerce Commission of New Zealand. (2006a). Annual Report 2006. Wellington.

Commerce Commission of New Zealand. (2006b). Commerce Commission to investigate mobile market [Press release]

Commerce Commission of New Zealand. (2008). 2007 Telecommunications Monitoring Report. Wellington, New Zealand.

Commerce Commission of New Zealand. (2011). Annual Report 2011. Wellington, New Zealand.

Commerce Commission of New Zealand. (2012). Annual Report 2012. Wellington, New Zealand.

Commerce Commission of New Zealand. (2013). Annual Report 2013. Wellington, New Zealand.

Commerce Commission of New Zealand. (2014a). Annual Report 2014. Wellington, New Zealand.

Commerce Commission of New Zealand. (2014b). Merger and Acquisition Guidelines. Wellington New Zealand.

Commerce Commission of New Zealand. (2015). 2014 Annual Telecommunications Monitoring Report. Wellington, New Zealand. 
Crotty, M. (1998). The Foundations of Social Research: Meaning and Perspective in the Research Process. London; Thousand Oaks: Sage.

Dacin, M. T., Goodstein, J., \& Scott, W. R. (2002). Institutional theory and institutional change: Introduction to the special research forum. Academy of Management Journal, 45(1), 45-56.

Dahlberg, L. (2001). The Internet and democratic discourse: Exploring the prospects of online deliberative forums extending the public sphere. Information, Communication \& Society, 4(4), 615-633.

Day, G. S., \& Montgomery, D. B. (1999). Charting new directions for marketing. The Journal of Marketing, 63(Special Issue), 3-13.

Dobson, G. (2006, 22 February). Letter to the Editor. The Dominion Post.

DS. (2016) /Interviewer: M. J. Gosling.

Dubois, A., \& Gadde, L.-E. (2014). “Systematic combining”-A decade later. Journal of Business Research, 67(6), 1277-1284.

Eagles, I., Longdin, L., Grantham, R., Prasad, R., Rickett, C., Cripps, C., Mapp, W., Gunasekara, G., \& Brown, L. (2001). Law in Business and Government in New Zealand (Third ed.). Auckland, New Zealand: Palatine Press.

Easton, G. (2002). Marketing: A critical realist approach. Journal of Business Research, 55(2), 103-109.

Easton, G. (2010). Critical realism in case study research. Industrial Marketing Management, 39(1), 118-128.

Eco, U. (1976). A Theory of Semiotics (Vol. 217): Indiana University Press.

Eco, U. (1992). Interpretation and overinterpretation: Cambridge University Press.

Eder, K. (2006). The public sphere. Theory, culture \& society, 23(2-3), 607-611. 
Eisenstadt, S. N., \& Schluchter, W. (2001). Public spheres and collective identities. New Brunswick: Transaction Publishers.

Elvey, A. (2006, 22 February). Letter to the Editor. The Dominion Post.

Evans, L., Grimes, A., Wilkinson, B., \& Teece, D. (1996). Economic Reform in New Zealand 1984-95: The Pursuit of Efficiency. Journal of Economic Literature, 34(4), 18561902.

Farmer, J. D. (2002). Market force, ecology and evolution. Industrial and Corporate Change, $11(5), 895-953$.

Ferree, M. M., Gamson, W. A., Gerhards, J., \& Rucht, D. (2002). Four models of the public sphere in modern democracies. Theory and Society, 31(3), 289-324.

Finch, J., \& Geiger, S. (2010). Positioning and relating: Market boundaries and the slippery identity of the market object. Marketing Theory, 10(3), 237-251.

Fourcade, M. (2007). Theories of Markets and Theories of Society. American Behavioral Scientist, 50(8), 1015-1034.

Geiger, S., Kjellberg, H., \& Spencer, R. (2012). Shaping exchanges, building markets. Consumption Markets \& Culture, 15(2), 133-147.

Geroski, P. A. (1998). Thinking creatively about markets. International Journal Industrial Organisation, 16(6), 677-695.

Giddens, A. (1984). The Constitution of Society: Outline of the Theory of Structuration. Cambridge: Polity Press.

Giddens, A. (1993). New Rules of Sociological Method: A Positive Critique of Interpretative Sociologies: Polity Press.

Ginev, D. (1998). Rhetoric and Double Hermeneutics in the Human Sciences. Human Studies, 21(3), 259-271. 
Glynos, J. (2011). The Place of the Fantasy in a Critical Political Economy: The Case of Market Boundaries. Cardozo L. Rev., 33, 2373.

Goggin, G. (2006). Notes on the history of the mobile phone in Australia. Southern Review: Communication, Politics \& Culture, 38(3), 4.

Gosling, M., Richard, J., \& Seo, Y. (2017). Markets and market boundaries: a social practice approach. Journal of Service Theory and Practice, 27(2), 408 - 426.

Granovetter, M. (1985). Economic Action and Social Structure: The Problem of Embeddedness. American Journal of Sociology, 91 (3 (Nov)), 481-510.

Gregor, S. (2006). The Nature of Theory in Information Systems. MIS quarterly, 30(3), 611642.

Grönroos, C. (1989). Defining Marketing: A Market-Oriented Approach. European Journal of Marketing, 23(1), 52-60.

Grönroos, C. (1994). Quo Vadis, marketing? Toward a relationship marketing paradigm. Journal of Marketing Management, 10(5), 347-360.

Guba, E. G., \& Lincoln, Y. S. (1994). Competing Paradigms in Qualitative Research. Handbook of qualitative research, 2, 163-194.

Gummesson, E. (1994). Service Management: An Evaluation and the Future. International Journal of Service Industry Management, 5(1), 77-96.

Gummesson, E. (2000). Qualitative Methods in Management Research (2nd ed.). Thousand Oaks, CA: Sage Publications.

Gummesson, E. (2002). Relationship Marketing in the New Economy. Journal of Relationship Marketing, 1(1), 37-57.

Hagberg, J., \& Kjellberg, H. (2010). Who performs marketing? Dimensions of agential variation in market practice. Industrial Marketing Management, 39(6), 1028-1037. 
Halkier, B., \& Jensen, I. (2011). Methodological challenges in using practice theory in consumption research. Examples from a study on handling nutritional contestations of food consumption. Journal of Consumer Culture, 11(1), 101-123.

Hargreaves, T. (2011). Practice-ing behaviour change: Applying social practice theory to proenvironmental behaviour change. Journal of Consumer Culture, 11(1), 79-99.

Hauser, G. A. (1999). Vernacular voices: The rhetoric of publics and public spheres: Univ of South Carolina Press.

Horsman, J., \& St John, S. (1992). Economics: A New Approach. Auckland: Longman Paul.

Hossain, M., Prevost, A. K., \& Rao, R. P. (2001). Corporate governance in New Zealand: The effect of the 1993 Companies Act on the relation between board composition and firm performance. Pacific-Basin Finance Journal, 9(2), 119-145.

Howell, B. (2007). Pendulous progress 20 years of NZ telcoms regulation. Competition and Regulation Times(24).

Howell, B., \& Obren, M. (2003). Telecommunications usage in New Zealand: 1993-2003. New Zealand Institute for the Study of Competition and Regulation.

Humphreys, A. (2010). Megamarketing: The Creation of Markets as a Social Process. Journal of Marketing, 74(2), 1-19.

Hunt, S. D. (1983). General Theories and the Fundamental Explanada of Marketing. Journal of Marketing, 47(4), 9-17.

Jessop, B. (2012). Cultural Political Economy, Spatial Imaginaries, Regional Economic Dynamics. Lancaster University, Cultural Political Economy Research Centre. Lancaster (CPERC Working Paper, 2012-04). Available online at http://www. lancaster. ac. uk/cperc/docs/Jessop\% 20CPERC\% 20Working\% 20Paper, 202, 012002. 
Jessop, B., Brenner, N., \& Jones, M. (2008). Theorizing sociospatial relations. Environment and planning D: society and space, 26(3), 389-401.

Jones, D. B., \& Monieson, D. D. (1990). Early Development of the Philosophy of Marketing Thought. The Journal of Marketing, 54(1), 102-113.

Kilduff, M., Funk, J. L., \& Mehra, A. (1997). Engineering identity in a Japanese factory. Organization Science, 8(6), 579-592.

Kjellberg, H., \& Helgesson, C.-F. (2006). Multiple versions of markets: Multiplicity and performativity in market practice. Industrial Marketing Management, 35(7), 839-855.

Kjellberg, H., \& Helgesson, C.-F. (2007). On the nature of markets and their practices. Marketing Theory, 7(2), 137-162.

Kjellberg, H., Storbacka, K., Akaka, M., Chandler, J., Finch, J., Lindeman, S., Löbler, H., Mason, K., McColl-Kennedy, J., \& Nenonen, S. (2012). Market futures/future markets: Research directions in the study of markets. Marketing Theory, 12(2), 219223.

Koopmans, R., \& Erbe, J. (2004). Towards a European public sphere? Vertical and horizontal dimensions of Europeanized political communication. Innovation: The European Journal of Social Science Research, 17(2), 97-118.

Korkman, O., Storbacka, K., \& Harald, B. (2010). Practices as markets: Value co-creation in e-invoicing. Australasian Marketing Journal (AMJ), 18(4), 236-247.

Kotler, P. (1986). Megamarketing. Harvard Business Review, 64(2), 117-124.

Land Transport (Road User) Rule 2004, § 7.3A (2004).

Lawson, T. (2005). The nature of heterodox economics. Cambridge Journal of Economics, $30(4), 483-505$.

Lawson, T. (2010). Ontology, modern economics, and pluralism. Economic pluralism, 99113. 
Lawson, T. (2013). What is this 'school'called neoclassical economics? Cambridge Journal of Economics, 37(5), 947-983.

Layton, R. A. (2007). Marketing Systems-A Core Macromarketing Concept. Journal of Macromarketing, 27(3), 227-242.

Layton, R. A. (2008). The Search for a Dominant Logic A Macromarketing Perspective. Journal of Macromarketing, 28(3), 215-227.

Layton, R. A. (2011). Towards a theory of marketing systems. European Journal of Marketing, 45(1/2), 259-276.

Layton, R. A. (2015). Formation, Growth, and Adaptive Change in Marketing Systems. Journal of Macromarketing, 35,3, 302-319.

Lefebvre, H., \& Nicholson-Smith, D. (1991). The Production of Space (Vol. 142): Oxford Blackwell.

Leonardi, P. M. (2011). When flexible routines meet flexible technologies: Affordance, constraint, and the imbrication of human and material agencies. MIS quarterly, 35(1), 147-167.

Levine, S., \& Roberts, N. S. (1991). The New Zealand General Election of 1990. Political Science, 43(1), 1-19.

Lindeman, S. (2012). Market formation in subsistence contexts: a study of informal waste trade practices in Tanzania and Brazil. Consumption Markets \& Culture, 15(2), 235257.

Lindseth, A., \& Norberg, A. (2004). A phenomenological hermeneutical method for researching lived experience. Scandinavian Journal of Caring Sciences, 18(2), 145153. 
Lloyd's. (2015). The early days. From the rise of Lloyd's as a maritime insurer to the growth of Lloyd's non marine market in the US. Retrieved from https://www.lloyds.com/lloyds/about-us/history/corporate-history/the-early-days

Löffler, G. (1998). Market areas-a methodological reflection on their boundaries.

GeoJournal, 45(4), 265-272.

M1. (2016) /Interviewer: M. J. Gosling.

M2. (2016) /Interviewer: M. J. Gosling.

Martin, D. M., \& Schouten, J. W. (2014). Consumption-Driven Market Emergence. Journal of Consumer Research, 40(5), 855-870.

Mason, J. (2002). Qualitative Researching (Second ed.). London: Sage Publications Ltd.

McGuigan, J. R., \& Moyer, R. C. (1989). Managerial Economics. St Paul, MN: West Publishing.

McLoughlin, D., \& Horan, C. (2002). Markets-as-networks: notes on a unique understanding. Journal of Business Research, 55(7), 535-543.

McMillan, J. (2002). Reinventing The Bazaar. A Natural History of Markets. New York: W.W. Norton and Co.

Mele, C., Colurcio, M., \& Russo-Spena, T. (2014). Research traditions of innovation: Goodsdominant logic, the resource-based approach, and service-dominant logic. Managing Service Quality, 24(6), 612-642.

Mele, C., Pels, J., \& Storbacka, K. (2015). A holistic market conceptualization. Journal of the Academy of Marketing Science, 43(1), 100-114.

Ménard, C., \& Shirley, M. M. (2005). Handbook of New Institutional Economics. Dordrecht, The Netherlands: Springer.

Miles, M. B., Huberman, A. M., \& Saldaña, J. (2013). Qualitative Data Analysis: A Methods Sourcebook: SAGE Publications, Incorporated. 
Milgrom, P. R., \& Roberts, J. (1992). Economics, Organisation and Management. Upper Saddle River, New Jersey: Prentice-Hall.

Miller, D. (2002). Turning Callon the right way up. Economy and Society, 31(2), 218-233. ML. (2016) /nterviewer: M. J. Gosling.

Morley, D., \& Robins, K. (1995). Spaces of identity: Global media, electronic landscapes and cultural boundaries. London: Routledge.

Myers, M. D. (1997). Qualitative research in information systems. Management Information Systems Quarterly, 21(2), 241-242.

Nenonen, S., Kjellberg, H., Pels, J., Cheung, L., Lindeman, S., Mele, C., Sajtos, L., \& Storbacka, K. (2014). A new perspective on market dynamics: Market plasticity and the stability-fluidity dialectics. Marketing Theory, 14(3), 269-289.

Nenonen, S., Möller, K., \& Storbacka, K. (2017). Market Innovation: Renewal of Traditional Industrial Networks Innovating in Practice (pp. 59-81): Springer.

Nenonen, S., \& Storbacka, K. (2011). On the marketness of markets. Paper presented at the Proceedings from The 2011 Naples Forum on Service: Service Dominant logic, Network \& Systems Theory and Service Science: integrating three perspectives for a new service agenda.

Nenonen, S., Storbacka, K., \& Rehl, S. (2014). Capabilities for Shaping and Making Markets. Paper presented at the 30th Annual Industrial Marketing \& Purchasing Conference, Bordeaux, France.

Nili, A., Tate, M., Johnstone, D., \& Gable, G. (2014). A Framework for Qualitative Analysis of Focus Group Data in Information Systems. Paper presented at the 25th Australasian Conference on Information Systems, Auckland, New Zealand.

NL. (2016) /Interviewer: M. J. Gosling. 
North, D. C. (2005). Institutions and the Performance of Economies Over Time. In C.

Menard \& M. M. Shirley (Eds.), Handbook of New Institutional Economics (pp. 21-

30). Heidelberg, Germany: Springer.

O'Driscoll, A. (2006). Reflection on contemporary issues in relationship marketing: Evidence from a longitudinal case study in the building materials industry. Journal of Marketing Management, 22(1-2), 111-133.

P1. (2016) /Interviewer: M. J. Gosling.

P2. (2016) /Interviewer: M. J. Gosling.

P3. (2016) /Interviewer: M. J. Gosling.

Papacharissi, Z. (2002). The virtual sphere: the internet as a public sphere. New Media and Society, 4(9), 9-27.

Parkin, M. (1993). Microeconomics. New York: Addison-Wesley.

Patterson, R., Mazzoleni, A., \& Pickering, G. (2011). Standard Terms Determination for the designated services of the mobile termination access services (MTAS) fixed-to-mobile voice (FTM), mobile-to-mobile voice (MTM) and short messaging services (SMS).

Wellington: Commerce Commission of New Zealand.

Penaloza, L., \& Venkatesh, A. (2006). Further evolving the new dominant logic of marketing: from services to the social construction of markets. Marketing Theory, 6 , 299-316.

Perez, C. (2009). Technological revolutions and techno-economic paradigms. Cambridge Journal of Economics, 34(1), 185-202.

Prensky, M. (2001). Digital Natives, Digital Immigrants part 1. On the Horizon, 9(5), 1-6.

PT. (2016) /Interviewer: M. J. Gosling.

R1. (2016) /Interviewer: M. J. Gosling.

R2. (2016) /Interviewer: M. J. Gosling. 
R3. (2016) /Interviewer: M. J. Gosling.

Real competition needed to broaden horizons. (2006, 24 February). The Dominion Post.

Rebstock, P., Mazzoleni, A., \& Pickering, G. (2008). Standard Terms Determination for the specified service co-location on cellular mobile transmission sites. Wellington: Commerce Commission of New Zealand.

Reckwitz, A. (2002). Toward a Theory of Social Practices: A Development in Culturalist Theorizing. European Journal of Social Theory, 5(2), 243-263.

RG. (2016) /Interviewer: M. J. Gosling.

Ridley, M. (2010). The Rational Optimist: How Prosperity Evolves. London: Fourth Estate. Ringing the changes. (2006, 15 February). The Dominion Post.

Ringold, D. J. (2006). The Morality of Markets, Marketing, and the Corporate Purpose. . In J. N. Seth \& R. S. Sisodia (Eds.), Does Marketing Need Reform?: Fresh Perspectives on the Future (pp. 64-68). Armonk, New York: M.E. Sharpe Inc.

Rosa, J. A., Porac, J. F., Runser-Spanjol, J., \& Saxon, M. S. (1999). Sociocognitive Dynamics in a Product Market. Journal of Marketing, 63(Fundamental Issues and Directions for Marketing), 64-77.

RV. (2016) /Interviewer: M. J. Gosling.

Rynes, S., \& Gephart jr, R. P. (2004). Qualitative Research and the Academy of Management Journal. The Academy of Management Journal, 47(4), 454-462.

Savitt, R. (1980). Historical research in marketing. The Journal of Marketing, 52-58.

Scaraboto, D., \& Fischer, E. (2013). Frustrated Fatshionistas: An Institutional Theory Perspective on Consumer Quests for Greater Choice in Mainstream Markets. Journal of Consumer Research, 39(6), 1234-1257.

Schatzki, T. R. (1996). Social practices: A Wittgensteinian approach to human activity and the social. Cambridge, United Kingdom: Cambridge University Press. 
Schau, H. J., Muñiz Jr, A. M., \& Arnould, E. J. (2009). How Brand Community Practices Create Value. Journal of Marketing, 73(5), 30-51.

Scobie, G. M., \& Janssen, J. (1993). Liberalising New Zealand's Economy: Rehabilitation and Recovery. Policy, 9(3), 5-9.

Scott, W. R. (1995). Institutions and Organizations. Thousand Oaks, CA: Sage Publications.

Scott, W. R. (2008). Approaching adulthood: the maturing of institutional theory. Theory and Society, 37(5), 427-442.

Seo, Y., \& Jung, S.-U. (2016). Beyond solitary play in computer games: The social practices of eSports. Journal of Consumer Culture, 16(3), 635-655. doi:1469540514553711

Seth, J. N., \& Sisodia, R. S. (2006). Introduction: Does Marketing Need Reform? Does Marketing Need Reform?: Fresh Perspectives on the Future. (pp. 3-13). Armonk New York: M E Sharpe Inc.

Shove, E., \& Pantzar, M. (2005). Consumers, Producers and Practices Understanding the invention and reinvention of Nordic walking. Journal of Consumer Culture, 5(1), 4364.

Shove, E., Pantzar, M., \& Watson, M. (2012). The Dynamics of Social Practice. London: Sage.

Spark New Zealand. (2014). Spark New Zealand Annual Report 2014. Auckland, New Zealand: Spark New Zealand.

Spiggle, S. (1994). Analysis and Interpretation of Qualitative Data in Consumer Research. Journal of Consumer Research, 491-503.

SS. (2016) /Interviewer: M. J. Gosling.

State-Owned Enterprises Act, 124 Stat. (1986).

Statistics New Zealand. (2017). Census. Retrieved from http://www.stats.govt.nz/Census.aspx 
Stewart, L. (1995). Bodies, visions, and spatial politics: a review essay on Henri Lefebvre's The Production of Space. Environment and Planning D, 13, 609-609.

Stigler, G. J., \& Sherwin, R. A. (1985). The Extent of the Market. The Journal of Law and Economics, 28(3), 555-585.

Storbacka, K., \& Nenonen, S. (2011a). Markets as configurations. European Journal of Marketing, 45(1/2), 241-258.

Storbacka, K., \& Nenonen, S. (2011b). Scripting markets: From value propositions to market propositions. Industrial Marketing Management, 40(2), 255-266.

Telecom New Zealand. (1992). Telecom New Zealand Annual Report 1992. Wellington, New Zealand.

Telecom New Zealand. (1993). Telecom New Zealand Annual Report 1993. Wellington, New Zealand.

Telecom New Zealand. (1994). Telecom New Zealand Annual Report 1994. Wellington, New Zealand.

Telecom New Zealand. (1995). Telecom New Zealand Annual Report 1995. Wellington, New Zealand.

Telecom New Zealand. (1996). Telecom New Zealand Annual Report 1996. Wellington, New Zealand.

Telecom New Zealand. (1997). Telecom New Zealand Annual Report 1997. Wellington, New Zealand.

Telecom New Zealand. (1998). Telecom New Zealand Annual Report 1998. Wellington, New Zealand.

Telecom New Zealand. (1999). Telecom New Zealand Annual Report 1999. Wellington, New Zealand. 
Telecom New Zealand. (2000). Telecom New Zealand Annual Report 2000. Wellington, New Zealand.

Telecom New Zealand. (2001). Telecom New Zealand Annual Report 2001. Wellington, New Zealand.

Telecom New Zealand. (2002). Telecom New Zealand Annual Report 2002. Wellington, New Zealand.

Telecom New Zealand. (2003). Telecom New Zealand Annual Report 2003. Wellington, New Zealand.

Telecom New Zealand. (2004). Telecom New Zealand Annual Report 2004. Wellington, New Zealand.

Telecom New Zealand. (2005). Telecom New Zealand Annual Report 2005. Wellington, New Zealand.

Telecom New Zealand. (2006). Telecom New Zealand Annual Report 2006. Wellington, New Zealand.

Telecom New Zealand. (2007). Telecom New Zealand Annual Report 2007. Wellington, New Zealand.

Telecom New Zealand. (2008). Telecom New Zealand Annual Report 2008. Wellington, New Zealand.

Telecom New Zealand. (2009). Telecom New Zealand Annual Report 2009. Wellington, New Zealand: Telecom New Zealand.

Telecom New Zealand. (2010). Telecom New Zealand Annual Report 2010. Wellington, New Zealand: Telecom New Zealand.

Telecom New Zealand. (2011). Telecom New Zealand Annual Report 2011. Auckland, New Zealand: Telecom New Zealand. 
Telecom New Zealand. (2012). Telecom New Zealand Annual Report 2012. Auckland, New Zealand: Telecom New Zealand.

Telecom New Zealand. (2013). Telecom New Zealand Annual Report 2013. Auckland, New Zealand: Telecom New Zealand,.

Telecommunications Act, 103 Stat. (2001).

Thompson, C. J. (1997). Interpreting Consumers: A Hermeneutical Framework for Deriving Marketing Insights from the Texts of Consumers' Consumption Stories. Journal of Marketing Research, 438-455.

Thorelli, H. B. (1986). Networks: Between Markets and Hierarchies. Strategic Management Journal, 7(1), 37-51.

Thornton, P. H., Jones, C., \& Kury, K. (2005). Institutional logics and institutional change in organizations: Transformation in accounting, architecture, and publishing. In P. H. Thornton \& C. Jones (Eds.), Research in the Sociology of Organizations (Vol. 23, pp. 125-170). Amsterdam, The Netherlands: Elsevier Ltd.

Thornton, P. H., \& Ocasio, W. (2008). Institutional Logics. In R. Greenwood, C. Oliver, R. Suddaby, \& K. Sahlin-Anderson (Eds.), The Sage Handbook of Organizational Institutionalism (pp. 99-128).

Urquhart, C., Lehmann, H., \& Myers, M. D. (2010). Putting the 'theory'back into grounded theory: guidelines for grounded theory studies in information systems. Information Systems Journal, 20(4), 357-381.

Vargo, S. L., Koskela-Huotari, K., Baron, S., Edvardsson, B., Reynoso, J., \& Colurcio, M. (2017). A systems perspective on markets-Toward a research agenda. Journal of Business Research, 79, 260-268.

Vargo, S. L., \& Lusch, R. F. (2004a). Evolving to a new dominant logic for marketing. Journal of Marketing, 68(1), 1-17. 
Vargo, S. L., \& Lusch, R. F. (2004b). The four service marketing myths remnants of a goodsbased, manufacturing model. Journal of Service Research, 6(4), 324-335.

Vargo, S. L., \& Lusch, R. F. (2008). Service-dominant logic: continuing the evolution. . Journal of the Academy of Marketing Science, 36(1), 1-10.

Vargo, S. L., \& Lusch, R. F. (2011). It's all B2B... and beyond: Toward a systems perspective of the market. Industrial Marketing Management, 40(2), 181-187.

Vargo, S. L., \& Lusch, R. F. (2014). Inversions of service-dominant logic. Marketing Theory, 14(3), 239-248.

Vargo, S. L., \& Lusch, R. F. (2016). Institutions and axioms: an extension and update of service-dominant logic. Journal of the Academy of Marketing Science, 44(1), 5-23.

Venkatesh, A., \& Penaloza, L. (2006). From Marketing to the Market. In J. N. Seth \& R. S. Sisodia (Eds.), Does Marketing Need Reform?: Fresh Perspectives for the Future (pp. 134-150). Armonk, New York: M.E. Sharpe.

Walsh, S. P., White, K. M., \& Young, R. M. (2008). Over-connected? A qualitative exploration of the relationship between Australian youth and their mobile phones. Journal of adolescence, 31(1), 77-92.

Warde, A. (2005). Consumption and Theories of Practice. Journal of Consumer Culture, $5(2), 131-153$.

Webster, F. E., Jr. (1992). The Changing Role of Marketing in the Corporation. Journal of Marketing, 56(4), 1-17.

Webster, F. E., Jr., \& Lusch, R. F. (2013). Elevating marketing: marketing is dead! Long live marketing! Journal of the Academy of Marketing Science, 41(4), 389-399.

Weiten, W. (2007). Psychology: Themes and variations: Themes and variations: Cengage Learning. 
Whetten, D. A., \& Mackey, A. (2002). A Social Actor Conception of Organizational Identity and Its Implications for the Study of Organizational Reputation. Business \& Society, 41(4), 393-414.

Wilson, H. S., \& Hutchinson, S. A. (1991). Triangulation of qualitative methods:

Heideggerian hermeneutics and grounded theory. Qualitative Health Research, 1(2), 263-276.

Wind, Y. (2006). Challenging the Mental Models of Marketing. In J. N. Seth \& R. S. Sisodia (Eds.), Does Marketing Need Reform?: Fresh Perspectives on the Future (pp. 95). Armonk New York: M E Sharpe Inc.

Zaltman, G., LeMasters, K., \& Heffring, M. (1982). Theory Construction in Marketing. New York: John Wiley \& Sons, Inc.

Zuckerman, E. W. (2003). Some Notes on the Relationship between Sociology and Economics (and Political Science): Cross Disciplinary Patterns over the 20th Century. Essay. MIT Sloan School of Management. 
APPENDICES 


\section{APPENDIX A Interview Protocol - Individuals}

\section{Section 1 - Research and Interview Objectives}

The research objective is to explore and catalogue those practices which parameterise markets. This phase of exploration involves interviews with participants in the New Zealand mobile telephone industry since 1994. This would help determine:

1. That the market can be defined by parameterising practices;

2. That the nine identified categories of parameterising practices that define the boundaries of a market are: information, technology, value propositions, competition, demand, legal and economic institutions, needs, space, and social and community meanings; or that

3. Other practices or redundant practices may be identified;

4. The influence of individual and combined parameterising practices varies over time;

5. Change in one or more parameterising practice may change the boundaries of a market; and

6. The greater the destabilisation of, and by, parameterising practices, the greater the changes in performances and institutional practices.

\section{Research Questions}

1. What parameterising practices can be identified?

2. How did these parameterising practices evolve?

3. What were the influences of evolving parameterising practices on market performances and institutional practices?

4. How does understanding of parameterising practices inform the market practice model?

5. What understandings do parameterising practices contribute to the social practices theoretical foundation of markets and marketing?

\section{Interview Objectives}

1. Ensure the participants understand the constructs and terminology to be discussed;

2. Ensure that each market phase is clearly identified.

3. Identify from the discussion the practices during each relevant market phase;

4. Identify current or new parameterisers or those that can be discarded; and

5. Identify those parameterisers that changed in the market over time. 


\section{Section 2: Introduction for the Participant}

Description of Project: Traditional thinking perceived markets as economic constructs. Contemporary understanding of markets sees them as social constructs reflecting their society. A defining element of societies is that they are somehow separate from other societies - there are boundaries around them. However, how to describe the boundaries of markets has been elusive. I am undertaking $\mathrm{PhD}$ research where I am developing a model of markets, and market boundaries, based on social practices and how the elements that constitute boundaries relate to each other as markets change.

Besides the theoretical contribution in describing markets and how they work and change, my two decades of experience as a corporate strategist suggests this approach would be useful for marketing and business strategy development, and would have policy implications in areas such as competition and consumer protection.

The social practices that constitute market boundaries are likely to be most observable during periods of change. The New Zealand mobile telecommunications market has seen substantial change since 1994, has been relatively free from exogenous influence, and so is ideal for this research. You have been a consumer in this market from its inception, and I would like to hear your story of adopting and using mobile communication devices from 1994 to the present day. Later, I will be interviewing executives involved in Telecom and Vodafone as far back as 1994. The interviews and the material developed from them will be confidential.

Format of Questions: Open-ended questions are used to gain a deeper understanding of what people did and said. Please feel free to talk about whatever comes to mind. The interview is iterative as we explore each market phase or era.

Involvement of other individuals and companies in this study: I am talking with people who directly or indirectly had the most impact on shaping the mobile communications market in New Zealand between 1994 and 2014. Similar conversations will be held with other users, and with executives of firms and regulators involved in this market.

Ethical Issues: Victoria University's high ethical standards and require me to inform you that:

1. Your answers will remain confidential and anonymous;

2. You can refuse to answer questions or discontinue this conversation at any time;

3. With your permission our conversation will be digitally recorded. Recording allows me to stay focused on the conversation and to note key points. The recording will be 
transcribed for analysis and a transcription made available to you as soon as possible. The recording will be destroyed at the end of the project.

4. If requested a summary of the thesis will be made available to you when the research is complete.

Do you have any reservations about me digitally recording this conversation? $\quad$ Yes No Do you have any questions before we start?

Participant Name:

Date:

Time Start

Time Finish

Place:

Interviewer 


\section{Section 3: Interview questions}

\section{General:}

Tell me about yourself, your occupation? How has this changed over the years?

Example Questions: We will now examine specific issues in each, say, five or ten-year phase.

1. Describe how you first came to have a mobile phone? What was it? What was most notable about it?

2. If this was personal, why did you decide to buy a device at this time? Why did you select this device? What was the main criteria for purchase? Describe the purchasing options. Want did you want? Why? What capabilities did it have, what did you use? Describe the purchase process.

3. If this was professional, what was the attitude of your organisation to the technology and who should have it for what purpose? Want did you want the device for? Why? What capabilities did it have, what did you use? Did the organisation have particular policies or practices? Were you constrained or hindered by them, or enabled? What was their influence? How did it change the way people connected with each other both inside and outside the organisation? And why this device?

4. Did you use this for business or for personal? Both? To what degree. What did you use the device for?

5. Describe the physical process of using this phone. How did you learn how to use it? What did you have to do differently?

6. What was your attitude to having this device? Did it make you feel somehow different to others, how? Was this a way of showing status? Did others see it that way? Did you feel somehow inclusive? In what way? Did it allow yourself greater control over your environment - a conquest of distance? What was the impact on your relationships with those close to you? With those who are usually more remote? How did you feel when actually using it in public? What did you do that you had not done before? What happened when it broke down, or you lost it?

7. Describe the attitude of other individuals to the use of the phone in general, and the use of this phone in particular? What were the attitudes of your colleagues, your customers, or your family? Did these constrain you? Amuse you? Enable?

8. What was the attitude of the community to mobile communications and to mobile communications providers? 
9. Did anyone else in your household have such a device? For what purpose?

10. Describe the providers, and the nature of the service, and their attitudes. How did companies compete for your business? What were they offering? What were they trying to achieve? Why did you use this company over that, or this phone over that?

11. What information was provided to you about these devices? What advertising do you recall? How did it influence you?

12. What pricing do you recall? How did that influence you?

13. Did you have a landline, a home computer? A GPS?

14. What was the uptake of technologies by colleagues, clients, friends and family, the broader community? How did this become apparent to you? What did this say to you?

15. How did technologies external to mobile services affect you and your friends, family and colleagues?

16. What were the technology issues at the time, both for mobile devices and for other related new technologies? How did you respond? How did the service providers respond? Were you satisfied? Did anything get in the way of what you wanted to do? What did you want more of? How did you let the providers of this technology know what you wanted or how you felt?

17. What was the nature of any innovation, both in the technology and in the use to which you put the technology?

18. Can you recall the political issues of the day, particularly in regard to these technologies? Do you remember what was in the newspapers about this?

19. How did this technology expand your social, physical and technical space? What were your priorities? Did you stay in touch with people just to stay in touch, did you have more to say? Did you feel perpetually contactable? Was this good?

20. As a result of this technology, what did you stop doing?

Thank you for that, now let us move forward. What was the next clear phase? Did you think of a new use, or did new capability become available?

Let us consider these points again in the light of the next phase of development Thank you for your participation. 
APPENDIX B - MARKET METRICS

\section{\begin{tabular}{|l|l|l|l|l|l|}
\hline 1990 & 1991 & 1992 & 1993 & 1994 & 195 \\
\hline
\end{tabular}}

Measurements

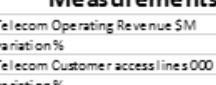

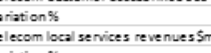

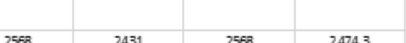

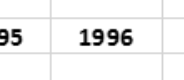

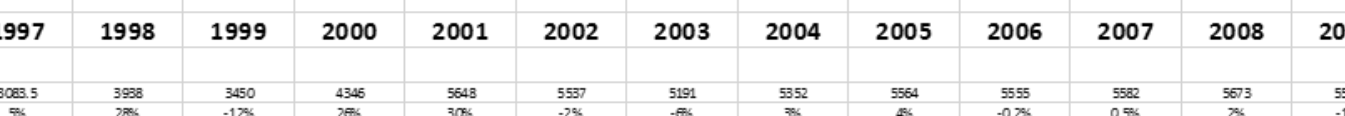

$2009 \quad 2010$

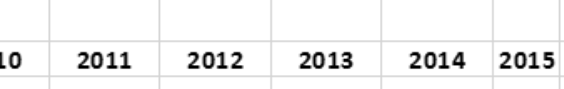

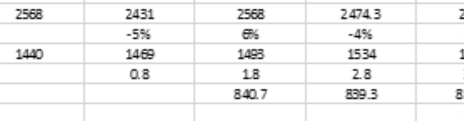

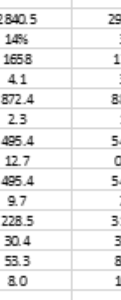

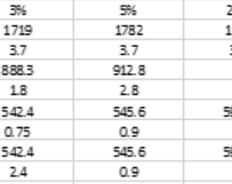

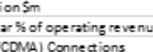

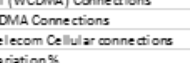

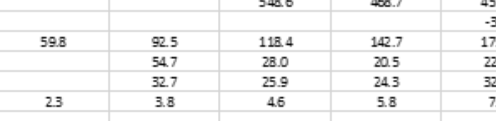

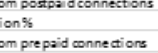

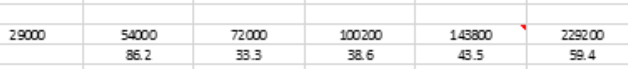

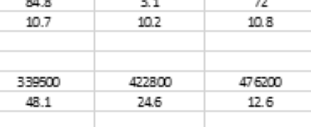

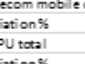

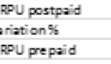

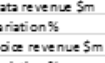

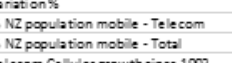

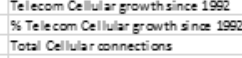

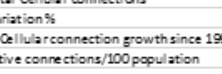

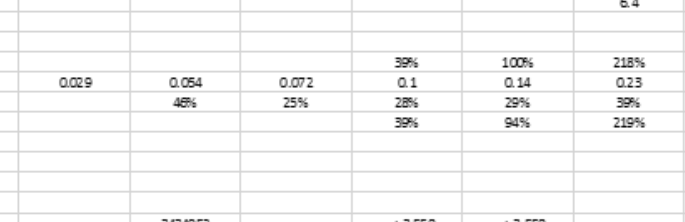

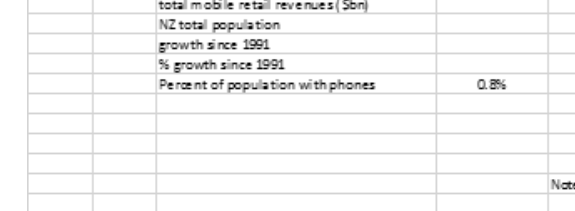

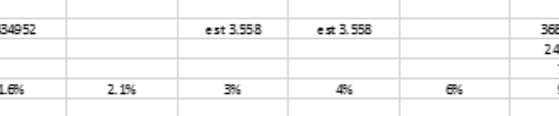

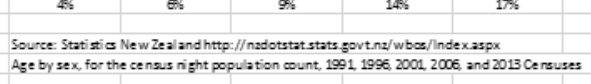

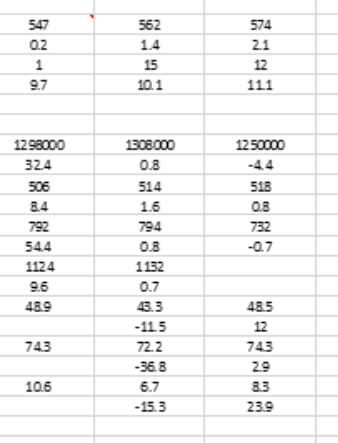

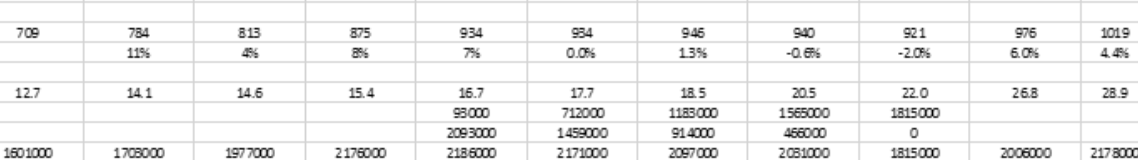

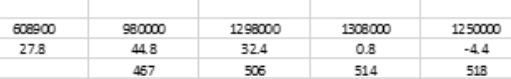

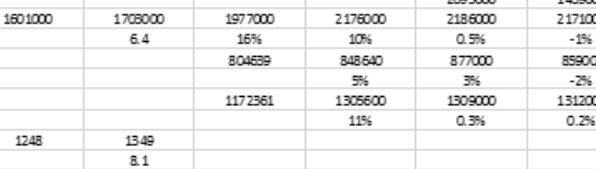

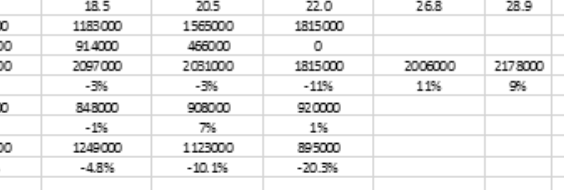

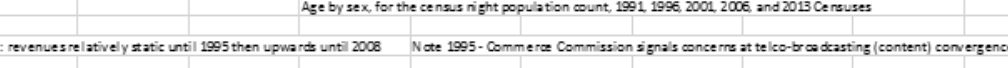

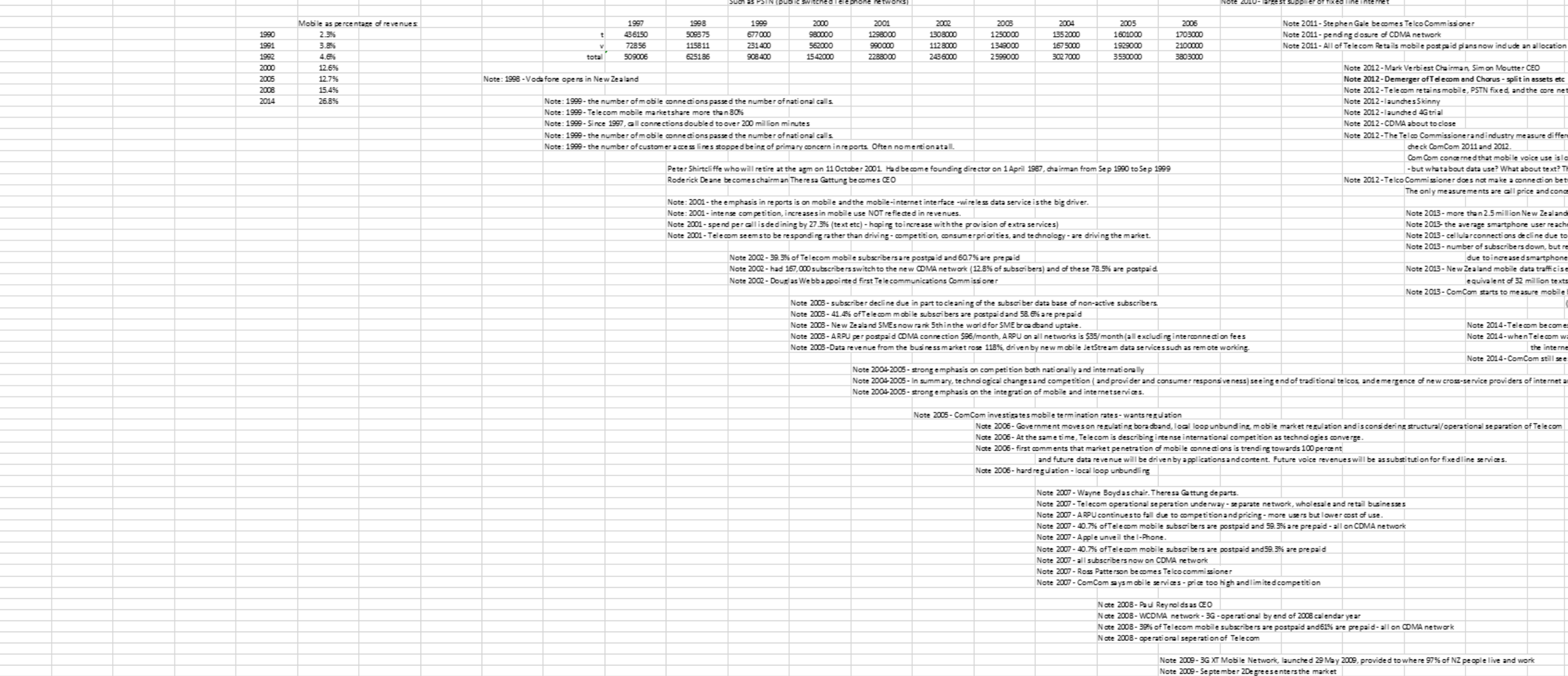

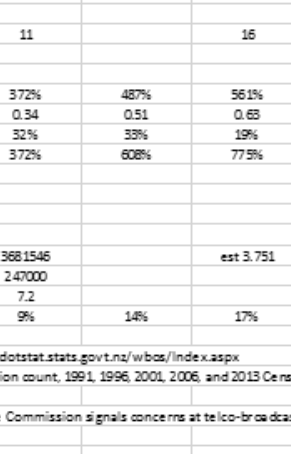
\begin{tabular}{l|l}
21 \\
205
\end{tabular}

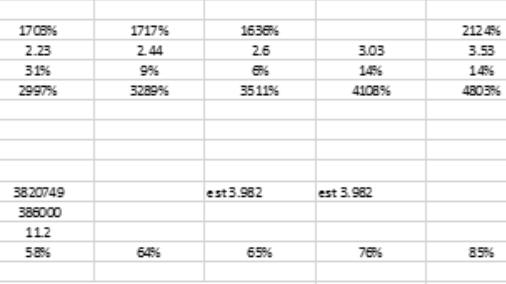
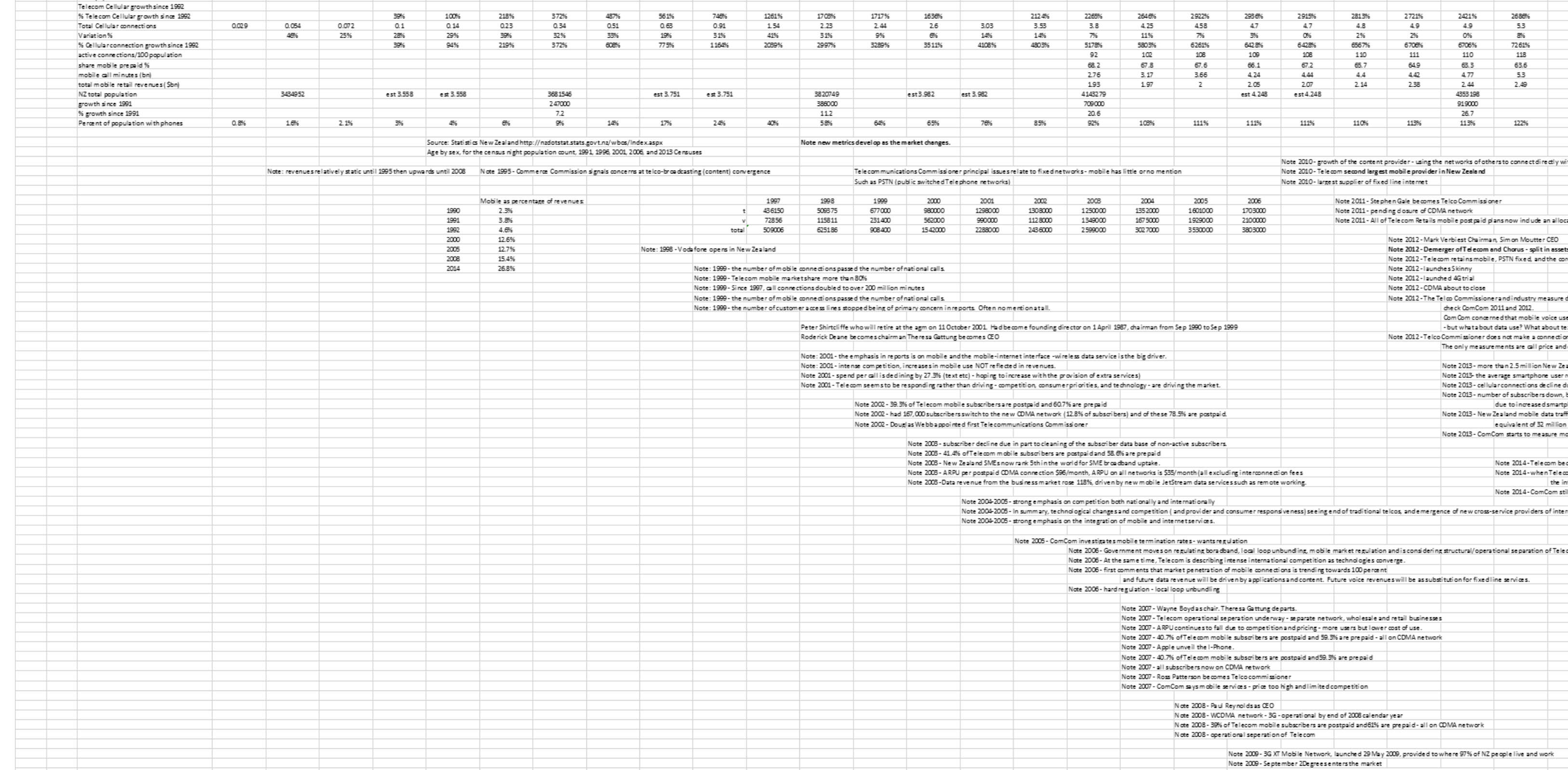

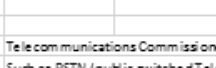

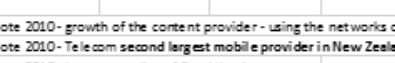

